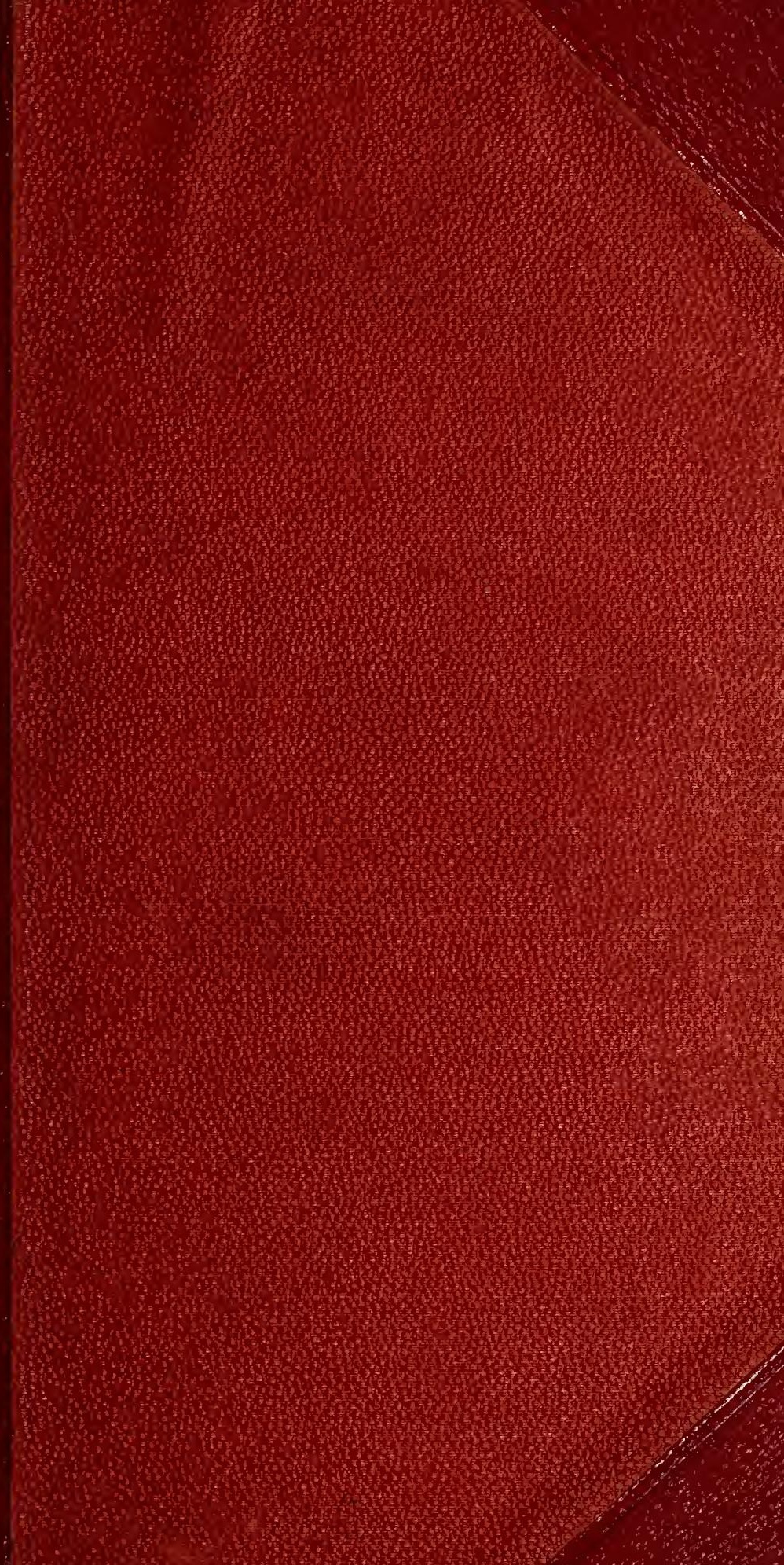









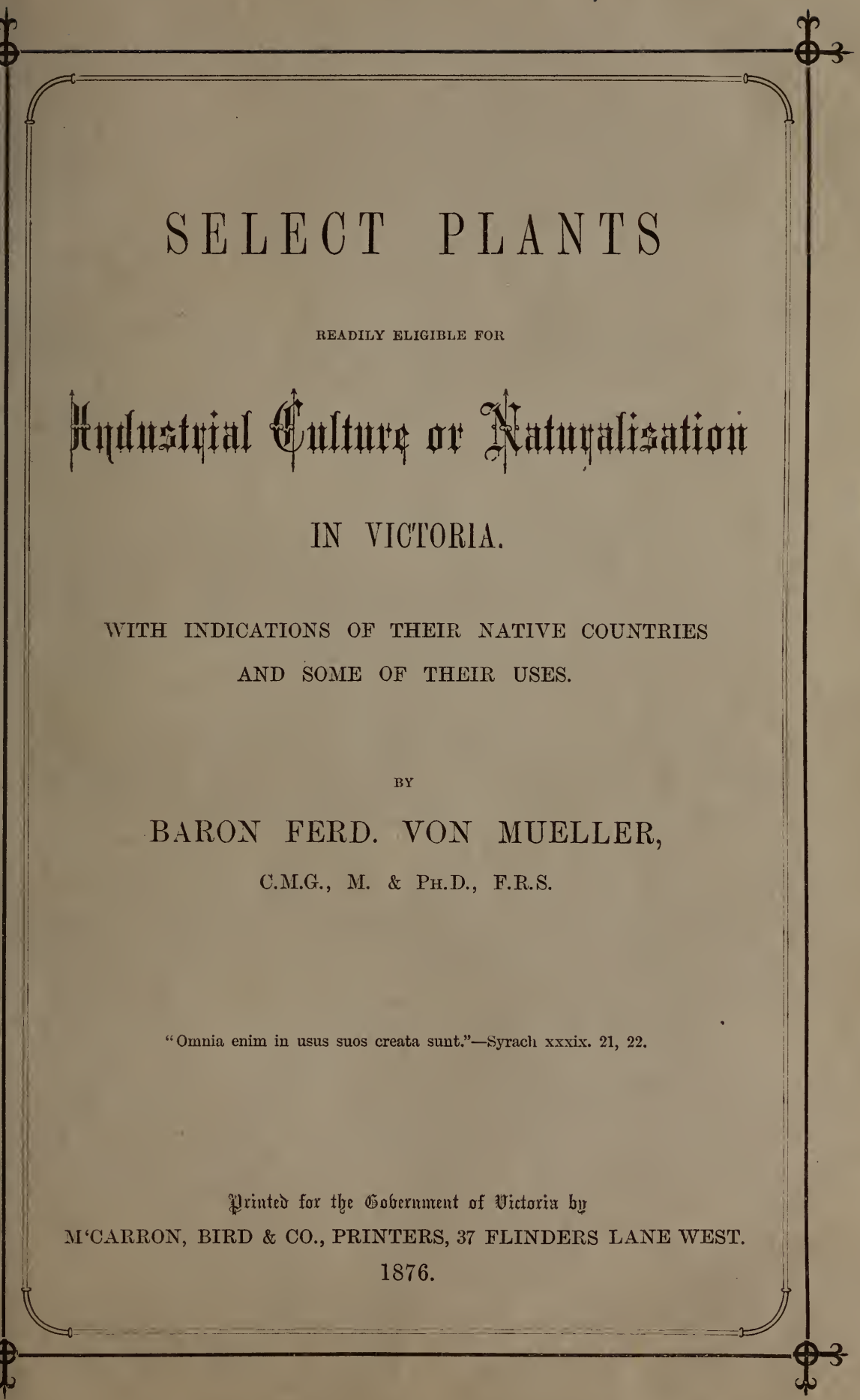


Gother mith samian twothitute affored an behalf aft the ofirtwian ly armments lyy the misiter. 


\title{
SELECT PLANTS
}

READILY ELIGIBLE FOR

\section{âlnoustrial đulture ox âduturalisation}

\author{
IN VICTORIA,
}

WITH INDICATIONS OF THEIR NATIVE COUNTRIES AND SOME OF THEIR USES,

BY

\section{BARON FERD. VON MUELLER,}

C.M.G., M. \& PH.D., F.R.S.

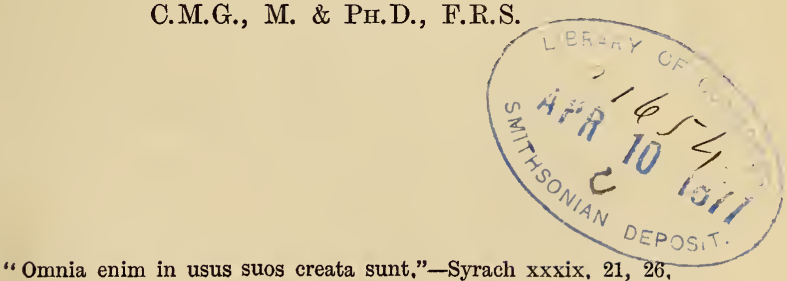

㩆rinted for the Gofermment of yietoria by M'CARRON, BIRD \& CO., FLINDERS LANE WEST, MELBOURNE. 1876. 



\section{PREFACE.}

IN the volumes, issued by our Acclimation Society from 1871 to 1875 , four contributions have appeared, concerning such industrial plants as are available for culture in this colony. These writings were mainly offered with a view of promoting the introduction and diffusion of the very many kinds of plants, which in our geographic latitudes may be extensively reared in forests, on fields or pastures. The prints, thus originated, became however accessible merely to the members of the Society, while frequent calls arose for these or some similar data throughout our community. The whole has therefore now been reissued in a rearranged and largely supplemented form as a departmental publication with ministerial approval. As stated in the preface to the original essays, they do not claim completeness either as a specific index or as a series of notes on the respective technologic applicability of the plants enumerated. But what these writings perhaps may aspire to is the aim of bringing together closely-arrayed some condensed notes in popular language on all the principal utilitarian plants hitherto known to prosper in extra-tropic zones. Information of this kind is widely scattered through many and often voluminous works in several languages, yet such volumes treating perhaps on countries with a climatic zone far more narrow than ours. Only a share of the books, which it was desirable to consult, were at my command, hence the necessity of successive further supplements, even irrespective of 
the needful reference to future discoveries, because in the progress of geographic, medical, technologic and chemical inquiries many new plants of utilitarian value are likely to be disclosed, and new uses of known plants to be elucidated. Thus, for instance, among the trees and shrubs, or herbs and grasses occurring in the middle and higher altitudinal zones of Africa, or nearer to us of New Guinea and the Sunda Islands, many specific forms may be expected to occur, which we could transfer as well to our colony as to other extra-tropic countries. Indeed, the writer would modestly hope, that his local efforts may prove to be of usefulness also to other countries outside of the tropics; and in this hope he is cheered by the generous action of an enlightened American, Mr. Ellwood Cooper, the Principal of the Santa Barbara College of California, who deemed the publications, now here reprinted for Australian use, also worthy of reissue in America. It was stated before, that the rapid progress of tillage almost throughout our colonial dominion is causing more and more a desire for general and particular indications of such plants, which a colder clime excludes from the northern countries, where many of our colonists spent their youth; and it must be clear to any reflecting mind, that in our latitudes as compared with the Middle European zones a vastly enlarged scope exists for cultural choice of plants. Indicative as these notes merely are, yet they may thus facilitate the selection. More extensive information can then be followed up in larger works extant elsewhere, or which Australian authorship may call forth for local requirements. The writer should even not be disinclined, under fair support and encouragement, to issue collateral to the present volume also another, exclusively devoted to the industrial plants of the hotter zones for the promotion of tropical culture, particularly in our Australian continent. Considerable difficulty was experienced in drawing the limits of the remarks admissible into the present pages, because a certain plant may be important only under particular climatic conditions and cultural applications, or it may have been overrated in regard to the copiousness and relative value of its yield. Thus it was not always easy to sift the chaff from the grain, when 
these notes were gathered; they might under less rigorous restrictions indeed have been indefinitely extended; and although the author for more than twenty years has been watching for industrial tests the plantsintroduced by him into the Melbourne Botanic Garden, he had still to a very large extent to rely implicitly on the experience of other observers elsewhere. Here also it may at once be stated, that in all instances, when calculations of measurements and weights were quoted, such represent the maximum always, as far as hitherto on record. To draw prominent attention to the primarily important among the very many hundreds of plants, referred to in these pages, the leading species have been designated with an asterisk. It has not been easy in numerous instances, to trace the first sources of that information on utilitarian plants, which we find recorded in the various volumes of phytologic or technologic literature; many original observations are however contained in the writings of Bernardin, Bentley, Brandis, Candolle, Collins, Drury, Flueckiger, Asa Gray, Grisebach, Hanbury, Hooker, King, Langethal, Lawson, Lindley, Loudon, Martius, Masters, Meehan, Michaux, Nuttall, Oliver, Pereira, Philippi, Porcher, Rosenthal, Seemann, Stewart, Trimen, Wittstein and also some others, to whose names is referred cursorily in the text. The volumes of the Agricultural Department of Washington, of the Austrian Apotheker-Verein and of several other periodicals have likewise afforded data utilised on this occasion.

In grouping together, at the close of this volume, all the genera enumerated, according to the products which they yield, facility is afforded for tracing out any series of plants about which special economic information may be sought, or which may prominently engage at any time the attention of the cultivator, the manufacturer or the artisan. Again, in placing together in index-form the respective industrial plants according to their geographic distribution, as has likewise been done in the concluding pages, it is rendered easy to order or obtain from abroad the plants of such other countries, with which any one of our colonists may be in relation through commercial, literary or other intercourse. Lists like the present may aid also in naming the plants and their products with 
scientific correctness in establishments of economic horticulture or in technologic or other educational collections. If the line of demarcation between the plants admissible into this list and those which should have been excluded has occasionally been extended in favour of the latter, then it must be pleaded, that the final importance of any particular species for a peculiar want, locality or treatment cannot often be fully foretold. Many plants of primary importance for our rural requirements alluded to now have long since been secured by the intelligent early pioneers of our colonisation, who timely strove to enrich also our cultural resources, and in these efforts the writer, so far as his public or private means did ever permit, has endeavoured for the past quarter of a century to take an honourable share. But although such plants are introduced, they are not in all instances as yet widely diffused, nor in all desirable localities tested. For the sake of completeness even the most ordinary cultural plants have not been passed, as the opportunity seemed an apt one, to offer a few cursory remarks on their value. The writer entertains a hope, that a copy of this plain volume will be placed in the library of each of our State-schools, to serve educational purposes also by occasional and perhaps frequent reference to these pages. The increased ease of communication, which has latterly arisen between Australia and most other parts of the globe, places us here now in a fair position for independent efforts, to promote introductions of new vegetable treasures from unexplored regions, or to submit neglected plants of promising value to unbiassed original tests. May it merely be instanced, that after the lapse of more than three centuries only the most scanty information is extant on the timber of Mexico, and that of several thousand tropical grasses not many dozen are tried for pastoral purposes. For inquiries of such kind every civilised State is striving to afford in well-planned, thoughtfully directed and generously supported special scientific establishments the needful aid, not merely for adding to the prosperity, comfort. and enjoyment of the present generation, but also with an anticipation of earning the gratitude of posterity, and this as a rule is done with a sensitive jealousy, to maintain also thereby for scientific 
dignity and industrial development the fair fame of the country. Friendly consideration will recognise, that to arouse more and more such a spirit for emulation has much inspired the writer to offer these pages, he trusting that enlightened statesmanship far and wide will foster this aim.

Melbourne, December 1876. 



\section{SELECT PLANTS}

READILY ELIGIBLE FOR

\section{VICTORIAN INDUSTRIAL CULTURE,}

WITH INDICATIONS OF THEIR NATIVE COUNTRIES

AND SOME OF THEIR USES.

AN ENUMERATION OFFERED BY

\section{BARON FERD. VON MUELLER,}

C.M.G., M.D., Ph.D., F.R.S., \&c.

Aberia Caffra, Hooker.

The Kai-Apple of Natal and Caffraria. This tall shrub serves for hedges. The rather large fruits are edible, and can be converted into preserves. Allied South African species are A. Zeyheri and A. tristis (Sonder).

Acacia acuminata, Bentham.

A kind of Myall from Western Australia, attaining a height of forty feet.

Acacia Arabica, Willdenow.

North and Central Africa, also in South-West Asia, growing in dry calcareous soil. This small tree can be utilised for thorny hedges, as also A. Seyal (Delile) and A. tortilis (Forskael). They all furnish the best Gum Arabic for medicinal and technical purposes. The Lac-insect lives also on the foliage, and thus in Sind the Lac is mainly yielded by this tree. The stem attains a circumference of ten feet. The astringent pods are valuable for tanning; the wood, known as "Sunt," is esteemed for planks of boats. A. gummifera (Willd.) and A. Ehrenbergiana (Hayne) are among the species, and yield Gum Arabic in North Africa.

Acacia Cavenia, Hooker and Arnott.

The Espino of the present inhabitants of Chili, the Cavan of the former population. A small tree with exceedingly hard wood, resisting underground moisture. The plant is well adapted for hedges. The pods, called Quirinca, serve as cattle food (Dr. Philippi). 


\section{Acacia concinna, Candolle.}

India. Praised by Dr. Cleghorn as a valuable hedge-shrub. The pod contains Saponin. So is likewise A. latronum (Willd.), a hedge-bush.

Acacia decurrens, Willdenow. (A. mollissima, Willd,; $A$. dealbata, Link.)

The Black Wattie and Silver Wattle. From the eastern part of South Australia, through Victoria and New South Wales, to the southern part of Queensland; in open plains a small or middle-sized tree, in deep forest recesses a lofty tree of singularly rapid growth. Its wood can be used for staves and many other purposes, but a chief use would be to afford the first shelter, in treeless localities, for raising forests. Its bark, rich in tannin, and its gum, not dissimilar to Gum Arabic, render this tree also important. The English price of the bark ranges generally from $£ 8$ to $£ 11$. It varies, so far as experiments under my direction have shown, in its contents of tannin from 18 to 33 per cent. In the mercantile bark the percentage is somewhat less, according to the state of its dryness-it retaining about 10 per cent. moisture. Any bare barren unutilised places might here be sown most remuneratively with the seeds of this Wattle-Acacia, to secure a regular and continuous supply of the bark, which necessarily must fall off under the indiscriminate arrangements of obtaining the bark from the natural localities of growth. The return would be within very few years; $1 \frac{1}{2}$ lb. of Black Wattle bark gives $11 \mathrm{~b}$. of leather, whereas 5lbs. of English Oak bark are requisite for the same results, but the tannic principle is not absolutely identical. The bark of the variety passing usually as the Silver Wattle (Acacia dealbata, Link), is generally of less value, often even fetching only half the price of that of the Black Wattle. The tannin of these Acacir yields a grey precipitate with the oxyde of salts of iron, and a violet colour with sub-oxydes; it is completely thrown down from a strong aqueous solution by means of concentrated sulphuric acid. The bark improves by age and desiccation, and yields about 40 per cent. of catechu, rather more than half of which is tannic acid. Bichromate of potash added in a minute quantity to the boiling solution of mimosa-tannin produces a ruby-red liquid, fit for dye-purposes, and this solution gives with the salts of sub-oxyde of iron black pigments, and with the salts of the full oxyde of iron red-brown dyes. 
Acacia falcata, Willdenow.

East Australia. One of the best of trees for raising a woody vegetation on drift-sand, as particularly proved at the Cape of Good Hope. Other species serve the same purpose, for instance-A. pycnantha, A. saligna, A. cyanophylla, A. salicina.

Acacia Farnesiana, Willdenow.

Dioscorides' small Acacia. Indigenous to South Asia; found westward as far as Japan; a native also of the warmer parts of Australia, as far south as the Darling River; found spontaneously in tropical and sub-tropical America, but apparently not in tropical Africa. Professor Fraas has recognised in this Acacia the ancient plant. The scented flowers are much sought after for perfumery. This may also be utilised as a hedge-plant, and a kind of Gum Arabic may be obtained from it.

Acacia fasciculifera, F. v. Mueller.

South Queensland. Desirable for culture on account of the excellence of its easily-worked wood.

Acacia glaucescens, Willdenow.

Queensland and New South Wales. Extreme height, about sixty feet. A kind of Myall, with hard, dark, prettilygrained but less scented wood.

Acacia harpophylla, F. v. Mueller.

Southern Queensland, where this tree, according to $\mathrm{Mr}$. Thozet, furnishes a considerable share of the mercantile wattle-bark for tanning purposes. Wood, according to Mr. O'Shanesy, brown, hard, heavy and elastic, used by the natives for spears.

Acacia homalophylla, Cunningham.

The Victorian Myall, extending into the deserts of New South Wales. The dark-brown wood is much sought for turner's work on account of its solidity and fragrance; perhaps its most extensive use is in the manufacture of tobaccopipes. Never a tall tree.

Acacia horrida, Willdenow.

The Doornboom or Karra-Doorn of South Africa. A formidable hedge-bush, with thorns often three inches long, readily available for impenetrable hedge-copses. It exudes also a good kind of gum. So A. Giraffæ (Burchell).

Acacia Melanoxylon, R. Brown.

The well-known Blackwood of our river-flats and moist forest-valleys, passing also under the inappropriate name of 
Lightwood. In irrigated valleys of deep soil the tree will attain a height of eighty feet, with a stem several feet in diameter. The wood is most valuable for furniture, railway carriages, boat-building, casks, billiard-tables, pianofortes (for sound-boards and actions), and numerous other purposes. The fine-grained wood is cut into veneers. It takes a fine polish, and is considered almost equal to Walnut. Our best wood for bending under steam. For further details refer to the volumes of the Melbourne Exhibitions of 1862 and 1867 .

Acacia pendula, All. Cunningham.

New South Wales and Queensland. Generally in marshy tracts of the interior. One of the Myall-trees.

Acacia pycnantha, Bentham.*

Victoria and South Australia. Though frequent in many parts of our colony, this tree, known as the Golden Wattle, deserves even here extensive cultivation, mainly for the sake of its bark, rich in tannin. It is of rapid growth, will succeed even in sandy tracts, and yields seeds copiously, which germinate with the greatest ease. One of the most important trees for binding waste sands. It is never a large tree. By improved methods the fragrant oil of the flowers could doubtless be fixed, though its isolation might be difficult and unremunerative. Experiments in the writere's laboratory have shown that the perfectly dried bark contains about 25 per cent. of mimosa-tannin. The aqueous infusion of the bark can be reduced by boiling to a dry extract, which in medicinal and other respects is equal to the best Indian catechu, as derived from Acacia catechu and A. sundra. It yields approximately 30 per cent., about half of which or more is mimosa tannic acid. This catechu is also of great use for preserving against decay articles subject to exposure in water, such as ropes, nets, fishing-lines, \&c. While, according to Mr. Simmons, the import of the bark of oaks and hemlock-spruce into England becomes every year less, and while the import of sumach and gambir does not increase, the annual demand has, since the last twenty years, become doubled. Probably, no other tanning plants give so quick a return in cultivation as our Acacia pycnantha, and particularly A. decurrens.

Acacia saligna, Wendland.

South-West Australia, where it is the principal tree chosen for tanner's bark. It is a wide-spreading small tree, fit for avenues. The bark contains nearly 30 per cent. of mimosatannin. 


\section{Acacia Seyal, Delile.}

In the Libyan and Nubian deserts. This thorny tree exudes a good kind of Gum Arabic. It is adapted for the most arid desert country. In any oasis it forms a large and shady tree.

Acacia stenophylla, A. Cunningham.

On banks of watercourses in the interior of Australia, as far south as the Murray River. A tree with exquisite hard dark wood, serving like Myall-wood.

Acacia Verek, Guillemin and Perrottet.

From Senegambia to Nubia. Affords the best white Gum Arabic of the Nile region, and a large quantity of this commercial article. A. Etbaica (Schweinf.) from the same region produces also a good mercantile gum.

Acer campestre, Linné.

The British Maple. Extends from Middle Europe to North Asia. Height forty feet, in shelter and deep soil ; the yellow and purple tints of its foliage in autumn render the tree then particularly beautiful. The wood is compact and fine-grained, and sought for choice furniture. The tree can be trimmed for hedge-growth. Comparatively quick of growth, and easily raised from seed. These remarks apply to many kinds of Maples.

Acer dasycarpum, Ehrhart.

The White Maple of North America. Likes rather a warmer climate than the other American Maples, and therefore particularly desirable for us here. Height fifty feet; wood pale and soft, stem sometimes nine feet in diameter. Much praised for street-planting; growth comparatively rapid. It produces no suckers, nor is the tree subject to disease. A most beautiful tree, with a stout stem and a magnificent crown, growing best on the banks of rivers with limpid water and a gravelly bed, but never in swampy ground, where the Red Maple takes its place. The wood is of less strength and durability than that of its congeners, but produces excellent charcoal. The tree also yields Maple-sugar, though not in such quantity as A. saccharinum.

Acer macrophyllum, Pursh.

Large Oregon-Maple. Tree up to ninety feet high, of quick growth; stem attaining sixteen feet in circuimference; wood whitish, beautifully veined. A beautiful shade-tree; delights on banks of streams. The inner bark can be utilised for baskets and superior mats; the wood is a substitute for hickory. 
Acer Negundo, Linné.

The Box-Elder of North America. A tree, deciduous like the rest of the Maples; attains a height of about fifty feet, and is rich in saccharine sap. Proved well adapted for our country. In California it is used extensively as a shade-tree.

Acer palmatum, Thunberg.

This beautiful tree with deeply-cleft leaves is indigenous to Japan, where various varieties with red and yellow tinged leaves occur. Should it be an aim to bring together all the kinds of Maples which could be easily grown in appropriate spots of Victoria, then Japan alone would furnish twenty-five species.

Acer plantanoides, Linné.

The Norway-Maple, extending south to Switzerland. Up to seventy feet high. The pale wood much used by cabinetmakers. Tint of the autumn-foliage golden yellow. A tree of imposing appearance, much recommended for ornamental gardening; it gives a denser shade than the other Maples.

Acer Pseudo-platanus, Linné.

The Sycamore-Maple or Spurious Plane. Attains a height of over 100 feet. The wood is compact and firm, valuable for various implements, instruments, and cabinet-work. It furnishes like some other Maples a superior charcoal. Will admit of exposure to sea-air. The sap also saccharine.

Acer rubrum, Linné.

The Red Maple of North America. A tree attaining eighty feet, fond of swampy places; wood close-grained. Grows well with several other Maples, even in dry open localities of this part of Australia, although the foliage may somewhat suffer from our hot winds. The foliage turns red in autumn. The tree grows most luxuriantly in swampy fertile soil. The wood is of handsome appearance, used in considerable quantity for saddle-trees, yokes, chairs and other furniture. That of old trees is sometimes cross-grained, and thus furnishes a portion of the curled Maple-wood, which is very beautiful and much in request for gun-stocks and inlaying. The tree yields also Maple-sugar, but like A. dasycarpum only in about half the quantity obtainable from A. saccharinum (Porcher).

Acer saccharinum, Wangenheim.*

The Sugar, Rock, or Hard Maple; one of the largest of the Maples. In the colder latitudes of North America, eighty feet high. The wood is strong, of rosy tinge, and when wellseasoned used for axle-trees, spokes, also for chairs; when knotty or curly it furnishes the birdseye and curly maplewood. In the depth of winter the trees, when tapped, will 
yield the saccharine fluid, which is so extensively converted into Maple-sugar, each tree yielding two to four $\mathrm{lb}$. a year. The trees can be tapped for very many years in succession, without injury. According to Porcher instances are on record of $33 \mathrm{lbs}$. of sugar having been obtained from a single tree in one season. The Sugar-Maple is rich in potash, furnishing a large proportion of this article in the United States. The bark is an important constituent in several of the Americon dyes. The tree is particularly recommended for our alpine regions. It bears a massive head of foliage on a slender stem. The autumnal colouring is superb. In the Eastern States of North America the Sugar-Maple is regarded as the best tree for shade-avenues. Numerous other Maples exist, among which as the tallest may be mentioned Acer Creticum (L.) of South Europe, forty feet; A. lævigatum, A. sterculiaceum and A. villosum (Wallich) of Nepal, fifty feet; A. pictum (Thunb.) of Japan, thirty feet.

\section{Achillea Millefolium, Linné.}

Yarrow or Millfoil. Europe, Northern Asia and North America. A perennial medicinal herb of considerable astringency, pervaded with essential oil, containing also a bitter principle (Achillein) and a peculiar acid, which takes its name from the generic appellation of the plant.

Achillea moschata, Wulfen.

Alps of Europe. The Genipi or Iva of the alpine inhabitants. This perennial herb ought to be transferred to our snowy mountains. With the allied A. nana (L.) and A. atrata (L.), it enters as a component into the aromatic medicinal Swiss tea. Many species of this genus, including the Yarrow, are wholesome to sheep. A. fragrantissima (Reichenbach) is a shrubby species from the deserts of Egypt, valuable for its medicinal flowers.

Achras sapota, Linné.

The Sapodilla-Plum of West India and Central Continental America. It is not improbable that this fine evergreen tree would produce its delicious fruit in East Gipps Land within Victorian boundaries, as tall palms and many other plants of tropical type occur there. Moreover Achras Australis, a tree yielding also tolerable good fruit, occurs as far south as Kiama in New South Wales, where the clime is very similar to that of many forest-regions of Victoria. Other sapotaceous trees, producing table-fruit, such as the Lucuma mamosa (the Marmalade-tree), Lucuma Bonplandi, Chrysophyllum Cainito (the Star-Apple), all from West India; and Lucuma Caimito of Peru might also be subjected to trial-culture in 
our warmest forest-valleys; so furthermore many of the trees of this order, from which gutta-percha is obtained (species of Isonandra, Sideroxylon, Ceratophorus, Cacosmanthus, Bassia, Mimusops and Imbricaria), may prove hardy in our sheltered woodlands, as they seem to need rather an equable humid mild clime than the heat of the torrid zone.

Aconitum Napellus, Linné.

The Monk's Hood. In the colder, especially mountainous parts of Europe and Northern Asia. A powerful medicinal plant of perennial growth, but sometimes only of biennial duration, variable in its forms. - It was first introduced into Australia, together with a number of other Aconits, by the writer of this communication. All the species possess more or less modified medicinal qualities, as well in their herb as in their root; but so dangerously powerful are they, that the plants can only be administered by the exercise of legitimate medical practice. Napellus-root, according to Dr. Wittstein, contains three alkaloids; Aconitin, Napellin and Narcotin. The foliage contains also a highly acrid, volatile principle, perhaps chemically not unlike that of many other Ranunculaceæ. Aconitin, one of the most potent of any of the medicinal substances in existence, can likewise be obtained from the Nepalese Aconitum ferox, and probably from several other species of the genus.

Acorus Calamus, Linné.

The Sweet Flag. Europe, Middle and North Asia, North America. A perennial pond or lake plant. The somewhat aromatic root is used as a stomachic, and also in the preparation of confectionery, in the distillation of gin and liqueurs, and in the brewing of some kinds of beer. The flavour of the root depends mainly on a peculiar volatile oil.

Actæa spicata, Linné.

The Baneberry. On forest-mountains, mainly in limestone soil of Europe, North Asia and North America. A perennial medicinal herb. Its virtue depends on peculiar acrid and bitter, as well as tonic principles. In North America, this species, and likewise A. alba, are also praised as efficacious antidotes against ophidian poisons.

\section{Adenostemum nitidum, Persoon.}

South Chili, where this stately tree passes by the appellations: Queule, Nuble and Aracua. Wood durable and beautifully veined. Fruit edible.

\section{Adesmia balsamica, Bertero.}

The Jarilla of Chili. A small shrub, remarkable for exuding a fragrant balsam of some technic value. 
Egiceras majus, Gaertner.

South Asia, Polynesia, North and East Australia. This spurious Mangrove-tree extends far south in New South Wales. It may be employed for staying the off-flow of mud by the tide, and for thus consolidating shores subject to inundation by sea-floods.

Eschynomene aspera, Linné.

The Solah of tropical Asia. A large perennial erect or floating swamp-plant, probably hardy in the warmer tracts of our colony. Introduced from the Botanic Gardens of Melbourne into the tropical parts of Australia. The pithhats are made from the young stems of this plant. The Solah is of less importance for cultivation than for naturalisation.

Esculus Hippocastanum, Linné.

The Horse-Chestnut tree. Indigenous to Central Asia. One of the most showy of deciduous trees, more particularly when during spring "it has reached the meridian of its glory, and stands forth in all the gorgeousness of leaves and blossoms." Height sixty feet. It will succeed in sandy soil on sheltered spots; the wood adapted for furniture; the seeds a food for various domestic animals; the bark a good tanning material. The wood remains free from insects. The tree ascends the Himalayas up to 10,000 feet. A variety occurs with thornless fruits. Three species occur in Japan, and several, but none of great height, in North America and South Asia.

Agaricus Cæesareus, Schaffer.

In the spruce-forests of Middle and South Europe. Trials might be made to naturalise this long-famed and highly delicious Mushroom in our forests when spruce-fir plantations are made. It attains a width of nearly one foot, and is of a magnificent orange colour. Numerous other edible Agarics could doubtless be brought into these southern colonies by the mere dissemination of the spores at apt localities. As large or otherwise specially eligible may here be mentioned A. extinctorius (L.), A. melleus (Vahl.), A. deliciosus (L.), A. giganteus (Sowerby), A. Cardarella (Fr.), A. Marzuolus (Fr.), A. eringii (Cand.), A. splendens (Pers.), A. odorus (Bulliard), A. auricula (Cand.), A. oreades (Bolt.), A. esculentus (Wulf.), A. mouceron (Tratt.), A. socialis (Cand.), all from Europe, besides numerous other highly valuable species from other parts of the globe.

Agave Americana, Linné.

The gigantic Aloe of Central America. It comes here into flower in about ten years. The pithy stem can be utilised 
for some of the purposes for which cork is usually employed, for instance, to form the bottoms of insect-cases. The honeysucking birds and the bees are very fond of the flowers of this prodigious plant. The leaves of this and some other Agaves, such as A. Mexicana, furnish the strong Pita-fibre, which is adapted for ropes, and even for beautiful textile fabrics. The strength of ropes of this fibre is considerably greater than that of hemp ropes, as well in as out of water. The leaves contain Saponin. The sap can be converted into alcohol, and thus the "Pulque" beverage is prepared from the young flower-stems. Where space and circumstances admit of it, impenetrable hedges may be raised in the course of some years from Agaves.

Agave rigida, Miller. (A. Ixtli, Karwinsky.)

Yucatan. The Chelem, Henequen and Sacci of the Mexicans, furnishing the Sisal-hemp. Drs. Perrine, Scott and Engelmann indicate several varieties of this stately plant, the fibre being therefore also variable both in quantity and quality. The yield of fibre begins in four or five years, and lasts for half a century or more, the plant being prevented from flowering by cutting away its flowerstalk when very young. The leaves are from two to six feet long and two to six inches wide; the flower-stem attains a height of twentyfive feet, the panicle of flowers about eight feet long, bearing in abundance bulb-like buds. Other large species of Agave, all fibre-yielding, are A. antillarum (Descourtil), from Hayti; A. Parryi (Engelmann), from New Mexico; A. Palmeri (Engelmann), from South Arizona, up to an elevation of 6000 feet.

Agrostis alba, Linné.

The Fiorin or White Bent-grass. Europe, North and Middle Asia, North Africa, North America. Perennial, showing a predilection for moisture; can be grown on peatsoil. It is the Herd-grass of the United States. It is valuable as an admixture to many other grasses, as it becomes available at the season when some of them fail. Sinclair regards it as a pasture-grass inferior to Festuca pratensis and Dactylis glomerata, but superior to Alopecurus pratensis. The variety with long suckers (A. stolonifera) is best adapted for sandy pastures, and helps to bind shifting sand on the seacoast, or broken soil on river-banks. It has a predilection for moisture, and luxuriates even on saline or wet soil or periodically inundated places, as well observed by Langethal. It is more a grass for cattle-country than for sheep-country, but wherever it is to grow the soil must be penetrable. Its 
turf on coast-meadows is particularly dense and of remarkable fineness. For sowing cnly one-sixth of the weight of the seeds as compared with those of the Rye-grass is needed.

Agrostis rubra, Linné. (A. borealis, Hartmann).

Northern Europe, Asia, and America. A perennial grass called Red-top, and also Herd-grass in the United States of North America. Mr. Meehan places it for pastoral value among grasses cultivated there next after Phleum pratense and Poa pratensis (the latter there called Blue-grass), and before Dactylis glomerata (the Orchard-grass of the United States).

Agrostis scabra, Willdenow.*

The Hair-grass of North America. Recently recommended as one of the best lawn-grasses, forming a dense turf. It will grow even on poor gravelly soil, and endure drought as well as extreme cold. Its fine roots and suckers spread rapidly, forming soon dense matted sods (according to Dr. Channing). It starts into new growth immediately after being cut; is for its sweetness picked by pasture animals preferentially; has proved one of the best grasses for dairy ground; and suppresses weeds like Hordeum secalinum. One bushel of seed to an acre is used for pasture-land, two bushels for lawns.

Agrostis vulgaris, Withering.

Europe, North Africa, Middle Asia, North America. One of the perennial grasses which disseminate themselves with celerity, even over the Horst of sandy soils. Though not a tall grass, it may be destined to contribute perhaps with Aira canescens and others largely to the grazing capabilities of the Australian desert lands; yet it will thrive also even in moist soil and alpine regions, and is essentially a grass for sheepcountry.

Ailantus glandulosa, Linné.

South-Eastern Asia. A hardy deciduous tree, sixty feet high, of rather rapid growth, and of very imposing aspect in any landscape. Particularly valuable on account of its leares, which afford food to a silkworm (Bombyx Cynthia), peculiar to this tree; wood extremely durable, pale yellow, of silky lustre when planed, and therefore valuable for joiners' work. In South Europe planted for arenues. Valuable also for reclaiming coast-sands.

Aira cæspitosa, Linné.

Widely dispersed over the globe. A fodder-grass, to be utilised for moist meadows. 
Albizzia dulcis, F. v. Mueller. (Pithecolobium dulce, Bentham.) Mexico. A valuable hedge-plant. The sweet pulp of the pod is wholesome.

Albizzia Julibrissin, Durazzini.

From Persia to Japan. A favourite ornamental shade-Acacia in South Europe.

Albizzia latisiliqua, F. v. Mueller. (Lysiloma latisiliqua, Bentham.)

Tropical America. A large spreading tree, probably hardy in the warmer tracts of Victoria. Diameter of trunk to three feet; wood excellent for select cabinet-work, excelling according to Nuttall the Mahogany in its variable shining tints, which appear like watered satin; it is white, hard, and close-grained.

Albizzia Lebbek, Bentham.

The Siris-Acacia of South Asia. Available in the warmer parts of our colony as a shade-tree. It produces also a good deal of gum.

Albizzia lophantha, Bentham. (Acacia lophantha, Willdenow.)

South-West Australia. One of the most rapidly-growing trees for copses and first temporary shelter in exposed localities, but never attaining to the size of a real tree. It produces seeds abundantly, which germinate most easily. For the most desolate places, especially in desert tracts, it is of great importance to create quickly shade, shelter, and copious vegetation. Cattle browse on the leaves. The bark contains only about 8 per cent. mimosa-tannin; but Mr. Rummel found in the dry root about 10 per cent. of saponin, valuable in silk and wool factories.

Albizzia Saman, F. v. Mueller. (Pithecolobium Saman, Benth.) Mexico. A lofty tree, particularly valuable for wet saline country, probably hardy in the warmer parts of our colony. The pulpy pods are edible.

Aletris farinosa, Linné.

The Colic-Root of the woodlands of North America. This pretty herb is of extreme bitterness, and can be medicinally administered as a tonic.

Aleurites cordata, R. Brown.

From Japan to Nepal, also in Bourbon. This tree for its beauty and durable wood deserves introduction into our plantations in the warm and humid districts. The oil of the seeds serves as varnish. Perhaps also in localities free of frost, would be of sufficiently quick growth the A. triloba 
(R. and G. Foster), the Candlenut-tree, a native of the tropics of both hemispheres, which furnishes a valuable dye from its fruits, and copious oil from its seeds. I found the tree able to endure the winters of Melbourne.

Alkanna tinctoria, Tausch.

On sandy places around the Mediterranean Sea. It yields the Alkanna-root, used for dyeing oleaginous and other substances. It might be naturalised.

Allium Canadense, Kalm.

North American Garlic. Could be cultivated or naturalised on moist meadows for the sake of its top bulbs, which are much sought for pickles of superior flavour.

Allium roseum, Linné.

Countries on the Mediterranean Sea. This, with Allium Neapolitanum (Cyrillo), one of its companions, yields edible roots, according to Heldreich.

Allium Schœenoprasum, Linné.

The Chives. Europe, Northern Asia and North America. Available for salads and condiments. This species of Allium seems not yet so generally adopted in our culinary cultivation as Allium Ascalonicum (the Shallot), A. Cepa (the ordinary Onion), A. fistulosum (the Welsh Onion), A. Porrum (the Leek) or A. sativum (the Garlic). A. Scorodoprasum, or the Sand-Leek of Europe and North Africa, resembles both Garlic and Shallot. A. Ampeloprasum is the British Leek, which extends over Middle and South Europe and West Asia, called in culture the Summer-Leek, a variety of which is the Early Pearl Leek.

Alnus glutinosa, Gaertner.

The ordinary Alder. Throughout Europe and extra-tropical Asia, up to seventy feet high ; well adapted for river-banks ; wood soft and light, turning red, furnishing one of the best charcoals for gunpowder; it is also durable under water, and adapted for turners' and joiners' work. 'The wood is also well suited for pump-trees and other underground work, as it will harden almost like stone. The tree is valuable for the utilisation of bog-land. A. incana (Willd.) extends to North America; it is of smaller size. The bark of several Alders is of great medicinal value, and a decoction will give to cloth saturated with ley an indelible orange colour (Porcher); it contains a peculiar tannic principle.

Aloe dichotoma, Linné fil.

Damara and Namaqua-land. This species attains a height of thirty feet and expands occasionally with its branches so far 
as to give a circumference of forty feet. The stem is remarkably smooth, with a girth sometimes of twelve feet. It is a yellow flowering species. A. Bainesii (Baker \& Dyer) is almost as gigantic as the foregoing. Both doubtless yield medical gum-resin like many others. A. Barberæ, which is closely related to A. Zeyheri, attains in Caffraria a height of forty feet, with a stem sixteen feet in circumference at three feet from the ground.

Aloe ferox, Miller.

South Africa. This species yields the best Cape-Aloe, as observed by Dr. Pappe. The simply inspissated juice of the leaves of the various species of this genus constitutes the Aloe drug. It is best obtained by using neither heat nor pressure for extracting the sap. By redissolving the aqueous part in cold water, and redncing the liquid through boiling to dryness, the extract of Aloes is prepared. All species are highly valuable in our colony, where they are hardy, and can be used, irrespective of their medicinal importance, to beautify any rocky or otherwise arid spot.

Aloe linguiformis, Miller.

South Africa. According to Thunberg, from this species the purest gum-resin is obtained.

Aloe plicatilis, Miller.

South Africa. The drug of this species acts milder than that of A. ferox.

Aloe purpurascens, Haworth.

South Africa. Again one of the plants which furnish the Cape Aloe of commerce. The South African Aloe aborescens (Miller) and A. Commelyni (Willdenow) are also drawn into use for Aloe, according to Baillon, Saunders and Hanbury.

Aloe socotrina, Lamarck. (A. vera, Linné).

Hills of the Island of Socotra. Extending as a native plant along the Red Sea and the shores of India. Also cultivated in Barbadoes and elsewhere, thus yielding the Socotrin-Aloe and Moka-Aloe.

Aloe spicata, Thunberg.

South Africa. This also provides Cape-Aloe. It is an exceedingly handsome plant.

Aloe vulgaris, Lamarck.

The Yellow-flowered Aloe. Countries around the Mediterranean Sea, also Canary Islands, on the sandy or rocky seacoast. Such places could also here readily be utilised for this and allied plants. Dr. Sibthorp identified this species with the 'A $A$ '́ $\eta$ of Dioscorides; hence it is not probable, that $A$. 
vulgaris is simultaneously also of American origin, although it is cultivated in the Antilles, and furnishes from thence the main supply of the Barbadoes-Aloe. In East India this species is also seemingly only existing in a cultivated state. Haworth found the leaves of this and of A. striata softer and more succulent than those of any other Aloe. It is said to be the only species with yellow flowers among those early known. It is also this species only, which Professor Willkomm and Professor Parlatore record as truly wild in Spain and Italy.

Aloe Zeyheri, Harvey.

South Africa. A magnificent, very tall species, doubtless valuable like the rest.

Aloexylon Agallochum, Loureiro.

Cochinchina, on the highest mountains; thus this tree would probably prove hardy here. The precious Aloe-wood, so famed for its balsamic fragrance and medicinal properties, is derived from this tree.

Alopecurus bulbosus, Linné.

Middle and South Europe. An important grass for salt marshes.

Alopecurus geniculatus, Linné.

Europe, Asia, North Africa. A good fodder-grass for swampy ground; easily naturalised.

Alopecurus pratensis, Linné.

Meadow-Foxtail Grass. Europe, North Africa, North and Middle Asia. One of the best of perennial pasture-grasses. Though so extensively cultivated for years in our colony, it is mentioned, for completeness' sake, in this list. It attains to its full perfection only after a few years' growth, as noticed by Sinclair. For this reason, it is not equal to Dactylis glomerata for the purpose of changing crops. Otherwise it is more nutritious than the latter, although the annual return in Britain proved less. Sheep thrive well on it. Sinclair and others found that this grass, when exclusively combined with white clover, will support from the second season five ewes and five lambs on an acre of sandy loam. But this grass, to thrive well, needs land not altogether dry. In all permanent artificial pastures this Alopecurus should form one of the principal ingredients, because it is so lasting and so nutritive. In our Alpine regions it would also prove prolific, and might convert many places there gradually into summer-runs. It is early-flowering, and likes the presence of lime in the soil. 
Alstonia constricta, F. v. Mueller.

Warmer parts of East Australia, particularly in the dry inland districts. The bark of this small tree is aromaticbitter, and regarded as valuable in ague, also as a general tonic.

Alstrœemeria pallida, Graham.

Chili. Palatable starch can be obtained from the root of this plant, which, for its loveliness alone, deserves a place in any garden. The tubers of others of the numerous Alstrœmerias can doubtless be utilised in a similar technic manner.

Althæa officinalis, Linné.

The Real Marsh-Mallow. Europe, North Africa, North and Middle Asia. A tall perennial herb, with handsome flowers. The mucilaginous root and also the foliage are used for medicinal purposes. The plant succeeds best on damp, somewhat saline soil.

Amarantus Blitum, Linné.

South Europe, North Africa, South West Asia. This annual herb is a favourite plant among allied ones for spinage; but not only species of this genus, but also many other Amarantaceæ serve as culinary herbs.

Amarantus paniculatus, Linné.

In tropical countries of Asia and also America. An annual herb, yielding half a pound of floury nutritious seeds on a square yard of ground in three months, according to Roxburgh. Extensively cultivated in India.

Amelanchier Botryapium, Candolle.

The Grape-Pear of North America. This fruit-tree attains a height of thirty feet. The purplish fruits are small, but of pleasant taste, and ripen early in the season. This bush or tree will live in sandsoil; but it is one of those hardy kinds particularly eligible for our Alps.

Amyris terebinthifolia, Tenore.

Brazil. Is here perfectly hardy, and is content in dry ground without any irrigation. It proved one of the best among the smaller avenue-trees, is beautifully spreading and umbrageous and probably of medicinal value.

Anacyclus Pyrethrum, Candolle.

Countries near the Mediterranean Sea. The root is used medicinally.

Andropogon argenteus, Candolle.

Pronounced by Leybold to be one of the best fodder-grasses of the Cordilleras of Chili. 
Andropogon avenaceus, Michaux. (Sorghum avenaceum, Tilld.)

North and Central America. This tall perennial grass lives in dry, sandy soil, and should here be tried for growth of fodder.

Andropogon bicolor, Roxburgh.

Warmer parts of Asia. One of the annual tall Sorghums.

It ripens its seeds in three or four months from the time of sowing, the produce in good soil being often upwards of one hundredfold. It is a wholesome grain.

Andropogon Calamus, Royle.

Central India. The Sweet Calamus of the Ancients. From this species the Gingergrass Oil of Nemaur is distilled, an article much used in perfumery.

Andropogon cernuus, Roxburgh. (Sorghum cernun Willd.)

One of the Guinea Corns. India, where it is much cultivated, and so also in other tropical countries It is perennial, and forms the "staff of life of the mountaineers" beyond Bengal. It reaches a height of 15 feet, with leaves over three feet long. The thick stems are rooting at the lower joints, and cattle are very fond of them. The grain is white. The specific limits of the various Sorghums are not well ascertained.

Andropogon citratus, Candolle.

The Lemon Grass of India. It yields an essential oil for perfumery; besides it is occasionally used for tea. This applies as well to Andropogon Nardus, L., and some allied grasses.

Andropogon Haleppensis, Sibthorp.

South Europe, warmer parts of Asia and North Africa. A rich perennial grass, cultivated often under the name of Cuba Grass. In our colony hardy up to 2000 feet elevation.

Andropogon Ivarancusa, Roxburgh.

One of the fragrant grasses of North India, much used like A. Schœnanthus.

Andropogon Martini, Roxburgh. (A. flexuosus, Nees.)

On the mountains of India. The fragant Citronella Oil is distilled in Ceylon and elsewhere from the leaves of this species. General Martin observed, that cattle are voraciously fond of this grass; but it imparts its fragrance to meat and milk.

Andropogon muricatus, Retzius.

India. A swamp-grass, with delightfully fragrant roots. 
Andropogon nutans, Linné. (Sorghum nutans, Gray.)

North America. A tall, nutritious, perennial grass, content with dry and barren soil.

Andropogon pertusus, Willdenow.

South Asia, tropical and sub-tropical Australia. Perennial. Mr. Nixon, of Benalla, regards it as one of the best grasses to withstand long droughts, while it will bear any amount of feeding. A. Haleppensis (recorded before) yields a very large hay-crop for mowing, as it may be cut half-a-dozen times in a season, should the land be rich. All kinds of stock have a predilection for this grass. It will mat the soil with its deep and spreading roots; hence it should be kept from cultivated fields.

Andropogon saccharatus, Roxburgh. (Sorghum saccharatum, Pers.)

Tropical Asia. The Broom-Corn. A tall annual species, splendid as a fodder-grass. From the saccharine juice sugar is obtainable. A sample of such, prepared from plants of the Melbourne Botanic Garden, was shown at the Exhibition of 1862. This Sorghum furnishes also material for a wellknown kind of brooms. A variety or a closely allied species yields the Caffir Corn (A. Caffiorum, Kunth). The plant can be advantageously utilized for preparing treacle. For this purpose, the sap is expressed at the time of flowering, and simply evaporated; the yield is about 100 gallons from the acre. In 1860, nearly seven millions of gallons of sorghum treacle were prodnced in the United States. The stem can be used as a culinary vegetable.

Andropogon Schœenanthus, Linné.

Deserts of Arabia. A scented grass, allied to the Indian oil-yielding Andropogons. The medicinal Siri-oil is prepared from the root. A similar species occurs in arid places of the interior of North Australia.

Andropogon Sorghum, Brotero. (Sorghum vulgare, Persoon).

The large Indian Millet or Guinea Corn, or the Durra. Warmer parts of Asia. A tall annual plant. The grains can be converted into bread, porridge and other preparations of food. It is a very prolific corn and to us particularly valuable for green fodder. The panicles are used for carpetbrooms, the fibrous roots for velvet-brushes. A kind of beer called "Merisa" is prepared from the seeds. Many others of the numerous species of Andropogon, from both hemispheres, deserve our attention. 


\section{Anemone Pulsatilla, Linné.}

Europe and Northern Asia. On limestone soil. This pretty perennial herb is of some medicinal importance.

Angophora intermedia, Candolle.

South East Australia. This is the best of the Angophoras, attaining a height of 50 feet, and growing with the rapidity of an Eucalyptus, but being more close and shady in its foliage. It would be one of our best trees to line public roads, and to effect shelter plantations.

Anona Cherimolia, Miller.

Tropical and sub-tropical South America. This shrub or tree might be tried in the frostless lower valleys of East Gipps Land, where humidity and rich soil will also prove favourable to its growth. It yields the Cherimoyer fruit. The flowers are very fragrant.

Anthemis nobilis, Linné.

The true Camomile. Middle and South Europe, North Africa. A well-known medicinal plant, here frequently used as edgings for garden plots. Flowers in their normal state are preferable for medicinal use to those, in which the rayflowers are produced in increased numbers. They contain a peculiar volatile oil and two acids similar to Angelica and Valeriana acid.

Anthemis tinctoria, Linné.

Middle and South Europe, Orient. An annual herb. The flowers contain a yellow dye.

Anthistiria avenacea, F. v. Mueller.

New South Wales and Queensland. A nutritious perennial pasture-grass.

Anthistiria ciliata, Linné, fil. (Anthistivia Australis, R. Brown.)

The well-known Kangaroo Grass, not confined to Australia, but stretching through Southern Asia also, and through the whole of Africa. It is mentioned here, because its growth should be encouraged by every means. There are several species of Anthistiria deserving introduction and naturalisation in our colony.

Anthoxanthum odoratum, Linné.

The scented Vernal Grass. Europe, North and Middle Asia, North Africa. A perennial, not of great value as a fattening grass, yet always desired for the flavour which it imparts to hay. Perhaps for this purpose the scented Andropogons might serve here also. On deep and moist soils it attains its greatest perfection. It is much used for mixing among 
permanent grasses on pastures, where it will continue long in season. It would live well in our Alps. The lamellarcrystalline Cumarin is the principle on which the odour of Anthoxanthemum depends.

Anthriscus Cerefolium, Hoffmann.

Europe and West Asia. The Chervil. An annual culinary plant, its herbage used as an aromatic condiment, but the root seemingly deleterious.

Anthyllis vulneraria, Linné.

The Kidney-Vetch. All Europe, North Africa, West Asia. This perennial herb serves as sheep fodder, and is particularly recommended for calcareous soils. It would also live on our Alps.

Apios tuberosa, Moench.

North America. A climber, with somewhat milky juice. The mealy tubers are edible.

Apium graveolens, Linné.

The Celery. Europe, North Africa, North and Middle Asia. It is here merely inserted with a view of pointing out, that it might be readily naturalized on our sea-shores.

Apium prostratum, La Billardière.

The Australian Celery. Extra-tropical Australia, New Zealand, extra-tropical South America. This also can be utilized as a culinary vegetable.

Apocynum cannabinum, Linné.

On river-banks in North America. This is recorded among plants yielding a textile fibre.

Aponogeton crispus, Thunberg.

From India to New South Wales. The tuberous roots of this water-herb are amylaceous and of excellent taste, though not large. The same remarks apply to A. monostachyus Linné fil.).

Aponogeton distachyos, Thunberg.

South Africa. This curious water-plant, introduced already, might be naturalized in our ditches, swamps and lakes, for the sake of its edible tubers. The scented flowering portion affords spinage.

Aquilaria Agallocha, Roxburgh.

On the mountains of Silhet and Assam. A tree of immense size, probably hardy in our warm forest-valleys. It furnishes the fragrant Calambac or Agallochum wood, known also as Aggur or Tuggur or the Aloe-wood of commerce, famed since ancient times. The odorous portion is only partially distributed through the stem. This wood is also of medicinal value. 
Arachis hypogrea, Linné.

The Earth-nut, Pea-nut or Ground-nut. Brazil. The seeds of this annual herb are consumed in a roasted state, or used for pressing from them a palatable oil. The plant is a very productive one, and yields a very quick return. It ranks also as a valuable fodder-herb; the hay is very nutritious, much increasing the milk of cows. A light somewhat calcareous soil is best fitted for its growth. On such soil, 50 bushels may be obtained from the acre.

Aralia cordata, Thunberg.

China. The young shoots provide an excellent culinary vegetable.

Araucaria Bidwilli, Hooker.

Bunya Bunya. Southern Queensland. A tree 150 feet in height, with a fine-grained, hard and durable wood, particularly valuable for furniture; the seeds are large and edible.

Araucaria Brasiliensis, A. Richard.

Brazilian Pine. A tree 180 feet high, producing edible seeds. Ought to be tried in our fern-gullies.

Araucaria Cookii, R. Brown.

In New Caledonia, where it forms large forests. Height of tree 200 feet.

Araucaria Cunninghami, Aiton.

Moreton-Bay Pine. East Australia, between $14^{\circ}$ and $32^{\circ} \mathrm{S}$. latitude. The tree gets 130 feet high. The timber is used for ordinary furniture.

Araucaria excelsa, R. Brown.

Norfolk-Island Pine. A magnificent tree, sometimes 220 feet high, with a stem attaining ten feet in diameter. The timber is useful for ship-building and many other purposes.

Araucaria imbricata, Pavon.

Chili and Patagonia. The male tree attains only a height of 50 feet, but the female reaches 150 feet. It furnishes a hard and durable timber, as well as an abundance of edible seeds, which constitute a main article of food of the natives. Eighteen good trees will yield enough for a man's sustenance all the year round. In our lowlands of comparative slow growth, but likely of far more rapid development, if planted in our ranges.

Araucaria Rulei, F. v. Mueller.

New Caledonia. A magnificent tree with large shining foliage, doubtless not merely of decorative but also of utilitarian value. A closely-allied species, A. Muelleri (Brogniart), comes with A. Balansæ and A. montana from 
the same island. The New Guinea Araucaria should also be introduced.

Arbutus Menziesii, Pursh.

North-West America. An evergreen tree, attaining a height. of 150 feet. I belongs to the coast-tract exclusively. Wood exceedingly hard. The tree requires a deep loamy soil (Bolander); it would here be valuable at least as a highly ornamental garden-plant.

Archangelica officinalis, Hoffmann.

Arctic zone and mountain regions of Europe. The stalks are used for confectionery; the roots are of medicinal use. Only in our Alps would this herb fully establish its value. The root is biennial and used in the distillation of some cordials.

Arctostaphylos uva ursi, Sprengel.

Alpine and Arctic Europe, North Asia and North America. A medicinal small shrub, which here could best be reared in the heath-moors of our Alpine regions.

Argania Sideroxylon, Roemer and Schultes.

The Argan-tree. Western Barbary, on dry hills. Its growth is here found to be slow; but it is a tree of longevity. Though comparatively low in stature, its foliage occasionally spreads to a circumference of 220 feet. It sends out suckers from the root. The fruits serve as food for cattle in Morocco; but here the kernels would be more likely to be utilized by pressing the oil from them.

Aristolochia Indica, Linné.

Tropical Asia and Polynesia. A perennial climber; the leaves famed as an alexipharmic. Can only be grown in places free from frost.

Aristolochia recurvilabra, Hance.

The green Putchuck of China. A medicinal plant, largely obtained at Ningpo. The present value of its export is from $£ 20,000$ to $£ 30,000$ annually.

Aristolochia Serpentaria, Linné.

The Snake-root of North America. The root of this trailing herb is valuable in medicine; it contains a peculiar volatile oil. Several other Aristolochiæ deserve culture for medicinal purposes, for instance,-Aristolochia ovalifolia (Guaco) and A. anguicida, from the mountains of Central America, should they prove hardy.

Aristotelia Macqui, L'Heritier.

Chili. The berries of this shrub, though small, have the pleasant taste of bilberries, and are largely consumed in Chili. The plant would thrive in our forest-valleys. 
Arnica montana, Linné.

Colder parts of Europe. This pretty herb is perennial, and of medicinal value. It is eligible for our sub-alpine regions. The active principles are:-Arnicin, volatile oil, cupron and capryl acid.

Arracacha xanthorrhiza, Bancroft.

Mountain regions of Central America. An umbelliferous herb. The roots are nutritious and palatable. There are yellow, purple and pale varieties.

\section{Artemisia Absinthium, Linné.}

The Wormwood. Europe, North and Middle Asia, and North Africa. A perennial herb, valuable as, a tonic and anthelmintic. Several other species of Artemisia deserve cultivation for medicinal purposes. Active principles:Absinthin, an oily substance indurating to a crystalline mass ; a volatile oil peculiar to the species.

\section{Artemisia Cina, Berg.}

Kurdistan. This herb furnishes the genuine Santonica seeds (or rather flowers and fruits), as a vermifuge of longestabished use. Some other Asiatic species yield a similar drug.

Artemisia Dracunculus, Linné.

The Tarragon or Estragon. North Asia. A perennial herb, used as a condiment. Its flavour rests on two volatile oils, one of them peculiar to the plant.

Artemisia Mutellina, Villars.

Alps of Europe. This aromatic, somewhat woody plant deserves to be established in our snowy regions.

Artemisia Pontica, Linné.

Middle and South Europe, West Asia. More aromatic and less bitter than the ordinary wormwood. Many other species of this genus deserve attention of the culturist.

Arundinaria falcata, Nees.

The Ringal or Ningala Bamboo of the Himalayas, at elevations from 3500 to 10,000 feet, forming close and dense thickets. It rises to the height of 40 feet, the canes durable, attaining a diameter of only four inches, applied to manifold useful purposes. The closely allied Jurboota Bamboo of Nepal, which occurs only in the cold altitudes of from 7000 to 10,000 feet, differs in solitary stems, not growing in clumps. The Tham or Khaptur Bamboo is from a still colder zone, at from 8500 to 11,500 feet, only 500 feet or less below the inferior limits of perpetual glaciers. (Major Madden.) 
Arundinaria macrosperma, Michaux.

Southern States of North America,-particularly on the Missisippi. This Bamboo-like reed forms there the canebrakes. It requires to be replanted after flowering in the course of years. Height 20 feet.

Arundo Ampelodesmos, Cyrillo.

South Europe, North Africa. Almost as large as A. Gynerium. The tough flower-stems and leaves readily available for tying.

Arundo conspicua, G. Forster.

New Zealand and Chatham Islands. Although not strictly an industrial plant, it is mentioned here as important for scenic effect, flowering before the still grander A. Sellowiana comes in bloom.

Arundo Donax, Linné.

The tall evergreen lasting Bamboo-reed of South Europe and North Africa. It is one of the most important plants of its class for quickly producing a peculiar scenic effect in picturesque plantations, also for intercepting at once the view to unsightly objects, and for giving early shelter. The canes can be used for fishing-rods.

Arundo Karka, Roxburgh.

India, China, Japan. The Durma mats are made of the split stems of this tall reed.

Arundo Pliniana, Turra.

On the Mediterranean and Adriatic Seas. A smaller plant than A. Donax, with more slender stems and narrower leaves, but similarly evergreen, and resembling the Donax reed also in its roots.

Arundo saccharoides, Grisebach. (Gynerium saccharoides, Humboldt).

Northern parts of South America. This species is here not yet introduced; but it is likely to prove hardy. Like the following, it is conspicuously magnificent.

Arundo Sellowiana, Schultes. (Arundo diocia, Spreng. non Louriero. Gynerium argenteum, Nees.)

The Pampas Grass of Uruguay, Paraguay and the La Plata

State. A grand autumnal flowering reed, with gorgeous feathery panicles. As an industrial plant it deserves here a place, because paper can be prepared from its leaves.

Asparagus acutifolius, Linné.

In all the countries around the Mediterranean Sea, also in the Canary Islands. Although a shrubby Asparagus, yet the root-shoots, according to Dr. Heldreich, are collected in 
Greece, and are tender and of excellent taste, though somewhat thinner than those of the ordinary herbaceous species. The shrub grows on stony rises, and the shoots are obtained without cultivation. A. aphyllus L. and A. horridus L., according to Dr. Reinhold, are utilised in the same manner, and all may probably yield an improved produce by regular and careful culture.

Asparagus albus, Linné.

Countries around the Mediterranean Sea and Canary Islands. Serves for garden hedges.

Asparagus laricinus, Burchell.

South Africa. Dr. Pappe observes of this shrubby species, that with some other kinds of that country it produces shoots of excellent tenderness and aromatic taste.

Asparagus officinalis, Linné.

Europe, North Africa, North Asia. The well-known Asparagus plant, which, if naturalized on our coast, would aid in binding the sand. The foliage contains Inosit-Sugar; the shoots contain Asparagin. Seaweeds are a good additional material for forcing Asparagus.

Astragalus arenarius, Linné.

Europe and Western Asia. A perennial fodder-herb for our sandy desert-country. The species, numerous in various parts of Europe and Asia, in California and some other parts of the globe, deserve attention for pastoral and agronomic purposes.

Astragalus Cephalonicus, Fischer. (A. aristatus, Sibthorp.) Cephalonia. A small shrub, yielding a good Tragacanth; and so probably also the true A. aristatus of l'Heritier is producing it.

Astragalus Cicer, Linné.

Middle and South Europe and Middle Asia. A nutritious and tasty perennial herb, much sought by pastoral animals. It requires, according to Langethal, deep friable grounds, and like most leguminous herbs calcareous ingredients in the soil.

Astragalus Creticus, Lamarck.

Candia and Greece. A small bush, exuding the ordinary vermicular Tragacanth. The pale is preferable to the brown sort.

Astragalus glycyphyllos, Linné.

Europe and North Asia. Succeeds on light soil, also in forest regions. It has been recommended as a perennial substantial fodder-plant. 
Astragalus gummifer, La Billardière.

Syria and Persia. This shrub also yields a good kind of Tragacanth.

Astragalus hypoglottis, Linné.

In the colder regions of Europe, Asia and North America. This perennial plant is regarded as a good fodder-herb on calcareous and gravelly soil, and would likely be of importance for our alps. Of the enormous number of supposed species of this genus (according to Boissier, not less than 750, merely in Asia Minor and the adjoining countries) many must be of pastoral value, like some of our closely-allied Swainsonas, though they also may include deleterious species.

Astragalus parnassi, Boissier (A. Cylleneous, Heldreich).

Greece. This small shrub furnishes there almost exclusively the commercial Tragacanth. It ascends to elevations of 7000 feet, becomes therefore alpine.

Astragalus strabiliferus, Royle.

Asiatic Turkey. The brown Tragacanth is collected from this species.

Astragalus verus, Olivier.

Asiatic Turkey and Persia. This shrub furnishes the Takalor or Smyrna Tragacanth, or it is derived from an allied species.

Atalantia glauca, J. Hooker.

New South Wales and Queensland. This desert-lemon is mentioned here to draw attention to the likelihood of its improving in culture, and to its fitness for being grown in arid land.

Atriplex hortensis, Linné.

North and Middle Asia. The Arroche. An annual Spinage plant.

Atriplex nummularium, Lindley.

From Queensland through the desert-tracts to Victoria and South Australia. One of the tallest and most fattening and wholesome of our pastoral salt-bushes, and although a native plant even here highly recommendable for artificial rearing, as the spontaneously growing plants, by close occupation of the sheep and cattle runs, have largely disappeared, and as this useful bush even here in many wide tracts does not exist.

Atriplex spongiosum, F. v. Mueller.

Through a great part of Central Australia, extending to the west coast. Available like the preceding, and like A. halimoides, A. vesicarium, A. holocarpum and several other native species for salt-bush culture. Unquestionably some of 
the scrubby Extra-Australian species, particularly those of the Siberian and Californian steppes, could be transferred advantageously to our salt-bush country to increase its value for sheep-pasture.

Atropa Belladonna, Linné.

The Deadly Nightshade. South and Middle Europe and Western Asia. A most important perennial medicinal herb. The highly powerful Atropin is derived from it, besides another alkaloï, the Belladonnin.

Avena elatior, Linné.

Europe, Middle Asia, North Africa. This tall grass should not be passed altogether on this occasion, although it becomes easily irrepressible on account of its wide-creeping roots. It should here be chosen for dry and barren tracts of country, it having proved to resist our occasional droughts even better than Rye-grass. The bulk yielded by it is great, it submits well to depasturing, and gives two or three crops of hay annually: it is, however, not so much relished by animals as many other grasses.

Avena fatua, Linné.

Wild Oat. Europe, North Africa, North and Middle Asia, eastward as far as Japan. The experiments of Professor Buckman indicate, that our ordinary Culture-Oat (Avena sativa, L.) is descended from this plant.

Avena flavescens, Linné. (Trisetum flavescens, Beauv.)

Yellowish Oat-Grass. Europe, North Africa, Middle and North Asia, eastward as far as Japan. One of the best of perennial meadow-grasses, living on dry soil : fitted also for our Alps. Lawson observes that it yields a considerable bulk of fine foliage, and that it is eagerly sought by sheep, but that it thrives best intermixed with other grasses. It likes particularly limestone soil, where it forms a most valuable under-grass, but is not adapted for poor sand nor will it stand well the traversing of pasture animals (Langethal).

Avena pratensis, Linné.

Meadow Oat-Grass. Europe, North Asia. It thrives well on dry, clayey soil ; it produces a sweet fodder, but not in so great proportion as several other less nutritious grasses. It is perennial, and well adapted for our snowy mountains, where it would readily establish itself, even on heathy moors. Recommended by Langethal for arid ground, particularly such as contains some lime, being thus as valuable as Festuca ovina. Eligible also for meadows under a system of irrigation. 
Avena pubescens, Linné.

Downy Oat-Grass. Europe, North and Middle Asia. A sweet perennial grass, requiring dry but good soil, containing lime. It is nutritious and prolific. One of the earliest kinds, but not well resisting traffic. Several good Oatgrasses are peculiar to North America and other parts of the globe. Their relative value as fodder-grasses is in many cases not exactly known, nor does the limit assigned to this little treatise allow of their being enumerated on this occasion.

Averrhoa Carambola, Linné.

Insular India. Dr. Hooker having found this small tree on the Upper Indus as far as Lahore, it may reasonably be anticipated that success would attend its rearing in the warmest and moistest parts of our colonial territory. The fruit occurs in a sweet and acid variety; the former is raw available for the table, the other for preserves. That of A. Bilimbi (Linné) is of similar use.

Avicennia officinalis, Linné.

From the coasts of South Asia to those of South Africa, all Australia and New Zealand. It is proposed by Dr. Herm. Behr, to plant this tree for consolidating muddy tidal shores. Azima tetracantha, Lamarck.

From South India to South Africa. A hedge-bush, growing freely in every kind of soil.

Baccharis pilularis, Candolle.

California. This evergreen bush, like B. consanguinea, is grown for hedges, used also for garlands, wrappers of flower bouquets and many decorative purposes, as cut branches do not wither for a considerable time. It attains a height of 15 feet (Professor Bolander).

Backhousia citriodora, F. v. Mueller.

South Queensland. Though only a small tree it is well worth cultivating for the fragrance of its lemon-scented foliage.

Bactris Gasipæs, Humboldt. (Guilielma speciosa, Mart.) The Peach Palm of the Amazon River, ascending to the warm-temperate regions of the Andes. Stems clustered, attaining a height of 40 feet. Dr. Spruce describes the large bunches of fruits as possessing a thick, firm and mealy pericarp, which, when cooked, has a flavour between potato and chestnut, but superior to either. To us, however, this palm would be mainly an object of grandeur. It is likely to endure our clime in the fern-tree gullies. 
Baloghia lucida, Endlicher. (Codicum lucidum, J. M.)

East Australia. A middle-sized tree. The sap from the vulnerated trunk forms, without any admixture, a beautiful red indelible pigment.

Balsamodendron Ehrenbergi, Berg.

Deserts of Arabia. This tree yields the Myrrha resin, but perhaps some other species may produce the same substance. Professor Oliver unites this with the following species.

Balsamodendron Mukul, Hooker.

Scinde and Beludschistan. Yields the Bdellium resin.

Balsamodendron Opobalsamum, Kunth. (B. Gileadense, Kunth).

Arabia and Nubia. This species furnishes Mekka or Gilead Balsam. B. Capense (Sonder) is a closely allied species from extra-tropical South Africa. Many other Balsam shrubs deserve introduction.

Bambusa arundinacea, Roxburgh.

The Thorny Bamboo of India. It requires rich, moist soil, and delights on river-banks. Is is of less height than Bambusa vulgaris; it also sends up from the root numerous stems, but with bending branches, thorny at the joints. According to Kurz it will thrive in a climate too dry for B. Tulda and B. vulgaris. The seeds of this and some other Bamboos are useful as food for fowls.

Bambusa aspera, Poiret.

Indian Archipelagus. Attains a height of 120 feet. Stems very strong and thick. This species ascends to elevations of 4000 feet.

Bambusa Blumeana, Schultes.

Insular India. This Bamboo with its spiny buds and dependent branchlets is, according to Kurz, one of the best for cattle-proof live hedges among the Asiatic species. In continental India B. nana and B. arundinacea are much used for the same purpose. Periodic trimming is required.

Bambusa spinosa, Roxburgh.

Bengal. A Bamboo attaining 100 feet in height. The central cavity of the canes is of less width than in most other species, thus the strength for many technic purposes is increased.

Bambusa vulgaris, Wendland.

The large unarmed Bamboo of Bengal. It attains a height of 70 feet, and stems may attain even a length of 40 feet in one season, though the growth is slower in our clime. It has proved to be capable of resisting the occasional night-frost of 
the lowlands of Victoria. It is the best for building bamboohouses. Immersion in water for some time renders the cane still firmer. To the series of large thornless Bamboos belong also Bambusa Tulda and Bambusa Balcooa of India, and Bambusa Thouarsii from Madagascar and Bourbon. These Bamboos are much used for various kinds of furniture, mats, implements and other articles. Besides this, Mrr. Kurz enumerates as among the best Asiatic Bamboos for building purposes :-Gigantochloa aspera, G. maxima, G. atter; while Mr. Teysmann for the same purpose notes G. apus. Kurz recommends further Bambusa arundinacea, B. Balcooa, B. Brandisii, B. polymorpha, Dendrocalamus Hamiltoni, Schizostachyum Blumei. In the Moluccas, according to Costa, Gigantochloa maxima or an allied species produces stems thick enough to serve, when slit into halves, for canoes. Bambons serve for masts and spars of small vessels. Bambusa Balcooa was found by Wallich to grow 12 feet in 23 days. Bambisa Tulda, according to Roxburgh, has grown at first at the rate of from 20 to 70 feet in a month. Fortune noticed the growth of several Chinese Bamboos to be two to two-and-a-half feet a day. There are many other kinds of Bamboo eligible among the species from China, Japan, India, tropical America, and perhaps tropical Africa. One occurs in Ainhem's Land.

Barbaræa vulgaris, R. Brown.

In the cooler regions of all parts of the globe, ascending to alpine zones. This herb furnishes a wholesome salad. As with other raw vegetables, particularly watercress (Nasturtium aquaticum, Trag), circumspect care is necessary to free such salads from possibly adherent echinococcus-ova or other germs of entozoa, particularly in localities where hydatids prevail.

Barosma serratifolia, Willdenow.

South Africa. This shrub supplies the medicinal Buccoleaves. B. crenulata, Hook. (Diosma crenulata, L.), is only a variety of this species. Active principles-a peculiar volatile oil, a peculiar resin, and a crystalline substance called Diosmin.

Basella lucida, Linné.

India. Perennial. This spinage-plant has somewhat the odour of Ocimum Basilicum; other species serve also culinary purposes.

Basella rubra, Linné.

From South Asia to Japan. This annual or biennial herb serves as a spinage of pleasant coloration. 
Batis maritima, Linné.

Central America and northward to Florida, also in the Sandwich Islands. This halorageous shrub can be used to fix tidal sediments for the reclamation of valuable harbour-lands.

Beesha elegantissima, Hasskarl.

Java, on mountains about 4000 feet high. Very tall and exceedingly slender; the upper branches pendulous. A hardy species of Bamboo.

Benincasa cerifera, Savi.

India. This annual plant produces a large edible gourd, which in an unripe state forms part of the composition of many kinds of currie.

Berberis Asiatica, Roxburgh.

Himalaya. One of the best among numerous species with edible berries. Among these may specially be mentioned B. lycium (Royle) and B. aristata (Candolle), which also yield valuable yellow dye-wood (Dr. Rosenthal).

Berberis buxifolia; Lamarck.

From Magelhaen's Straits to Chili. This bush, according to Dr. Philippi, is the best among the South American species for berries, which are comparatively large, black, hardly acid, but slightly astringent. In Valdivia and Chiloe they are frequently consumed.

Berberis Darwinii, Hooker.

Chiloe and South Chili. Considered one of the most handsome of all shrubs for garden hedges. Several other evergreen Berbery shrubs serve the same purpose.

Beta vulgaris, Linné**

The Beet or Mangold Root. Middle and South Europe, Middle Asia, North Africa. This well-known perennial or biennial herb ought to engage the general and extensive attention of our farming population. The herb is most valuable as a palatable and nutritious spinage; the root is of importance not only as a culinary vegetable, but, as well known, also for its content of sugar, fit to be crystallised. That of Beet, indeed, is now almost exclusively consumed in Russia, Germany, Austria, France, Sweden and Belgium; and these countries not only produce the Beet sugar, but also export it largely to the neighbouring States. The white Sicilian Beet is mainly used for salads, spinage and soups. The thick-ribbed variety serves like Asparagus or Seakale, dressed like Rhubarb. Cereal soil, particularly such as is fit for barley, is generally adapted also for the culture of Beet. The rearing of the root, and the manufacture of the 
sugar, can be studied from manifold works; one has been compiled by Mr. N. Levy, of this city. A deeply-stirred, drained soil, rich in lime, brings the saccharine variety of Beet to the greatest perfection. The Imperial Beet yields from 12 to 20 per cent. sugar. The Castlenauderry, the Magdeburg, the Siberian Whiterib and the Vilmorin Beet are other varieties rich in sugar. About five lbs. of seeds are required for an acre. In rotation of crops, the Beet takes its place best between barley and oats. In Middle Europe the yield averages 14 tons of Sugar Beet to the acre, and as many hundred weight of raw sugar. The mercantile value of the root, at our distilleries, ranged from $20 \mathrm{~s}$. to $30 \mathrm{~s}$. per ton. In our clime, the Beet harvest can be extended over a far longer time of the year than in Middle Europe. The extraction of the sap is effected generally by hydraulic pressure. The juice is purified with lime and animal coal. Excess of lime is removed by carbonic acid, and the purified and decolourized juice is evaporated in vacuum pans, with a view to preventing the extensive conversion of the crystallisable sugar into treacle. The production of Beet-sugar needs far less labour than that of cane-sugar, and the harvest is obtained in so short a time as eight months. Beet has shown itself subject neither to alarming diseases nor to extensive attacks of insects. Beet is grown in extra-tropical zones like ours, while the sugar-cane is a plant confined to tropical and sub-tropical latitudes. Beet culture, by directly or indirectly restoring the refuge, ameliorates the soil to such an extent, that in some parts of Germany land, so utilized, has risen to fourfold its former value. Beet, furthermore, affords one of the most fattening stable-fodders; and thus again an ample supply of manure. In Middle Europe now about one-sixth of all the arable land is devoted to Beet, yet the produce of cereals has not become reduced, while the rearing of fattened cattle has increased. Notwithstanding a heavy tax on the Beet-sugar factories in Europe, the industry has proved prosperous, and assumes greater and greater dimensions. In 1865, the sugar consumption of Europe amounted to $31,676,497$ cwt., one-third of which had been locally supplied by the Beet, from over one thousand Beetsugar factories. Treacle obtained from beet is distilled for alcohol. For establishing remunerative factories on a large and paying scale, it has been suggested that farmers' companies might be formed. For ascertaining the percentage of sugar in Beet, saccharometers are used. In Germany, some scientific periodicals are exclusively devoted to the fostering of this industry. 


\section{Betula alba, Linné.*}

The ordinary Birch of Europe and extratropical Asia. It attains a height of 80 feet, and would here thrive best in moist glens of the ranges, or in the higher regions of our mountains, where it would form up at the Alpine zone excellent shelter plantations. The durable bark serves for roofing. Wood white, turning red. The oil of the bark is used in preparing the Russian leather.

Betula lenta, Willdenow.

The Cherry Birch of North America. A tree of middle size, liking moist ground. Bark aromatic. Wood rose-coloured or dark, fine-grained, excellent for furniture. Several Birches occur in Japan, which might well be tried here.

Betula lutea, Michaux.

The yellow or grey Birch of North-East America. Adapted for moist forest land. In size and most other respects similar to B. lenta.

Betula nigra, Linné.

The River Birch of North America. One of the tallest of Birches. If grown on the banks of a limpid stream, it will bear intense heat. The wood is compact, of a light colour.

Betula papyracea, Aiton.

The Paper Birch of North America. A larger tree than B. alba, with a fine-grained wood and a tough bark; much used for portable canoes. It likes a cold situation.

Boehmeria nivea, Gaudichaud.*

The Ramee or Rheea. Southern Asia, as far east as Japan. This bush furnishes the strong and beautiful fibre woven into fabric, which inappropriately is called grass-cloth. The bark is softened by hot water or steam, and then separable into its tender fibres. The best is obtained from the young shoots; it is glossy, tough and lasting, combining to some extent the appearance of silk with the strength of flax. The ordinary market value of the tibre is about $£ 40$ per ton; but Dr. Royle mentions that it has realized, at times, £120. The seeds are sown on manured or otherwise rich and friable soil. In the third year, or under very favourable circumstances even earlier, it yields its crops, as many as three annually. The produce of an acre has been estimated at two tons of fibre. This latter, since Kaempfer's time, has been known to be extensively used for ropes and cordage in Japan. Our rich and warmest forest-valleys seem best adapted for the Ramee, as occasional irrigation can be also there applied. In the open grounds of Victoria it 
suffers from the night-frosts, although this does not materially injure the plant, which sends up fresh shoots, fit for fibre, during the hot season. The plant has been cultivated and distributed since 1854, in the Botanic Garden of Melbourne, where it is readily propagated from cuttings, the seeds ripening rarely there. Cordage of this Boehmeria is three times as strong as that of hemp. Other species require to be tested, among them the one which was recently discovered in Lord Home's Island, namely Boehmeria calophleba.

Bongardia Rauwolfi, C. A. Meyer.

From Greece through Turkey to the Caucasus. A perennial herb, the leaves of which are utilised like culinary sorrel.

Boronia megastigma, Nees.

In West Australia on margins of swamps. This remarkable bush is recorded here as an emblem of mourning, its external blackish flowers rendering it especially eligible for graves. Industrially it interests us on account of its powerfully fragrant blossoms, for the sake of which this bush will deserve to be cultivated. The scent might be extracted by Mr. Bosisto's process.

Borrago officinalis, Linné.

South Europe, Orient. An annual herb, occasionally used for medicinal purposes or as an admixture to salad.

Boswellia papyrifera, A. Richard.

Morocco, Nubia, and Abyssinia, forming entire forests about Bertat on the Atlas. This tree exudes a kind of Olibanum resin and represents apparently one of the hardest species of this and allied genera.

Bouteloua barbata, Lagasca.

North and Central America. One of the Gramma-grasses of the prairies, called with some other species also Muskit-grass. Annual. For nutritive value famed.

Brabejum stellatifolium, Linné.

South Africa. The nuts of this shrub are edible, resembling those of our Macadamia ternifolia, to which also in foliage and flowers Brabejum is closely allied. The nuts are also similar to those of the Chilian Guevina Avellana. The fruit should be roasted, as otherwise it is deleterious.

Brachychiton acerifolium, F. v. Mueller.

The East Australian Flame-tree. An evergreen shade-tree, with magnificent trusses of crimson blossoms. Like B. populneum (R. Br.), eligible for promenade-lines, when celerity of growth is no object. The mucilaginous sap, when exuded, indurates to a kind of Tragacanth. 


\section{Brassica alba, Visiani. (Sinapis alba, Linné.)}

White Mustard. Europe, North Africa, North and Middle Asia. An annual. The seeds are less pungent than those of the Black Mustard, but used in a similar manner. The young leaves of both are useful as a culinary and antiscorbutic salad. Dr. Masters enumerates Brassica Chinensis, B. dichotoma, B. Pekinensis, B. ramosa and B. glauca among the mustards, which nndergo cultivation in various parts of Asia, either for the fixed oil of their seeds or for their herbage. From $15 \mathrm{lbs}$. to $20 \mathrm{lbs}$. of seeds of the White Mustard are required for an acre. In the climate of California, similar to ours, $1400 \mathrm{lbs}$. of seeds have been gathered from an acre.

\section{Brassica Chinensis, Linné.}

China and Japan. Serves like the following for cabbage, and may in cultivation produce new varieties. B. cretica (Lam.), a woody Mediterranean species.

Brassica juncea, J. Hook and Thoms. (B. Willdenowii, Boiss.; Sinapis juncea, Linné).

From Middle Africa to China. According to Colonel Drury, cultivated all over India for sarepta mustard seeds; also a good salad plant.

\section{Brassica nigra, Koch. (Sinapis nigra, Linné.)}

The Black Mustard. Europe, North Africa, Middle Asia. An annual. The seeds, simply crushed and then sifted, constitute the mustard of commerce. For medicinal purposes the seeds of this species are preferable for sinapisin and other purposes. In rich soil this plant is very prolific; and in our forest-valleys it is likely to remain free from the attack of aphis. Chemical constituents:-a peculiar fixed oil, crystalline sinapin, the fatty sinapisin, Myron-acid and Myrosin.

\section{Brassica oleracea, Linné.}

An annual or biennial coast-plant, indigenous to various parts of Europe. It is mentioned here with a view of showing that it might be naturalized on our rocky and sandy sea-shores. From the wild plant of the coast originated various kinds of cabbages, broccoli, cauliflower, Brussels sprouts, kail, kohlrabi, \&c. Other races of this species are collectively represented by Brassica Rapa, L. (B. campestris, L.), the wild Navew, yielding most of the varieties of turnips, some with other cultivated forms transferred to us from ancient times. Again, other varieties are comprehended within Brassica Napus, L., such as the Swedish and Teltower turnips, while the rape-seed, so important for its oil (Colza), 
is also derived from a form of B. Napus. The rape should be produced here as an agrarian produce, giving a rapid return, wherever it should remain free of aphis. The hardier turnips could be produced on our highest Alps, as they are grown still within the Arctic circle, and, according to Dr. J. Hooker, at a height of 15,000 feet in the Himalaya mountains.

Bromus asper, Murray.

Europe, North and Middle Asia. A good perennial fodder grass for wood-regions, but like Festuca gigantea late in the season.

Bromus erectus, Hudson.

Europe, North Africa. Important as a perennial nutritious grass for dry limestone regions; much liked by cattle and sheep.

Bromus unioloides, Humboldt.* (B. Schraderi, Kunth.)

Here called the Prairie Grass. From Central America it has spread over many parts of the globe. The writer saw it disseminated in the mountains of St. Vincent's Gulf as early as 1847. It is one of the richest of all grasses, grows continuously and spreads readily from seeds, particularly on fertile and somewhat humid soil, and has proved as a lasting and nutritious fodder-grass or pasture-grass one of our best acquisitions.

Broussonetia papyrifera, Ventenat.

The Paper Mulberry. Islands of the Pacific Ocean, China, Japan, perhaps only truly indigenous in the last-named country. The bast of this tree or shrub can be converted into very strong paper. It can also be used as a textile fabric; furthermore the fabrics made from it can be dressed with linseed oil for waterproof coverings. In cultivation the plant is kept like an osier. The leaves cannot be used for silkworms. European fabrics have largely superseded the clothing made of this plant in the South Sea Islands.

Buchloa dactyloides, Torrey.*

The true Buffalo-grass of Kansas. Diœcious, creeping, only rising to half a foot or less. It is extremely fattening, but apt to be suppressed by coarser grasses on places where these are not trampled out or kept down by the pasture animals.

Buddleya Madagascariensis, Lamarck.

Madagascar. Of the numerous species of Buddleya, the most eligible for shelter copses on account of its great size and always tidy appearance, as well as vigour and celerity of growth. It is ever-flowering. 
Butea frondosa, Roxburgh.

The Dhak or Pulas of India. This magnificent tree extends to the Himalaya mountains, and therefore might here be a proper one for acclimatisation. It is very rich in a peculiar kind of kino. The Lac-insect is also nourished by this tree, and might be transferred to us with it.

Butomus umbellatus, Linné.

The Flowering Rush. Europe, North and Middle Asia. This elegant perennial water-plant is mentioned here more for its value in embellishing our lakes and watercourses than for the sake of its roots. The latter, when roasted, are edible. The plant would live in our sub-alpine rivulets.

Buxus sempervirens, Linné.

The Turkey Box-tree. South Europe, North Africa, SouthWest Asia. This slow-growing tree should timely be planted, to provide the indispensable box-wood for wood engravers and musical instrument makers, as yet no good substitute for it having been discovered. The box-tree needs calcareous soil for its best development. Among allied species B. Balearica attains a height of 80 feet. Other congeners are B. subcolumellaris, B. Cubana, B. Purdieana, B. citrifolia, B. acuminata, B. lævigata, B. Vahlii, B. gonoclada, B. retusa, B. glomerata, B. Wrightii, all from West India; further, B. Madagascarica, B. longifolia from Turkey, B. Wallichiana from the Himalayas and B. microphylla from Japan, but neither of any of these, nor of the various species of the allied Indian genus Sarcococca, nor of several species of the Andine genus Styloceras, does it appear to be known what relation their wood may hold to that of the true boxtree, and whether they are more rapid in growth.

Cæsalpinia brevifolia, Bentham.

Chili. The pods of this shrub are extraordinarily rich in tannic acid, and hence valuable for tanneries (Philippi).

Cæesalpinia coriaria, Willdenow.

Wet sea-shores of Central America. Might be naturalised in our salt marshes. Colonel Drury states, that each fullgrown tree produces annually about $100 \mathrm{lbs}$. of pods, the husk of which, commercially known as Divi-Divi, is regarded as the most powerful and quickly acting tanning material in India. The mercantile price of the pods is from $£ 8$ to $£ 13$ per ton.

Cæesalpinia Gilliesii, Wallich. (Poinciana Gilliesii, Hooker.) La Plata States. This beautiful hardy bush can be utilized for hedges. 
Cæsalpinia Sappan, Linné.

South Asia. The wood funishes red dye. This shrub can also be utilised for hedges. It would likely prove hardy here in places free of frost.

Cæsalpinia sepiaria, Roxburgh.

South Asia, east to Japan. Can be utilized in the warmer tracts of our colony as a hedge-bush. It can advantageously be mixed for hedge-growth with Pterolobium lacerans (R. Br.), according to Dr. Cleghorn.

Cæsalpinia tinctoria, Humboldt.

Chili. The bark yields a red dye.

Cajanus Indicus, Candolle.

The Catjang; in Assam, called Gelooa-mah. A shrubby plant of India and tropical Africa, probably available for profitable culture and naturalization in the warmer parts of our colony. It sustains itself on dry ground, and yields the pulse known as Dhal, Urhur and Congo-pea. The plant lasts for about three years. Attains a height of 15 feet, and has yielded in the richest soil of Egypt 4000 lbs. of peas to the acre. A crop is already obtained in the first year. The seeds can be used as peas in the green as well as mature state. Several species of Cajanus of the Atylosia section, indigenous to the warmer parts of Australia, might be tested here for the sake of the economic value of their seeds. The insect, active in the formation of Lac, lives extensively on the Cajanus, according to Mr. T. D. Brewster, of Assam. Silkworms live also on it.

Calamagrostis longifolia, Hooker.

North America. Excellent for fixing drift-sand.

Calamintha Nepeta, Hoffmansegg.

It is of the strongest odour among several species, but not of so pleasant a scent as C. incana (Boiss.) and C. grandiflora (Moench).

Calamintha officinalis, Moench.

Middle and South Europe and Middle Asia, North Africa. A perennial herb, used like melissa as a condiment.

Calamus montanus, T. Anderson.

Himalaya, up to 6000 feet. A hardy climbing palm. The aged canes are naked. "The light but strong suspensionbridges, by which the large rivers of Sikkim are crossed, are constructed of this palm. It supplies material for the strongest ropes for dragging logs of wood from the forests. The most durable baskets and the cane-work of chairs are manufactured from the slit stems. Walking-sticks and 
riding-canes made of this species are exported from Sikkim in considerable quantity." Many other Calami serve similar purposes, but probably few or perhaps none are equally hardy.

Callitris quadrivalvis, Ventenat.

North Africa. A middling-sized tree, yielding the true Sandarac resin.

Calyptranthes aromatica, St. Hilaire.

South Brazil. This spice-shrub would likely prove hardy here, the flower-buds can be used almost like cloves, the berries like allspice. Several other aromatic species are eligible for test culture.

Camelina sativa, Crantz.

Middle and South Europe, temperate Asia. An annual herb, cultivated for the sake of its fibre and the oil of its seeds. It is readily grown after corn crops, yields richly even on poor soil and is not atacked by aphis. Mr. W. Taylor obtained 32 bushels of seeds from an acre, and from these $540 \mathrm{lbs}$. of oil. The return is within a few months.

Canna Achiras, Gillies.

Mendoza. One of the few extra-tropic Cannas, eligible for Arrow-root culture.

Canna coccinea, Roscoe.

West India. Yields with some other Cannas the particular Arrow-root, called "Tous les mois."

Canna edulis, Edwards.

The Adeira of Peru. One of the hardiest of Arrow-root plants, and thus well-adapted for our clime. Seeds, even if many years old, will germinate. This species has yielded excellent starch at Melbourne, Western Port, Lake Wellington, Ballarat and other localities, from plants supplied at the Botanic Garden. The Rev. Mr. Hagenauer, of the Gippsland Aboriginal Mission station, obtained $220 \mathrm{lbs}$. of Arrow-root from one-eighth of an acre of this Canna. The gathering of the roots is effected about April. The plants can be set out in ordinary ploughed land. Captain James Hall, of Hastings, prepared also largely the starch from this root. Starch grains remarkably large.

Canna flaccida, Roscoe.

Carolina. Probably also available for Arrow-root, though in first instance like many congeners chosen only for ornamental culture.

Canna glauca, Linné.

One of the West Indian Arrow-root Cannas. 
Cannabis sativa, Linné.

The Hemp-plant ; indigenous to various parts of Asia, as far west as Turkey and as far east as Japan. Cultivated for its fibre since ancient times. Particularly in hot climes it exudes the "Churras," a resinous substance of narcotic intoxicating property. The foliage contains also a volatile oil, while the seeds yield by pressure the well-known fixed Hemp-oil. The staminiferous plant is pulled for obtaining the fibre in its best state immediately after flowering; the seeding plant is gathered for fibre at a later stage of growth. Good soil, well-drained, never absolutely dry, is needed for successful Hemp culture. Hemp is one of the plants yielding a full and quick return within the season. The summer temperatures of St. Petersburg $\left(67^{\circ}\right.$ F.) and of Moscow $\left(62^{\circ} \mathrm{F}\right.$.) admit yet of the cultivation of this plant. The Hemp as a narcotic plant serves as a protection against insects on cultural fields, if sown along their boundaries.

Capparis sepiaria, Linné.

From India to the Philippine Islands, ascending to cool elevations and living in arid soil. A prickly bush, excellent for hedges. Dr. Cleghorn mentions also as hedge-plants C. horrida (L. fil.), C. aphylla (Roth), C. Roxburghii (Cand.), some of which yield also capers.

Capparis spinosa, Linné.

South Europe and North Africa, South Asia and North Australia. A somewhat shrubby and trailing plant, deserving even for the sake of its handsome fiowers, a place in any garden. It sustains its life in the most arid deserts. The frosts of our lowlands do not destroy this plant. The flowerbuds and young berries preserved in vinegar with some salt form the Capers of commerce. Samples of Capers, prepared from plants of the Botanic Garden, are placed in our Industrial Museum, together with many other industrial products emanating from the writer's laboratory. The Caper-plant is propagated either from seeds or suckers; it is well able to withstand either heat or drought. The buds after their first immersion into slightly salted vinegar are strained and afterwards preserved in bottles with fresh vinegar. Chemical principle: Glycosid.

Capsicum annuum, Linné.

Central America. An annual herb, which yields the Chillies and thus also the material for Cayenne Pepper. Chemical principle: Capsicin, an acrid soft-resinous substance.

Capsicum baccatum, Linné.

The Cherry-Capsicum. A perennial plant. From Brazil 
brought to tropical Africa and Asia, where now other PepperCapsicums are likewise naturalized.

Capsicum frutescens, Linné. (C. fastigiatum, Blume.)

Tropical America. The berries of this shrubby species are

likewise converted into Cayenne Pepper.

Capsicum longum, Candolle.

Some of the hottest parts of America. An annual herb, also yielding Cayenne Pepper. Fraas believes this plant, as an oriental one, to have been known already to Teophrastos and Dioscorides. C. grossum (Willd.) is also mentioned by Colonel Drury as a very pungent species. Our summers admit of the successful growth of at least the annual species of Capsicum in all the lowlands.

Caragana arborescens, Lamarck.

The Pea-tree of Siberia. The seeds are of culinary value, but particularly used for feeding fowl. The leaves yield a blue dye (Dr. Rosenthal).

Carex arenaria, Linné.

Europe and North Asia. One of the most powerful of sedges for subduing rolling sand, not attracting pasture animals by its foliage. The roots are of medicinal value.

Carex Moorcroftiana, Falconer.

The Loongmur of the Alps of Thibet. One of the best of sedges for staying the shifting sand by its deeply penetrating and creeping roots. It forms an intricate network on the surface and beneath; outliving most other fodder-plants at its native places, it becomes available for cattle and horse-food, particularly in the cold of winter, and is held to be singularly invigorating to pasture-animals.

Carissa Arduina, Lamarck.

South Africa. A shrub with formidable thorns, well adapted for boundary lines of gardens, where rapidity of growth is not an object. Quite hardy at Melbourne. C. ferox (E. Meyer) and C. grandiflora (A. de Cand.), are allied plants of equal value. The East Australian, C. Brownii (F. von Mueller) can be similarly utilized. The flowers of all are very fragrant. C. Carandas (Linné), extends from India to China; its berries are edible.

Carpinus Betulus, Linné.

The Hornbean. A tree 80 feet high. Middle and South Europe. Wood pale, of a horny toughness and hardness, close-grained, but not elastic. This tree would serve to arrest the progress of bushfires, if planted in copses or hedges like willows and poplars around forest plantations. A smaller 
species, Carpinus Americana, Mich., yields the Ironwood of North America. Four species occur in Japan (C. cordata, C. erosa, C. laxiflora, C. japonica (Blume). Carpinus viminea. (Wallich) is a species with durable wood from the middle regions of Nepal.

Carthamus tinctorius, Linné.

From Egypt to India. The Safflower. A tall annual rather. handsome herb. The florets produce yellow, rosy, ponceau and other red shades of dye, according to various admixtures. Pigment principles: Carthamin and Carthamusyellow. For domestic purposes it yields a dye ready at. hand from any garden. In India the Carthamus is also cultivated for the sake of the oil, which can be pressed from the seeds.

Carum Ajowan, Bentham. (Ptychotis Ajowan, Candolle.) India. The fruits of this annual herb form an excellent. culinary condiment with the flavour of thyme. Its peculiar oil is accompanied by Cymol and Thymol.

Carum Bulbocastanum, Koch.

Middle of South Europe, North Africa, Middle Asia, on limestone soil. The tuberous roots serve as a culinary vegetable, the fruits as a condiment.

Carum Capense, Sonder.

South Africa, where the edible, somewhat aromatic root is. called Fenkelwortel.

\section{Carum Carui, Linné.}

The Caraway-plant. Perennial. Europe, North and Middle Asia. It might be naturalized in our Alps and also along our sea-shores. The Caraway-oil is accompanied by two chemical principles: Carven and Carvol.

Carum ferulifolium, Koch. (Bunium ferulifolium, Desfont.). A perennial herb of the Mediterranean regions. The small tubers are edible.

Carum nigrum, Royle.

Himalaya. With C. gracile this yields caraway-like fruits.

Carum Petroselinum, Bentham. (Apium Petroselinum, Linné.)

The Parsley. The biennial well-known herb, indigenous"to South Europe and the Orient. Essential oil peculiar with Stearopten.

Carum segetum, Bentham. (Ansthum segetum, Linné.) Around the Mediterranean Sea, extending to Middle Europe. An aromatic annual herb, available for culinary purposes. 


\section{Carya alba, Nuttall.*}

The Shellbark-Hickory. A deciduous tree, 90 feet high, which delights in rich forest soil; a native of North America. Wood strong, elastic, and tenacious, but not very durable. Yields the main supply of hickory nuts. All the hickories are extensively used in North America for hoops.

Carya amara, Nuttall.

The Bitternut Tree or Swamp Hickory. A tree, 80 feet high, in swampy grounds of North America. Wood less valuable than that of other hickories.

\section{Carya glabra, Torrey.* (Carya porcina, Nuttall).}

The Hognut Tree. A tree, 80 feet high, in forest-land of North America. Wood very tough; the heart-wood reddish or dark-coloured; much used for axletrees and axehandles.

Carya microcarpa, Nuttall.

The Balsam Hickory. North America. A fine lofty tree, attaining a height of 80 feet, and a stem of two feet in diameter. The wood is white and tough, and possessed of most of the good qualities of C. tomentosa, to which this species is also in other respects allied. The nut is of a pleasant taste, but small. (Nuttall.)

Carya oliviformis, Nuttall.

The Pecan Nut-tree of North America. A handsome lofty tree up to 70 feet high, with a straight trunk. Its wood is coarse-grained, heavy and compact, possessing great strength and durability. The nuts, which are usually abundant, are from an inch to an inch and a-half long, and are the most delicious of all walnuts; they form an object of commerce in the Southern States. Although the wood of all the hickories is not adapted for building purposes, as it is easily attacked by insects, and soon decays if exposed to the weather, yet its great strength and elasticity render it. extremely useful for implements, articles of furniture, hoops, and many minor uses, besides supplying locally the very best of fuel. Hickories, even when very young, do not well bear transplantation, except perhaps C. amara. C. alba and C. glabra would be particularly recommendable for the sake of their timber and C. oliviformis on account of its fruit. The bark of all the hickories contains yellow dye principles; by addition of copperas an olive colour is produced, by addition of alum a green colour.

\section{Carya sulcata, Nuttall.*}

The Furrowed Hickory and Shellbark Hickory of some districts; also Shagbark Hickory. A tree, 80 feet high, in 
damp woods of North America. Heart-wood pale-coloured. Seed of sweet pleasant taste.

Carya tomentosa, Nuttall.*

The Mocker Nut-tree or White Heart Hickory. A big tree of North America. Likes forest soil, not moist. Heartwood pale-coloured, remarkable for strength and durability. Seeds very oily. Nut small, but sweet. A variety produces nuts as large as an apple.

Caryota Alberti, F. v. Mueller.

The Albert Paim, known only from the most northern parts of Queensland; nevertheless, this noble palm would probably endure our winters as it lives at Sydney without protection.

Caryota urens, Linné.

India. One of the hardier Palms, ascending according to Dr. Thomas Anderson the Himalayas to an altitude of 5000 feet, yet even there attaining a considerable height, though the temperature sinks in the cooler season to $40^{\circ}$ Fahrenheit. The trunk furnishes a sago-like starch. This Palm flowers only at an advanced age, and after having produced a succession of flowers dies away. From the sap of the flowers Toddy and Palm-sugar are prepared, like from the Cocos and Borassus Palm, occasionally as much as 12 gallons of Toddy being obtained from one tree in a day. The fibre of the leaf-stalks can be manufactured into very strong ropes, also into baskets, brushes and brooms. The outer wood of the stem serves for turnery.

Cassia acutifolia, Delile.

Indigenous or now spontaneous in Northern and tropical Africa and South-westAsia. Perennial. Themerely dried leaflets constitute part of the Alexandrian and also Tinnevelly Senna. In Victoria it will be only in the warmest northern and eastern regions, where Senna can perhaps be cultivated to advantage.

Cassia angustifolia, Vahl.

Northern and tropical Africa and South-western Asia, indigenous or cultivated. Perennial. Yields Mecca-Senna, also the Bombay and some of the Tinnevelly Senna.

Cassia fistula, Linné.

South Asia. The long pods of this ornamental tree contain an aperient pulp of pleasant taste; of medicinal value; also used in the manufacture of cake-tobacco. Traced by Dr. Hooker to the dry slopes of the central Himalayas.

Cassia Marylandica, Linné.

An indigenous Senna plant of the United States of North America. Perennial. 
Cassia obovata, Colladon.

South-west Asia ; widely dispersed through Africa as a native or disseminated plant. Perennial. Part of the Alexandrian and also Aleppo Senna is derived from this species, less esteemed and less collected however than the other species. Several of the Australian desert Cassias of the group of C. artemisioides may also possess purgative properties. The odour of their foliage is almost that of Senna.

Castanea sativa, Miller.* (C. vesca, Gærtner).

The Sweet Chestnut Tree. South Europe and temperate Asia, as far as Japan, and a variety with smaller fruits extending to North America. It attains an enormous age; at Mount Etna an individual tree occurs with a stem 204 feet in circumference. The wood is light and coarse-grained; the importance of the tree rests on its adaptability for shade plantations, its nutritious nuts and timber value.

Castaneopsis argentea, A. Candolle.

A lofty tree in the mountains of India, produces also edible chestnuts. Other species of the genus Castaneopsis are valuable.

Castaneopsis chrysophylla, A. de Candolle.

The Oak-Chestnut of California and Oregon. A tree attaining a large size and beautiful outlines. The leaves are golden yellow underneath. Wood durable.

Casuarina Decaisneana, F. von Mueller.

Central Australia, where it is the only species of the genus. This tree is one of the largest among its congeners, and particularly valuable for arid regions.

Casuarina equisetifolia, Forster.

East Africa, South Asia, North Australia, Polynesia. Attains a maximum height of 150 feet. Splendid for fuel, giving great heat and leaving little ashes. The timber is tough.

Casuarina Fraseriana, Miquel.

South-West Australia. A middle-sized tree; the wood easily split into shingles, and also used for furniture, as it does not rend. This tree is adapted even for sterile heath-land.

Casuarina glauca, Sieber.

The Desert Sheoak, widely distributed through Australia, but nowhere in forest-like masses. This species attains, in favourable places, a height of 80 feet. Its hard durable wood is valuable. Important for its rapid growth, resistance to exposure for shelter plantation, and a speedy supply of fuel, a remark which applies also to the following species. 
Casuarina quadrivalvis, La Billardière.

The Coast Sheoak of South-east Australia, but not merely living in coast-sand, but also on barren places up to the hills inland. Height to 60 feet. The male tree is very eligible for avenues, the foliage of the species being drooping. Cattle are fond of the foliage. For arresting the ingress of coastsand by belts of timber, this is one of the most important trees. It produces, like other Casuarinas, seeds early and copiously, and is easily raised.

Casuarina suberosa, Willdenow.

The Erect Sheoak of South-east Australia. Height to 40 feet. A beautiful shady species. Casuarina trichodon (Miq.) and C. Huegeliana (Miq.) are arboreous species of South-west Australia, all valuable for their wood.

Casuarina torulosa, Aiton.

New South Wales and Queensland. The wood of this handsome tree is in demand for durable shingles and furniture work; it is also one of the best for oven fuel.

Catalpa bignonioides, Walter.

On the Gulf of Mexico. A tree in warm humid climatic zones of remarkable celerity of growth. Mr. Meehan regards the wood to be as durable as that of the best chestnut trees, and observed a stem in twenty years to attain a diameter of three feet, even in the clime of New York.

Catha edulis, Forskoel.

Arabia and Eastern Africa. The leaves of this shrub under the designation Kafta or Cat are used for a tea of a very stimulating effect, to some extent to be compared to that of Erythroxylon Coca. To us here the plant would be mainly valuable for medicinal purposes.

Ceanothus rigidus, Nuttall.

California. One of the best of hedge-shrubs, available for dry situations. Evergreen; up to 12 feet high; the branches become densely intricate. In the coast-tracts it is replaced by C. thyrsiflorus, Esch., which can also be used for hedges and copses, and will live in mere coast-sand. C. prostratus, Benth., likes to form natural mats on slopes formed by roads and slides, which it gradually covers, and with its pretty blue flowers soon decorates (Professor Bolander).

Cedrela Taona, Roxburgh.*

The Singapore Cedar. A mere variety of this is the Red Cedar of East Australia (Cedrela Australis, Cunn.) The light beautiful wood, easily worked and susceptible of high polish, is much in request for furniture, for the manufacture of pianofortes, for boat-building and a variety of other work. 
As this important tree is largely extirpated in the cedar brushes, it is highly desirable to form of it in our rich forest gullies independent plantations for future local supply. The Red Cedar is hardy at Melbourne, but in our open exposed gardens and poor soil of slow growth.

Cedronella cordata, Bentham.

United States of North America. A perennial herb, fragrant like the following.

Cedronella triphylla, Moench.

Madeira and Canary Islands. A shrubby plant with highly scented foliage. The volatile oil obtainable from it resembles that of Melissa, but is somewhat camphoric.

Celtis Australis, Linné.

The Lotus-tree of South Europe and North Africa. Of longevity, 50 feet high, available for avenues. Berries edible. Wood hard and dense, eligible particularly for turner's and and carver's work.

Celtis Occidentalis, Linné.

The Huckberry-tree. A fine forest-tree in Ohio, and other parts of North America. Height, 80 feet. The variety called C. crassifolia is the best. The sweet fruits edible. Wood elastic and fissile.

Cephælis Ipecacuanha, Richard.

Brazil, in woods of mountains, consociated with Palms and Eern-trees. It is not unlikely, that this herb, which is perennial and yields the important medicinal Ipecacuanha root, would live in our warmer forest-regions, such as those of East Gipps Land. Active principles: Emetin and Ipecacuanha-acid.

Cephalotaxus Fortunei, Hooker.

China and Japan. This splendid yew attains a height of 60 feet, and is very hardy.

Ceratonia Siliqua, Linné.

The Carob-tree of the Mediterranean regions. It attains a height of 30 feet and resists drought well ; succeeds best on a calcareous subsoil. Wood pale red. The saccharine pods, Algaroba or St. John's Bread, of value for domestic animals. The seeds germinate readily. - The exportation of the beans for cattle-food from Creta alone is now about 180,000 tons annually. (Dr. Masters.)

Cercocarpus ledifolius, Nuttall.

California. Rises in favourable spots to a tree 40 feet high, with a stem diameter of $2 \frac{1}{2}$ feet. The wood is the hardest known in California. C. parvifolius is of lesser dimensions. 


\section{Cereus Quixo, Gay.}

Chili. This stately Cactus attains a height of 15 feet, and is one of the hardiest species. The charming snow-white flowers are followed by sweetish mucilaginous fruits, available for the table (Philippi). C. giganteus (Engelmann), from New Mexico, which attains the stupendous height of 50 feet, with a proportionate columnar thickness, yields also edible fruits, and lives unprotected in our clime. It has been intro. duced by the writer many years ago.

Ceroxylon andicola, Humboldt.

The Wax Palm of New Granada, ascending the Andes to 11,000 feet. One of the most majestic and at the same time one of the most hardy of all palms, attaining occasionally a height of 180 feet. The trunk exudes a kind of resinous wax, about $25 \mathrm{lbs}$. being obtainable at a time from each stem; this by admixture to tallow is used for candles. There are several other andine palms, which could be reared in our forests or in sheltered positions at our dwellings, but some of them are not even yet phytographically circumscribed.

Cervantesia tomentosa, Ruiz and Pavon.

Forest-mountains of Peru. This tree yields edible seeds. It is likely to prove hardy in our lower forest-regions.

Chærophyllum bulbosum, Linné.

Middle Europe and Western Asia. The Parsnip-Chervil. A biennial herb. The root a good culinary esculent.

Chærophyllum sativum, Lamarck. (Anthriscus Cerefolium, Hoffmann.)

The Chervil. Middle and South Europe, Western Asia. An annual herb, available for salads and condiments, but the root deleterious.

Chamæerops excelsa, Thunberg.

South China. This Fan Palm is highly desirable, although not tall as the name would indicate. Has stood $16^{\circ}$ Cels. below freezing-point with only a slight litter. (Count de Saporta.)

Chamærops Fortunei, Hooker.

North China. The Chusan Palm. It attains a height of about 12 feet and endures like the following species considerable frost. The leaves can be employed for plaiting palm-hats. Other hardy palms might be naturalized and used for various purposes, irrespective of their ornamental features. 
Chamærops humilis, Linné.

The dwarf Fan-Palm of South Europe and North Africa. It is very decorative for garden plantations, particularly also eligible for scenic effect.

Chamærops Hystrix, Fraser.

The Blue Palmetto of Florida and Carolina. Another dwarf Fan-Palm.

Chamærops Khasyana, Griffith.

In the Himalayas at elevations from 4000 to 8000 feet. Allied to C. Martiana.

Chamærops Martiana, Wallich.

Ascends the mountains of Nepal to 5000 feet. Attains a height of 50 feet and is altogether a noble object.

Chamærops Ritchieana, Griffith.

Arid mountains of Affghanistan; seemingly the only Palm of that country. Has also proved hardy even in England.

Chelidonium majus, Linné.

Europe and Western Asia. The Celandine. A perennial herb of medicinal value. Chemical principles: Chelerythrin and Chelidonin; also a yellow pigment: Chelidoxanthin.

Chenopodium ambrosioides, Linné.

Tropical America. An annual medicinal herb. Chenopodium anthelminticum is a perennial variety of this species.

Chenopodium auricomum, Lindley.

From the Darling River to Carpentaria and Arnhem's Land. A tall perennial herb, furnishing a nutritious and palatable spinage. It will live in arid desert regions.

Chenopodium Blitum, F. v. Mueller. (Blitum virgatum, Linné.)

From South Europe to India. An annual herb, extensively in use there as a cultivated spinage-plant. The fruits furnish a red dye. The genus Blitum was reduced to Chenopodium by the writer in Caruel's Giornale Botanico some years ago. C. capitatum (Blitum capitatum, Linné) may not be really a distinct species. C. Quinoa, Willdenow, from Chili, deserves hardly recommendation for culture, though a nutritious spinage, it being apt to stray as a weed into cultivated fields. Some of these sorts of plants are useful to anglers, as attracting fish, when thrown into rivers or lakes. 
Chloris truncata, R. Brown.

South-eastern Australia, as far south as Port Phillip. This perennial and showy grass is regarded by Mr. Walter Bissill as an excellent summer and autumn grass, of ready growth and relished by pasture animals. $C$. ventricosa ( $\mathrm{R} . \mathrm{Br}$.) is another valuable East-Australian species.

Chlorogalum pomeridianum, Kunth.

California, frequent on the mountains. This lily-like plant attains a height of eight feet. The heavy bulb is covered with many coatings, consisting of fibres, which are used for cushions, mattresses, \&c.; large contracts are entered into for the supply of this material on a very extensive scale (Professor Bolander). The inner part of the bulb serves as a substitute for soap, and it might be tried whether it can be utilised for technological purposes like the root of Saponaria.

Chloroxylon Swietenia, Candolle.

The Satin-wood. Mountains of India. Like the allied Flindersias, possibly this tree would prove hardy here in naturally sheltered places, the cognate Cedrela Taona advancing in East Australia southward to the 35th degree. A resin, valuable for varnishes, exudes from the stem and branches.

Chrysanthemum roseum, Adam.

South-West Asia. This perennial herb, with C. carneum, yields the Persian insect-powder.

Cicer arietinum, Linné.

South Europe and Orient. The Gram. An annual herb, valuable as a pulse for pasture animals. The seeds can also be converted into pea-meal or be used otherwise for culinary purposes.

Cichorium Endivia, Linné.

South Europe, Orient, Middle Asia. A biennial plant, used since ancient times as a culinary vegetable.

Cichorium Intybus, Linné.

Chicory. A well-known perennial plant, indigenous to Europe, North Africa and North and West Asia. The roots much used as a substitute for coffee. This plant requires a rich deep loamy soil, but fresh manure is detrimental to the value of the root. It is also a good fodder-plant, especially for sheep. The root can also be dressed and boiled for culinary purposes. The leaves useful for salad.

Cimicifuga racemosa, Elliott.

The Black Snake-root of North America. A perennial herb of medicinal value, the root possessing emetic properties. 
Cinchona Calisaya, Ruiz.*

Yellow Peru Bark tree. Andes of Peru and Bolivia, 5000 to 6000 feet above the ocean. This tree attains a height of 40 feet. It yields the Yellow Bark, and also part of the CrownBark. It is one of the richest yielders of Quinin, and produces besides Cinchonidin.

Cinchona micrantha, Ruiz and Pavon.

Cordilleras of Bolivia and Peru. This tree attains a height of 60 feet, and from it part of the Grey and Huanuco Bark as well as Lima Bark are obtained. It is comparatively rich in Cinchonin and Quinidin, contains however also Quinin.

Cinchona nitida, Ruiz and Pavon.

Andes of Peru and Ecuador. This tree rises to 80 feet under favourable circumstances. It also yields Grey Bark and Huanuco Bark, besides Loxa Bark. It will probably prove one of the hardiest species. It contains predominantly Cinchonin and Quinidin.

Cinchona officinalis Linné (partly).* (Cinchona Condaminea, Humboldt).

Andes of New Grenada and Peru, at a height of 6000 to 10,000 feet. Yields Crown or Brown Peru Bark, besides part of Loxa Bark. Comparatively rich in Quinin and Cinchonidin. The temperature of the middle regions of the Andes, where this tree grows, is almost the same as that of the Canary Islands. Superabundance of moisture is particularly to this species pernicious. The Crispilla variety endures a temperature occasionally as low as $27^{\circ} \mathrm{F}$.

Cinchona lancifolia (Mutis) is considered by Weddell a variety of C. officinalis. This grows on places where the mean annual temperature is that of Rome, with however less extremes of heat and cold. It yields part of the Pitaya Bark.

Cinchona Pitayensis must also be referred to C. officinalis as a variety. This attains a height of 60 feet and furnishes also a portion of the Pitaya Bark. It is this particular Cinchona, which in Upper India yielded in some instances the unprecedented quantity of 11 per cent. alkaloids, nearly 6 per cent. Quinin, the rest Quinidin and Cinchonin.

In Java some of the best results were obtained with Cinchona Hasskarliana Miq., a species seemingly as yet not critically identified.

Cinchona succirubra, Paron.*

Middle andine regions of Peru and Ecuador. A tree attaining a height of 40 feet, yielding the red Peru Bark, rich in 
Quinin and Cinchonidin. It is this species, which is predominantly cultivated on the mountains of Bengal. It has been found hardy in Lower Gippsland and the Westernport district. It grew in Madeira at an elevation of 500 feet, after having been planted two and a-half years, to a height of 20 feet, flowering freely. All these Cinchonas promise to become of importance for culture in the warmest regions of our forest-land, on places not readily accessible or eligible for cereal culture. The Peruvian proverb that Cinchona trees like to be "within sight of snow" gives some clue to the conditions, under which they thrive best. They delight in the shelter of forests, where there is an equable temperature, no frost, some humidity at all times both in air and soil, where the ground is deep and largely consists of the remnants of decayed vegetable substances and where the subsoil is open. Drippage from shelter-trees too near will be hurtful to the plants. Closed valleys and deep gorges, into which cold air will sink, are also not well adapted for Cinchona-culture. In our colony we ought to consociate the Perubark-plants with naturally growing fern-trees, but only in our warmest valleys of richest soil. The best temperature for Cinchonas is from $53^{\circ}$ to $66^{\circ} \mathrm{F}$.; but they mostly will endure in open places a minimum of $32^{\circ} \mathrm{F}$; ; in the brush shades of the Botanic Garden of Melbourne, where years ago already Cinchonas were raised by the thousands, they have even resisted uninjured a temperature of a few degrees less, wherever the wind had no access, while under such very slight cover the Cinchonas withstood also a heat of a few degrees over $100^{\circ} \mathrm{F}$. The plants are most easily raised from seeds, best under some cover such as mats, and they are seeding copiously already several years after planting. The contents of alkaloids in the bark can be much increased by artificial treatment, if the bark is only removed on one side of the stem and the denuded part covered with moss, under which in one year as much bark is formed as otherwise requires three years' growth, such forced bark moreover containing the astounding quantity of as much as $25 \%$ alkaloids, because no loss of these precious substances takes place by gradual disintegration through age. The Cinchona-plants are set out at distances of about 6 feet. The harvest of bark begins in the fourth or fifth year. The price varies in Europe from 2s. to 9s. per lb. according to quality. The limits assigned to this literary compilation do not admit of entering further into details on this occasion, but I may yet add, that in the Darjeeling district over three millions of Cinchona plants were in cultivation in 1869, raised in Government plantations. 
Cinna arundinacea, Linné.

North America. There recorded as a good fodder-grass; perennial, somewhat sweet-scented. Blyttia suaveolens (Fries) is, according to Dr. Asa Gray, a variety with pendant flowers.

Cinnamomum Camphora, Nees.*

The Camphor-tree of China and Japan, attaining a height of about 40 feet. It endures the occasional frosts of Port Phillip, though the foliage will suffer. The wood, like all other parts of the tree, is pervaded by camphor, hence resists the attacks of insects.

Cistus creticus, Linné.

Countries at the Mediterranean Sea. This shrub, with C. cyprius (Lam.) furnishes the best Ladanum resin. Other species yield a less fragrant product.

Citrus Aurantium, Linné.*

The Orange (in the widest sense of the word). A native of South Asia. A tree of longevity, known to have attained the age of 600 years or more. Any specific differences, to distinguish C. Aurantium from C. medica, if they once existed, are obliterated now through hybridisation, at least in the cultivated forms. In Central India a peculiar variety is under culture, producing two crops a year. The blossoms of February and March yield their ripe fruit in November and December, whereas from the flowers of July mature fruits are obtained in March and A pril. To prevent exhaustion only alternate fruiting is allowed. As prominent varieties of ' $\mathrm{C}$. Aurantium may be distinguished:-

Citrus Bigaradia, Duhamel. The Bitter Orange. This furnishes from its flowers the Neroli Oil, so delicious and costly as a scent. It is stated that Orange-flowers to the value of $£ 50$ might be gathered from the plants of an acre within a year. The rind of the fruit is used for candied orange-peel. Bitter principle: Hesperidin in the rind, Limonin in the seed.

Citrus dulcis, Volkamer. The Sweet Orange, of which many kinds occur. The St. Michael Orange has been known to bear in the Azores on sheltered places 20,000 fruits on one tree in a year. Neroli Oil is obtained from the flowers of this and allied varieties.

Citrus Bergamium, Risso. From the fruit-rind of this variety Bergamotte Oil is obtained, but also oil from the flowers. The Mellarosa variety furnishes a superior oil and exquisite confitures.

Citrus decumana, Linné. The Shaddock of Pompelmos. The fruit will exceptionally attain a weight of $20 \mathrm{lbs}$. The pulp and thick rind can both be used for preserves. 
Citrus nobilis, Loureiro. The Mandarin-Orange. The thin peel separates most readily from the deliciously flavoured sweet pulp. There are large and small fruited Mandarin Oranges; the Tangerine variety is one of them.

\section{Citrus Australasica, F. von Mueller.}

Coast-forests of extra-tropic East Australia. A shrubby species, with oblong or almost cylindrical fruits of lemon-like taste, measuring two to four inches in length. They are thus very much larger than those of Atalantia glauca of the coast and the desert-interior of tropic Australia, which are also of similar taste. These plants are entered together with the following on this list, merely to draw attention to them, as likely capable of improrement of their fruit through culture.

Citrus Japonica, Thunberg.

The Kumquat of Japan. A shrubby Citrus with fruits of the size of a gooseberry, from which on account of their sweet peel and acid pulp an excellent preserve can be prepared.

\section{Citrus medica, Linné.*}

The Citron (in the widest sense of the word). Indigenous to Southern Asia. For convenience's sake it is placed here as distinct from the preceding species. As prominent varieties of the Citrus medica may be distinguished:-

Citrus Cedra, Gallesio. The real Citron. From the acid tubercular fruit essential oil and citric acid can be obtained, irrespective of the ordinary culinary use of the fruit. A large variety with thick rind furnishes candied the Citrionate or Succade. The Cedra Oil comes from a particular variety.

Citrus Limonium, Risso. The Real Lemon. From the fruit of this is largely pressed the Lemon-juice, while the thin smooth aromatic peel serves for the production of volatile oil or for condiments. The juice of this fruit is particularly rich in citric acid. A large variety is the Rosaline Lemon.

Citrus Lumia, Risso. The Sweet Lemon, including the PearLemon with large pear-shaped fruit. Rind thick and pale; pulp not acid. This variety serves for particular condiments. Citrus Limetta, Risso. The real Lime. The best lime-juice is obtained from this variety, of which the Perette constitutes a form.

Citrus Planchoni, F. von Mueller. (C. Australis, Planchon, partly.)

Forests near the coast of sub-tropic East Australia. A noble tree, fully 40 feet high, with globular fruits about the size of a walnut, called Native Oranges. The species has first appeared under the above name in the "Report on the Vegetable Products of the Intercolonial Exhibition of 1867." 
Cladrastis tinctoria, Rafinesque.

North America. The wood of this tree produces a saffronyellow dye.

Cochlearia Armoracia, Linné.

The Horseradish. Middle Europe and Western Asia.

Perennial. The volatile oil of the root allied to that of Mustard.

Cochlearia officinalis, Linné.

Shores of Middle and North Europe, North Asia and North America. A biennial herb, like the allied C. Angelica and C. Danica valuable as an antiscorbutic; hence deserving naturalisation. It contains a peculiar volatile oil.

Cocos Australis, Martius.

From Brazil to Uruguay and the La Plata States. One of the hardiest of all Palms, hardier even than the Date Palm, withstanding unprotected a cold of $8^{\circ} \mathrm{C}$. below freezingpoint, at which temperature oranges and almonds are injured or destroyed.

Coffea Arabica, Linné.

Mountains of South-West Abyssinia. The Coffee-plant. This shrub or small tree has been admitted into this list not without great hesitation, merely not to be passed. The cultivation within Victorian boundary can only with any prospect of success be tried in the warmest and simultaneously moistest regions, such as East Gipps Land, frost being detrimental to the Coffee-plant. In Ceylon the Coffee regions are between 1000 and 5000 feet above the ocean, but Dr. Thwaites observes, that the plant succeeds best at an elevation from 3000 to 4500 feet, in places where there is a rainfall of about 100 inches a year. The temperature there rises hardly ever above $80^{\circ} \mathrm{F}$., and almost never sinks below $45^{\circ} \mathrm{F}$. Coffee requires moist weather whilst it ripens its fruit, and a season of drier weather to form its wood. For further particulars see the papers of the Planters' Association of Kandy. Chemical principles: Coffein, a peculiar tannic acid and Quina acid.

Colchicum auctumnale, Linné.

Middle and South Europe, West Asia. The Meadow Saffron. The seeds and roots of this pretty bulbous-tuberous herb are important for medicinal use. The plant has been introduced by the writer with a view of being cultivated on moist meadows in our ranges. Active principle: Colchicin.

Colocasia antiquorum, Schott.

From Egypt through South Asia to the South Sea Islands, apparently also indigenous in the warmer parts of East 
Australia. The Taro. The stem-like tuberous starchy roots lose their acridity by the process of boiling, roasting or baking. It is the Kolkas of the Arabs and Egyptians, to them one of the most esteemed and abundant vegetables. Immense quantities are harvested and kept during the winter. The plant proved hardy in the Botanic Garden of Melbourne. The tops of the tubers are replanted for a new crop. Taro requires a rich moist soil and would grow well on banks of rivers. For scenic culture it is a very decorative plant. Colocasia esculenta is a variety of this species.

Colocasia Indica, Kunth. (Alocasia Indica, Schott). South Asia, South Sea Islands and East Australia. Cultivated for its stem and tubers on swamps or rivulets. This stately plant will rise in favourable localities to a height of 12 feet, the edible trunk attaining a considerable thickness, the leaves sometimes measuring three feet in length. In nsing the stem and root for food great care is needed to expel by the heating process all acridity. Colocasia odora and C. macrorrhiza seem varieties of this species. Several other Aroid plants deserve attention for test-culture on account of their edible roots, among them Cyrtosperma edule, Seemann, from the Fiji Islands.

Combretum butyraceum, Caruel.

The Butter-tree of Caffraria and other parts of South-East Africa. The Caffirs call the fatty substance obtained from this tree Chiquito. It is largely used by them as an admixture to their food, and exported also. It contains about one quarter Olein and three quarters Margarin. This butterlike fat is extracted from the fruit, and is of an aromatic flavour. The tree should be hardy in the warmer and milder parts of Victoria.

Conium maculatum, Linné.

The Hemlock. Europe, North Africa, North and West Asia. A biennial herb, important for medicinal purposes. It should however not be allowed to stray from its plantations, as it is apt to be confounded with culinary species of Anthriscus, Chærophyllum and Myrrhis, and may thus cause as a most dangerous plant disastrous mistakes. Active principles: Coniin, in the fruit also Conhydrin.

Conopodium denudatum, Koch.

Western Europe. The small tuberous roots of this herb, when boiled or roasted, are available for food and known as Earth Chestnuts. The plant is allied to Carum Bulbocastanum. 
Convolvulus floridus, Linné fil.

Canary Island. A shrubby not climbing or winding species. With C. scoparius it yields the Atlantic Rosewood from stem and root.

Convolvulus Scammonia, Linné.

Mediterranean regions and Asia Minor. A perennial herb. From the root is obtained the purgative resin Scammonia.

Convolvulus scoparius, Linné fil.

Teneriffe. One of the Rosewood plants.

Copernicia cerifera, Martius.

Brazil. This magnificent Fan-Palm, like so many others of this noble order, may prove hardy in our latitudes. It resists drought in a remarkable degree, and prospers also on a somewhat saline soil. This palm in all probability would prove fitted for the country along the Murray-river. The stem furnishes starch, the sap yields sugar, the fibres of the leaves are converted into ropes, which resist decay in water, and can also be used for mats, hats, baskets and brooms, and many other articles are prepared from the leaves. The inner part of the leafstalks serves as a substitute for cork. Mainly however this palm is valued for its Carnauba-wax, with which the young leaves are coated, and which can be detached by shaking; it is harder than beeswax and is used in candle manufacture. Each tree furnishes about $4 \mathrm{lbs}$. annually. In 1862 no less than 2,500,000 lbs. were imported into Great Britain, realising about $£ 100,000$.

Corchorus acutangulus, Lamarck.

Tropical Africa, South Asia and North Australia. This species is specially mentioned by some writers as a Jute-plant.-A particular machine has been constructed by Mr. Le Franc, of New Orleans, for separating the Jute fibre. With it a ton of Jute fibre is produced in a day by four men's work, and it leaves no butts and refuse. This apparatus can also be used for other fibre plants. The seeds of the Corchorus, which spontaneously drop, will reiterate the crop.

Corchorus capsularis, Linné.*

From India to Japan. One of the principal Jute-plants. An annual, attaining a height of about a dozen feet, when closely grown, with almost branchless stem. A nearly allied but lower plant, Corchorus Cunninghami, F. v. Mueller, occurs in tropical and subtropical East Australia. Jute can be grown where cotton and rice ripen, be it even in localities comparatively cold in the winter, if the summer's warmth is long and continuous. The fibre is separated by steeping the full-grown plant in water from five to eight days, and it is 
largely used for rice- and cotton-bags, carpets and other similar textile fabrics, and also for ropes. About 60,000 tons are annually exported from India to England, and a large quantity also to the United States. Jute is sown on good land, well ploughed and drained, but requires no irrigation, although it likes humidity. The crop is obtained in the course of four or five months, and is ripe when the flowers turn into fruit capsules. Good paper is made from the refuse of the fibre.

Corchorus olitorius, Linné.*

South Asia and North Australia. Furnishes, with the foregoing species, the principal supply of Jute-fibre. As it also is an annual, it can be brought to perfection in our summers. The foliage can be used for spinage. The fibre is not so strong as hemp, but very easily prepared. It will not endure exposure to water. The allied Corchorus trilocularis, L., of Indian origin, is likewise a native of eastern tropical and subtropical Australia.

Cordyline Banksii, J. Hooker.

New Zealand. This lax and long-leaved Palm-lily attains a height of 10 feet; its stem is usually undivided. This and the following species have been admitted into this list for a double reason, because not only are they by far the hardiest, quickest growing and largest of the genus, and thus most sought in horticultural trade for scenic planting; but also because they furnish from the leaves a superior fibre for ropes and other purposes. The small seeds are produced in great abundance, and germinate with extreme readiness. These Palm-lilies ought to be naturalised in our ranges by mere dissemination.

Cordyline Baueri, J. Hooker. (C. Australis, Endlicher, not J. Hooker.)

Norfolk Island. The stem of this stately species attains a height of 40 feet, and becomes in age ramified. It is very intimately allied to the following :--

Cordyline Forsteri, F. v. Mueller. (C. Australis, J. Hooker, not Endlicher.)

New Zealand. The stem of this noble thin-leaved plant attains a height of 40 feet, and is branched. Aged leaves readily separable; berries, blue.

Cordyline indivisa, Kunth.

New Zealand. The stem of this thick and rigid-leaved palm-like species rises to a height of 20 feet, and remains undivided. Leares finally fire inches broad; yield the Toifibre. Aged leaves persistent in a perfectly downward position for many years. Panicle at first crect. Berries, white. 
Cordyline $\mathrm{Ti}$, Schoot.

China. The roots in a roasted state are edible. The leaves, like those of other species, can be utilised for textile fibre.

Coriandrum stivum, Linné.

Orient and Middle Asia. An annual or biennial herb, much in use for condiments. The essential oil peculiar.

Corylus Colurna, Linné.

The Constantinople Nut-tree, the tallest of Hazels, attaining 60 feet in height, of rather quick growth. This, as well as the European Hazel (Corylus Avellana, L.) and the Japan Hazel (C. heterophylla, Fischer) might be grown for copses in our forest-gullies.

Corynocarpus lævigata, Forster.

The Karaka of New Zealand and the principal forest-tree of the Chatham Islands, attaining a height of 60 feet. The wood is light, and used by the natives for canoes. The pulp of the fruit is edible. Cattle browse on the foliage. In rich humid soil the tree can be adopted for avenues.

Corynosicyos edulis. (Cladosicyos edulis, J. Hooker.)

Guinea. A new cucumber-like plant, with edible fruits about one foot long, and three inches in diameter.

Crambe cordifolia, Steven.

From Persia and the Caucasus to Thibet and the Himalayas up to 14,000 feet. The root and foliage of this Kale afford an esculent. C. Kotschyana (Boiss.) is an allied plant.

Crambe maritima, Linné.

Sea-Kale. Sand-coasts of Europe and North Africa. A perennial herb; the young shoots used as a wholesome and agreeable vegetable.

Crambe Tataria, Wulfen.

From Southern Europe to the Orient. Perennial. Likewise used for culinary purposes.

Cratægus æstivalis, Torrey and Gray.

The Apple Haw. Southern States of North America. The small juicy fruit of an agreeable acid taste.

Cratægus apiifolia, Michaux.

North America. Highly serviceable for hedges.

Cratægus Azarolus, Linné.

Welsh Medlar. South Europe and South-West Asia. The pleasantly acidulous fruits are much used for preserves.

Cratægus coccinea, Linné.

North-American Whitethorn. A valuable hedge.plant; also very handsome. Spines strong. 
Cratægus cordata, Aiton.

Southern States of North America. Also much employed for hedges.

Cratægus Crus-Galli, Linné.

North America. The Cockspur-Thorn. Regarded as one of the best species for hedges. Spines long and stout.

Cratægus Oxyacantha, Linné.

Europe, North Africa, North and West Asia. The ordinary

Hawthorn or Whitethorn. Recorded here as one of the most eligible among deciduous hedge-plants.

Cratægus parvifolia, Aiton.

North America. For dwarf hedges. Spines long, slender, sharp and numerous.

Cratægus pyracantha, Persoon.

The Firethorn. South Europe. This species is evergreen

It is likewise adapted for hedges, but slower in growth than Hawthorn, but not difficult to rear.

Cratægus tomentosa, Linné.

North America. Fruit edible. By the species mentioned the list of American Hedgethorns is probably not yet exhausted.

Crithmum maritimum, Linné.

The real Samphire. Sea-shores of Middle and South Europe, North Africa and the Orient. A peremnial herb. Settlers on the coast might readily disseminate and naturalize it. It is held to be one of the best plants for pickles, the young leaves being selected for that purpose.

Crocus sativus, Linné.

The Dye-Saffion. South Europe and Orient. The stigmata of this particular autumnal flowering Crocus constitute the costly dye substance. The best is collected from the flowers, just as they daily open in succession. At our stage of colonisation it would not be remunerative to grow Saffion commercially; but as the plant is well adapted for our clime, it might be planted out into various unoccupied mountain localities, with a final view to naturalise it, and to render it thus available at a later period from native sources.

Crocus serotinus, Salisbury. (C. odorus, Bivona.)

South Europe. Also this species produces Saffron rich in pigment. The bulbs of several are edible.

Crotalaria Burhia, Hamilton.

Beludschistan, Affghanistan, Scinde. The perennial herb grows in arid places and yields like the following Sunn-fibre. 
Crotalaria juncea, Linné.

The Sunn-Hemp. Indigenous to South Asia, and also widely dispersed through tropical Australia. An annual herb, rising under favourable circumstances to a height of 10 feet. In our colony Sunn can only be cultivated in the warmest and moistest localities. It comes in four or five months to maturity. The plant can also be grown as a fodder-herb for cattle. It requires rich friable soil. If a superior soft fibre is desired, then the plant is pulled while in flower; if strength is the object, then the plant is left standing until it has almost ripened its seeds. The steeping process occupies about three days. For the purpose of obtaining branchless stems it is sown closely.

Crotalaria retusa, Linné.

Asia, America and Australia within the tropics. A perennial herb. Its fibre resembles that of C. juncea, and is chiefly used for ropes and canvas. Others of the multitudinous species of Crotalaria deserve to be tested for their fibres.

Croton lacciferus, Linné.

Ceylon, up to 3000 feet. Suitable for the warmer forestregions here, to obtain from this tree its peculiar exuding lac-resin.

Crozophora tinctoria, Necker.

South Europe, North Africa and Orient. An annual herb. The turnsole-dye is prepared by exposure of the juice to the air, or by treating it with ammonia.

Cryptomeria Japonica, Don.

Japan and Northern China. A slender evergreen tree, 100 feet high. It requires forest-valleys for successful growth. The wood is compact, very white, soft and easy to work. In the Azores preferred even to the Pinus Haleppensis for timber culture, on account of its still more rapid growth in that insular clime.

Cucumis cicatrisatus, Stocks.

Scinde, where it is called "Wungee." The edible ovate fruit is about 6 inches long.

Cucumis Citrullus, Seringe. (Citrullus vulgaris, Schraeder.) Mediterranean regions. The Water-Melon. It is simply mentioned here, to indicate the desirability of naturalising it in the interior-deserts, where no Cucurbita and only a single kind of edible Cucumis (C. acidus, Jacquin), with fruits not larger than a pigeon's egg, is indigenous. In South African deserts it has become spontaneously established, and retained the characters of the cultivated fruit. 
Cucumis Colocynthis, Linné. (CitrullusColocynthis, Schrader). From the Mediterranean regions to India. An annual herb. The medicinal extract of Colocynth is prepared from the small gourd of this species. Active principle: Colocynthin.

Cucumis Conomon, Thunberg.

Japan. An annual. The large fruit is used for preserves.

Cucumis Melo, Linné.

The Melon. Originally from the country about the Caspian Sea. The best varieties might also be naturalised in our sanddeserts, particularly in places where some moisture collects. Some of the Bokhara varieties are remarkably luscious and large. Apparently remunerative results have been gained in Belgium from experiments to cultivate Melons for sugar and treacle. The seeds, thus obtained in quantity, become available for oil-pressing. The root contains Melonemetin.

Cucumis Momordica, Roxburgh.

Cultivated in India. It produces Cucumbers two feet long, bursting slowly when ripe into several divisions. Young the fruit is used like Cucumbers, aged like Melons.

Cucumis sativus, Linné.

The Cucumber. Egypt. Indicated here merely for completeness' sake, also because Gherkin-pickling ought to become a more extended local industry. Dr. G. King brought under notice and culture the Chinese Cucumber "Solly-Qua," which attains a length of seven feet. It must be trained on walls or trellises, to afford to the fruit sufficient scope for suspension.

Cucumis utilissimus, Roxburgh.

Mountains of Bengal. An annual like the other species. Fruit of the size and shape of an ostrich's egg with the flavour of Melons. These fruits will keep for several months.

Cucurbita maxima, Duchesne.

Large Gourd. Turkey. Instances are on record of fruits having weighed over 2 cwt. Also this species is eligible for naturalisation in the interior. Amongst other purposes it serves for calabashes.

Cucurbita Melopepo, Linné.

The Squash. May be regarded as a variety of C. Pepo. It will endure storage for months.

Cucurbita moschata, Duchesne.

The Musky Gourd. Doubtless also from the Orient. 
Cucurbita $\mathrm{Pepo}$, Linné.

The Pumpkin and Vegetable Marrow. Countries on the Caspian Sea. Its naturalisation in the desert would be a boon. The seeds on pressure yield a fixed oil; they are also anthelmintic. C. melanosperma, A. Braun, is not edible.

Cudrania Javensis, Trecul.

New South Wales and Queensland, South and East Asia to Japan, East Africa. This climbing thorny shrub can be utilised for hedges. Fruit edible, of pleasant taste; the root furnishes a yellow dye.

Cuminum Cymimum, Linné.

North Africa. The fruits of this annual herb are known as Cumin and used for certain condiments, as also in medicine. Cuminum Hispanicum, Merat, is similar. Essential oil peculiar.

Cupressus Benthami, Endlicher.

Mexico, at 5000 to 7000 feet. A beautiful tree, 60 feet high. The wood is fine-grained and exceedingly durable.

Cupressus Lawsoniana, Murray.* (Chamcecyparis Lawsoniana, Parl.)

Northern California. This is a splendid red-flowered cypress, growing 100 feet high, with a stem of 2 feet in diameter, and furnishes a valuable timber for building purposes, being clear and easily worked.

Cupressus Lindleyi, Klotzsch.

On the mountains of Mexico. A stately cypress, up to 120 feet high. It supplies an excellent timber.

Cupressus macrocarpa, Hartweg.

California, from Monterey to Noyo, in the granite as well as sandstone formation, sometimes in Sphagnum-moors. This beautiful and shady tree attains the height of 150 feet, with a stem of 9 feet in circumference, and is one of the quickestgrowing of all conifers, even in poor dry soil. One of the best shelter-trees on sea-sands, naturally following the coastline, never extending many miles from the shores, and occurring in localities where the temperature does not rise above $80^{\circ}$ F., nor sinks below the freezing-point (Bolander).

Cupressus Nutkænsis, Lamb. (Chamcecyparis Nutkcensis, Spach.)

The Yellow Cedar or Cypress of Alaska and the neighbouring States. Height of tree, 100 feet. Timber hard, durable, tough and close, also scented, worked with ease, used for boat-building and other purposes, the bast for mats and ropes. Can be trimmed for hedge-growth. 
Cupressus obtusa, F. von Mueller. (Retinospora obtusa, S. and Z.)

Japan. Attains a height of 80 feet; stem 5 feet in circumference. It forms a great part of the forests at Nipon. The wood is white-veined and compact, assuming, when planed, a silky lustre. It is used in Japan for temples. There are varieties of this species with foliage of a golden and of a silvery-white hue.

Two other Japanese cypresses deserve introduction, namely: C. breviramis (Chamcecyparis breviramea, Maxim.), and C. pendens (Chamcecyparis pendula, Maxim.)

Cupressus pisifera, F. von Mueller. (Chamacyparis pisifera, S. and Z.)

Japan. It attains a height of 30 feet, producing also a variety with golden foliage.

Cupressus sempervirens, Linné.

Common Cypress of South Europe. Height of tree up to 80 feet. It is famous for the great age it reaches, and for the durability of its timber, which is next to imperishable. At present it is much sought for the manufacture of musical instruments.

Cupressus thurifera, Humboldt, B. and K.*

Mexican White Cedar; 3000 to 4500 feet above sea-level. A handsome pyramidal tree, upwards of 40 feet high.

Cupressus thuyoides, Linné. (Chamacyparis sphceroidea, Spach).

White Cedar of North America; in moist or morassy ground. Height of tree 80 feet; diameter of stem 3 feet. The wood is light, soft, and fragrant; it turns red when exposed to the air; it is extensively used for a great variety of purposes. The aged wood resists the succession of dryness and moisture better than any other cypress.

Cupressus torulosa, Don.*

Nepal Cypress. Northern India; 4500 to 8000 feet above sea-level. Average ordinary height 40 feet, but much larger dimensions are on record, requiring perhaps confirmation. The reddish fragrant wood is as durable as that of the Deodar Cedar, highly valued for furniture. The tree seems to prefer limestone soil.

Cycas Normanbyana, F. v. Mueller.

A noble Queensland species, deserving introduction, and capable of being shipped to long distances in an upgrown state without emballage. 
Cyeas revoluta, Thunberg.

The Japan Fern-Palm. The trunk attains in age a height of about six feet, and is rich in sago-like starch. The slow growth of this plant renders it to us valuable for no other purpose than scenic decorative culture; it endures the climate of Melbourne without protection. Cycas angulata, R. Br., may also prove hardy, and would prove a noble horticultural acquisition, as it is the most gigantic of all Cycader, attaining a height of 70 feet in tropical East Australia. Like the Zamia stems also the trunks of Cycas admit of translocation even at an advanced age.

Cymopterus glomeratus, Candolle.

Western States of North America. Root edible (Dr. Rosenthal).

Cynara Cardunculus, Linné.

The Cardoon. Mediterranean regions. A perennial herb. The bleached leaf-stalks serve as esculents.

Cynara Scolymus, Linné.

The Artichoke. South Europe and North Africa. The receptacles and the base of the flower scales well-known as a vegetable. The plant is perennial and here merely mentioned as entitled to extended culture in grouping this with other stately plants. Several other species are worthy of cultivation.

Cynodon Dactylon, Persoon.*

Widely dispersed over the warmer parts of the globe, thus as indigenous reaching the northern parts of our colony. An important grass for covering bare harren land, or binding drift-sand, or keeping together the soil of abrupt declivities, or consolidating earth-banks against floods. It is not without value as a pasture-grass, resists extreme drought, and may become of great importance to many desert tracts. The dispersion is best effected by the creeping rooting stems, cut into short pieces; each of these takes root readily. In arable land this grass, when once established, cannot easily be subdued. The stems and roots are used in Italy for preparing there the Mellago graminis. Roxburgh already declared this grass to be by far the most common and useful of India, that it flowers all the year, and that it forms three-fourths of the food of the cows and horses there.

Cynosurus cristatus, Linné.

The Crested Dogstail-Grass. Europe, North Africa, West Asia. A perennial grass, particularly valuable as withstanding drought, the roots penetrating to considerable depth. The stems can also be used for bonnet plaiting. Though 
inferior in value for hay this grass is well adapted for permanent pasture, as it forms a dense turf without suffocating other grasses or fodder-herbs.

\section{Cyperus corymbosus, Rottboell.}

India. This stately perennial species may be chosen to fringe our lakes and ponds. It is extensively used for mats in India.

Cyperus esculentus, Linné.

South Europe, West Asia, various parts of Africa. Produces the "Chufa" or Ground Almond, an edible root which contains 27 per cent. of starch, 17 per cent. of oil and 12 per cent. of saccharine substance. This plant does not spread like the C. rotundus, and can be reared on sand-land, though in rich loose soil the harvest is far more plentiful. The tubers, of which 100 to 150 can be obtained from each plant, are consumed either raw or cooked. Hogs root them up for food. The oil surpasses in excellence of taste all other oils used for culinary purposes. The roasted tubers are a fair substitute for coffee. The root of the North American C. phymatodes (Muehlenberg) is also nutty.

Cyperus Papyrus, Linné.

The Nile Papyrus. Though no longer strictly an utilitarian plant, as in ancient times, it could scarcely be passed on this occasion, as it ought to become valuable in the horticultural trade. Its grand aspect recommends it as very decorative for aquatic plantations.

Cyperus proliferus, Linné fil.

Canary Islands. The "Tagasaste." This tall herb is recommended as a fodder-plant in countries exposed to drought.

Cyperus Syriacus, Parlatore.

The Syrian or Sicilian Papyrus. This is the Papyrus-plant usual in garden cultivation. The plants in our Botanic Garden attain a height of eight feet, but suffer somewhat from frost. Other tall Cyperi deserve introduction, for instance C. giganteus, Rottboell, from West India and Guiana, these kinds of plants being hardier than others from the tropics.

Cyperus tegetum, Roxburgh.

India. This Galingale-rush might be naturalised on riverbanks, to obtain material for the superior mats made of it in Bengal. The fresh stems are slit longitudinally into three or four pieces, each of which curls round by exsiccation, and can then be worked into durable and elegant mats. 
Cyperus textilis, Thunberg. (Cyperus vaginatus, R. Brown.) Widely dispersed over the Australian continent, but not yet noticed in Tasmania and New Zealand. It is restricted to swampy localities, and thus is not likely to stray into ordinary fields. It is our best indigenous fibre-plant, and it is likewise valuable as being with ease converted into pulp for good writing-paper, as shown by me some years ago. Its perennial growth allows of regular annual cutting. Within Victorian territory this Galingale-rush is particularly common on the Nurray-fiats.

Cytisus scoparius, Link. (Spartium scoparium, Linné.) The Broom-bush. Europe, North Asia. Of less significance as a broom-plant than as one of medicinal value. It can also be used for tanning purposes. Most valuable for arresting drift-sand. An alkaloid (Spartein) and a yellow dye (Scoparin) are obtainable from this Broom-bush.

\section{Dacrydium Colensoi, Hooker.}

New Zealand. A beautiful tree, growing 50 feet in height and producing hard and incorruptible timber; chiefiy eligible for our alpine regions.

Dacrydium cupressinum, Solander.

New Zealand. Native name, Rima; the Red Pine of the colonists. This stately tree acquires the height of 200 feet, and furnishes a hard and valuable wood, very lasting for fences, but readily decaying in waterworks. Mr. Kirk recommends the timber on account of its great strength for girders and heavy beams anywhere under cover. With other New Zealand conifers particularly eligible for our forestvalleys. A most suitable tree for cemeteries, on account of its pendulous branches.

Dacrydium Franklini, Hooker fil.

Huon Pine of Tasmania; only found in moist forest recesses, and might be planted in our dense fern-tree gullies. Height of tree, 100 feet; stem circumference, 20 feet. The wood is highly esteemed for ship-building and various artisans' work.

Dactylis cæespitosa, Forster. (Poa Forsteri, Steudel.)

Fuegia, Falkland's Island, South Patagonia. The Tussockgrass. Thrives in cold countries near the sea in pure sand, at the edge of peat-bogs. It would likely prosper in our Alpine moors. It is perennial, and reaches to a height of seven feet. It is very nutritious, and much sought by herds. The base of the stem is nutty and edible.

Dactylis glomerata, Linné.*

Europe, North Africa, North and Middle Asia. The Cocks- 
foot-grass. Perennial. One of the best of tall pasture grasses, adapted as well for dry as moist soil, thus even available for wet clays. It will live also under the shade of trees in forests. Its yield of fodder is rich and continuous, but its stems are hard. It is already largely cultivated, and has become naturalised. It is generally liked by cattle, unless when by understocking or neglect it has been allowed to become rank. Langethal observes:- "What the Timothygrass is for the more dry sandy soil, that is the Cocksfootgrass for more binding soil, and no other (European) grass can be compared to it for copiousness of yield, particularly if the soil contains a fair quantity of lime. $\mathrm{I}_{\mathbf{a}^{+}}$grows quickly again after the first cutting and comes early on in the season. The nutritive power of this grass is of the first class."

Dammara alba, Rumph. (D. Orientalis, Lamb.)

Agath Dammar. Indian Archipelagus and mainland. A large tree 100 feet high, with a stem of 8 feet in diameter; straight and branchless for two-thirds its length. It is of great importance on account of its yield of the transparent Dammar resin, extensively used for varnish.

Dammara Australis, Lambert.*

Kauri Pine. North island of New Zealand. This magnificent tree measures, under favourable circumstances, 180 feet in height and 17 feet in diameter of stem; the estimated age of such a tree being 700 or 800 years. It furnishes an excellent remarkably durable timber, straight-grained, and much in use for masts, boats, superior furniture, casks, and particularly sought for decks of ships, lasting for the latter purpose twice as long as the deal of many other pines. It is also available for railway break-blocks and for carriages, and regarded as one of the most durable among timber of the coniferæ. Braces, stringers, and tie-beams of wharves remained, according to Professor Kirk, for very many years in good order under much traffic. In bridge-building the Kauri timber gave also excellent results; it can also be used advantageously for railway sleepers. Kauri ought to be extensively introduced into our denser forests. Auckland alone exports about $£ 20,000$ worth of Kauri timber annually. It is easily worked, and takes a high polish. It yields besides the Kauri resin of commerce, which is largely got from under the stem of the tree. The greatest part is gathered by the Maoris in localities formerly covered with Kauri forests; pieces weighing $100 \mathrm{lbs}$. have been found in such places.

Dammara macrophylla, Lindley.

Santa Cruz Archipelagus. A beautiful tree, 100 feet high, resembling $\mathrm{D}$. alba. 
Dammara Moorei, Lindley.

New Caledonia. Height of tree about 50 feet.

Dammara obtusa, Lindley.

New Hebrides. A fine tree, 200 feet high, with a long clear trunk; resembling $\mathrm{D}$. A ustralis.

Dammara ovata, Moore.

New Caledonia. This tree is rich in Dammar resin.

Dammara robusta, Moore.

Queensland Kauri. A tall tree, known from Rockingham's Bay and Wide Bay. It thrives well even in open, exposed, dry localities at Melbourne.

Dammara Vitiensis, Seemann.

In Fiji. Tree 100 feet high; probably identical with Lindley's D. longifolia.

Danthonia Cunninghami, J. Hooker.

New Zealand. A splendid alpine fodder-grass with large panicles.

Danthonia nervosa, J. Hooker.

Extra-tropic Australia. One of the best of nutritious swamp-grasses.

Danthonia pectinata, Lindley.

New South Wales, Queensland and North Australia, in the arid interior regions. A perennial desert-grass, resisting drought; sought with avidity by sheep, and very fattening to them.

Danthonia triticoides, Lindley.

Of nearly the same natural distribution as the preceding, and equalling that species in value. Both so important as to deserve rearing even in their native countries.

Daucus Carota, Linné.

Europe, North Africa, extra-tropic Asia east to Japan. The Carrot. Admits of naturalisation along our shores. Beyond the ordinary culinary utilisation it serves for the distillation of a peculiar oil. The chemical substances Carotin and Hydrocarotin are derived from it.

Debregeasia edulis, Weddell.

The Janatsi-itsigo or Toon-itsigo of Japan. Berries of this bush edible, fibre valuable for textile fabrics. A few Indian species, with fibre resembling that of Boehmeria, ascend to the Himalayas for several thousand feet, and may therefore be hardy here, namely, D. velutina, D. Wallichiana, D. hypoleuca; the latter extends to Abyssinia, where it has been noticed at elevations of 8000 feet. On mountains in Java occurs D. dichotoma. 
Dendrocalamus giganteus, Munro.

Malacca and the adjacent islands. Habit of Gigantochloa maxima, therefore one of the mightiest of all Bamboos.

Dendrocalamus strictus, Nees.

India, particularly Bengal. Grows on drier ground than. Bambusa arundinacea. It is also smaller and quite straight. Its strength and solidity render it fit for many select technic purposes.

Desmodium triflorum, Candolle.

In tropical regions of Asia, Africa and America. A densely matted perennial herb, alluded to on this occasion as recommendable for places too hot for ordinary clover and as representing a large genus of plants, many of which may prove of pastoral value. Dr. Roxburgh already stated that it helps to form the most beautiful turf in India, and that cattle are very fond of this herb. Colonel Druryinforms us, that it is springing up in all soils and situations, supplying there the place of Trifolium and Medicago.

Digitalis purpurea, Linné.

Greater part of Europe. The Foxglove. A biennial and exceedingly beautiful lierb of great medicinal value, easily raised. Chemical principles: Digitalin, Digitaletin and three peculiar acids.

Dioscorea aculeata, Linné.*

The Kaawi-Yam. India, Cochin-China, South Sea Islands. Stem prickly, as the name implies, not angular. Leaves alternate, undivided. It ripens later than the following species, and requires no reeds for staking. It is propagated from small tubers. This Yam is of a sweetish taste, and the late Dr. Seemann regarded it as one of the finest esculent roots of the globe. A variety of a bluish hue, cultivated in Central America (for instance at Caracas), is of very delicious taste. In the warmest parts of our colony this and the following species are likely to come to perfection.

Dioscorea alata, Linné.*

The Uvi-Yam. India and South Sea Islands. The stems are four-angled and not prickly. The tubers, of which there are many varieties, will attain under favourable circumstances a length of eight feet, and the prodigious weight of one hundred pounds! This species, and the preceding one, are the two principal kinds cultivated in tropical countries. D. alata is in culture supported by reeds. It is propagated from pieces of the old root, and comes in warm climes to perfection in about seven months. The tubers may be baked or boiled. It is this species, which has been successfully 
cultivated in New Zealand, and also in the Southern States of North America.

Dioscorea globosa, Roxburgh.

India. Roxburgh states this to be the most esteemed Yam in Bengal.

Dioscorea hastifolia, Nees.

Extra-tropic Western Australia, at least as far south as $32^{\circ}$. It is evidently one of the hardiest of the Yams, and on that account deserves particularly to be drawn into culture. The tubers are largely consumed by the aborigines for food; it is the only plant on which they bestow any kind of cultivation, crude as it is.

Dioscorea Japonica, Thunberg.* (D. Batatas, Decaisne.)

The hardy Chinese and Japan Yam. This species, which is not prickly, has been cultivated some years in our Botanic Garden. The material here for comparison is not complete, but seems to indicate, that $\mathrm{D}$. transversa, R. Br., and $\mathrm{D}$. punctata, R. Br., are both referable to $\mathrm{D}$. Japonica. If this assumption should prove correct, then we have this Yam along the coast tracts of North and East Australia as far south as latitude $33^{\circ}$. In Australia we find the wild root of good taste.

Dioscorea nummularia, Lamarck.

The Tivoli Yam. Continental and Insular India, also South Sea Islands. A high climbing prickly species, with opposite leaves. Roots cylindrical, as thick as an arm; their taste exceedingly good.

Dioscorea oppositifolia, Linné.

India and China. Not prickly. One of the edible Yams.

Dioscorea pentaphylla, Linné.

Continental and Insular India, also South Sea Islands. Likewise a good Yam. A prickly species, with alternate divided leaves.

Dioscorea purpurea, Roxburgh.

India. In Bengal considered next best to $\mathrm{D}$. alata.

Dioscorea quinqueloba, Thunberg.

Japan, and there one of several Yam-plants with edible tubers. Among numerous congeners are mentioned as providing likewise root-vegetables : D. piperifolia (Humboldt) from Quito, D. esurientum (Fenzl) from Guatemala, D. tuberosa and D. conferta (Velloza) from South Brazil, D. Cayennensis (Lamarck) from tropical South America, D. triphylla (Linné) from tropical Asia, D. deltoidea (Wallich) from Nepal. Of these and many other species the relative 
quality of the roots, and the degree of facility of their field cultivation, require to be more ascertained.

Dioscorea sativa, Linné.

South Asia, east as far as Japan, also in the South Sea Islands, and North and tropical East Australia, likewise recorded from tropical Africa. Stem cylindrical, not prickly. The acrid root requires soaking before boiling. It has proved hardy in the Southern States of North America.

Dioscorea spicata, Roth.

India. Root used like those of other species.

Dioscorea tomentosa, Koenig.

Ooyala Yam. India. The nomenclature of some of the Asiatic species requires further revision.

Dioscorea trifida, Linné fil.

Central America. One of the Yams there cultivated. Various other tuberous Dioscorea occur in tropical countries; but their respective degree of hardiness, taste and yield are not recorded or ascertained. The length of the Victorian warm season is probably sufficient for ripening all these Yams.

\section{Diospysos Ebenum, Koenig.*}

Ceylon, where it furnishes the best kind of Ebony-wood. It is not uncommon up to 5000 feet in that island, according to Dr. Thwaites, hence I would recommend this large and valuable tree for test plantations in East Gippsland and in other lowland forest-regions of our colony, where also D. quæsita and D. oppositifolia (Thwaites), the best Calamander trees and D. Melanoxylon, should be tried. Many other species of Diospyros could probably be introduced from the mountains of various tropical regions, either for the sake of their ebony-like rood or their fruit. Black Ebony-wood sinks in water. The price in England ranges from $£ 8$ to $£ 10$ per ton, from 700 to 1000 tons being imported into Britain annually for pianoforte-keys, the string-holders of musical instruments and other select purposes. The following species yield Ebony-wood, according to Hiern, some of which may prove hardy. Indian: D. Ebenum Koen., D. melanoxylon Roxb., D. silvatica Roxb., D. Gardneri Thw., D. hirsuta L. fil., D. discolor, Willd., D. Embryopteris Pers., D. Ebenaster Retz., D. montana Roxb., D. insignis Thw., D. Tupru Hamilt., D. truncata Zoll., D. ramiflora Wall.; African: D. Dendo Welw., D. mespiliformis Hochst.; Mauritius : D. tesselaria Poiret; Madagascar: D. haplostylis Boivin, D. microrhombus Hiern. 
Diospyros Kaki, Linné fil.

The Date-plum of China and Japan. A slow-growing not very productive tree, here recorded for completeness. The fruit is yellow or pink or dark purple, variable in size, but never larger than an ordinary apple; it can readily be dried on strings. A hard and soft variety occur. It has ripened at Sydney.

Diospyros Lotus, Linné.

From Northern China to the Caucasus. The ordinary Dateplum. The sweet fruits of this tree, resembling black cherries, are edible, and also used for the preparation of syrup. The wood, like that of $\mathrm{D}$. chloroxylon, is known in some places as green Ebony; it must however not be confounded with other kinds, such as are furnished by some species of Excœcaria, Nectandra and Jacaranda.

Diospyros Virginiana, Linné.

The North American Ebony or Parsimon. A tree 60 feet liigh. Wood very hard and blackish. The sweet variety yields a good table fruit.

Diposis Bulbocastanum, Candolle.

Chili. The tubers of this perennial herb are edible (Philippi).

Dipsacus fullonum, Linné.

Fuller's Teazel. Middle and South Europe and Middle Asia. A tall biennial herb. The thorny fruit-heads in use for fulling in cloth factories. The import during one of the last years into England was valued at $£ 5000$. The plant is most easily raised. The use of these Teazels has not yet been superseded by any adequate machinery.

Dolichos Lablab, Linné.

Warmer parts of Africa; probably thence spread widely through the tropics. An annual herb, sometimes lasting through several years. The young pods as well as the ripe seeds available for culinary use, but not of all varieties. It delights in rich soil, and ripens in hot countries within three months; its yield is about fortyfold according to Roxburgh. The whole plant forms excellent stable-feed for cattle.

Dolichos uniflorus, Lamarck.

Tropical and sub-tropical Africa and Asia. An annual herb. well adapted for stable pulse.

Dorema Ammoniacum, Don.

Persia, on mountains up to 4000 feet. A tall perennial herb yielding the Gum-resin Ammoniacum, which might be obtained from plants to be introduced into our snowy mountains. 
Dracocephalum Moldavica, Linné.

North and Middle Asia. An annual showy scent-herb.

Drimys Winteri, R. and G. Forster.

Extra-tropical South America. The Canelo of Chili, sacred under the name of Boighe to the original inhabitants. Attains in river-valleys a height of 60 feet. The wood never attacked by insects (Dr. Philippi); thus the Australian species may be equally valuable.

Ecballion Elaterium, Richard.

Mediterranean regions and Orient. The Squirting Cucumber. An annual. The powerful purgative Elaterium is prepared from the pulp of the fruit. Chemical principles: Elaterid, Elaterin, Hydroelaterin.

Ehrharta Diplax, F. v. Mueller. (Microlcena av enacea, J. Hooker.

New Zealand. This tall perennial grass is fond of woodlands, and deserves introduction. It is likely to prove a rich pasture-grass. A few other Australian species, particularly of the section Tetrarrhena, are readily accessible to us, and so indeed also the South African Ehrhartas, all adapted for our clime, the majority perennial, and several of superior value. Ehrharta caudata, Munro, is indigenous in Japan.

Ehrharta stipoides, La Billardière.

Extra-tropic Australia, also New Zealand. A perennial grass, which keeps beautifully green all through the year. For this reason its growth for pasturage should be encouraged, particularly as it will live on poor soil. $\mathrm{Mr}$. W. H. Bacchus, of Ballarat, considers it nearly as valuable as Kangaroo-Grass, and in the cool season more so. $\mathrm{He}$ finds it to bear over-stocking better than any other native grass, and to maintain a close turf. It is however not always copiously seeding.

Elæagnus parvifolius, Royle.

From China to the Himalayas. This bush has been introduced as a hedge-plant into North America, and, according to Mr. Meehan, promises great permanent success, as it achieved already a high popularity in this respect. Several other species might well be experimented on in the same manner.

Elegia nuda, Kunth.

South Africa. A rush, able with its long root to bind moving sand; it also affords good material for thatching (Dr. Pappe). Many of the tall Restiacer of South Africa would prove valuable for scenic effect in the gardens and 
conservatories, and among these may specially be mentioned Cannamois cephalotes (Beauv).

Eleusine Coracana, Gaertner.

Southern Asia, east to Japan. Though annual, this grass is worthy of cultivation on account of its height and nutritiveness. The large grains can be used like Millet. E. Indica (Gaertner) only differs as a variety. It extends to tropical Australia and is recorded also from many other tropical countries.

Eleusine stricta, Roxburgh.

India. The increase of grain of this annual grass in rich soil is at times five-hundredfold. E. Tocusso, Fresenius, is a valuable kind from Abyssinia, seemingly allied to E. stricta. The Arabian and Himalaian E. flagellifera, Nees, is perennial. Other species of Eleusine are deserving of trial.

Elymus arenarius, Linné.*

The Sea Lyme-Grass. Europe and North Asia, on sandcoasts. One of the most important and vigorous of grasses for binding drift-sand on the sea-shores. The North American E. mollis, Trinius, is allied to this species.

Elymus condensatus, Presl.

The Bunch-Grass of British Columbia and California. This is favourably known as adapted for sandland.

Embothrium coccineum, R. and G. Forster.

From Chili to Magellan's Straits. The Notra or Ciruelillo of Chili. A tree of exquisite beauty, but seldom extending to beyond 30 feet in height. The wood is utilised for furniture. E. lanceolatum is merely a variety (Dr. Philippi). The equally gorgeous E. emarginatum of the Peruvian Andes and E. Wickluami from Mount Bellenden-Ker of North Queensland deserve, with the East Australian allied Stenocarpus sinuatus, a place in any sheltered gardens or parks of the warm temperate zone.

Encephalartos Denisonii, F. v. Mueller.

New South Wales and Queensland. This noble Pine-Palm is hardy here, and to be regarded as a most desirable acquisition to our garden sceneries, along with E. spiralis, E. Preissii and the South African species. All admit of translocation even when of large size and when many years old. The stems, with an unusual tenacity of life, remain sometimes dormant after removal for several years.

Engelhardtia spicata, Blume.

The spurious Walnut-tree of the mountains of Java and the Himalayas. It reaches a height of 200 feet. 


\section{Ervum Lens, Linné. (Lens esculenta, Moench.)}

Mediterranean regions, Orient. The Lentil. Annual, affording in its seeds a palatable and nutritious food. A calcareous soil is essential for the prolific growth of this plant. The leafy stalks, after removal of the seeds, remain a good stablefodder. The variety called the Winter Lentil is more prolific than the Summer Lentil.

\section{Erythroxylon Coca, Lamarck.*}

Peru. This shrub is famed for the extraordinarily stimulating property of its leaves, which pass under the names of Spadic and Coca. They contain two alkaloids, Cocain and Hygrin, also a peculiar tannic acid. More than $£ 600,000$ worth is annually collected. The Peruvians mix the leaves with the forage of mules, to increase their power of enduring fatigue. Whether any of the many other species of Erythroxylon possess similar properties seems never yet to have been ascertained.

Eucalyptus acmenoides, Schauer.

New South Wales and East Queensland. The wood used in the same way as that of E. obliqua (the Stringybark-tree), but superior to it. It is heavy, strong, durable, of a light colour, and has been found good for palings, flooring-boards, battens, rails, and many other purposes of house carpentry (Rev. Dr. Woolls).

Eucalyptus amygdalina, La Billardière.

In our sheltered springy forest-glens attaining not rarely a height of over 400 feet, there forming a smooth stem and broad leaves, producing also seedlings of a foliage different to the ordinary state of E. amygdalina, as occurs in more open country. This species or variety, which might be called Eucalyptus regnans, represents the loftiest tree in British territory, and ranks next to the Sequoia Wellingtonia in size anywhere on the globe. The wood is fissile, well adapted for shingles, rails, for house-building, for the keelson and planking of ships and other purposes. La Billardière's name applies ill to any of the forms of this species. Seedlings raised on rather barren ground near Melbourne have shown the same amazing rapidity of growth as those of E. globulus; yet, like those of E. obliqua, they are not so easily satisfied with any soil. It has endured the frosts of the milder parts of England, with E. polyanthemos, and E. viminalis. In New Zealand it has survived the cold, where E. globulus succumbed. E. amygdalina, E. urnigera, E. coccifera, E. rostrata and E. corymbosa have proved at Rome, according to the Rev. M. Gildas, more hardy than E. globulus, E. diversicolor, E. resinifera, 
E. longifolia and E. melliodora. Professor Balfour observed that $\mathrm{E}$. viminalis has stood since thirty years in the open air at Haddington (South Scotland), attaining a height of 50 feet and a base of 8 feet in circumference; shelter against hard winds in these cases is imperative The now well-known medicinal Eucalyptus oil, the distillation of which was initiated by the writer, is furnished in greater or smaller proportion by all the different species. It was first brought extensively into commerce by Mr. Bosisto, who has the credit of having ascertained many of the properties of this oil for technic application.

Eucalyptus botryoides, Smith.

From East Gipps Land to South Queensland. One of the most stately among an extensive number of species, remarkable for its dark-green shady foliage. It delights on river-banks. Stems attain a length of 80 feet without a branch, and a diameter of 8 feet. The timber usually sound to the centre, adapted for water-work, waggons, knees of boats, \&c. Posts of it very lasting, as no decay was observed in fourteen years.

Eucalyptus brachypoda, Turczaninow.

Widely dispersed over the most arid extra-tropical as well as tropical inland regions of Australia. One of the best trees for desert tracts; in favourable places 150 feet high. Wood brown, sometimes very dark, hard, heavy and elastic, prettily marked; thus used for cabinet-work, but more particularly for piles, bridges and railway sleepers (Rev. Dr. Woolls).

Eucalyptus calophylla, R. Brown.

South-West Australia. More umbrageous than most Eucalypts and of comparatively rapid growtl. The wood is free of resin when grown on alluvial land, but not so when produced on stony ranges. It is preferred to that of $\mathrm{E}$. marginata and E. cornuta for rafters, spokes and fence rails; it is strong and light, but not long lasting underground. The bark is valuable for tanning, as an admixture to Acacia bark.

Eucalyptus citriodora, Hooker.

Queensland. It combines with the ordinary qualities of many Eucalypts the advantage of yielding from its leaves a rather large supply of volatile oil of excellent lemon-like fragrance.

Eucalyptus cornuta, La Billardière.

South-West Australia. A large tree of rapid growth, preferring a somewhat humid soil. The wood is used for various artizan's work, and there preferred for the strongest 
shafts and frames of carts and other work requiring hardness, toughness and elasticity.

Eucalyptus crebra, F. v. Mueller.

The Narrow-leaved Ironbark-tree of New South Wales and Queensland. Wood reddish, hard, heavy, elastic and durable, much used in the construction of bridges, also for waggons, piles, fencing, \&c. E. melanophloia, F. v. M., the Silver-leaved Ironbark-tree, and E. leptophleba, E. trachyphloia and E. drepanophylla are closely allied species of similar value. They all exude astringent gum-resin in considerable quantity, resembling kino in appearance and property.

Eucalyptus diversicolor, F. v. Mueller.

The Karri of South-west Australia. A colossal tree, exceptionally reaching the height of 400 feet, with a proportionate girth of the stem. Furnishes good timber for ship and boat planks, particularly for masts, likewise for wheels. Fair progress of growth is shown by the young trees, planted even in dry exposed localities in Melbourne. The shady foliage and dense growth of the tree promise to render it one of our best for avenues. In its native localities it occupies fertile, rather humid valleys.

Eucalyptus Doratoxylon, F. v. Mueller.

The Spear-wood of South-West Australia, where it occurs in sterile districts. The stem is slender and remarkably straight, and the wood of such firmness and elasticity, that the nomadic natives wander long distances to obtain it as material for their spears.

Eucalyptus eugenioides, Sieber.

New South Wales. Regarded by the Rev. Dr. Woolls as a fully distinct species. Its splendid wood, there often called blue-gum-tree wood, available for many purposes, and largely utilised for shipbuilding.

Eucalyptus globulus, La Billardière.

Blue-Gum-tree of Victoria and Tasmania. This tree is of extremely rapid growth, and attains a height of 400 feet, furnishing a first-class wood; shipbuilders get keels of this timber 120 feet long; besides this they use it extensively for planking and many other parts of the ship, and it is considered to be generally superior to American Rock Elm. A test of strength has been made between some Blue Gum, English Oak, and Indian Teak. The Blue Gum carried 14 lbs. weight more than the Oak and $17 \mathrm{lbs} .4$ ozs. more than Teak upon the square inch. Blue-Gum wood, besides for shipbuilding, is very extensively used by carpenters for all kinds of out- 
door work, also for fence-rails, railway-sleepers-lasting about nine years-for shafts and spokes of drays, and a variety of other purposes. E. globulus is hardier than Orange and Lemon plants.

Eucalyptus gomphocephala, Candolle.

The Tooart of South-west Australia; attains a height of 120 feet, the clear trunk up to 50 feet long. The wood is closegrained, hard, and not rending. It is used for shipbuilding, wheelwright's work, and other purposes of artisans.

Eucalyptus goniocalyx, F. v. Mueller.

From Cape Otway to the southern parts of New South Wales. A large tree which should be included among those for new plantations. Its wood resembles in many respects that of E. globulus. For house-building, fence-rails and similar purposes it is extensively employed in those forestdistricts where it is abundant, and has proved a valuable timber.

Eucalyptus Gunnii, J. Hooker.

Victoria, Tasmania and New South Wales, at alpine and subalpine elevations. The other more hardy Eucalypts comprise E. coriacea, E. alpina, E. urnigera, E. coccifera and E. vernicosa, which all reach heights covered with snow for several months in the year.

Eucalyptus hemiphloia, F. v. Mueller.

New South Wales and South Queensland. To be regarded as a timber-tree of great excellence, on the authority of the Rev. Dr. Woolls. It is famous for the hardness and toughness of its timber, which is used for shafts, spokes, plough-beams and similar utensils.

Eucalyptus Leucoxylon, F. v. Mueller.

The ordinary Ironbark-tree of Victoria and some parts of South Australia and New South Wales. It attains a height of 100 feet, and supplies a valuable timber, possessing great strength and hardness; it is much prized for its durability by carpenters, shipbuilders, \&c. It is largely employed by waggonbuilders for wheels, poles, \&c.; by shipbuilders for top-sides, treenails, the rudder (stock), belaying-pins, and other purposes; it is also used by turners for rough work. This is considered the strongest wood in our colony. It is much recommended for railway-sleepers, and extensively used in underground mining work. It is very extensively employed for the handles of axes and other implements by Victorian manufacturers. As the supply of its very durable timber is falling short, and as it is for some purposes superior to that of almost any other Eucalypt, the regular culture of this tree over wide areas should be 
fostered, especially as it can be raised on stony ridges not readily available for ordinary husbandry. The wood is sometimes pale, or in other localities rather dark. The tree is generally restricted to the lower Silurian sandstone and slate formation with ironstone and quartz. It is rich in kino. E. Leucoxylon has, next to E. rostrata, thriven best about Lucknow (in India) among the species tried there for forest-culture. E. sideroxylon is a synonym.

Eucalyptus maculata, Hooker.

The Spotted Gum-tree of New South Wales and South Queensland. A lofty tree, the wood of which is employed in ship-building, wheelwright's and cooper's work. The heartwood as strong as that of British Oak (Rev. Dr. Woolls).

Eucalyptus marginata, Smith.*

The Jarrah or Mahogany-tree of South-West Australia, famed for its indestructible wood, which is attacked neither by Chelura nor Teredo nor Termites, and therefore so much sought for jetties and other structures exposed to sea-water, also for any underground work, and largely exported for railway-sleepers. Vessels built of this timber have been enabled to do away with all copper-plating. It is very strong, of a close grain and a slightly oily and resinous nature; it works well, makes a fine finish, and is by shipbuilders here considered superior to either Oak, Teak, or indeed any other wood.. The tree grows chiefly on ironstone ranges. At Melbourne it is not quick of growth, if compared to our Blue Gum (E. globulus, Lab.) or to our Stringybark (E. obliqua, l'Her.), but it is likely to grow with celerity in our ranges. Instances are on record of the stem having attained a girth of 60 feet at 6 feet from the ground through the formation of buttresses.

Eucalyptus obliqua, L'Heritier.*

The ordinary Stringybark tree, attaining gigantic dimensions. The most extensively distributed and most gregarious of all Eucalypts, from Spencer's Gulf to the southern parts of New South Wales, and in several varieties designated by splitters and other wood-workers by different names ; most extensively used for cheap fencing rails, palings, shingles and any other rough wood-work, not to be sunk underground nor requiring great strength or elasticity. The bulk of wood obtained from this tree in very poor soil is perhaps larger than that of any other kind, and thus this species can be included even here, where it is naturally common and easily redisseminated, among the trees for new forest-plantations in barren woodless tracts of our own country, to yield readily and early a supply of cheap and easily fissile wood. 
Eucalyptus paniculata, Smith.

The White Ironbark-tree of New South Wales. All the trees of this series are deserving of cultivation, as their wood, though always excellent, is far from alike, and that of each species preferred for special purposes of the artisan.

Eucaiyptus phœnicea, F. v. Mueller.

Carpentaria and Arnhem's Land. Of the quality of the timber hardly anything is known, but the brilliancy of its scarlet flowers recommends this species to a place in any forest or garden-plantation. For the same reason also E. miniata, from North Australia, and E. ficifolia, from South-West Australia, should be brought extensively under cultivation.

Eucalyptus pilularis, Smith.

The Black-butt tree of South Queensland, New South Wales and Gipps Land. One of the best timber-yielding trees about Sydney, of rather rapid growth (Rev. Dr. Woolis). It is much used for flooring-boards.

Eucalyptus platyphylla, F. v. Mueller.

Queensland. Regarded by the Rev. Julian Tenison Woods as one of the best of shade-trees, and seen to produce leaves sometimes a foot and a half long and a foot wide. This tree is available for open exposed localities, where trees from deep forest-valleys would not thrive.

Eucalyptus polyanthemos, Schauer.

East Australia. A tree up to 150 feet high, which furnishes an extremely hard and lasting timber, in great demand for mining purposes, also for wheelwright's work; for fuel this wood is unsurpassed.

Eucalyptus resinifera, Smith.

The Red Mahogany Eucalypt of South Queensland and New South Wales. A superior timber-tree, according to the Rev. Dr. Woolls, the wood being much prized for its strength and durability. It has proved one of the best adapted for a tropical clime.

Eucalyptus robusta, Smith.

New South Wales. The timber in use for ship-building, wheelwright's work and many implements, such as mallets, \&c.

Eucalyptus rostrata, Schlechtendal.*

The Red Gum of Victoria, South Australia and many river flats in the interior of the Australian continent. Although a native tree of this colony, it has been introduced into this list on account of its wood being of extraordinary endurance underground, and for this reason so highly valued for fence- 
posts, piles, and railway.sleepers; for the latter purpose it will last at least a dozen years, and, if well selected, much longer. It is also extensively used by shipbuilders for main-stem, stern-post, inner-post, dead-wood, floor-timbers, futtocks, transoms, knight-head, hawsepieces, cant, stern, quarter and fashion timber, bottom-planks, breasthooks and riders, windlass, bowrails, \&c. It should be steamed before it is worked for planking. Next to the Jarrah from West Australia, this is the best wood for resisting the attacks of seaworms and white ants. For other details of the uses of this and other native trees refer to the Reports of the Victorian Exhibitions of 1862 and 1867 . The tree attains a height of fully 100 feet. The supply for our local wants falls already short, and cannot be obtained from Tasmania, where the tree does not naturally exist. E. rostrata was observed by Dr. Bonavia in the province of Oude to thrive well in places where E. globulus, E. obliqua and E. marginata perished under the extreme vicissitudes of the clime. It will live in swamps.

Eucalyptus siderophloia, Bentham.

The Large-leaved or Red Ironbark-tree of New South Wales and South Queensland. According to the Rev. Dr. Woolls this furnishes one of the strongest and most durable timbers of New South Wales; with great advantage used for railwaysleepers and for many building purposes. It is harder even than the wood of E. sideroxylon, but thus also worked with more difficulty.

Eucalyptus Stuartiana, F. v. Mueller.

South-East Australia. A splendid tree, attaining a height of 200 feet, and furnishing a very durable tough wood.

Eucalyptus tereticornis, Smith.*

From East Queensland to Gipps Land. Closely allied to E. rostrata and seemingly not inferior to it in value.

Eucalyptus tesselaris, F. v. Mueller.

North Australia and Queensland. Furnishes a brown, rather elastic wood, not very hard, available for many kinds of artisan's work, and particularly sought for staves and flooring. The tree exudes much astringent gum-resin (P. O'Shanesy).-Many other Eucalypts could have been mentioned as desirable for wood culture, but it would have extended this enumeration beyond the limits assigned to it. Moreover, the quality of many kinds is not yet sufficiently ascertained, or not yet fully appreciated even by the artisans and woodmen. All the Eucalypts are valuable for the production of tar, pitch, acetic acid, potash and various dye substances. 
Euclea myrtina, Burchell.

South Africa. Berry small, black, but edible. To us this plant would hardly be more than an ornamental bush.

Euclea undulata, Thunberg.

South Africa. Berry small, red, edible. Other shrubby species from the same portion of the globe yield also esculent fruits, which under superior culture may vastly improve.

Eucryphia cordifolia, Cavanilles.

The Muermo or Ulmo of Chili. This magnificent evergreen tree attains a height of over 100 feet, producing a stem of sometimes 6 feet in diameter. The flowers are much sought by bees. For oars and rudders the wood is preferred in Chili to any other (Dr. Philippi). We possess congeneric trees in Tasmania (E. Billardieri) and in New South Wales (E. Moorei).

Eugenia cordifolia, Wight.

Ceylon, up to 3000 feet high. Fruit of one inch diameter.

Eugenia Hallii, Berg.

Quito. Fruit of large size.

Eugenia maboides, Wight.

Ceylon, up to 7000 feet elevation. Fruit of the size of a small cherry (Dr. Thwaites).

Eugenia Malaccensis, Linné.

The large Rose-Apple. India. Although strictly a tropical tree, it has been admitted into this list as likely adapted for our warmer forest-regions. The leaves are often a foot long. The large fruits of rosy odour are wholesome and of agreeable taste. E. Jambos, L., also from India, produces likewise excellent fruit.

Eugenia myrtifolia, Sims.

East Australia. A handsome bush with palatable fruits.

Eugenia Nhanica, Cambessedes.

South Brazil. The berries, which are of plum size, are there a table-fruit.

Eugenia pyriformis, Cambessedes.

Uvalho do Campo of South Brazil. Fruit of pear size.

Eugenia revoluta, Wight.

Ceylon, up to heights of 6000 feet; berry one inch in diameter.

Eugenia rotundifolia, Wight.

Ceylon, up to 8000 feet, rejoicing therefore in a cool or even cold climate. 
Eugenia supra-axillaris, Spring.

The Tata of South Brazil. Fruit large.

\section{Eugenia Zeyheri, Harvey.}

South Africa. A tree attaining 20 feet in height. The berries are of cherry size and edible. The relative value of the fruits of many Asiatic, African and American species of Eugenia remains to be ascertained; many of them furnish doubtless good timber, and all more or less essential oil; some probably also superior fruit. All such, even tropical trees, should be tested in East Gipps Land and other warm tracts of our colony, inasmuch as many of them endure a cooler clime than is generally supposed. Hence Anona muricata, L., the Soursop bush of West India, should also be subjected to test culture for the yield of its sweet fragrant melon-like fruit, and not less so Anona squamosa, L., the Sweetsop shrub or tree of Central America, for the sake of its very pleasant fruit.

Eupatorium triplinerve, Vahl. (E. Ayapana, Ventenat.) Central America. A perennial somewhat shrubby herb, possibly hardy in the warmer parts of our colony. It is used as a medicinal plant, also as an alexipharmic. It contains Eupatorin and much essential oil, peculiar to the plant.

Euryale ferox, Salisbury.

From tropical Asia to Japan. Though less magnificent than the grand Victoria Regia, this closely allied Waterlily is much more hardy, and would live unprotected in ponds and lakes of our colony. Though not strictly an industrial plant, it is not without utility, and undergoes some sort of cultivation in China for yielding its edible roots and seeds.

Euryangium Sumbul, Kaufmann.

Central Asia. Yields the true Sumbul-root.

Excæcaria sebifera, J. M. (Stillingia sebifera, Michaux.) The Tallow-tree of China and Japan. The fatty coating of the seeds yields the regetable tallow. The wood is so hard and dense as to be used for printing blocks; the leaves furnish a black dye. The tree endures the night-frosts of our open lowlands, though its foliage suffers.

Fagopyrum cymosum, Meissner.

The perennial Buck-Wheat or rather Beech-Wheat of the Indian and Chinese highlands. Can be used with other species for spinach and for obtaining from the leaves a blue dye.

Fagopyrum emarginatum, Babington.

Chinese and Himalayan Mountains, where it is cultivated for its seeds. Annual. 
Fagopyrum escluentum, Moench.

Central Asia. The ordinary Buck-Wheat. This annual herb succeeds on the poorest soil. The crushed amylaceous seeds can be converted by boiling or baking into a palatable and wholesome food. As an agrarian plant it can with advantage be raised as a first crop on sandy heath-land, newly broken up, for green manure. The period required for the cyclus of its vegetation is extremely short. Thus it can be reared on our higher Alps.

Fagopyrum Tataricum, Moench.

Middle and North Asia. Yields for the higher mountain regions a still safer crop than the foregoing, otherwise the remarks offered in reference to $\mathrm{F}$. esculentum apply also to F. Tataricum.

Fagopyrum triangulare, Meissner.

In the Himalayan Mountains, ascending naturally to regions 11,500 feet high. An annual. F. rotundatum, Babington, seems a variety of this species. It is cultivated for food like the rest.

Fagus Cunninghami, Hooker.

The Victorian and Tasmanian Beech. A magnificent evergreen tree, attaining large dimensions, and only living in cool damp rich forest-valleys, not rarely 200 feet high. The wood much used by carpenters and other artisans, the Myrtlewood of the trade. It requires to be ascertained by actual tests in the forests, whether the allied tall evergreen New Zealand Beeches possess any advantage over ours for forestculture; they are--Fagus Menziesii (Hooker) the Red Birch of the colonists; Fagus fusca (Hooker) the Black Birch; Fagus Solandri (Hooker) the White Birch. A magnificent beech, Fagus Moorei (F. von Mueller) occurs in New England.

Fagus Dombeyi, Mirbel.

The Evergreen Beech of Chili, called there the Coigue or Coihue. Of grand dimensions. Canoes out of its stem can be obtained of a size to carry ten tons freight. The wood is still harder than that of the following species, with the qualities of which it otherwise agrees (Dr. Philippi). This species extends to the Chonos group and perhaps still further south, and thus might be of value even for Middle European forest culture.

Fagus obliqua, Mirbel.

The Roble of Chili, called Coyam by the original inhabitants. A tall tree with a straight stem, attaining three to four feet diameter. Wood heavy and durable, well adapted for posts, 
beams, girders, rafters, joists, \&c., but not for flooring. One of the few Chilian trees with deciduous foliage (Dr. Philippi). Its value as compared to that of the European Beech should in our forest-plantations be tested.

Fagus procera, Poeppig.

Another deciduous Beech of Chili, where it passes by the names of Reulé or Rauli. Of still more colossal size than the Roble. Wood fissile, but well adapted for staves; it is finer in grain than that of F. obliqua, and much used for furniture (Dr. Philippi).

Fagus silvatica, Linné.

The deciduous Beech of Britain, of most other parts of Europe and extra-tropical Asia, and as Fagus ferruginea, Ait., in a particular variety, extending through North America. The trunk has been measured in height 118 feet, the head 350 feet in diameter; the wood is hard, extensively used by joiners and ship-builders and the manufacturers of various implements; the wood resists great pressure. Beech-tar contains a considerable proportion of paraftine ; the ash from any portion of this tree is rich in phosphate of lime. An allied Beech, Fagus Sieboldii, Endl., occurs in Japan. All these could here be grown to advantage only in our springy mountain-forests.

Fatsia papyrifera, Bentham. (Arabia papyrifera, Hooker; Panax papyrifer, F. v. Mueller.)

Island of Formosa. The Rice-paper plant, hardy in the lowlands of Victoria, and of scenic effect in garden-plantations; the pith furnishes the material for the so-called rice-paper.

Ferula galbaniflua, Boissier.

Persia; on mountains 4000 to 8000 feet high. This tall perennial herb might be transferred to our Alps, for obtaining locally from it the gum-resin Galbanum.

Ferula longifolia, Fischer.

South Russia. The aromatic long roots furnish a pleasant vegetable (Dr. Rosenthal).

Festuca coiron, Steudel.

Chili. A valuable perennial fodder-grass, according to the testimony of Dr. Philippi.

Festuca distichophylla, J. Hooker.

Victoria, South Australia, Tasmania, New South Wales. This dwarf, creeping grass is of great value for binding soil, forming rough lawns, edging garden-plots on arid places, and covering coast-sand. 
Festuca dives, F. v. Mueller.*

Victoria, from West Gipps Land to Dandenong and the sources of the rivers Yarra and Goulburn. One of the most magnificent of all sylvan grasses, not rarely 12 feet and exceptionally to 17 feet high. Root perennial. This grass deserves to be brought to any forest-tracts, as it prospers in shade; along rivulets in deep soil it assumes its grandest forms. The large panicle affords nutritious forage.

\section{Festuca elatior, Linné.*}

The Meadow Fescue. Europe, North Africa, North and Middle Asia. A perennial grass, attaining a height of several feet. There are several varieties of this species. The tallest follows rivers readily as far down as the tides reach. The ordinary form is well adapted for permanent pastures, has tender leaves, produces excellent hay and is early out in the season. It can be mixed advantageously with $\mathrm{F}$. ovina. It is superior to ryegrass in produce and improves with age. F. arundinacea, Schreb., F. pratensis, Huds. and F. loliacea, Huds. are varieties of this species.

Festuca flava, F. v. Mueller. (Poa flava, Gronov; Tricuspis sesleriodes, Torr.; Uralepis cuprea, Kunth.)

The tall Redtop Grass of the Eastern States of North America. A perennial sand-grass, with wide panicles.

Festuca gigantea, Villars.

Europe and Middle Asia. A perennial good forest-grass.

Festuca heterophylla, Lamarck.

Mountains of Europe. This perennial grass attains a height of five feet; it produces a proportionately great bulk of fodder, and serves as an admixture to grasses of hay or pasture-lands, particularly the former (Lawson). It is best fitted for our alpine and highest forest-tracts, which in course of time and perhaps early so, will be sought for close pastoral occupation, when territorial areas will become less easily acquired.

Festuca Hookeriana, F. v. Mueller.

Alps of Australia and Tasmania. A tall perennial grass, evidently nutritious, required to be tried for pastoral culture and perhaps destined to become a meadow-grass of colder countries.

Festuca litoralis, La Billardière.

Extra-tropic Australia and New Zealand. An important grass for binding drift-sand on sea-shores. 
Festuca ovina, Linné.

Sheep-Fescue. Europe, North and Middle Asia, North America, found also in South America and the Alps of Australia and New Zealand. This species like F. elatior is obtainable with facility. F. duriuscula, L., and F. rubra, L., are varieties. A perennial grass, thriving on widely different soil, even moory and sandy ground. It yields a good produce, maintains its virtue, resists drought and is also well adapted for lawns and the swards of parks.

Festuca purpurea, F. v. Mueller. (Uralepis purpurea, Nuttall ; Tricuspis purpurea, A. Gray.

South-East coast of North America. A tufty sand-grass, but annual.

Festuca silvatica, Villars.

Middle and South Europe. A notable forest-grass. F. drymeia (Mert. and Koch), a grass with long creeping roots, is closely allied. Both deserve here test culture.

Festuca spadicea, Linné.

Alps of Europe. This grass would thrive on the heights of our snowy mountains. Perennial.

The space does not admit of entering here into further details of the respective value of many species of Festuca which might advantageously be introduced from various parts of the globe for rural purposes.

Ficus Carica, Linné.*

Orient. The ordinary Fig-tree. It attains an age of several hundred years. In our latitudes and clime a prolific tree. The most useful and at the same time the most hardy of half-a-thousand recorded species of Ficus. The extreme facility with which it can be propagated from cuttings, the resistance to heat, the comparatively early yield and easy culture recommend the Fig-tree to be chosen, where it is an object to raise masses of tree-vegetation in widely treeless landscapes of the warmer zones. Hence the extensive plantations of this tree, made in formerly woodless parts of Egypt; hence the likelihood of choosing the Fig as one of the trees for extensive planting through favourable portions of our desert-wastes, where moreover the fruit could be dried with particular ease. Caprification is unnecessary, even in some instances injurious and objectionable. Two mainvarieties may be distinguished, that which produces two crops a year and that which yields but one. The former includes the grey or purple Fig, which is the best, the white Fig and the golden Fig, the latter being the finest in appearance but not in quality. The main variety, which bears only 
one crop a year, supplies the greatest quantity of Figs for drying, among which the Marseillaise and Bellonne are considered the best. The Barnisote and the Aubique produce delicious large fruits, but they must be dried with fire-heat, and are usually consumed fresh. The ordinary drying is effected in the sun. For remarks on this and other points concerning the Fig, the valuable tract recently published by the Rev. Dr. Bleasdale should be consulted. The first crop of figs grows on wood of the preceding year, the last crop however on wood of the current year. Varieties of particular excellence are known from Genoa, Savoy, Malaga, Andalusia.

\section{Ficus columnaris, Moore and Mueller.}

The Banyan-tree of Lord Howe's Island, therefore extra tropical. One of the most magnificent productions in the whole empire of plants. Mr. Fitzgerald, a visitor to the island, remarks that the pendulous air-roots, when they touch the ground, gradually swell into columns of the same dimensions as the older ones, which already became converted into stems, so that it is not apparent which was the parent trunk; there may be a hundred of stems to the tree, on which the huge dome of dark evergreen foliage rests, but these stems are all alike, and thus it is impossible to say whence the tree comes or whither it goes. The allied Figtrees of continental East Australia have great buttresses, but only now and then a pendulous root, approaching in similarity the stems of Ficus columnaris. The Lord Howe's Island Fig-tree is more like F. macrophylla than F. rubiginosa; but $\mathbf{F}$. columnaris is more rufous than either. In humid, warm sheltered tracts of Victoria, this grand vegetable living structure may be raised as an enormous bower for shade and for scenic ornament. The nature of the sap, whether available for caoutchouc or other industrial material, requires yet to be tested.

Ficus Cunninghami, Miquel.

Queensland, in the eastern dense forest-regions. Mr. O'Shanesy designates this as a tree of sometimes monstrous growth, the large spreading branches sending down roots, which take firm hold of the ground. One tree measured was 38 feet in circumference at two feet from the ground, the roots forming wall-like abutments, some of which extended 20 feet from the tree. Several persons could conceal themselves in the large crevices of the trunk, while the main branches stretched across a space of about 100 feet. A kind of caoutchouc can be obtained from this tree. A still 
more gigantic Fig-tree of Queensland is F. colossea (F. v. M.), but it may not be equally hardy, not advancing naturally to extra-tropic latitudes. This reminds of the great Council-tree, F. altissima.

Ficus elastica, Roxburgh.*

Upper India. A large tree, yielding its milk-sap copiously for caoutchouc. Already Roxburgh ascertained 60 years ago, that India-rubber could be dissolved in Cajaput oil (so similar to our Eucalyptus oil), and that the sap yielded about onethird of its weight caoutchouc. This tree is not of quick growth in the changeable and often dry clime of Melbourne, but there is every prospect, that it would advance rather rapidly in any of our extensively unutilised forest-gullies, and that copious plantations of it there would call forth a new local industry. Mr. S. Kurz states, that also F. laccifera (Roxburgh) from Silhet is a caoutchouc Fig-tree, and that both this and F. elastica yield most in a ferrugineous clay soil on a rocky substratum; further, that both can bear dryness, but like shade in youth. Several other species of tropical Figs, as well American as Asiatic, are known to produce good caoutchouc, but it is questionable whether any of them would prosper in our southern latitudes; nevertheless for the conservatories of botanic gardens all such plants should be secured with a view of promoting public instruction.

Ficus Indica, Linné.

The Banyan-tree of India, famed for its enormous expansion and air roots. Although not strictly an utilitarian tree, it is admitted here as one of the most shady trees, adapted for the warmer and moister regions of this colony. At the age of 100 years, one individual tree will shade and occupy about one and a-half acres, and rest on 150 stems or more, the main stem often with a circumference of fifty feet, the secondary stems with a diameter of several feet. At Melbourne, the tree suffers somewhat from the night-frosts.

Ficus macrophylla, Desfontaines.*

The Moreton Bay Fig-tree, which is indigenous through a great part of East Australia. Perhaps the grandest of our avenue-trees, and among the very best to be planted, although in poor dry soil its growth is slow. In our latitudes it is quite hardy in the lowland. The foliage may occasionally be injured by grasshoppers. Easily raised from seed.

Ficus rubiginosa, Desfontaines.

New South Wales. One of the most hardy of all Fig-trees, and very eligible among evergreen shade-trees. It is 
estimated that the genus Ficus comprises about 600 species, many occurring in cool mountain-regions of tropical countries. The number of those, which would endure our clime, is probably not small.

Ficus Sycamorus, Linné.

The Sycamore Fig-tree of the Orient, copiously planted along the roadsides of Egypt. The shady crown extends to a width of 120 feet. Though introduced, we have as yet no local means of raising this tree in quantity, and must therefore rely on fresh importations of cuttings or more particularly seeds.

Fitzroya Patagonica, J. Hooker.*

Chili, as far south as Chiloe. The Alerce of the Chilians. Grows on swampy moory places. A stately tree, 100 feet high. The diameter of the stem reaches sometimes the extraordinary extent of 15 feet. The wood is almost always red, easily split, light, does not warp, stands exposure to the air for half a century, and in Valdivia and Chiloe almost all buildings are roofed with shingles of this tree (Dr. Philippi). The outer bark produces a strong fibre, used for caulking ships. Like Libocedrus tetragona this tree should be extensively planted in our unutilised swampy moors in the mountains.

Flacourtia Ramontchi, l'Heritier. ( $F$. sapida, Roxburgh). India up to Beloochistan. This and F. cataphracta (Roxb.) form thorny trees with somewhat plum-like fruits. With other species they can be adopted for hedge-copses.

Flemingia tuberosa, Dalzell.

Western India. The tubers of this herb are said to be edible. Another species, F. vestita, is on record as cultivated in North-Western India for its small esculent tubers.

Flindersia Oxleyana, F. v. Mueller.

The Yellow Wood of New South Wales and Queensland. Other species occur there, among which F. Bennettiana is the best for avenue purposes.

Flueggea Japonica, C. Richard.

China and Japan. The mucilaginous tubers can be used for food, a remark which applies to many other as yet disregarded liliaceous plants.

Fœniculum officinale, Allioni.

The Fennel. Mediterranean regions, particularly on limestone soil. A perennial or biennial herb, of which two primary varieties occur-the so-called sweet variety having fruits almost twice as large as the other. The herb and fruits are in use as condiments and the latter also for medicine. The fruits are rich in essential oil, containing much Anethol. 
Fourcroya Cubensis, Haworth.

West India and continental tropical America. A smaller species than the following, but equally utilised for tibre and impenetrable hedges. F. flavo-viridis (Hooker), from Mexico, is still smaller.

Fourcroya gigantea, Ventenat.

Central America. With species of Yucca, Agave, Dracæna, Cordyline, Phormium, Doryanthes and this and a few other Fourcroyas, we have gigantic liliaceous plants available industrially for fibre. Frost injures the leaves of this species. Scape up to 30 feet high.

Fourcroya longæva, Karw. and Zucc.

High mountains of Guatemala and Mexico, at an elevation of about 10,000 feet. One of the most gigantic and magnificent of all liliaceous or amaryllideous plants, in volumen only surpassed by Dracæna Draco, the Dragon-tree of the Canary Islands. This is the only known high-stemmed species, the trunk attaining a height of 50 feet, and huge panicle of flowers 40 feet more. It dies, like many allied plants, after flowering. The species is recorded here as a fibre-plant, but with us would mainly or solely be kept for its ornamental grandeur.

Fragaria Chiloensis, Aiton.

In various of the colder parts both of North and South America. Chili-Strawberry.

Fragaria collina, Ehrhart.

In various parts of Europe. Hill-Strawberry.

Fragaria grandiflora, Ehrhart. ( $F$. Ananas, Miller.)

Various colder parts of America. Closely allied to $\mathrm{F}$. Chiloensis. Ananas-Strawberry.

Fragaria Illinoensis, Prince.

North America. Hovey's Seedling and the Boston kind from this plant.

Fragaria pratensis, Duchesne. (Fragaria elatior, Ehrhart.) In mountain-forests of Europe. Cinnamon-Strawberry. Hautbois.

Fragaria vesca, Linné.

Naturally very widely dispersed over the temperate and colder parts of the Northern Hemisphere. Wild Wood Strawberry. From this typical form probably some of the other Strawberries arose. Middle forms and numerous varieties now in culture were produced by hybridisation. These plants, though abounding already in our gardens, are mentioned here, because even the tenderest varieties could be 
naturalised in our ranges. Any settler living near some brook or rivulet might readily set out some plants which with others, similarly adapted, would gradually spread with the current.

Fragaria Virginiana, Miller.

North America. Scarlet Strawberry.

Fraxinus Americana, Linné.*

The White Ash of North America. A large tree, 80 feet high, which delights in humid forests. Timber valuable, better resisting extreme heat than the common Ash. The Red Ash (Fraxinus pubescens, Lam.), the Green Ash (F. viridis, Mich.), the Black Ash (F. sambucifolia, Lam.), and the Carolina Ash (F. platycarpa, Mich.), are of smaller size.

Fraxinus Chinensis, Roxburgh.

It is this Ash on which a peculiar wax is produced by Coccus Pela, perhaps also on some species of Ligustrum. About 40,000 lbs. are exported annually according to $\mathrm{Mr}$. Bernardini. F. ornus is well adapted for a promenade-tree, and is earlier in foliage than F. excelsior, F. Americana and most other Ash-trees.

Fraxinus excelsior, Linné.

The ordinary Ash of Europe and West Asia. Height 80 feet, of comparatively quick growth, known to attain an age of nearly 200 years. Rich soil on forest-rivulets or river-banks suit it best; wood remarkably tough and elastic, used for agricultural and other implements, for oars, axletrees and many other purposes. Six peculiar kinds of Ash-trees occur in Japan, some also in the Indian highlands; all might be tried here.

Fraxinus floribunda, Don. Nepal Ash, 40 feet high.

Fraxinus Oregana, Nuttall.

California and Oregon Ash. A tree up to eighty feet in height, preferring low-lying alluvial lands. The wood of this fine species is nearly white, tough and durable, often used for oars and handles of implements. Though allied to F. sambucifolia it is very superior as a timber-tree. Ash-trees will grow readily in the shade of other trees.

Fraxinus Ornus, Linné.*

The Manna-Ash of the Mediterranean regions. Height about 30 feet. It yields the medicinal manna.

Fraxinus quadrangulata, Michaux.* The Blue Ash of Nortl America. One of the tallest of the Ashes, 70 feet high, with an excellent timber. 
Fraxinus viridis, Michaux.

The Green Ash of North America. Height 70 feet; wood excellent.

Frenela Actinostrobus, Mueller (Actinostrobus pyramidalis, Miq.)

From South-West Australia. Though only a shrub, it is placed here on record as desirable for introduction, because it grows on saline desert-flats, where any other conifers will not readily succeed. It may become important for coast cultivation.

Frenela Macleayna, Parlatore.

New South Wales. A handsome tree, of regular pyramidal growth, attaining a height of $70 \mathrm{feet}$; the timber is valuable.

Frenela Parlatorei, F. v. Mueller.

South Queensland. Recommended by Mr. F. M. Bailey as a shade-tree. It attains a height of sixty feet. Several other Frenelas are worthy of forest-culture.

Frenela verrucosa, A. Cunningham.

Also several other species from Victoria and other parts of Australia are among the trees, which may be utilised for binding the coast- and desert-sand. They all exude Sandarac.

Garcinia Travancorica, Beddome.

Madras Presidency, up to elevations of 4500 feet. This seems to be the hardiest of the superior Gamboge trees, hence there is some prospect of its prospering in our warmer forests.

Garuleum bipinnatum, Lessing.

South Africa. A perennial herb of medicinal properties, and like numerous other plants there and elsewhere, praised as an alexipharmic, but all requiring close reinvestigation in this respect.

Gaultiera Myrsinites, Hooker.

North California, Oregon, British Columbia. The fruit of this procumbent shrub is said to be delicious. It would prove adapted for our alps.

Gaultieria Shallon, Pursh.

North-Western America. This handsome spreading bush would yield its pleasant edible berries in abundance, if planted on our snowy mountains, where it would likely become naturalised.

Gaylussacia frondosa, Torrey and Gray.

The Blue Tangleberry of North America. A bush with deciduous foliage. Berry sweet. 
Gaylussacia resinosa, Torrey and Gray.

The Black Huckleberry of North America. A dwarf shrub with deciduous leaves. It likes swampy woodlands, and thus would find ample space in our forest-ranges. Berry of pleasant taste. Perhaps some of the South American species produce also edible fruits.

Geitonoplesium cymosum, Allan Cunningham.

Through the whole East Australian forests. It is mentioned here to draw attention to the fact, that special culture may convert this into an Asparagus plant, as Mr. P. O'Shanesy has found, that the young shoots offer a fair substitute for Asparagus.

Gelsemium nitidum, Michaux.

Southern States of North America and Mexico. A twining shrubby plant of medicinal value, long since introduced into Australia by the writer, like numerous other plants of industrial or therapeutical importance. Active principle Gelseminin. The scent of the flowers has also come into use as a cosmetic.

Genista monosperma, Lamarck.

Mediterranean regions. One of the best of broom-bushes for arresting sand-drift. G. sphærocarpa, Lamarck, is of like use, and comes also from the Mediterranean Sea.

Gentiana lutea, Linné.

Sub-Alpine tracts of Middle and South Europe. A perennial most beautiful herb, yielding the medicinal Gentian-root. It could be easily raised in our higher mountains. Chemical principles: Gentian-bitter and Gentianin.

Gigantochloa apus, Kurz. (Bambusa apus, Roemer and Schultes.)

Indian Archipelagus, at elevations up to 5000 feet. Height of stem to 60 feet. When young it is used for strings and ropes.

Gigantochloa aspera, Kurz.

Java. Found by Zollinger to attain a maximum height of 170 feet.

Gigantochloa atter, Kurz.

Java, in the region from 2000 to 4000 feet. Height of stems to 70 feet. One of the extensively cultivated species.

Gigantochloa maxima, Kurz.

Java. Height to 120 feet, the stems nearly a foot thick. One of the most extensively cultivated of all A siatic bamboos, ascending into mountain regions. 
Gigantochloa nigro-ciliata, Kurz. (Oxytenanthera nigrociliatc, Munro.)

Continental and insular India. Stems to 130 feet long.

Gigantochloa robusta, Kurz.

Mountains of Java. Height to 100 feet. Kurz noticed in Java the early growth to be nearly 18 feet in a month, the principal branches only commencing when the shoot had reached a height of about 70 feet. Some Java bamboo is known to measure at a height of about 120 feet still 22 inches in girth.

Gigantochloa verticillata, Munro. (Bambusa verticillata, Blume.)

The Whorled Bamboo of India. It attains a height of 100 feet ; in damp heat it grows at the astonishing celerity of 40 feet in about three months, according to Bouché. The young shoots furnish an edible vegetable like G. Apus and Bambusa Bitung.

Ginkgo biloba, Linné. (Salisburia adiantifolia, Smith.)

Ginkgo-tree. China and Japan. A deciduous fan-leaved tree, 100 feet high, with a straight stem 12 feet in diameter. The wood is white, soft, easy to work, and takes a beautiful polish. The seeds are edible, and when pressed yield a good oil. Ginkgo-trees are estimated to attain an age of 3000 years.

Gladiolus edulis, Burchell.

Interior of South Africa. The bulb-like roots are edible, and taste like chestnuts when roasted.

Gleditschia triacanthos, Linné.

The deciduous Honey Locust-tree of North America. Height up to 80 feet. Wood hard, coarse-grained, fissile. Sown closely, this plant forms impenetrable, thorny, not readily combustible hedges. An allied species, the G. horrida, Willd., in East Asia. The Water Locust-tree of North America (G. monosperma, Walt.) will grow in swamps to 80 feet.

Glycine hispida, Bentham. (Soja hispida, Mœnch.)

An annual herb of India, China and Japan. The beans are one of the main ingredients of the condiment known as Soja. Glycine Soja, Siebold and Zuccarini, is said to be a distinct plant, but probably serving the same purpose.

Glycyrrhiza echinata, Linné.

South Europe and Orient. From the root of this herb at least a portion of the Italian Liquorice is prepared. The root is thicker than that of the following. The Russian Liquorice-root is derived from this species. It is less sweet. 
Glycyrrhiza glabra, Linné.

South Europe. The extract of the root of this herb constitutes the ordinary Liquorice. The plant grows here most vigorously. The Liquorice of some utility in medicine, but also used in porter breweries. Chemical principle: Glycyrrhizin.

Gonioma Kamassi, E. Meyer.

South Africa. This small tree furnishes the yellow Kamassiwood, much sought for carpenter's tools, planes and other select articles of wood-work; also for wood engraving, according to Dr. Pappe. Flowers deliciously fragrant.

Gordonia lasianthus, Linné.

The Loblolly Bay. North America. A handsome tree, growing to a height of 60 feet; flowers snowy white. The wood is extremely light, of a rosy hue and fine silky texture, but unfit for exposure. The bark is extensively employed for tanning in the Southern States. Available for swampy coast-lands.

\section{Gossypium arboreum, Linné.*}

The Tree-Cotton. India, Arabia. A tall perennial species, but not forming a real tree, yielding cotton in the first season already. Leaves long-lobed. Bracts with few teeth. Petals yellow or in age pink or purple. Seeds brown, disconnected, after the removal of the cotton-fibre greenishvelvety. The cotton of long staple, but a variety occurs with short staple. The New Orleans Cotton (G. sanguineum, Hassk.) belongs to this species. Dr. Seemann connects also the ordinary G. herbaceum, L., as a variety with G. arboreum. The cotton-fibre is crisp, white, opaque and not easily separable.

Gossypium Barbadense, Linné.*

West India. Sea Island Cotton. Leaves long-lobed. Petals yellow. Seeds disconnected, black, after the removal of the cotton-fibre naked. The cotton of this species is very long, easily separable and of a silky lustre. This species requires low-lying coast-tracts for attaining to perfection. Perennial, and yielding like the rest a crop in the first season. Cultivated largely in the Southern States of North America, also in South Europe, North Africa, Queensland and various other countries.

Gossypium herbaceum, Linné.*

Scinde, Cabul and other parts of tropical and sub-tropical Asia, much cultivated in the Mediterranean countries. Perennial. Leaves short-lobed. Petals yellow. Seeds disconnected, after removal of the cotton-fibre grey-velvety. 
Distinguished and illustrated by Parlatore as a species, regarded by Seemann as a variety of G. arboreum. Staple longer than in the latter kind, white, opaque, not easily seceding. Even this species, though supposed to be herbaceous, will attain a height of 12 feet. A variety with tawny fibre furnishes the Nankin Cotton.

Gossypium hirsutum, Linné.*

Upland or Short-staple Cotton. Tropical America, cultivated most extensively in the United States, Southern European and many other countries. Perennial. Seeds brownish-green, disconnected, after the removal of the cotton-fibre greenish-velvety. Staple long, white, almost of a silky lustre, not easily separable. A portion of the Queensland Cotton is obtained from this species. It neither requires the coast-tracts nor the highly attentive culture of G. Barbadense.

Gossypium religiosum, Linné.* (G. Peruvianum, Cavan). Tropical South America. Kidney Cotton, Peruvian or Brazilian Cotton. Leaves long-lobed. Petals yellow. Seeds black, connected. The cotton is of a very long staple, white, somewhat silky and easily seceding from the seeds. A tawny variety occurs. This is the tallest of all cotton Bushes, and it is probably this species, which occurs in the valleys of the Andes as a small tree, bearing its cotton while frosts whiten the ground around.

Gossypium Taitense, Parlatore. (G. religiosum, Banks and Solander).

In several islands of the Pacific Ocean. A shrub. Petals white. Seeds disconnected, glabrous after the removal of the fulvous cotton-fibre, which secedes not with readiness.

Gossypium tomentosum, Nuttall.* (G. Sandvicense, Parlat.; G. religiosum, A. Gray).

Hawaia. Perennial. Petals yellow. Seeds disconnected, after the removal of the tawny cotton-fibre, fulvous-velvety, not easily parting with their cotton. The Cotton-roots are a powerful remedial agent, which, however, should only be used by legitimate medical practice. The barks of Hamamelis Virginiana and Viburnum prunifolium are antidotes (Phares and Durham).

For limitation of species and varieties Parlatore's "Specie dei Cotoni" (Florence, 1866) and Todaro's "Osservazioni su Cotone" may be consulted; information on culture may be sought in Porter's "Tropical Agriculturist" and in Mallet's work on "Cotton" (London, 1862).

There are many parts of our colony, in which all these species of Gossypium could be cultivated, and where a fair or even 
prolific Cotton-crop may be obtained. Good Cotton for instance has been produced on the Goulburn River, the Loddon, the Avoca and the Murray Rivers, particularly in places where water could be applied. All cultivated kinds of Cotton-plants are either naturally perennials or become such in favourable climes, although they may be treated strictly as annuals. Some of them will indeed in particular instances grow to the height of 20 feet. The geographic parallels, between which Cotton-culture is usually placed, are stretching in various girdles between the $36^{\circ}$ N.L. and $36^{\circ}$ S.L. The primary advantages of this important culture are: A return in a few months, comparatively esay field operations, simple and not laborious process of collecting the crop, and requirement of but little care in the use of the gin-machine in finally preparing the raw material for the market, the woolly covering of the seeds constituting the cotton of commerce. The oil obtained by pressure from the seeds is useful for various technic purposes, and the oil-cake can be used like most substances of similar kind for very fattening stable-feed. Sea Island Cotton was raised in splendid perfection in the northern parts of Victoria fully fifteen years ago from seeds, extensively distributed by the writer; but the want of cheap labour has hitherto militated against the extensive cultivation of the Cotton, and so also against the culture of tea and many other industrial plants. Cotton having been raised far away from the influence of the sea-air, it would be worthy of attempts, to naturalise various kinds of Cotton in the oases of our deserts, irrespective of regular culture. Our native Gossypium of the interior produces no fibre worth collecting. Cotton-plants have a predilection for gently undulating or sloping ground, with light soil and a moderate supply of moisture. In the most favourable climes, such as that of Fiji, Cotton produces flowers and fruits throughout the year, but the principal ripening falls in the dry season. From two hundred to three hundred plants or more can be placed on an acre. As many as seven hundred pods have been gathered from a single plant at one time, twelve to twenty capsules yielding an ounce of mercantile Cotton. Weeding is rendered less onerous by the vigorous growth of the plants. Cotton comes well in for rotation of crops. Major Clarke has ascertained that crossing cannot be effected between the Oriental and Occidental kinds of cotton. A high summer temperature is needed for a prolific Cotton harvest. Intense heat, under which even maize will suffer, does not injuriously affect Cotton, provided the atmosphere is not dry in the extreme. The soil should not be wet, but of a kind that naturally absorbs and retains humidity, without over satura- 
tion. In arid regions it is necessary to irrigate the Cottonplant. Heavy rains at the ripening period are injurious if not destructive to the Cotton-crop. Dry years produce the best returns, yet aqueous vapour in the air is necessary for the best yield. In colder localities the balls or capsules continue to ripen after the frosts prevent the formation of new ones. Porous soils resting on limestones and metamorphic rocks are eminently adapted for Cotton-culture. The canebrake soil of the North American Cotton-regions absorbs ammonia to a prodigous extent.

Grevillea robusta, Cunningham.

Our beautiful Lawn-tree, indigenous to the subtropical part of East Australia, 100 feet high, of rather rapid growth, and resisting drought in a remarkable degree; hence one of the most eligible trees for desert-culture. Our cultivated trees yield now already an ample supply of seeds. The wood is valued particularly for staves of casks.

Grumilea cymosa, E. Meyer.

South Africa. Dr. Pappe describes the wood of this tree as beautifully citron-yellow.

Guadua angustifolia, Kunth. (Bambusa Guadua, Humboldt and Bonpland.)

New Granada, Ecuador and probably others of the Central American States. This Bamboo attains a height of 40 feet, and might prove hardy in sheltered places of our lowlands.

Guadua latifolia, Kunth. (Bambusa latifolia, Humboldt. and Bonpland.)

One of the tall Bamboos of Central America, from whence several other lofty Bamboos may be obtained, among them the almost climbing Chusqueas. This Gaudua is stouter than any Indian Bamboo. In tropical America native Bamboos are planted for hedges.

Guevina Avellana, Molina. (Quadria heterophylla, Ruiz and Pavon.)

The evergreen Hazel-tree of Chili, extends from Middle Chili to the Chonos Archipelagus. One of the most beautiful trees in existence, attaining a height of 30 feet. The snowy white flower-spikes produced simultaneously with the ripening of the coral-red fruit. In the cooler southern regions the tree attains considerable dimensions. The wood tough and elastic, used for boatbuilding (Dr. Philippi). The fruit of the allied Brabejum stellatifolium can only be utilised with caution and in a roasted state as an article of diet, because it is noxious or even absolutely poisonous in a raw state. 


\section{Guilandina Bonduc, Linné.}

Widely dispersed through the intertropical regions of both hemispheres with G. Bonducella, L. Both would be well adapted for hedges in the warmer parts of our colony.

Guizotia oleifera, Candolle.

India and probably also Abyssinia. The Ramtil-oil is pressed from the seeds of this annual herb, which yields its crop in three months. The oil is much used like Sesamum-oil, as well for culinary as technic purposes.

Gunnera Chilensis, Lamarck.

Caracas to Patagonia, chiefly on cliffs. A most impressive plant for scenic groups in gardens. Darwin measured leaves 8 feet broad and 24 feet in circumference. The acidulous leaf-stalks serve as a vegetable; the thick roots are used for tanning and dyeing. G. macrophylla, Blume, is a native of Java and Sumatra, where it occurs on mountains, up to 6000 feet.

Gymnocladus Canadensis, Lamarck.

The Chicot. A North American timber and avenue tree, attaining a height of 80 feet; allied to Gleditschia, but, as the name implies, thornless. The wood is strong, tough, compact, fine-grained, and assumes a rosy colour.

Hagenia Abyssinica, Willdenow. (Brayera anthelminthica, Kunth).

Abyssinia, at elevations from 3000 to 8000 feet. A tall tree, admitted in this list because its flowers have come into medicinal use. It is, moreover, quite eligible for ornamental plantations.

Harina caryotoides, Roxburgh.

Assam, Chittagong and Darjeeling. A dwarf, tufted, hardy Palm, desirable for decorative purposes.

Harpullia Hillii, F. v. Mueller.

The Tulip-wood of Queensland. One of the most valuable of the numerous kinds of trees indigenous there for select cabinet-work.

Hedeoma pulegioides, Persoon.

The Pennyroyal of North America. An annual herb of aromatic taste, employed in medicine.

Hedysarum coronarium, Linné.*

The Soola Clover. South Europe. One of the best of perennial fodder-herbs. It carries with it also the recommendation of being extremely handsome. 
Heleocharis tuberosa, Roemer and Schultes.

China, where it is called Matai or Petsi. This rush can be subjected to regular cultivation in ponds for the sake of its edible wholesome tubers. $\mathrm{H}$. plantaginea and $\mathrm{H}$. fistulosa of India and our own native $\mathrm{H}$. sphacelata are allied plants.

\section{Helianthus annuus, Linné.*}

The Sunflower. Peru. This tall showy and large-flowered annual is not without industrial importance. As much as fifty bushels of seeds, or rather seed-like nutlets, have been obtained from an acre under very favourable circumstances, and as much as fifty gallons of oil can be pressed from such a crop. The latter can be used not only for machinery, but even as one of the best for the table. Otherwise the seeds afford an excellent fodder for fowl. The stalks furnish a good textile fibre and the blossoms yield a brilliant lasting yellow dye. About six pounds of seeds are required for an acre. The plant likes calcareous soil. Several allied North American species deserve perhaps rural culture. The return from a Sunflower-field is attained within a few months.

Helianthus tuberosus, Linné.

Brazil. Sunflower Artichoke. Inappropriately passing under the name Jerusalem Artichoke. The tubers are saccharine and serve culinary purposes. As fodder, they increase the milk of cows to an extraordinary degree. The foliage serves also well as fodder. The plant is propagated from the smallest but undivided tubers, placed like potatoes, but at greater interstices. The root is not susceptible to frost. The plant would be valuable for our alps. The yield is as large as that of potatoes, with less labour, and continues from year to year in fairly-treated land, uninterruptedly and spontaneously. The stem is rich in textile fibre. The percentage of crystalline sugar is largest during the cold season, namely 5-6/100. During the summer the starch-like Inulin prevails. This plant can only be brought to full perfection in a soil rich in potash.

Helichrysum lucidum, Henckel. (H. bracteatum, Willdenow.)

Throughout the greater part of Australia. The regular cultivation of this perennial herb would be remunerative to supply its everlasting flowers for wreaths, just like those of $\mathrm{H}$. orientale, Tournefort, from Candia, are largely grown and sold in South Europe to provide grave-wreaths. Furthermore, the lovely Helipterum Manglesii, F. v. M., from West Australia, could for like purposes be profitably reared on a large scale with several other Australian 
everlastings. Some South African species of Helichrysum and Helipterum are also highly eligible for these purposes of decoration.

Heliotropium Peruvianum, Linné.

Andes of South America. A perennial somewhat shrubby plant. Among various species of Heliotrop this one can best be utilised for the distillation of the scented oil.

Helleborus niger, Linné.

Forest-mountains of Middle and South Europe. The Christmas Rose of British Gardens. A perennial handsome herb. The roots are used in medicine.

Hemarthria compressa, R. Brown.

South Asia, South Africa, extra-tropic Australia. This perennial, though somewhat harsh, grass is recommendable for moist pastures, and will retain a beautiful greenness throughout the year. $\mathrm{H}$. uncinata is a closely allied plant.

Heracleum Sibiricum, Linné.

Colder regions of Europe and Asia. A very tall biennial herb with leaves of enormous size. Recently recommended for sheep-fodder in the Alpine regions. The plant could also be turned to account for scenic effect in horticulture.

Hibiscus cannabinus, Linné. (H. radictus, Cavanilles.) Tropical Asia, Africa, and Australia. An annual showy herb. The stem yields a hemp-like fibre. Stems up to twelve feet high without ramification if closely sown. Rich soil on the Nile has yielded over 3000 lbs. of clear fibre from one acre. The bearing strength is often found to be more than of the Sunn-fibre. The leaves serve as sorrel-spinach. Several other Hibisci can be utilised in the same manner.

Hibiscus esculentus, Linné.

West India and Central America. A tall herb. The mucilaginous seed-capsules are known as Ochro, Bandakai or Gobbo, and used as culinary vegetables. Our summers bring them to maturity. The leaves of this and allied species can be used as pot-herbs.

Hibiscus Ludwigii, Ecklon and Zeyher.

South Africa. A tall shrubby and highly ornamental species, desirable also as yielding a fibre of great strength and toughness.

Hierochloa redolens, R. Brown.

South-eastern Australia, almost confined to the Alps; in Tasmania and New Zealand also found in the lowlands, occurring likewise in the Antarctic islands and the southern extremity of America. A tall perennial nutritious grass, with the 
odour of Anthoxanthum. It is worthy of dissemination on moist pasture-land. $H$. borealis of the colder regions of the Northern Hemisphere accompanies here in the south $\mathrm{H}$. redolens, but is a smaller grass. These grasses are particularly valuable for their fragrance as constituents of hay, the odorous principle, like in Anthoxanthum, Melilotus and Asperula, being Cumarin. Hierochloas are particularly appropriate for cold, wet, moory grounds.

Hippocrepis comosa, Linné.

The Horseshoe-Vetch. Middle and South Europe, North Africa. A perennial fodder-herb, not without importance. Likes stony ground, hence adapted for our "stony rises ;" but delights, like most leguminous herbs, in limestone soil. The foliage is succulent and nutritious. Langethal recommends it for a change after Saintfoin pastures fail. It furnishes not quite as much, but an earlier fodder.

Holcus lanatus, Linné.*

Europe, North Africa, Middle Asia. A well-known and easily disseminated perennial pasture-grass, of considerable fattening property. For rich soil better grasses can be chosen, but for moist, moory, or sandy lands and also for forests it is one of the most eligible grasses, yielding an abundant crop; it is however rather disliked by cattle as well as horses.

Holcus mollis, Limné.*

Of nearly the same geographic range and utility as the preceding species. Particularly admissible for sandy forest-land.

Holoptelea integrifolia, Planchon. (Ulmus integrifolia, Roxburgh.)

The Elm of India, extending from the lowlands to subalpine regions. A large tree, with timber of good quality. Foliage deciduous.

Hordeum deficiens, Steudel.

The Red Sea Barley. One of the two-rowed Barleys, cultivated in Arabia and Abyssinia. Allied to this is $\mathrm{H}$. macrolepis (A. Br.), a native of Abyssinia.

Hordeum distichon, Linné.

Central Asia. The ordinary two-rowed Barley. To this species belong: the ordinary English Barley, the Chevalier, the Annat, the Dunlop, the long-eared, the black, the large, the Italian and the Golden Barley, along with other kinds. A variety with grains free from the bracts constitutes the Siberian and the Haliday Barley, which however is less adapted for malt. Dry barley-flour, heated at the temperature of boiling water during several hours, constitutes Hufe- 
land's meal for invalids. Barley-culture might be carried on in many parts of our Alps. Marly and calcareous lands are particularly fit for its culture. It resists moderate spring frosts.

Hordeum hexastichon, Linné.

Orient. The regularly six-rowed Barley. This includes among other varieties the Red, the Scotch, the Square and the Bear Barley. Seeds less uniform in size than those of H. distichon. The so-called skinless variety is that in which the grain separates from the bracts. Langethal observes, that it is most easily raised, requires less seed-grain than ordinary barley, has firmer stems, is less subject to the rust disease and to bending down.

Hordeum secalinum, Schreber. (H. pratense, Hudson.) Europe, North and Middle Asia, North America. Perennial. Famed as the best fattening grass of many of the somewhat brackish marsh pastures on the North Sea. It never fruits when kept down by cattle, and suppresses finally nearly all other grasses and weeds.

Hordeum vulgare, Linné.

Orient. The four-rowed Barley, though rather six-rowed with two prominent rows. Several varieties occur, among them: the Spring, Winter and Black Barley, the Russian, the French, the Naked and the Wheat Barley. Pearl Barley is obtained from the Winter variety, which also surpasses Summer Barley in rigour of stems and rich and early yield, it being the earliest cereal in the season; the straw is copious and nutritious, and the grain is rich in gluten, hence far better adapted for flour than for malt. Summer Barley also passes under the name of Sand Barley; it is inferior in yield to $\mathrm{H}$. distichon, but is content with a less fertile, even sandy soil, and comes in a month's less time to ripeness. In alpine regions with a summer of sixty or seventy days without frost it still ripens. The Naked Barley is superior to many other varieties for peeled Barley, but inferior for brewing; the grain is also apt to drop (Langethal). Malt is important as an antiscorbutic remedy. Chemical principles of malt: Asparagin; a protein substance: Diastase; an acid and Cholesterin.fat.

Hordeum zeocriton, Linné.

Central Asia. Also a two-rowed Barley. To this species belong the Sprat, the Battledore, the Fulham and the Putney Barley, the Rice Barley, the Turkish Barley and the Dinkel. This species might be regarded as a variety of $\mathrm{H}$. distichon. The grains do not drop spontaneously and this variety is securer than others against sparrows, requires however a superior soil, and is harder in straw (Langethal). 
Hovenia dulcis, Thunberg.

Himalaya, China, Japan. The pulpy fruit-stalks of this tree are edible. $\mathrm{H}$. inæqualis, D. C., and $\mathrm{H}$. acerba, Lindl., are mere varieties of this species.

\section{Humulus Lupulus, Linné.*}

The Hop-plant. Temperate zone of Europe, Asia and North America. This twining perennial unisexual plant has proved to yield enormously on river-banks in rich soil or on fertile slope, where irrigation could be effected, particularly so within our territory along the river-valleys of Gipps Land and in other similar localities. A pervious especially alluvial soil, fertile through manure or otherwise, appliances for irrigation natural or artificial, and also shelter against storms, are some of the conditions for success in Hop-growth, and under such conditions the rearing of Hops will prove thus far profitable in countries and localities of very different mean temperature. A dry summer-season is favourable to the ripening and gathering of Hops. On the Mitchell River, in Gipps Land, $1500 \mathrm{lbs}$. have been obtained from an acre. In Tasmania large crops have been realised for very many years. The plant might be readily naturalised on riverbanks and in forest-valleys. The scaly fruit-cones form the commercial Hops, whose value largely depends on the minute glandular granules of Lupuline. Hops impart their flavour to beer, and principally by their tannic acid prevent acetous fermentation and precipitate albuminous substances from the malt. Hop-pillows are recommended to overcome want of sleep. Many of the substitutes of Hops are objectionable or deleterious. The refuse Hops of breweries possess double the value of stable manure. Active principles of Hop leaves and fruits: A peculiar volatile and a bitter acid substance. The fibre of the stem can be made into cords and paper.

Hydnum imbricatum, Linné.

In pine-forests of Europe. A wholesome Mushroom of delicious taste, which we should endeavour to naturalise in our pine plantations. Other recommendable European species are :H. erinaceum, Pers., H. coralloides, Scop., H. album, Pers., H. diversidens, Fries, H. auriscalpium, Linné, H. subsquamosum, Batsch, H. lævigatum, Sw., H. violascens, Alb., H. infundibulum, Sw., H. fuligineo-album, Schm., H. graveolens, Brot., H. Caput Medusæ, Nees, H. Hystrix, Fries. These and other edible fungi are given on the authority of Rosenthal's valuable work.

Hydrangea Thunbergi, Siebold.

Japan. The leaves of this shurb give a peculiar Tea, called there the "Tea of Heaven." 
Hydrastis Canadensis, Linné.

North America. The Yellow Poccoon. A perennial herb, utilised in medicine. The root contains two alkaloids: Berberin and Hydrastin. The root tinges brilliantly yellow, admitting of its use along with indigo for rich green colours.

Hymenæa Courbaril, Linné.

Tropical and Southern sub-tropical America. A tree of colossal size and remarkable longevity. Timber hard, extremely ponderous, close-grained, used for select wheelwork, trenails, beams and planks in various machinery. A fragrant amber-like resin, known as West India Copal, exudes from the stem. The beans of the pod are lodged in a mealy pulp of honey-like taste, which can be used for food. The possibility of the adaptability of this remarkable tree to the warmer parts of Victoria needs to be ascertained.

Hymenanthera Banksii, F. v. Mueller.

South-East Australia, New Zealand, Norfolk Island. A tall spiny shrub, well-adapted for close hedges, where rapid growth is not required. It stands clipping well. Flowers profusely fragrant.

Hyoscyamus niger, Linné.

The Henbane. Europe, North Africa, extra-tropic Asia. An important medicinal herb of one or two years' duration. It contains a peculiar alkaloid : Hyoscyamin.

Hyphæne Argun, Martius.

Nubia. Probably hardy in the warmer parts of our colony.

Hyphæne coriacea, Gaertner.

Equatorial Eastern Africa. The dichotomous Palm of the sea-coast regions. It attains a height of 80 feet.

Hyphæne crinita, Gaertner. (H. Thebaica, Martius.)

Abyssinia, Nubia, Arabia and Egypt, as far as $31^{\circ} \mathrm{N}$., and southward to the Zambesi, Nyassa and Sofala. The Gingerbread-Palm or Doum-Palm. It is much branched and attains a height of about 30 feet. The mealy husk of the fruit is edible. Grows away from the sea.

Hyphæne ventricosa, Kirk.

Zambesi. Loftier than the other species. Stem turgid towards the middle. Fruit large.

Hypochœris apargioides, Hooker and Arnott.

Chili. A perennial herb. The root is used for culinary purposes like that of the Scorzonera Hispanica.

Hypochœris Scorzoneræ, F. von Mueller. (Achyrophorus Scorzonerce, Candolle.)

Chili. Of the same use as $\mathrm{H}$. apargioides. Allied species of probably similar utility exist in Western South America. 
Ilex Cassine, Linné.

Southern States of North America. A Tea-bush, to which also remarkable medicinal properties are ascribed.

Ilex Paraguensis, St. Hilaire.

Uruguay, Paraguay and Southern Brazil. The Maté. This Holly-bush is inserted into this list rather as a stimulating medicinal plant, than as a substitute for the ordinary Teaplant. Chemical principles: Coffein, Quina-acid and a peculiar tannic acid, which latter can be converted into Viridin-acid.

Illicium anisatum, Linné.

China and Japan. The Star-Anis. An evergreen shrub or small tree. The starry fruits used in medicine and as a condiment. Their flavour rests on a peculiar volatile oil with Anethol. This species and a few others deserve culture also as ornamental bushes.

Imperata arundinacea, Cyrillo.

South Europe, North Africa, South and East Asia, Australia. Almost a sugar-cane in miniature. Valuable for binding sand, especially in wet localities.

Indigofera Anil, Linné.

Recorded as indigenous to West India, and as extending naturally through Continental America from Carolina to Brazil. A shrub several feet high. Pods sickle-shaped, short, compressed. One of the principal Indigo plants under cultivation both in the eastern and western hemispheres. Only in the warmest parts of our colony can we hope to produce Indigo with remunerative success. But many of the hardier species seem never yet tested for pigment. Already 114 are recorded alone from extra-tropical Southern Africa. An Indigofera of Georgia, said to be wild, perhaps I. Anil, yields an excellent product. The pigment in all instances is obtained by maceration of the foliage, aeration of the liquid and inspissation of the sediment.

Indigofera argentea, Linné. (I. coerulea, Roxburgh). Tropical and extra-tropical Northern Africa, Arabia, India. A shrub several feet high, closely allied to I. Anil, and likewise a good Indigo-plant.

Indigofera tinctoria, Linné.

Warmest part of Asia, as far east as Japan, recorded also from tropical Africa and even Natal. A shrubby plant, attaining a height of six feet. Pods straight, cylindrical, many-seeded. Extensively cultivated in warm zones for Indigo, and probably hardy in our northern and eastern low- 
land regions. The plant is frequently sold fresh by the grower to the factories. The Indigo-plant requires a rich friable soil, neither too moist nor too dry. The seeds are sown in furrows about a foot apart, and in hot damp climes the plant can already be cut in about two months, as soon as it begins to flower; in six or eight weeks it yields a second crop, and under favourable circumstances as many as four crops can be gathered in a year. The plants have to be renewed every year as the old ones do not yield such an abundant produce. Bright sunshine favours the development of the dye-principle, but frequent rains cause a more luxuriant growth (Hartwig).

\section{Inula Helenium, Linné.}

The Elecampane. Middle and South Europe, Middle Asia eastward to Japan. A perennial herb. The bitter and somewhat aromatic root, for the sake of its stimulating and tonic properties, is used in medicine. It contains also the amylaceous Inulin and the crystalline Helenin.

\section{Ipomœa Batatas, Poiret.* (Batatas edulis, Choisy).}

The Sweet Potato. Tropical South America. First brought to Europe from Brazil. It proved well adapted also for our part of Australia and for New Zealand. The tubers afford a palatable food, more nutritious than ordinary potatoes. Varieties with red, white and yellow roots occur. Each tuber weighs generally from $3 \mathrm{lbs}$. to $5 \mathrm{lbs}$, but may occasionally attain to 56lbs. The yield is from 200 to 300 bushels from an acre.

Ipomæa Batatilla, G. Don.

Cooler regions of Venezuela. The tubers serve as sweet potatoes. Similarly useful I. plantanifolia, Roem. et Schult., from Central America, and I. mammosa, Choisy, from Amboina.

Ipomøea paniculata, R. Brown.

Almost a cosmopolitan plant on tropical coasts; thus indigenous to North Australia and the warmer parts of East Australia. The tubers also of this species are edible. If hardy, the plant would deserve cultivation.

Ipomœa purga, Wenderoth.

Mountains of Mexico. The true Jalap. This species yields the medicinal Jalap root. It has recently been cultivated with apparent success even at New York. Thus it is entitled to a trial in our warm woodlands. Active principle: the resinous Convolvulin. I. Orizabensis, Ledanois, yields also Jalap, according to Hanbury. 
Ipomœea simulans, Hanbury.

Mexico. From this species the Tampico Jalap, or rather the Sierra Gorda Jalap, is derived. I. operculata, Mart., yields the Brazilian Jalap.

Isatis indigotica, Fortune.

North China. Perennial, almost shrubby. The use is similar to that of the following plant.

Isatis tinctoria, Linné.

Dyer's Woad. From the Mediterranean regions through part of the Orient, apparently extending as far as Japan. A tall herb of two years' duration. The blue dye is obtained from the fermented leaves. It succeeds best in rich limestone ground. Many other species of Isatis, mostly Asiatic, may produce perhaps dye with equal advantage. Boissier enumerates merely as Oriental twenty-eight kinds.

Jasminum grandiflorum, Linné.

From India to Japan. Flowers white. Extensively cultivated in South Europe. The delicate scent is withdrawn either by fixed oils or alcoholic distillation. The pecuniary yield obtainable from Jasmin cultivation seems vastly overrated, even if inexpensive labour should be obtainable.

Jasminum odoratissimum, Linné.

Madeira. Shrubby like the rest. Flowers yellow. Used like the foregoing and following for scent. This may be prepared by spreading upon wool or cotton, slightly saturated with olive oil or other fixed oil, the flowers, and covering them with other layers so prepared. The flowers are renewed from time to time until the oil is thoroughly pervaded by the scent, when the latter is withdrawn by alcohol. Other modes of extracting the oil exist.

Jasminum officinale, Linné.

From the Caucasus to China. Flowers white. This is the principal species cultivated in South Europe for its scent.

Jasminum Sambac, Aiton.

From India to Japan. It would probably endure our cool season in the northern and eastern regions. It has the richest perfume of all. The bush attains a height of twenty feet, and is almost climbing. The flowers are white, and must be collected in the evening before expansion. The relative value of many other species of Jasmin, nearly all from the warmest parts of Asia, seems in no instance to have been ascertained, so far as their oils or scents are concerned. Our Australian species are also deliciously fragrant, amongst which J. lineare, Br., occurs in our Victorian deserts, while 
also J. didymum, Forst.; J. racemosum, F. v. M.; J. simplicifolium, Forst.; J. calcareum, F. v. M. and J. suavissimum, Lindl., reach extra-tropic latitudes.

Jubrea spectabilis, Humboldt.

The tall and stout Coquito-Palm of Chili. Well adapted for our extra-tropic latitudes. A kind of treacle is obtained from the sap of this Palm. The small kernels are edible.

Juglans cinerea, Linné.*

The Butternut-tree of North America. About 50 feet high; stem-diameter 4 feet. Likes rocky places in rich forests. Wood lighter than that of the Black Walnut, durable and free from attacks of insects. It is particularly sought for panels of coaches, corn-shovels, wood dishes and similar implements, as it is not liable to split, nor heavy. The leaves, bark and husk are of medicinal importance, and so are those of other species.

Juglans cordiformis, Maximowicz.

Japan. This species approaches in many respects $J$. Sieboldiana.

Juglans Mandschurica, Maximowicz.

Corea and Mandschurica. This Walnut is allied to J. cinerea of North America.

Juglans nigra, Linné.*

Black Walnut-tree. Attains a height of 70 feet; trunk 4 feet in diameter; found in rich forest-land in North America. Wood purplish-brown, turning dark with age, strong, tough, not liable to warp or to split; not attacked by insects. Wood stored for many years is the best for gun-stocks. For the sake of its compactness, durability and its susceptibility to high polish, it is much sought for elegant furniture, stairrails and other select purposes. Seed more oily than the European walnut.

Juglans regia, Linné.*

The ordinary Walnut-tree of Europe, but of Central Asiatic origin; it attains a height of fully 80 feet, and lives many centuries. Wood light and tough, much sought for gunstocks, furniture and other things. The shells of the nut yield black pigment. Trees of choice quality of wood have been sold for $£ 600$, the wood being the most valuable of Middle Europe. In some departments of France a rather large quantity of oil is pressed from the nuts, which, besides serving as an article of diet, is used for the preparation of fine colours. To obtain first-class fruit, the trees are grafted in France (Michaux). An almost huskless variety occurs in the north of China. Can be grown in cold localities, as it lives 
at 2000 feet elevation in Middle Europe. The Californian Walnut-tree (Juglans rupestris, Engelmann) and the Chinese Walnut-tree (Juglans Mandchurica, Maxim.) ought to be introduced here.

Juglans Sieboldiana, Maximowicz.

Throughout Japan, where it forms a large tree.

Juglans stenocarpa, Maximowicz.

From the Amoor territory. Allied to J. Mandschurica.

Juniperus Bermudiana, Linné.*

The Pencil-Cedar of Bermuda and Barbadoes. This species grows sometimes 90 feet high, and furnishes a valuable red durable wood, used for boatbuilding, furniture and particularly for pencils, on account of its pleasant odour and special fitness. Many of the plants called Thuya or Biotia Meldensis in gardens, belong to this species.

Juniperus brevifolia, Antoine.

In the Azores up to 4800 feet; a nice tree with sometimes silvery foliage.

Juniperus Cedrus, Webb.

A tall tree of the higher mountains of the Canary Islands.

Juniperus Chinensis, Linné**

In temperate regions of the Himalaya, also in China and Japan. This tree is known to rise to 75 feet. Probably identical with the Himalayan Pencil-Cedar (Juniperus religiosa, Royle); it is remarkable for its reddish close-grained wood.

Juniperus communis, Linné.

One of the three native coniferæ of Britain, attaining under favourable circumstances a height of nearly 50 feet, of medicinal uses; the berries also used in the preparation of gin.

Juniperus drupacea, La Billardière. Plum-Juniper.

A very handsome long-leaved Juniper, the Habhel of Syria. It attains a height of 30 feet, and produces a sweet edible fruit, highly esteemed throughout the Orient.

Juniperus excelsa, Bieberstein.

In Asia Minor, 2000 to 6000 feet above the sea-level. A stately tree, 60 feet high.

Juniperus flaccida, Schlechtendal.

In Mexico, 5000 to 7000 feet high. A tree of 30 feet in height, rich in resin, similar to Sandarac.

Juniperus foetidissima, Willdenow.

A tall and beautiful tree in Armenia and Tauria, 5000 to 6500 feet. 


\section{Juniperus Mexicana, Schiede.}

Mexico, at an elevation of 7000 to 11,000 feet. A straight tree, 90 feet high, stem 3 feet diameter, exuding copiously a resin similar to Sandarac.

Juniperus occidentalis, Hooker.

North California and Oregon, at 5000 feet. A straight tree, 80 feet high, with a stem of 3 feet diameter.

Juniperus Phœnicea, Linné.

South Europe and Orient. A small tree, 20 feet high, yielding an aromatic resin.

Juniperus procera, Hochstetter.

In Abyssinia. A stately tree, furnishing a hard useful timber. Juniperus recurva, Hamilton.

On the Himalayas, 7500 to 15,000 feet high. A tree attaining 30 feet in height.

Juniperus sphærica, Lindley.

North China. A handsome tree, 40 feet high.

Juniperus Virginiana, Linné.

North American Pencil Cedar or Red Cedar. A handsome tree, 50 feet high, supplying a fragrant timber, much esteemed for its strength and durability; the inner part is of a beautiful red colour, the outer is white; it is much used for pencils. It is not bored by insects. The tree grows best near the sea.

Juniperus Wallichiana, J. Hooker and Thomson.

From the Indus to Sikkim, at elevations from 9000 to 15,000 feet. Attains a height of 60 feet. Desirable for transfer to our Alps. Wood similar to that of J. excelsa. (Stewartand Brandis.)

Justicia Adhatoda, Linné.

India; enduring the climate of the lowlands of Victoria. This bush possesses anti-spasmodic and febrifugal properties. It can be utilised also as a hedge-plant.

Kentia Baueri, Seemann.

The Norfolk Island Palm. Height forty feet.

Kentia Belmoriana, Moore and Mueller.

The Curly Palm of Lord Howe's Island. About 40 feet high. With its congeners, evidently destined to grace our gardens, and to become also important for horticultural traffic abroad.

Kentia Canterburyana, Moore and Mueller.

Umbrella Palm of Lord Howe's Island. Likewise a tall and hardy palm.

Kentia Mooreana, F. von Mueller.

Dwarf Palm of Lord Howe's Island, where it occurs only on the summits of the mountains. 
Kentia sapida, Blume.

The Nika-Palm of New Zealand and the Chatham Islands. It also attains a height of forty feet, and is one of the hardiest of all Palms. The unexpanded flower-spikes can be converted as Palm-cabbage into food.

Kœleria cristata, Persoon.

Widely dispersed over the globe. A perennial grass of fair nutritive quality, sustaining itself on dry soil. The closely allied $\mathrm{K}$. glauca can be sown with advantage on coast-sand.

Krameria triandra, Ruiz.

Chili, Peru and Bolivia, at elevations from 3000 to 8000 feet. This pretty little shrub can be grown on sandy ridges in an equable clime. It produces the medicinal Ratanhia root, well-known also as a dentifrice. Some other species have similarly astringent roots, particularly K. Ixine (Loefling), from Central America and West India. Some could be chosen to aid in adorning and diversifying our gardens.

Lactuca sativa, Linné.

South Asia. The ordinary annual Lettuce, in use since remote antiquity. It is not without value, especially as a sedative, for medicinal purposes. L. Scariola, Linné, seems to be the wild state of the garden Lettuce. L. altissima, Bieberstein, is a variety attaining a height of nine feet. All yield Lactucarium.

Lactuca virosa, Linné.

Middle and South Europe, North Africa, Middle Asia. A biennial. The inspissated juice of this Lettuce forms the sedative Lactucarium.

Lapageria rosea, Ruiz and Pavon.

Chili. A half-woody Climber with large showy flowers. The berries, which are of the size of a hen's egg, are sweet and edible.

Lardizabala biternata, Ruiz and Pavon.

Chili. A climber with stems of enormous length. Might be naturalised in our forests for obtaining the tough fibre for cordage. In its native country the torrified stems are used instead of ropes, according to Dr. Philippi.

Laserpitium aquilegium, Murray.

Middle and South Europe. The stems of this perennial herb are edible. The fruits serve as a condiment.

Lathyrus Cicera, Linné.

Countries at or near the Mediterranean Sea; also, Canary Islands. An annual, similar in its use to L. sativus, furnishing a tender palatable fodder, on sandy soil. L. Clymenum, L., from the same regions, serves similar purposes. 
Lathyrus macrorrhizus, Wimmer. (Orobus tuberosus, Linné).

Europe, West Asia. This herb would establish gradually pasturage in sterile forest-regions, and could with some allied species be disseminated in our Alps.

Lathyrus pratensis, Linné.

Europe, North and Middle Asia. The Meadow Pea. A good perennial pasture-herb. It can also be utilised for forest pastures, like L. silvestris. The yield is considerable, and the herbage, though bitter, relished by sheep. The plant spreads easily, particularly on fresh ground. L. tuberosus (L.) can likewise be utilised as a fodder-herb; its tubers are edible but very small.

Lathyrus sativus, Linné.

Middle and South Europe. The Jarosse. An annual forageherb; the pods also available for culinary purposes. Superior according to Langethal's observations to Vetches in quality of fodder and seed, but inferior in yield, content with a lighter soil, hence often chosen for first sowing on sandlands. Lime in the soil increases the return. Can only be used with great caution, as its frequent or continuous use induces, like L. Cicera, paralysis, not only to man, but also to horses, cattle, and birds. Probably other species of Lathyrus could advantageously be introduced.

Laurelia aromatica, Poiret.

Southern Chili. A colossal tree, in Valdivia the principal one used for flooring. Wood never bored by insects, and well apt to stand exposure to the open air, far superior to that of L. serrata, the Vouvan or Huahuoa, which tree predominates over L. aromatica, in the far south of Chili (Dr. Philippi).

Laurus nobilis, Linné**

Asia Minor. The Warrior's Laurel of the ancients. The leaves are in much request for various condiments, and the peculiar aroma of these Bay-leaves cannot be replaced by any others, unless those of Lindera Benzoin.

Lavandula angustifolia, Ehrhart. (L. vera, Candolle.)

Countries around and near the Mediterranean Sea. The Lavender-plant, of somewhat shrubby growth, from which by distillation the best Oil of Lavender is prepared. It lives on dry soil, but is less hardy than the following.

Lavandula latifolia, Villars. (L. spica, Candolle.) South Europe, North Africa. Also from this species much Lavender-oil is obtained. 
Lavandula Stœechas, Linné.

South Europe, North Africa. Topped Lavender. This shrub can also be utilised for oil-distillation and other purposes, for which the two other Lavenders are used. The quality of the oil of these species seems to differ according to their locality of growth.

Lavatera arborea, Linné.

Tree-Mallow of Middle Europe and the countries at the Mediterranean Sea. A tall biennial plant of rapid growth. The ribbon-like bast is produced in greater abundance than in most other malvaceous plants. The Tree-Mallow might easily be naturalised on our shores. Perhaps it might serve with allied plants for green manure.

Lawsonia alba, Lamarck.

North and Middle Africa, Persia, Arabia, India and NorthWestern Australia. The Henne or Henna-Bush. It may become of use as a dye-plant in parts of our colony free of frost The orange pigment is obtained from the ground foliage. The plant can also be used for garden-hedges.

Leersia oryzoides, Swartz.

Middle and South Europe, various parts of Asia, Africa and America. A perennial nutritious swamp-grass. Other Leersias from both hemispheres are deserving of introduction.

Lepidium latifolium, Linné.

Europe, North Africa, Middle and North Asia. A perennial herb of peppery acridity, much used for some select sauces.

Lepidium sativum, Linné.

The Cress. Orient. Annual. Irrespective of its culinary value, Cress is of use as one of the remedies in cases of scurvy. Active principle: a volatile oil and the bitter Lepidin.

Lepidosperma gladiatum, La Billardière.

The Sword-Sedge of the sea-coasts of extra-tropic Australia. One of the most important plants for binding sea-sand, also yielding a paper material as good as Sparta.

Leptospermum lævigatum, F. von Mueller. (Fabricia lcevigata, Gaertner.)

The "Sandstay." Sea-shores and sand-deserts of extra-tropic Australia, but not extending to Western Australia. This shrub or small tree is the most effectual of all for arresting the progress of drift-sand in a clime like ours. It is most easily raised by simply scattering in autumn the seeds on the sand and covering them loosely with boughs.

Lespedeza striata, Hooker and Arnott.*

China and Japan. An annual herb, which in North America has proved of great use. Mr. Meehan states it to be identical 
with the Hoop Koop plant, and that it has taken possession of much waste land in the Southern States. It grows there wonderfully on the hot dry soil, and the cattle like it amazingly.

Leucadendron argenteum, Brown.

The Silver-tree of South Africa is included on this occasion among forest-trees, because it would add to the splendour of our woods, and thrive far better there than in our gardens. Moreover, with this tree many others equally glorious might be established in our mild forest-glens as a source of horticultural wealth, were it only to obtain in future years a copious supply of seeds. Mention may be made of the tall Magnolia trees of N. America (Magnolia grandiflora, L., 100 feet high; M. umbrella, Lam., 40 feet; M. acuminata, 80 feet; M. cordata, Michx., 50 feet; M. Fraseri, Walt., 40 feet; M. macrophylla, Michx., 40 feet); M. Yulan, Desf., of China, 50 feet; Magnolia Campbelli, Hook., of the Himalayas, 150 feet high and flowers nearly a foot across; M. sphærocarpa, Roxb., also of the Indian Highlands, 40 feet; the Mediterranean Styrax-tree (Styrax officinalis, L.); Stenocarpus sinuosus, Endl., of East Australia (the most brilliant of the Proteaceæ); the crimson and scarlet Ratas of New Zealand (Metrosideros florida, Sm.; M. lucida, Menz.; M. robusta, Cunn., 80 feet high; M. tomentosa, Cunn., 40 feet); Fuchsia excorticata, L., also from New Zealand, stem two feet in diameter; the crimson-flowered Eucalyptus ficifolia of West A ustralia ; Rhododendron Falconeri, Hooker, from UpperIndia, 50 feet high, leaves 18 inches long. In the sassafras gullies, here alluded to, also may be planted the great Melaleuca Leucadendron, L., the true Asiatic Cajaput-tree, which grows to a height of 100 feet; even the North European Holly (Ilex Aquifolium), which occasionally rises to 60 feet, though both from regions so distant.

Levisia rediviva, Pursh.

North-West America. The root of this herb is large and starchy, formerly extensively used by the native inhabitants. The plant deserves trial-culture.

Leyssera gnaphalioides, Linné.

South Africa. A perennial herb of aromatic scent and taste. Much used there as a medicinal tea.

Liatris odoratissima, Willdenow.

Southern States of North America. A perennial herb occurring on swampy places.

Libocedrus Chilensis, Endlicher.

In cold valleys on the southern Andes of Chili, 2000 to 5000 feet. A fine tree, eighty feet high, furnishing a hard resinous wood of a yellowish colour. 
Libocedrus decurrens, Torrey.

White Cedar of California, growing on high mountains. Attains a height of fully 200 feet, with a stem twenty-five feet in circumference.

Libocedrus Doniana, Endlicher.

North Island of New Zealand, up to 6000 feet elevation. A forest-tree 100 feet high, stem three feet and more in diameter. The wood is hard and resinous, of a dark reddish colour, fine-grained, excellent for planks and spars.

Libocedrus tetragona, Endlicher.*

On the Andes of North Chili, at an elevation of 2000 to 5000 feet, growing as far south as Magelhaen's Straits, especially in moist moory localities. This species has a very straight stem and grows 120 feet high. The wood, though soft and light, is resinous and will resist underground decay for a century and more, like that of Fitzroya Patagonica; for railway-sleepers this timber is locally preferred to any other (Dr. Philippi); it is also highly esteemed for various artisan's work ; it is quite white.

Ligustrum Japonicum, Thunberg.

The Japan Privet. A shrub, evergreen or nearly so, promising to become a valuable hedge-plant. It grows like the ordinary European Privet readily from cuttings.

Limonia acidissima, Linné.

India, up to 4000 feet; hardy in England. This shrub or small tree has fruit of extreme acidity.

Lindera Benzoin, Blume.

From Canada to the Gulf of Mexico, there called the Spice Laurel. An aromatic bush, one of the hardiest of the order. The aroma of the foliage much like that of the bay-leaves.

Linum usitatissimum, Linné.*

The Flax-plant. Orient. A well-known annual, which yields the fibre for linen and the linseed oil. Flax-culture is doubtless destined to become an important industry among us. Few plants find a wider congeniality of soil and climate, and few give a quicker return. Good and deep soil, particularly of forests, well-drained, is requisite for successful Flax-culture. The Flax belongs to the potash plants. Change of seed-grain is desirable. Thick sowing extends the length and flexibility of the fibre. 'To obtain the best fibre, the plant must be pulled when the seeds commence to ripen. If the seeds are allowed in part to mature, then both fibre and seeds may be turned to account. If the seed is left to ripen completely, then the fibre is generally discarded. The seed yields by pressure about 22 per cent. of oil. The residue can either be prepared as linseed meal or be utilised as adnixture to stable- 
fodder. The demand for both fibre and oil is enormous. The value of our import of raw fibre in 1871 was already $£ 15,634$, while the import of oil was $£ 22,469$. Two principal varieties are under culture: a tall sort, with smaller flowers, closed capsules, and dark seeds; a dwarf sort, more branched (even if closely sown), with larger flowers and capsules, the seedvessels opening spontaneously and with elasticity, while the seeds are of a pale colour. None of the perennial species of Linum are so manageable in culture as the ordinary annual Flax.

Lippia citriodora, Kunth.

Peru, Chili, La Plata States, Brazil. An evergreen shrub, yielding scented oil.

Liquidambar Altingia, Blume.

At the Red Sea and in the mountains of India and New Guinea, at 3000 feet, and probably hardy in the warmer parts of our colony. The tree attains a height of 200 feet. It yields the fragrant balsam known as liquid Storax.

Liquidambar orientalis, Miller.* (L. imberbe, Aiton.)

Asia Minor. Also this tree yields liquid Storax, which is vanilla-scented, containing much Cumarin, and thus used for imparting scent to some sorts of tobacco and cigars, also for keeping moths from woollen clothing. Its use in medicine is more limited than in perfumery.

Liquidambar styraciflua, Linné.

The Sweet Gum-tree. In morasses and on the springs of the forests of North America, with a wide geographic range. The tree attains vast dimensions of its crown; the stem ten feet in diameter. The terebinthine juice hardens, on exposure, to a resin of benzoin odour. Wood fine-grained.

Liriodendron tulipifera, Linné.

The Tulip-tree of North America. One of the largest trees of the United States, and one of the grandest vegetable productions of the temperate zone. In deep fertile soil it attains a height of sometimes 140 feet, with a straight, clear stem up to nine feet in diameter. The Tulip-wood, also inappropriately called Poplar, is highly esteemed and very extensively used wherever this tree abounds, uniting lightness with strength and durability. It is of a light yellow colour, fine-grained, compact, is easily worked and takes a good polish. It is employed for house-building, inside as well as outside, for bridges, for furniture, coach-building, implements, and a variety of other purposes. As this tree is difficult to transplant, it should be grown on the spot where it is to remain. Though of slow growth, it would be a great acquisition for the rich lands of our mountain-forests. 


\section{Lithospermum canescens, Lehmann.}

North American Alkannet. This, as the vernacular name indicates, offers also a dye-root.

Lithospermum hirtum, Lehmann.

North American Alkanna. A showy perennial herb; the root yields a red dye.

Lithospermum longiflorum, Sprengel.

North America. A red pigment can also be extracted from the root of this species.

Livistona Australis, Martius.

East Australia. Our own and only Palm-tree in Victoria, occurring in East Gipps Land (in the latitude of Melbourne), and there attaining a height of 80 feet. The young leaves can be plaited as a material for cabbage-tree hats.

Livistona Chinensis, R. Brown.

South China and Japan. A very decorative Fan-palm, hardy in our lowlands.

Lolium perenne, Linné.

$*$

Europe, North Africa, Western Asia. The peremnial Ryegrass, mentioned here for completeness' sake. L. Italicum (Al. Br.), the Italian Rye-grass, seems to be only a variety. One of the most important of all pasture-grasses, also almost universally chosen for lawn-culture. It produces an abundance of seeds, which are readily collected and easily vegetate. It comes early to perfection. Nevertheless the produce and nutritive powers are considerably less than those of Dactylis glomerata, Alopecurus pratensis and Festuca elatior; but it pushes forward earlier than the last-mentioned grass, while the ripening of seeds is less defective than in Alopecurus. Rye-grass though naturally living but a few years, maintains its ground well by the ease with which it disseminates itself spontaneously. Several sorts, which scarcely can be called varieties, are under cultivation. Rye-grass stands the dry heat of our summers well. It is likely to spread gradually over the whole of the Australian continent, and may play an important part in our pastoral affairs and also in ameliorating the clime of the desert districts. Sheep should not be continually kept on Rye-grass pasture, otherwise they may become subject to fits similar to those produced by L. temulentum. It is one of the best grasses to endure traffic on roads or paths, particularly on soil not altogether light. It is one of the few among important grasses which can be sown at any season. The Italian Rye-grass is preferentially chosen as an early temporary shelter for tenderer but more lasting grasses on pastures, thus also furnishing a good collateral return in the first season. 


\section{Lotus corniculatis, Linné.}

Birdsfoot-Trefoil. Europe, North Africa, North and Middle Asia, extra-tropical Australia. A deep-rooting perennial herb, readily growing on pasture-land, sandy links and heathy places. This plant is well deserving cultivation on light inferior soil, on which it will yield a greater bulk of herbage than any of the other cultivated clovers; it is highly nutritious, and eaten with avidity by cattle and sheep. From the great depth to which its roots penetrate, it is not liable to be injured by drought. It well fills out vacant places between higher fodder-herbs on meadows; it is always somewhat saline and welcome among hay. L. tenuis, Kitaibel, is a valuable variety of the coasts. The nearly allied L. major yields a still greater amount of herbage, it is particularly suited for bushy and moist localities, and it attains its greatest luxuriance on soils which have some peat in their composition (Lawson). Here in Australia this Lotus shows a decided predilection for wet meadows.

\section{Lotus Tetragonolobus, Linné.}

Countries on the Mediterranean Sea. Though annual, this herb is highly valued for sheep pastures. The green pods serve as a substitute for Asparagus. The allied L. siliquosus, Linné, is perennial, and occurs in a succulent form on seacoasts.

Lupinus albus, Linné.

The White Lupine. Countries at the Mediterranean Sea, also in the Orient. An annual quick-growing herb, valuable for fodder and for green manure. It is famed as the "Tramoso" in Portugal, to suppress sorrel and other obstinate weeds by its close and easy growth. The lentil-like seeds, after the bitter principle (Lupinin) has become removed through boiling or soaking in salt water, become edible. The Mediterranean blue-flowered Lupine (L. angustifolius, L.) is superior to the yellow Lupine for seed harvest, but inferior in other respects. It would lead too far to enumerate here many others of the numerous species of Lupines, of which unquestionahly very many are eligible for agrarian purposes, while all are acceptable as hardy, elegant and easily grown garden-plants. One (L. perennis, L.) extends in America to the Northern States of the Union and Canada; fourteen are recorded from South Europe, seventeen from Brazil, and numerous species from other parts of America, where the limits of the genus are about Monte Video southward and about Nootka Sound northward. The majority of the species are perennial. The Egyptian L. Termis, Forsk., is closely allied to L. albus, and of equal use. 


\section{Lupinus arboreus, Sims.*}

South America. This and another somewhat shrubby species, namely L. albifrons (Bentham), of California, have been used there for the reclamation of sand, on account of their long tap roots, the latter having been traced to depths of twenty-five feet, while the stems were only three feet high. The germination is easy and the growth rapid on the sanddowns. For aiding the young Lupines for the first two months, to get hold of the sand, barley is sown with them, as the latter sprouts in a few days and holds the sand in the second week; the Lupine subsequently covers the sand with a dense vegetation in less than a year.

Lupinus Douglasii, Agardh.

California. This somewhat woody species can, along with L. arboreus and L. Chamissonis, Escholtz (L. albifrons, Bentham), like many perennial Lupines from other countries, be used for binding the sand.

Lupinus luteus, Linné.

The Scented Yellow Lupine. Countries in the vicinity of the Mediterranean Sea. This likewise annual species is predominantly in use through Middle Europe to improve sandy soil. It can also be employed like some other Lupines as a fodder-herb. About 90lbs. of seeds are required for an acre. Langethal observes: "What the Saintfoin does for the poorest limestone or marly soil, that the Yellow Lupine carries out for sand-land." Mr. Joseph Augustin speaks of a yellowflowering Lupine which attains in the Azores sometimes a height of twelve feet in three months.

Lupinus varius, Linné.

The Blue Lupine. Also a Mediterranean annual, used like the above congeners; but a few others are under cultivation as Blue Lupines. Some of the American, particularly Californian species, are regarded for agrarian purposes superior to the Mediterranean kinds.

Lycium Afrum, Linné.

Africa and South-West Asia. Can with many other species be utilised as a hedge-bush.

Lycopodium dendroideum, Michaux.

North America. This, with L. lucidulum, Michaux, has become there a great article of trade, being in request for bouquets and wreaths, and both plants, after having been dyed of various colours, are used as ornaments in vases, \&c. (Meehan). These clubmosses are mentioned here to draw attention to similar plants indigenous in this colony, viz., L. varium, L. clavatum, L. densum, L. laterale and Selaginella uliginosa. 
Lygeum Spartum, Linné.

Regions at the Mediterranean Sea. This perennial grass serves much like the ordinary Esparto-grass.

Lyperia crocea, Ecklon.

South Africa. The flowers of this shrub produce a fine orange dye, and are also in use for medicinal purposes.

\section{Maba geminata, R. Brown.}

One of the Ebony-trees in Queensland. Wood, according to Mr. O'Shanesy, black towards the centre, bright-red towards the bark, close-grained, hard, heavy, elastic and tough. It takes a high polish, and is recommended for veneers. Maba fasciculosa, F. v. M., has the outer wood white and pink. Several other species exist in Queensland, which may likely give good substitutes for Ebony-wood.

Macadamia ternifolia, F. von Mueller (Helicia ternifolia, F. M.) The Nut-tree of sub-tropic East Australia, attaining a height of 60 feet; hardy, as far south as Melbourne; in our forestvalleys likely of fair celerity of growth. The nuts have the taste of hazels.

Maclura aurantiaca, Nuttall.

The Osage Orange, or North American Bow-wood, or Yellowwood. Texas, Arkansas, Louisiana. This thorny deciduous shrub or tree can be well trained into hedges. It is unisexual, and will in favourable localities on rich river banks attain a height of sixty feet, with a stem two to three feet thick, thus becoming available as a timber-tree. It resists severe frosts. The saplings furnish stakes for vines, which are very lasting. The wood serves well for bows, buggy-shafts, carriage-poles, and similar articles. The root yields an excellent dye. Our own thorny Maclura Calcar Galli (Morus Calcar Galli, A. Cunningh.) of extra-tropical East Australia, which moreover possesses small edible fruits, deserves attention for live fences. Neither of the two is readily subject to blight or attacks of insects. The latter produces suckers and from the root a yellow dye. M. tinctoria (D. Don), which furnishes the Fusticwood of Central and South America, may prove hardy here.

Magnolia macrophylla, Michaux.

Eastern States of North America. Although not cultivated for any special purposes of the arts or of technics, yet this tree is admitted here into this list as one of the grandest of its kind, as well in foliage as flowers. It attains a height of forty feet, its leaves are from one to three and a-half feet long, while its flowers attain a diameter of fully one foot. M. grandiflora, L., attains on the Mississippi a height of eighty feet. 
Maharanga Emodi, A. de Candolle.

Nepal. The root produces like that of Alkanna tinctoria a red dye.

Mallotụs Philippinensis, J. M. (Rottlera tinctoria, Roxburgh.)

South Asia and East Australia, in jungle-country, extending into New South Wales. Though not of great importance this bush should not be passed on this occasion, inasmuch as the powdery substance investing the seed capsules constitutes the Kamala, which can be employed not only as an orange dye, but also as an anthelmintic remedy. The Hindoo silkdyers use it for an orange colour, obtained by boiling the Kamala with carbonate of soda.

Mangifera Indica, Linné.

South Asia. An evergreen tree, up to 70 feet high. Possibly the Mango Tree could be made to bear its delicious fruit in the warm and humid forest regions of East Gippsland. In the Himalayas its culture for fruit ascends to 3500 feet.

Manihot Aipi, Pohl.

The Sweet Cassava. Tropical South America, but traced as far south as the Parana River. The root is reddish and harmless; it can therefore be used, unlike those of the following species, without any further preparations than boiling as a culinary esculent, irrespective of its starch being also available for Tapioca. Both are somewhat woody plants, several feet high, and they are too important to be left altogether unnoticed on this occasion, although we have no evidence that they will prove productive even in those parts of Victoria which are free of frost. The Aipi has ligneous tough fibres, stretching along the axis of the tubers, while generally the roots of the following species are free of this central woody substance.

Manihot utilissima, Pohl.

The Bitter Cassava or Tapioca-plant. Tropical South America. Closely allied to the former, producing varieties with roots of poisonous acridity, and with tubers perfectly harmless. The tubers attain a length of three feet; they can be converted into bread or cakes, the volatile poison of the milky sap being destroyed through pressing of the grated root in first instance, and the remaining acridity is expelled by the heating process. The starch, heated in a moist state, furnishes the Tapioca. Manihot is abundantly cultivated at Caracas, where the singularly uniform temperature throughout the year is only $60^{\circ}$ to $70^{\circ} \mathrm{F}$. It is a very exhausting crop, and stands thus in need of rich soil and manuring. The propagation is effected by cuttings from the ligneous 
part of the stem. The soil, destined for Cassava, must not be wet. In warm countries the tubers are available in about eight months, though they still continue to grow afterwards. The growth of the plant upwards is checked by breaking off the buds. The Bitter Cassava is the more productive of the two. The yellowish tubers attain sometimes a weight of 30lbs. They do not become soft by boiling like Aipi.

Maoutia Puya, Weddell.

India, on mountains up to 4000 feet. It is taller than Boehmeria nivea, and furnishes a similar fibre. This shrub belongs to a tribe of the Nettle order, not possessing burning acridity. None of the true Nettles, such as the Girardinias, nor allied stinging plants have been recommended in this index, although from some an exquisite fibre is derived, as the writer wishes to guard against the introduction of any burning species, which possibly might disseminate itself in a mischievous manner in our ranges, and then probably could not again be suppressed.

\section{Maranta arundinacea, Linné.}

The true Arrowroot-plant. West India, Florida, Mexico to to Brazil. The plant is introduced into this list not without hesitation, as it seems to require a warmer clime than ours to attain perfection. It furnishes most of the West Indian Arrowroot, although other species, such as M. nobilis, M. Allouya, M. ramosissima, are also cultivated for a similar starch of their tubers. Porcher observes that it still flourishes as far north as Florida, producing even in the pine-lands from 200 to 300 bushels of tubers to the acre. M. Indica, Tuss., is merely a variety.

Marlea Vitiensis, Bentham.

New South Wales and Queensland. A middle-sized tree, generally with a gouty trunk; wood bright yellow with fine undulating rings, black towards the centre. Fruit edible (P. O'Shanesy).

Marliera glomerata, Bentham. (Rubachia glomerata, Berg). The Cambuca of sub-tropical Brazil. The fruits attain the size of apricots, and are much used for food (Dr. Rosenthal).

Marliera tomentosa, Cambessedes.

Extra-tropical Brazil. The Guaparanga. The sweet berries of this tall shrub are of the size of cherries.

Matricaria Chamomilla, Linné.

The annual Chamomile. Europe, North and Middle Asia. A highly useful herb in medicine. In many parts of the European continent it is much more extensively used than the ordinary perennial Chamomile. The infusion of the 
flowers has rather a pleasant taste without strong bitterness. The flowers serve as a tonic and especially as a sudorific, and possess a peculiar volatile oil. Marrubium vulgare, $L_{\text {. }}$, is not prominently mentioned, as it is already rather copiously naturalised.

Matricaria glabrata, Candolle.

The South African Chamomile. This annual herb is there in renown as an excellent substitute for the European Chamomile (Dr. Pappe).

Mauritia flexuosa, Linné.

From Guiana to Peru and Brazil. This noble Palm may prove hardy here, as it is known to ascend up to 4000 feet along the Eissequibo. As Palms like Bamboos prove here to be among the hardier of tropical plants, also experiments for naturalising M. vinifera, Martius, might be instituted. This attains a height of 150 feet, leaves 15 feet long, and spouts from the incised stem a copious viny sap.

Maytenus Boaria, Molina. (Boaria Molince, Candolle; Maytenus Chilensis, Candolle.)

Chili. An evergreen tree, assuming in the southern provinces considerable dimensions. Wood extremely hard. Cattle and sheep browse with predilection on the foliage; hence the trees are cut down when in protracted snowfalls or in times of drought forage becomes scarce (Dr. Philippi).

Medicago arborea, Linné.

South Europe, particularly Greece. This shrubby yellow Lucerne is of value for dairy farmers, as it much promotes the secretion of milk. This genus includes several other species of pastoral value.

Medicago lupulina, Linné.

The Black Medick. Europe, Asia and North America. An annual or biennial pasture-herb, easily grown and not without nutritive importance. Langethal observes: It effects for argillaceous soils what the white clover does for sandy moist soils. It will even succeed in moory ground, provided such contains some lime. It suits also particularly for sheeppastures.

Medicago sativa, Linné.

Orient; now spread through Middle and South Europe and Middle Asia. The purple Medick, Aifalfa or Lucerne. A perennial fodder-herb of great importance, and already largely utilised in our colony, perhaps descended from the English Medicago falcata, which also deserves naturalisation. Lucerne keeps here green and fresh in the hottest season of the year, even in dry and comparatively barren ground, but developes 
itself for field-culture with the greatest vigour on river-banks or when subjected to a judicious system of irrigation, particularly in soil rich in lime. Its deeply penetrating roots render the plant particularly fit for fixing fenced embankments or hindering the washing away of soil subject to occasional inundations. Much iron in the soil or stagnant water are detrimental to Lucerne culture, while friable warm soil promotes much its growth. Langethal records instances of Lucerne having yielded on the same field under favourable circumstances for'fifteen years four or five cuts annually. For sandy tracts a yellow variety (M. media, Pers.) deserves preference.

Melaleuca parviflora, Lindley.

Extra-tropic Australia. A tall bush or small tree. One of our most important plants for fixing moving coast-sands.

Melaleuca trichostachya, Lindley.

Tropical East Australia. A small tree deserving attention as eligible for saline land, on which it can be raised much more easily than Myoporum insulare. M. Thozet observes that it occurs in places where it is bathed by the tides; also that large saplings without roots can be transplanted. M. Leucadendron, L., the Cajaput-tree of South Asia and Eastern Australia, is also adapted for saline sea-shores, and can be planted in salt swamps for subduing malarian vapours where no Eucalyptus could live. Its bark protects it against conflagrations. M. ericifolia, Smith, of South-East Australia, is the only species known to the writer which will admit of transplantation in a up-grown aged state, and it is also one of the few species which will thrive in brackish water. Thus it may be destined to aid with Salicornias, Avicennias, Atgiceras, Batis ana some other plants to reclaim low muddy shore-lands from sea-floods. M. squarrosa, Smith, of South-East Australia, can also be grown in swamps to subdue miasmata. It attains exceptionally the height of 60 feet with a stem of two feet in diameter.

Melia Azedarach, Linné.

South Asia, North and also East Australia, and there to far extra-tropical latitudes. As an avenue-tree not without importance, because it will successfully cope with dryness of clime and sterility of soil. It recommends itself also for retaining the foliage till very late in the season, and for producing abundance of fragrant flowers. A black-fruited Melia seems as yet little known. The wood is considered of value for some kinds of musical instruments. 
Melianthus major, Linné.

South Africa. The leaves of this stately plant are very efficacious as antiseptics, also in cases of scald head, ringworm and various other cutaneous diseases (Dr. Pappe). Its effect of promoting granulation is very remarkable (Dr. A. Brown).

Melica ciliata, Linné.

Europe and Middle Asia. A perennial fodder-grass, particularly desirable for sheep. Best for dry gypsy or calcareous ground.

Melica nutans, Linné.

The Pearl-grass. Europe and North and Middle Asia, enduring an alpine clime, and living also in the shade of forests. It produces suckers, and affords good herbage in woody regions, so also M. uniflora. Several other species are on record from various parts of the globe, among which M. mutica, of North America, seems to deserve special attention.

Melicocca bijuga, Linné.

Central America, on mountains. So many sapindaceous trees of the Cupania series have been shown by my own experiments to be hardy here, that now also this important member of the series could be admitted into this list. The pulp of the fruit is of grape taste; the seeds can be used like sweet chestnuts.

Melilotus alba, Desrouss.

The Cabul or Bockhara Clover. Middle and Southern Europe, North Africa, Middle Asia. A biennial herb. On account of its fragrance it is of value for admixture to hay. It is also a good bee-plant. Flowers white. Odorous principle: Cumarin.

Melilotus cœrulea, Lamarck.

South Europe and North Africa. An annual very odorous fodder-herb. It forms an ingredient of the green Swiss cheese, which owes its flavour and colour chiefly to this plant.

Melilotus officinalis, Desrouss.

Europe and Middle Asia. Also biennial, or lasting through several yeurs if prevented from flowering. Contains also Cumarin. An allied species is M. macrorrhiza, Pers. Both serve purposes similar to those for which M. alba is employed. Grown on the coast it becomes less odorous.

Melissa officinalis, Linné.

The Balm-herb. South Europe and Middle Asia. A perennial herb, valuable for its scent, which depends on a peculiar volatile oil. It is also valuable as a bee-plant. 
Melocanna bambusoides, Trinius. (Beesha Rheedei, Kunth.) The berry-bearing Bamboo, from Chittagong and other mountainous parts of India. It is a thornless Bamboo, growing on dry slopes of hills. Height up to seventy feet; circumference towards base, one foot; growth beautifully erect.

Melocanna humilis, Roeper.

India. More slender than the preceding species, and attaining only a height of twenty feet.

Melocanna Travancorica. (Beesha Travancorica, Beddome.)

A new Bamboo from Travancore, worthy of introduction.

Mentha piperita, Linné**

The Peppermint. Middle Europe. This well-known perennial herb is important for its peculiar essential oil, which here by culture is produced in good quality. This distilled oil is in considerable demand, and would be best obtained from plants cultivated in the mountain-regions or naturalised along the forest-rivulets. Eminent authorities refer the Peppermint as a variety to Mentha aquatica (L.), the Water-Mint of Europe, North Africa, West and North Asia, from which the true Crisp-Mint (M. crispa, L.) is again derived, as well as the Bergamot-Mint (M. citrata, Ehrh.)

Mentha Pulegium, Linné.

The true Penny-royal. Europe, Western Asia, North Africa.

A perennial scent-herb, yielding a peculiar ethereal oil. It likes moist soil.

Mentha rotundifolia, Linné.

Middle and South Europe, North Africa, Western Asia. Fond of wet places, which by the culture of this and other Mints may be profitably utilised. In odour this Mint approaches to Melissa. The French and Italian Crisp-Mint is partly derived from this species. Closely allied to the following, and often regarded as a variety of M. viridis, L.

Mentha silvestris, Linné.

The Horse-Mint. Europe, North Africa, temperate Asia. Perennial. One of the Crisp-Mints is derived from this species.

Mentha viridis, Linné.

The Spear-Mint. Middle and South Europe. Perennial. A particular sort of Crisp-Mint (M. crispata, Schrad.) belongs to this species.

Our native Mints, M. Australis, M. gracilis and M. saturejoides, R. Br., yield also oil of good flavour. M. laxiflora, Benth., is far the largest and most abundant of these plants. 
Menyanthes trifoliata, Linné.

Inappropriately called the Bog-bean. Europe, North and Middle Asia, North America. In springy and spongy bogs. A perennial herb of great beauty, which could be naturalised with facility in our Alps. The root is starchy. The whole plant is pervaded with a bitter principle, largely derived from Menyanthin. The plant is used medicinally as a tonic and febrifuge.

Meriandra Abyssinica, F. v. Mueller. (MT. Benghalensis Bentham.)

Abyssinia, on high mountains. A shrub of penetrating odour, utilised much like sage.

Mesembryanthemum acinaciforme, Linné.

The Hottentot-Fig of South Africa. Under the same vernacular name is also comprised the distinct M. edule, $\mathrm{L}$. Both, together with our own M. æquilaterale, Haworth, which extends also widely along the American West Coast, should be transferred into any of the most inhospitable desert-regions, as they afford in the inner part of their fruit a really palatable and copious food.

Metrosideros tomentosa, A. Cunningham.

North Island of New Zealand. Could be grown for timber on rocky sea-shores. Height to 80 feet, trunk stout, but comparatively short. The timber, according to Mr. Kirk, deserves attention as one of the most durable for the framework in ship-building, for jetties, docks, sills. Other species with dense timber occurring in New Zealand are M. lucida (Menzies) and M. robusta (A. Cunn.), all ornamental trees with crimson flowers.

Microseris Forsteri, J. Hooker.

The Native Scorzonera of extra-tropical Australia and New Zealand. A perennial herb deserving attention, as likely its roots would enlarge and improve through culture. On the summits of our snowy mountains the plant developes itself most luxuriantly. The aborigines use the root for food. The plant would prove hardy in Middle Europe.

Milium effusum, Linné.

English Millet-Grass. Europe, North and Middle Asia, North America. Perennial, suited for damp forest-land particularly, the pastoral capabilities of which it enhances. On river-banks it attains a height of six feet. It is relished by cattle. The seeds can be used like Millet, the stems for the manufacture of superior straw-hats. It is a great favourite with pheasants and many other birds for the sake of its seeds, which ripen early in the season. 
Mimosa rubicaulis, Lamarck.

India. A hedge-bush, almost inapproachable. It has proved hardy at the Botanic Garden of Melbourne.

Monarda didyma, Linné.

North America. A perennial odorous herb, producing the medicinal Osnego or Beebalm Tea. M. punctata, L., is also of very strong scent, and so M. fistulosa, L., with several others.

Monetia barlerioides, L'Heritier.

South Africa. A hedge-shrub.

Morchella esculenta, Persoon. (M. conica, Persoon.)

Europe, Asia, North and Central America. With M. semilibera this Morel has been found in Victoria and New South Wales; its spread should be encouraged by artificial means, as it is a wholesome esculent. European superior species, probably admitting of introduction, are :-M. Gigas, Pers., M. deliciosa, Fries, which extends to Java, M. patula, Pers., the Bell-Morel; and several others occur there or in other parts of the globe. Though these fungi show a predilection for pine-forests, they are not dependent on them ; thus the writer found M. esculenta in our Eucalyptus forests, and this late in the autumn. They can all be dried and preserved for culinary purposes.

Moringa pterygosperma, Gaertner.

The Horse-Radish tree of India, abundant into the middle regions of the mountains. The long pods are edible; the seeds are somewhat almond-like and rich in oil. M. aptera, Gaertner, occurs from Abyssinia and Egypt to Arabia and Syria.

Morus alba, Linné.*

The White Mulberry-tree. China. This tree in several varieties provides the food for the ordinary Chinese silk-insect (Bombyx Mori). Silk was produced in Italy already 600 years ago, and there this branch of industry has flourished ever since. In China, Silk was reeled since 4500 years. This may demonstrate the permanency of an industry which we wish to establish here extensively under a similar sky. "One pound of silk is worth its weight in silver, and this pound may be produced (so far as the food of the Bombyx is concerned) from thirty pounds of Mulberry-leaves or from a single tree, which thus may be brought to yield annually the material for sixteen yards of Gros de Naples." The White Mulberrytree is of extremely easy growth from cuttings, also readily raised from well-matured seeds. It is usually unisexual, and attains tinally a very large size. It can be grown in climes 
where no longer olives will thrive. Spots for Mulberryculture must not be over-moist, when the leaves are to be utilised for the Bombyx. In 1870, according to the British Trade Journal, the produce of cocoons amounted in Europe to $£ 16,588,000$; in Asia to $£ 28,112,000$; in Africa to $£ 44,000$; in the South Sea Islands to $£ 24,000$; in America to $£ 20,000$; - thus giving a general total of $£ 44,788,000$. Superior varieties of Mulberry can be grafted with ease on ordinary stock. M. Indica (L.), M. macrophylla (Morett.), M. multicaulis (Perott.), M. Morettiana (Jacq.), M. Chinensis (Bertol.), M. latifolia (Poir.), M. Italica (Poir.), MI. Japonica (Nois.), M. Byzantina (Sieb.), MI. nervosa (Del.), M. pumila (Nois.), M. tortuosa (Audib.), as well as the Constantinople Mulberry are merely forms of Mr. alba, to which probably also M. Tartarica (L.) and M. pabularia (Jacquem.) belong. The variety known as M. Indica produces black fruits. The planting of Mulberry-trees has recently assumed enormous dimensions in California, where in 1870 between seven and eight millions were planted. The process of rearing the silk-insect is simple and involves no laborious exertions. The cocoons, after they have been properly steamed, dried and pressed, find readily purchasers in Europe, the price ranging according to quality from $3 \mathrm{~s}$. to $6 \mathrm{~s}$. per $1 \mathrm{~b}$. The eggs of the silkworm sell at a price from 16 s. to $£ 2$ per ounce, and in $1870 \mathrm{Japan}$ had to provide two millions of ounces of silk-ova for Europe, where the worms had extensively fallen victims to disease. Instances have been recorded in California, where eight tons of leaves were gathered in the first year from the Mulberry-trees of one acre, and thirty tons in the next year. As an example of the profit thus to be realised, a Californian fact may be cited, according to which $£ 700$ were the clear gain from three and a-half acres, the working expenses having been $£ 93$. The Commissioner of Agriculture of the United States has estimated that under ordinary circumstances an acre should support from 700 to 1000 Mulberry-trees, producing 5000lbs. of leaves fit for food when four years old. On this quantity of leaves can be reared 140,000 worms, from which ova at a net profit ranging from $£ 80$ to $£ 240$ per acre will be obtained by the work of one person. Mr. C. Brady, of Sydney, thinks the likely proceeds of silk-culture to be from $£ 60$ to $£ 150$ for the acre. The discrepancies in calculations of this kind are explained by differences in clime, soil, attention and treatment.

The White Mulberry-tree has been very copiously distributed from the Melbourne Botanic Garden since many years. A very palatable fruit is obtained from a variety cultivated in 
Beloochistan and Affghanistan. Morus Tartarica (L.) resembles M. alba. Its juicy fruit is insipid and small. The leaves are not generally used for silkworms.

The results of Mr. Brady's experience on the varieties of the Morus alba are as follows:- In the normal form the fruits are white with a purplish tinge more or less deep, the bark is pale, the leaf is also of a pale hue, not very early nor very tender, nor very abundant. It may be grown on moist ground as long as such is drained, or it will live even on poor loose gravelly soil bordering on running water. The Cevennes variety is a free grower, affords a large quantity of leaves though of rather thick consistence; all varieties of the Morus Bombyx like these leaves at all stages of their age. It is also called the rose-leaved variety. The silk which it yields is substantial in quantity and also good in quality. It does best on rich dry slopes. The bushy Indian variety has a fine leaf of beautiful green, which though light in weight is abundantly produced. It can be cut back to the stem three or four times a year; the leaves are flat, long and pointed, possess a fine aroma, and are relished by every variety of the ordinary silk-insect, though not all thrive equally well on it. The silk derived from this variety is excellent, but not always so heavy in quantity as that produced from the rosy variety. It prefers rich low-lying bottoms, is a greedy feeder, but may thus be made to cover an extraordinary breadth of alluvial or manured land in a marvellous short space of time. At Sydney, Mr. Brady can provide leaves from this Indian variety all through the year by the removal of cuttings, which will strike their roots almost at any season. It ripens also seeds readily, and should be kept at bush size. It requires naturally less space than the other kinds. A fourth variety comes from North China; it has heart-shaped flat thickish leaves, which form very good food for the silkworm. Mr. Brady, as well as Mr. Martelli, recommend very particularly the variety passing under the name of Morus multicaulis for the worms in their earliest stages. The former recommends the Cape variety also; the latter wishes also the variety called Morus Morettiana to be used on account of its succulent nutritious foliage, so well adapted for the insect while yet very young, and also on account of producing the largest amount of food within the shortest time. The Manila variety, known as Morus multicaulis, comes several weeks earlier into bearing than most other sorts, and should therefore be at hand for early hatched worms.

The Muscardine-disease is produced by Botrytis Bassiana, while the still more terrible Pedrine-disease is caused by a minute 
vibrio-like organism. Countries like ours, happily free of these pests, can thus rear healthy silk-ova at a high premium for exportation.

The White Mulberry-tree with others, offering food to the silkworms, should be planted copiously everywhere for hedges or copses.

Morus celtidifolia, Humboldt.

From Peru to Mexico, ascending to 7000 feet. The fruit also of this Mulberry-tree is edible. MI. insignis, Planchon, from New Granada, is a similar species.

Morus nigra, Linné.*

The Black Mulberry-tree. South Russia and Persia. Highly valuable for its pleasant refreshing fruits. It is a tree of longevity, instances being on record of its having lived through several centuries. It is also very hardy. The leaves also of this species afford food for the ordinary silk-moth. The tree occurs usually unisexual. M. atropurpurea, Roxb., from Cochin-China, is an allied tree. The cylindrical fruit-spike attains a length of two inches.

Morus rubra, Linné.

The Red MIulberry-tree of North America is the largest of the genus, attaining a height of 70 feet; it produces a strong and compact timber.

Musa Cavendishii, Lambert. (Musa regia, Rumph; Musa Chinensis, Sweet; Musa nana, Loureiro.)

The Chinese Banana. A comparatively dwarf species, the stem attaining only a height of about five or six feet. Its robust and dwarf habit render it particularly fit for exposed localities, and this is one of the reasons why it is so extensively cultivated in the South Sea Islands. The yield of fruit is profuse (as much as 200 to 300 fruits in a spike), and the flavour excellent. This as well as MI. sapientum and MI. paradisiaca ripen still their fruits in Madeira and Florida.

Musa Ensete, Gmelin.

Bruce's Banana. From Sofala to Abyssinia, in mountain regions. This magnificent plant attains a height of thirty feet, the leaves occasionally reaching to the length of twenty feet, with a width of three feet, being perhaps the largest in the whole empire of plants, exceeding those of Strelitzia and Ravenala, and surpassing even in quadrate measurement those of the grand water-plant Victoria Regia, while excelling in comparative circumference also the largest compound frond of Angiopteris evecta, or divided leaf of Godwinia Gigas, though the compound leaves of some palms are still larger. The inner part of the stem and the young spike of the Ensete can be boiled to serve as a table esculent, but the fruit is. 
pulpless. This plant produces no suckers, and requires several years to come into flower and seed, when it dies off like the Sago-plant, the Caryota-palm, and others, which flower but once without reproduction from the root.

Musa Livingstoniana, Kirk.

Mountains of Sofala, Mozambique, and the Niger regions. Similar to M. Ensete; seeds much smaller. Possibly requiring no protection here in favourable places.

Musa paradisiaca, Linné.

The ordinary Plantain or Pisang. India. Among the most prolific of plants, requiring the least care in climes adapted for its growth. Stem not spotted. Bracts purple inside. In this as well as the foregoing and the following, new shoots are produced from the root, to replace annually the fruitbearing stem. The fruit of this is often prepared by some cooking process. Very many varieties are distinguished, and they seem to have sprung from the wild state of M. sapientum. The writer did not wish to pass this and the allied plants unnoticed, as they will endure our clime in the warmest localities of the colony, where under more careful attention they are likely to mature with regularity their fruit. They require rich and humid soil. Plantain-meal is prepared by simply reducing the dried pulp to powder. It is palatable, digestible, and nourishing.-M. ordinary Banana or Sweet Plantain, is a variety. It is one of the most important plants yielding nutritious delicious fruits. The stem is spotted. Bracts green inside. The leaves and particularly the stalks and the stems of this and other species of Musa can be utilised for producing a fibre similar to Manilla Hemp. The fruit of this is used chiefly unprepared; it is generally of a yellow colour. Numerous varieties are distinguished. As much as a hundredweight of fruit is obtained from a plant annually in tropical climes. At Caracas, where the temperature is seldom much above or below $60^{\circ} \mathrm{F}$., the Plantain and Banana plants are very productive, being loaded with fruits twelve to fifteen inches long, on mountains about 5000 feet high. In our dry Murray regions the winter temperature seems too low for the successful development of these plants except on sheltered spots. Requires infinitely less care within its geographic latitudes than the potato; contains along with much starch also Protein compounds. Many Indian populations live almost exclusively on the fruit.

Musa simiarum, Rumph. ( $M$. corniculata, Loureiro; $M$. acuminata, Co'l.)

From Malacea to the Sunda-Islands. About half-a-hundred 
marked varieties of this species, called mainly Peesangs in India, are under cultivation there, especially on the A rchipelagus, while M. sapientum occurs wild more frequently on the mainland. Though the latter is principally cultivated on the Indian continent, yet it never equals in delicacy the cultivated forms of M. simiarum, the fruit of which sometimes attains a length of two feet (Kurz).

Musa troglodytarum, Linné. (M. uranoscopos, Rumph.)

India, and apparently indigenous also in the Fiji and other islands of the Pacific Ocean. The fruit-stalk of this species stands upright; the edible fruits are small, reddish, or orangecoloured. The Chinese M. coccinea, Ait., a dwarf ornamental species, has also the fruit-spike straight.

Myoporum lætum, Forster.

New Zealand, where it is called $\mathrm{Ngaio}$ by the aborigines. As a shelter-tree it is equal to our M. insulare for the most exposed parts of the coast. It is excellent for shade, and its wood takes a fine polish. It can be raised on the beach from cuttings. Uprooted it will produce new roots if covered in near the sea. Sheep and horses browse on the foliage.

Myrica cerifera, Linné.

The Wax-Myrtle. Sandy sea-coast of North America. This shrub helps to bind the rolling sand; it has fragrant leaves ; the fruits are boiled, and the floating wax, which can be converted into candles, is skimmed off.

Myrica cordifolia, Linné.

South Africa. This bushy plant arrests the influx of the sea-sand; it also yields remuneratively wax from its fruits.

Myrica Faya, Aiton.

Madeira, Azores and Canary Islands. A small tree. The drupaceous fruits are used for preserves. M. sapida, Wallich, an Indian mountainous species, has also edible fruits.

Myrica quercifolia, Linné.

South Africa. This and M. cordifolia and the following are the principal wax-bushes there. Many other species from different parts of the globe are available for trial-culture, but none has as yet been discovered in Australia.

Myrica serrata, Lamarck.

South Africa. Shrub only about three feet high. The Myrica-wax is heavier, harder and more brittle than bees-wax, but melts easier. It is obtained from the fruits throughout the cool season. The sowing of seeds is done after the first rain of the cool months has steadied the sand. 
The plant can also be multiplied from cuttings. The subterraneous trunk is creeping, and in age of considerable length (Dr. Pappe).

Myrrhis odorata, Scopoli.

The Sweet Chervil or Cicely. Mountains of Middle and South Europe and Asia Minor, particularly in forests. A perennial aromatic herb, used for salad and culinary condiments. It could here be naturalised in the forests, and would endure the climate of our highet alps; a second species, M. occidentalis, Benth., occurs in Oregon.

Myrtus acmenoides, F. v. Mueller.

Queensland. The fragrant leaves of this and of $M$. fragrantissima used for flavouring tea, according to Mr. P. O'Shanesy.

Myrtus communis, Linné.

The Bridal Myrtle. This bush of ancient renown should not be passed; it is industrially in requisition for myrtle wreaths.

Myrtus edulis, Bentham. (Myrcianthes edulis, Berg.)

Uruguay. A tree attaining a height of about twenty-five feet. Berries of one and a-half inches diameter, of pleasant taste.

Myrtus Luma, Molina.

South Chili. A tree fully one hundred feet high in the virgin forests. Wood very hard and heavy, much sought for press-screws, wheel-spokes and select implements (Dr. Philippi).

Myrtus Meli, Philippi.

South Chili. Of the same use as the foregoing species, and in this manner most favourably contrasting with the numerous other myrtaceous trees of Chili.

Myrtus nummularia, Poiret.

The Cranberry-Myrtle. From Chili to Fuegia, also in the Falkland Islands. This trailing little plant might be transferred to the turfy moors of our alpine mountains. Dr. Hooker describes the berries as fleshy, sweet and of agreeable flavour. Allied species occur in the cold zone of the Peruvian Andes.

Myrtus tomentosa, Aiton.

India and China. This showy shrub ascends to 8000 feet high. The berries are dark purple, of cherry size, pulpy, and of aromatic sweetness. Various other Myrtles with edible berries are known from different warm countries. 
Myrtus Ugni, A. Gray.

The Chilian Guava. A hardy shrub, freely bearing its small but pleasantly-aromatic berries.

Nageia (Podocarpus) amara, Blume.

Java, on high volcanic mountains. A large tree, sometimes 200 feet high.

Nageia (Podocarpus) andina, Poeppig. (Prumnopithys elegans, Philippi.)

The Lleuque of Chili. A stately tree with clusters of edible cherry-like fruits. The wood is yellowish and fine-grained, and is chosen for elegant furniture work.

Nageia (Podocarpus) bracteata, Blume.

Burmah, Borneo, Java, up to 3000 feet. The close-grained wood is highly prized. The allied N. neriifolia from the Himalayas has proved hardy here.

Nageia (Podocarpus) Chilina, Richard.

The Manniu and Lahual of the Chilians. Height to 100 feet, with corresponding thickness of stem. Wood white, of excellent quality.

Nageia (Podocarpus) coriacea, Richard.

West India. This tree attains a height of fifty feet, and advances to elevations of 8000 feet. Other species of both hemispheres should be tested here.

Nageia (Podocarpus) cupressina, R. Brown.

Java and Phillipine Islands. Height of tree 180 feet; furnishing a highly valuable timber.

Nageia (Podocarpus) dacrydioides, A. Richard.

In swampy ground of New Zealand; the "Kahikatea" of the Maories, called White Pine by the colonists. Height of tree 150 feet; diameter of stem four feet. The white sweet fruit is eaten by the natives; the wood is pale, close-grained, heavy. It will not stand exposure to wet, but is one of the best for flooring-boards. The strength is equal to that of Rimu, according to Kirk; but it is more readily attacked by boring insects.

Nageia (Podocarpus) elata, R. Brown.

East Australia. A fine timber-tree of great height.

Nageia (Podocarpus) elongata, L'Heritier.

South Africa. With N. Thunbergi and with Erythrina Caffra and Oreodaphne bullata, this is the tallest tree of Capeland and Caffraria, although it does not advance beyond seventy feet. The yellowish wood is highly valuable, deallike, not resinous. The stems can be used for top-masts and yards of ships. 
Nageia (Podocarpus) ferruginea, Don.

Northern parts of New Zealand. The Black Pine of the colonists; native name "Miro." Height of tree 80 feet; it produces a dark-red resin of a bitter taste: the wood is of a reddish colour, very hard; will stand exposure to sea-water. Fruit, solitary.

Nageia (Podocarpus) Lamberti, Klotzsch. Brazil. A stately tree, yielding valuable timber.

Nageia (Podocarpus) nubigena, Lindley. Southern Chili, generally a companion of N. Chilina, with which it agrees in its dimensions and the utility of its timber.

Nageia (Podocarpus) Purdieana, Hooker.

Jamaica, at 2500 to 3500 feet. This quick-growing tree attains a height of 100 feet.

Nageia (Podocarpus) spicata, Brown.

Black Pine or Matai of New Zealand. Fruit spicate. Tree 80 feet high; wood pale, soft, close and durable; used advantageously for piles, machinery, stringers, braces, mill-wright's work, house-blocks, railway-sleepers, also weather-boards, flooring-boards. (Kirk.)

Nageia (Podocarpus) Thunbergi, Hooker.

South Africa. Superior in the quality of its wood to N. pruinosa, E. Meyer, and even N. elongata; it is brightyellow, fine-grained and very handsome when polished (Dr. Pappe).

Nageia (Podocarpus) Totara, Don.*

New Zealand. A fine tree, 120 feet high, with a stem of twenty feet in circumference; it is called Mahogany Pine by the colonists. The reddish close-grained and durable wood is valuable both for building and for furniture, and is also extensively used for telegraph-posts; it is considered the most valuable timber of New Zealand. Used for piles of bridges, wharves and jetties, and in other naval architecture; the heart-wood resists for a long time decay, and the attacks of the Teredo, according to Mr. Thos. Kirk. It ranks below Kauri in strength, but equals it in durability. It is one of the most lasting woods for railway-sleepers. When used for piles, the bark should not be removed from the timber. - Many other tall timber-trees of the genus Podocarpus or Nageia occur in various parts of Asia, Africa and America, doubtless all desirable, but the quality of their timber is not well known, though likely in many cases excellent. Nageia is by far the oldest published name of the genus. 
Nardostachys Jatamansi, Candolle.

Mountains of Bengal and Nepal. The Spikenard. A perennial herb, famous already in ancient times as a medicinal plant. The root contains an ethereal oil and bitter principle. This drug is often also obtained from N. grandiflora, Cand.

Nelumbo lutea, Caspary.* (Nelumbium luteum, Willdenow.) In North America, north to $44^{\circ}$; also in Jamaica. This magnificent perennial water-plant carries with it the type of Nelumbo nucifera, but seems more hardy and thus better adapted for our latitudes, the Pythagorean Bean not descending in Australia naturally beyond the $23^{\circ}$, although also this species may perhaps live in the warmer parts of our colony. The tuberous roots of both species resemble the Sweet Potato and are starchy; the seeds are of particularly pleasant taste. To us the plants would be of great value as ornamental aquatics. The leaves of $\mathrm{N}$. lutea are from one to two feet in diameter. The flowers measure one-half to one foot across. The capsular fruit contains from twenty to forty nut-like seeds. The plant in congenial spots displaces nearly all other water-vegetation by the vigour of its growth.

Nelumbo nucifera, Gaertner.* (Nelumbium speciosum, Willdenow.)

The Pythagorean Bean. Egypt; at the Caspian and Aral Seas $\left(46^{\circ}\right.$ N.); Persia; through India, where in Cashmere it occurs at an elevation of 5000 feet; China; Japan; Amur; $\left(46^{\circ} \mathrm{N}\right.$.) ; tropical Australia as far south as $23^{\circ}$. The occurrence of this grand plant at the Ima, at Pekin and at Astrachan proves sufficiently, that we can naturalise it in Victoria. The Nelumbo requires deep water with a muddy bottom. The large white or rosy flowers are very fragrant. The seeds retain their vitality for several years. According to the ancient Egyptian method they are placed in balls of muddy clay and chaff and then sunk into the water.

Nephelium lappaceum, Linné.

India. This tree furnishes the Rambutan or Rampostan fruit, similar to the Litchi and Logan fruit. As one species of Nephelium is indigenous as far south as Gipps Land, and as all the species seem to require rather a moist mild forestclime than great atmospheric heat, we may hope to bring also this tree here in favourable spots to perfect bearing.

Nephelium Litchi, Cambessedes.

South China, Cochin-China and Philippine Islands. An evergreen tree, producing the Litchi-fruit. The pulpy arillus is of extremely pleasant taste, though not large. 
Nephelium Longanum, Cambessedes.

India and Southern China. The Longan-fruit is obtained from this tree; it is smaller than that of the Litchi-tree.

Nicotiana multivalvis, Lindley.

The Native Tobacco of the Columbia River. An annual. This with the following species can be utilised for certain kinds of Tobacco.

Nicotiana Persica, Lindley.

The Shiraz Tobacco. Persia. Annual. This can be brought to perfection only in cool mountain-regions. The mode of culture is somewhat different to that of the ordinary Tobacco. Moderate irrigation is favourable. The plants when ripe are cut off and stuck into the ground again until they become yellow. They are then heaped together for a few days in the drying-house. They are then packed into thin strata and placed into bags, for pressure and daily turning.

Nicotiana quadrivalvis, Pursh.

The Native Tobacco of the Missouri. An annual.

Nicotiana repanda, Willdenow.

Cuba, Mexico, Texas. Annual. It is utilised for some of the Havannah Tobaccoes.

Nicotiana rustica, Linné.

Tropical America. Annual. Some sorts of Eastern India Tobacco, of Manilla Tobacco and of Turkey Tobacco are derived from this particular species.

Nicotiana Tabacum, Linné.*

The ordinary Tobacco-plant of Central America. Annual. Various districts with various soils produce very different sorts of Tobacco, particularly as far as Havour is concerned, and again various climatic conditions will affect vastly the Tobacco-plant in this respect. We can thus not hope to produce for instance Manilla or Havannah Tobacco in our latitudes, but we can anticipate to produce good sorts of our own, more or less peculiar, or we may aspire to producing in our rich and frostless forest-valleys a Tobacco similar to that of Kentucky, Maryland, Connecticut and Virginia, parts of Victoria resembling in climate very much these countries. Frost is detrimental to the Tobacco-plant; not only particularly when young must it be guarded against it, but frost will also injure the ripe crop. Mr. Politz consider the scarcity of dew in some of our districts to militate against the production of the best kinds, otherwise the yield as a rule is large, and the soil in many places well-adapted for this 
culture. Leaves of large size are frequently obtained. The moister and warmer northern and eastern regions of our colony are likely to produce the best Tobacco, if the final preparation of the leaf for the manufacturer is effected by experienced skill. The cruder kinds are obtained with ease, and so leaves for covering cigars. Virgin soil with rich loam is the best for Tobacco-culture, and such soil should also contain a fair proportion of lime and potash, or should be enriched with a calcareous manure and ashes, or with welldecomposed stable-manure. The seedlings, two months or less old, are transplanted. When the plants are coming into flower the leading top-shoots are nipped off, and the young shoots must also be broken off. A few weeks afterwards the leaves will turn to a greenish-yellow, which is a sign that the plants are fit to be cut, or that the ripe leaves can gradually be pulled. In the former case the stems are split; the drying is then effected in barns by suspension from sticks across beams. The drying process occupies four or five weeks and may need to be assisted by artificial heat. Stripped of the stalks the leaf-blades are then tied into bundles to undergo sweating or a kind of slight fermentation. It does not answer to continue Tobacco-culture beyond two years on the same soil uninterruptedly. A prominent variety is Nicotiana latissima (Miller) or N. macrophylla (Lehm.), yielding largely the Chinese, the Orinoco and the Maryland Tobacco. Latakia Tobacco, according to Dyer, is prepared by submitting the leaves for several months to fumigation from firwood. The dangerously powerful Nicotin, a volatile acrid alkaline oily liquid, and Nicotianin, a bitter aromatic lamellar substance, are both derived from Tobacco in all its parts and are therapeutic agents.

Niemeyera prunifera, F. v. Mueller. (Lucuma prunifer a, Bentham.)

The Australian Cainito. An evergreen tree, sparingìy dispersed from the North of New South Wales through the coast-forests of Queensland. The fruit is of a plum-like appearance and edible. Culture is likely to improve its quality.

Nyctanthes Arbor tristis, Linné.

India, up to Assam. This arborescent shrub may be grown in any moist regions of this colony free of frost, for the exquisite fragrance of its flowers, from which essence of Jasmin can be obtained.

Nyssa aquatica, Linné.

North America. The Tupelo. This large deciduous tree can be reared in pools and deep swamps, thus for aquatic scenery. 
The spongy roots of this species serve as a substitute for cork and the floats of nets.

Nyssa multiflora, Wangenheim.

Eastern States of North America, where it is called the Forest Tupelo or Black Gum-tree (Dr. Asa Gray). Suited for forest-soil, has horizontal branches and a "light, flat spray, like the Beech." The wood is very hard, but light and almost unwedgeable; it serves for hubs of wheels, pumps, sideboards of carts, trays, bowls, dippers, mortars, wooden shoes, and various turner's work. The foliage turns bright crimson in autumn. The fruits are pleasantly acidulous like those of $\mathrm{N}$. capitata (Walter) and of some other species, and often used for preserves.

Nyssa uniflora, Walter.

Eastern States of North America. The Swamp Tupelo. Wood soft, that of the roots very light and spongy, thus used for corks (Dr. Asa Gray). Attains a height of eighty feet. The mucilaginous fruits are edible.

Ocimum Basilicum, Linné.

The Basil. Warmer parts of Asia and Africa. An annual herb, valuable for condiments and perfumery. Several varieties exist, differing considerably in their scent. A crystalline substance is also obtained from this and similar species. O. canum (Sims) is closely allied.

Ocimum gratissimum, Linné.

Recorded from India, the South Sea Islands and Brazil, as indigenous. Somewhat shrubby. This is also a scent-plant like the following, and is one of the best of the genus. $O$. viride (Willd.) from tropical Africa seems a variety.

Ocimum sanctum, Linné.

Arabia, India, tropical Australia. A perennial herb. The odour of the variety occurring in North Australia reminds of anise; the smell of the variety growing in East Australia resembles cloves. O. tenuiflorum, L., seems to be another variety. Probably other species, as well cis- as transAtlantic, can be used like Basil.

Ocimum suave, Willdenow.

East Africa. A scrubby species.

Olea Europæa, Linné.*

The Olive-tree. From South-western Asia; naturalised in the countries around the Mediterranean Sea. A tree not of great height, but of many centuries' duration and of un- 
abating fecundity. The well-known Olive-oil is obtained from the fruit. Certain varieties of the fruit, preserved in vinegar or salt liquid before perfectly ripe, are also much used for the table. For this purpose the fruit is generally macerated previously in water containing potash and lime. The gum-resin of the Olive-tree contains the crystalline Olivil. The oil of the drupaceous fruit is a most important product of countries with climates similar to that of Victoria. Its chemical constituents are :-30 per cent. crystalline Palmitin; 70 per cent. Olein, through which Olive-oil belongs to those kinds which are not drying. The wild variety of the Olive-tree has usually short blunt leaves and thorny branches. Long continued droughts, so detrimental to most plants, will affect the Olive but slightly. It thrives best on a free loamy calcareous soil, even should it be strong and sandy, but it dislikes stiff clay. Proximity to the sea is favourable to it, and hill-sides are more eligible for its culture than plains. The ground must be deeply trenched. Manuring with well-decayed substances is requisite annually, or every second or third year according to circumstances. Irrigation will add to the productiveness of the plant. Mons. Riordet distinguishes three main varieties, of which he recommends two: 1, the Cayon, a small-sized tree, which comes into bearing already after three or four years, but it bears fully only every second year; its oil is fine with some aroma. 2, the Pendulier, a larger tree, with long drooping branches, yielding an oil of first-rate quality. Mons. Reynaud, "Culture de l'Olivier," separates twelve varieties, as cultivated in France, and recommends among them:1, the Courniau or Courniale, also called Plante de Salon, bearing most prolifically a small fruit and producing an excellent oil. 2, the Picholine, which by pruning its top branches is led to spread over eight square yards or more. It is of weeping habit, yields a good oil in fair quantity and resists well the attack of insects. 3, the Mouraou or Mourette, a large tree furnishing also oil of a very fine quality. Olive-trees require judicious pruning immediately after the fruit is gathered, when the sap is comparatively at rest. They may be multiplied from seeds, cuttings, layers, suckers, truncheons or estacas and old stumps, the latter to be split. The germination of the seeds is promoted by soaking the nutlets in a solution of lime and woodash. The seedlings can be budded or grafted after a few years. Truncheons or estacas may be from one to many feet long and from one inch to many inches thick; they are placed horizontally into the ground. Olive plantations at Grasse are worth from $£ 200$ to $£ 250$ per acre. For many details 
the tract on the "Culture of Olive and its Utilisation," here recently issued by the Rev. Dr. Bleasdale, should be consulted, as it rests largely on its author's observations during a long stay in Portugal. The Olive-oil imported in 1871 into Victoria was valued at $£ 15,538$.

The following notes are derived from the important "Tratado del Cultivo del Olivo en Espana," by the Chev. Capt. José de Hidalgo-Tablada (second edition, Madrid 1870). The Olive-tree will resist for a short time considerable frost $\left(-15^{\circ}\right.$ C.) provided the thawing takes place under fogs or mild rain (or perhaps under a dense smoke). It requires for ripening its fruit about one-third more annual warmth than the vine. The Olive zones of South Europe and North Africa are between the $18^{\circ}$ and $44^{\circ} \mathrm{N}$. latitude. An elevation of about 550 feet corresponds in Spain, as far as this culture is concerned, to one degree further north. Olives do not grow well on granite soil. The fruit produced on limestone formations is of the best quality. Gypsum promotes the growth of the tree (which thus may perhaps prosper in parts of the Murray-desert, underlaid with gypsum). An equable temperature serves best; thus exposure to prevailing strong winds is to be avoided. The winter temperature should not fall below $-7^{\circ} \mathrm{C}$. The content of oil in the fruit varies from 10 to 20 per cent.; sometimes it even exceeds the latter proportion. In the Provence at an average 24lbs. of Olive-oil are consumed by each individual of the population, in Andalusia about 30lbs. For obtaining the largest quantity of oil the fruit must be completely ripe. Hand-picked Olives give the purest oil. Knocking the fruit from the branches with sticks injures the tree and lessens its productiveness in the next year. About thirty Olive-trees can be planted conveniently on an acre for permanence; each tree under ordinary circumstances will produce fruits for $4 \mathrm{lbs}$. to $5 \mathrm{lbs}$. of oil annually. Spain alone produces about 250,000,000lbs. of Olive-oil a year.

\section{SPANISH VARIETIES.}

A.-Varieties of early maturation, for colder localities:-

1. Var. pomiformis, Clem.

Manzanillo. (French: Ampoulleau). Fruit above an inch in diameter, spherical, shining black. Putamen broad and truncate.

2. Var. regalis, Clem.

Sevillano. (French: Pruneau de Catignac). Fruit about an inch in diameter, ovate-spherical, blunt, bluish-black. 
3. Var. Bellotudo or Villotuda.

Fruit about an inch long, egg-shaped; pericarp outside darkred, inside violet.

4. Var. Redondillo.

Fruit ovate-spherical, nearly an inch long. Pericarp outside bluish-black, inside whitish. A rich yielder.

5. Var. ovalis, Clem.

Lechin, Picholin, Acquillo. (French: Saurine). Fruit broad-oval, two-thirds of an inch long. A copious yielder.

6. Var. argentata, Clem.

Nevadillo blanco; Doncel; Zorzalena; Moradillo; Ojiblanco; Olivo lucio. Fruit broad-ovate, an inch long, very blunt, not oblique. Quality and quantity of oil excellent.

7. Var. Varal blanco.

(French: Blanquette). Fruit ovate, globular, three-fourths of an inch long, neither pointed nor oblique, outside blackishred.

8. Var. Empeltre.

Fruit ovate, an inch loug, equable. Rich in oil of excellent quality, also one of the best for pickles. Pericarp outside violet, inside white.

9. Var. Racimal.

(French: Bouteillan, Boutiniene, Ribien, Rapugette). Fruit violet-coloured, globose-ovate, about an inch long; neither pointed nor oblique. Bears regularly also on less fertile soil, and is one of the earliest to ripen.

10. Var. Varal negro.

Alameno. (French: Cayon, Nasies). Fruit violet-black, spotted, globose-ovate, nearly an inch long, somewhat pointed. Bears richly.

11. Var. Colchonuda.

Fruit spheric, outside red, inside white, one inch in diameter, slightly pointed. Produces a large quantity of good oil.

12. Var. Ojillo de Liebre.

Ojo de Libre. Fruit nearly spheric, outside violet-black; about one inch long, somewhat oblique. One of the less early varieties.

13. Var. Carrasquena.

(French: Redouan de Cotignat). Fruit black-red, almost spherical, slightly oblique, about an inch long. Valuable both for oil and preserves, but liable to be attacked by various insects.

14. Var. Hispalensis, Clem.

Gordal; Ocal; Olivo real. Fruit black-grey, oblique, spherical, measuring fully an inch. Rather a large and quick-growing tree. Fruit used in the green state for preserves, not used for table oil. 
15. Var. Verdejo.

Verdial. (French: Verdal, Verdan). Fruit black-violet, oblique-spheric, pointed, about one inch long. Furnishes good oil and resists best of all the cold.

B. - Varieties of late maturation, for warmer localities:-

16. Var. maxima, Clem.

Madrileno; Olivo morcal. Fruit over an inch long, cordateglobose, strongly pointed. Less valuable for oil than for preserves.

17. Var. rostrata, Clem.

Cornicabra. (French: Cournaud, Corniaud, Courgnale, Pl. de Solon, Pl. de la Fane; Cayon, Rapunier, Grasse). Strong and tall, less tender. Fruit black-reddish, over an inch long, oval, much pointed. Good for oil.

18. Var. ceratocarpa, Clem.

Cornezuelo. (French: Odorant, Luquoise, Luques). Fruit fully an inch long, oval, pointed.

19. Var. Javaluno.

Fruit black-grey, over an inch long, egg-shaped, somewhat oblique, gradually pointed. Rich in good oil; can also be chosen for preserves; much subject to attacks of insects.

20. Var. Picudo.

Fetudilla. Fruit fully an inch long, egg-shaped, blunt at the base, pointed at the apex, with black-grey pulp. Pericarp easily separable. Employed both for oil and preserves.

21. Var. Nevadillo negro.

Fruit egg-shaped, fully an inch long, with turned pointed apex. One of the richest of all varieties in yield. Endures considerable cold and ripens not quite late.

All these Spanish varieties show rather long lanceolate leaves of more or less width.

\section{FRENCH VARIETIES.}

(Some verging into the Spanish kinds).

22. Var. angulosa, Gouan.

Galliningue, Laurine. For preserves.

23. Var. Rouget.

Marvailletta. Produces a fine oil.

24. Var. atrorubens, Gouan.

Salierne, Saverne. Fruit dusted white. Furnishes one of the best of oils.

25. Var. variegata, Gouan.

Marbée, Pigale, Pigau. Purple fruit with white spots.

26. Var. Le l'alma.

Oil very sweet, but not largely produced.

27. Var. atrovirens, Ros.

Pointue, Punchuda. Fruit large with good oil. 
28. Var. rubicans, Ros.

Rougette. Putamen small. Yield annual and large.

29. Var. alba, Ros.

Olive blanche, Blancane, Vierge. This with many others omitted on this occasion is an inferior variety.

30. Var. Caillet Rouge.

Figanier. Small tree. Fruit large, red. Oil good and produced in quantity.

31. Var. Caillet Blanche.

Fruit almost white, produced annually and copiously, yielding a rather superior oil.

32. Var. Raymet.

Fruit large, reddish. Oil copious and fine. This variety prefers flat country.

33. Var. Cotignac.

Pardignière. Fruit middle-sized, blunt. Oil obtained in quantity and of excellent quality. This wants much pruning.

34. Var. Bermillaon.

Vermillon. Yields also table-oil and resists cold well.

Many other apparently desirable varieties occur, among which the Italian Oliva d'ogni mese may be mentioned, which ripens fruits several times in the year, and furnishes a pleasant oil and also berries for preserves.

Onobrychis sativa, Lamarck.*

The Saintfoin, or Esparsette, or Cocks-head Plant. South and Middle Europe, Middle Asia. A deep-rooting perennial fodder-herb, fond of marly soil, and living in dry localities. It is thus well adapted also for the limestone formation of the lower Murray River. It prepares dry calcareous soil also for cereal culture. Stagnant underground humidity is fatal to this plant. It prospers still where Red Clover and Lucerne no longer succeed. Sheep cannot so well be turned out on young Saintfoin fields as cattle. The hay is superior even to that of Lucerne and Clover. The plant will hold out from five to seven years (Langethal).

Ophelia Chirata, Grisebach. (Agathotes Chirata, D. Don). Widely dispersed over the higher mountain-regions of India. A perennial herb, considered as one of the best of tonics; it possesses also febrifugal and antarthritic properties. Its administration in the form of an infusion, prepared with cold water, is the best. Besides O. elegans (Wight) some of the other Upper Indian, Chinese and Japanese species deserve probably equal attention. Hanbury and Flückiger mention as Chiratas or Chirettas of Indian bazaars: O. angustifolia (D. Don), O. densiflora (Grisebach), O. elegans (Wight) and 
0. multiflora (Dalzell), besides species of Exacum and Andrographis. All come from the cooler uplands.

Opuntia coccinellifera, Miller.

Mexico and West India. The Cochineal Cactus. On this and O. Tuna, O. Hernandezii and perhaps a few others subsists the Coccus, which offers the costly Cochineal dye. Three gatherings can be effected in the year. About 1200 tons used to be imported annually into Britain alone, and a good deal also to other countries, valued at about $£ 400$ for the ton. The precious Carmin-pigment is prepared from Cochineal.

Opuntia Dillenii, Candolle.

Central America. A Tuna-like Cactus, serving for uninflammable hedges, and perhaps also for the rearing of the Coccus Cacti. It is particularly eligible for barren land.

Opuntia elatior, Miller.

Central America. A hedge-plant with formidable thorns.

Opuntia Ficus Indica, Miller.

Central America, north as far as Florida. Serves for hedges. Pulp of fruit edible.

Opuntia Hernandezii, Candolle.

Mexico. Affords also food for the Coccus Cacti.

Opuntia Missouriensis, Candolle.

From Nebraska to New Mexico. Mr. Meehan found this Cactus covered with the Cochineal Coccus, and points to the fact that this insect will live through the intense cold, which characterises the rocky mountains of the Colorado regions.

Opuntia Rafinesquii, Engelmann.

North America. The most northern of all species, extending to Lake Michigan.

Opuntia spinosissima, Miller.

Mexico and West India. Stem columnar with pendant branches. Also a good hedge-plant.

Opuntia Tuna, Miller.

West India, Ecuador, New Granada, Mexico. Irrespective of its value as the principal Cochineal-plant, this Cactus is also of use for hedges. It will attain a height of twenty feet. The pulp of the fruit is edible. With the other species hardy at least in our lowlands.

Opuntia vulgaris, Miller.

Central America, northward to Georgia, southward to Peru. Adapted for hedges and like the rest not inflammable, thus particularly valuable along railway lines. The fruit almost smooth, also eatable. A dye can also be prepared from its 
pulp and that of allied species. Numerous other species are here industrially eligible for hedging purposes.

Oreodoxa regia, Humboldt.

West India. This noble Palm attains a height of sixty feet. It has proved hardy in Southern Brazil, and would probably endure our clime. The stem is thickened at the middle, and from it, like from the much taller O. oleracea (Martius), starch can be obtained.

Origanum Dictamnus, Linné.

Candia. Like the following a scent-plant of somewhat. shrubby growth.

Origanum Majorana, Linné.

North Africa, Middle Asia, Arabia. A perennial herb, used for condiment, also for the distillation of its essential oil.

Origanum Maru, Linné.

Palestine. Perennial and very odorous.

Origanum Onites, Linné.

Countries at the Mediterranean Sea. Somewhat shrubby and strongly-scented.

Origanum vulgare, Linné.

The ordinury Marjoram. All Europe, North Africa, North and Middle Asia. A scented herb of perennial growth, containing a peculiar volatile oil. It prefers limestone soil. $\quad 0$. hirtum (Link.), O. virens (Hoffmannsegg) and O. normale (D. Don) are closely-allied plants of similar use. Several other Marjorams, chiefly Mediterranean, are of value.

Ornithopus sativus, Brotero.

South Europe and North Africa. The Seratella or Serradella. An annual herb, larger than the ordinary Birdsfootclover. It is valuable as a fodder-plant on sterile soil. It requires, like the smaller $O$. perpusillus, no lime, but improves in growth on gypsum land, of which there is much in the Murray desert.

Oryza sativa, Linné.*

The Rice-plant. South Asia and North Australia. Annual like most cereals. The many rivulets in our ranges afford ample opportunities for irrigating Rice-fields: but these can be formed with full advantage only in the warmer parts of the colony, where rice will ripen as well as in Italy, China, or the Southern States of the American Union. Among the numerous varieties of Indian Rice may be noted as prominent sorts: The Early Rice, which ripens in four months and is not injured by saline inundations. The hardier Mountain Rice, which can be raised on comparatively dry ground, and 
which actually perishes under lengthened inundation, but which is less productive. The Glutinous Rice, which succeeds as well in wet as almost dry places, and produces black or reddish grains. In the rich plains of Lombardy, irrigated from the Alps, the average crop is estimated at forty-eight bushels for the acre annually. The spirit distilled from Rice and molasses is known as Arrack.

Oryza latifolia, Humboldt and Bonplaud.

Central America. This species is said to be perennial and to attain a height of eighteen feet. It deserves here trialculture, and may prove a good fodder-grass on wet land in warm localities. O. perennis (Moench) seems closely allied.

Osmitopsis asteriscoides, Cassini.

South Africa. A camphor-scented shrub, much in use there for medicinal purposes (Dr. Pappe).

Ostrya carpinifolia, Scopoli.

South Europe and Orient. The Hop Hornbean. A deciduous tree, 60 feet high.

Ostrya Virginica, Willdenow.

Leverwood-tree of North America, 40 feet high, in rich woodlands. Wood singularly hard, close-grained and heavy, in use for levers and other implements, for mill-cogs, wheels, \&c. Cattle browse on the foliage.

Oxalis crassicaulis, Zuccarini.

Peru. This seems one of the best of those Woodsorrels, which yield a tuberous edible root. Amongst others $O$. tuberosa (Mol.) and O. succulenta (Barn.) from Chili, as well as O. carnosa (Mol.) and O. conorrhiza (Jacq.) from Paraguay, might be tried for their tubers.

Oxalis esculenta, Otto and Dietrich.

Mexico, there with O. tetraphylla (Cavanilles), O. Deppei (Loddiges), O. violacea (Linné) and several others producing tuberous starchy wholesome roots ; the first mentioned gives the largest yield. As similarly useful may be mentioned among many others-O. crenata (Jacquin), from Chili and $O$. enneaphylla (Cavanilles), from the Falkland Islands and Magelhaen's Straits.

Oxytenanthera Thwaitesii, Munro.

Ceylon, on mountains from 4000 to 6000 feet high. A dwarf but handsome Bamboo, reaching only a height of 12 feet.

Oxytropis pilosa, Candolle. (Astragalus pilosus, Linné.)

Europe, West Asia. This perennial plant furnishes fair pasture-herbage; the numerous other species, twenty-four alone enumerated as oriental by Boissier, should be tested. 
All these plants might be classed as Astragals. They are mostly content with poor soil.

Pachyma Hœlen, Fries.

China. This large Truffle occurs particularly in the province of Souchong. Flavour most agreeable.

Pachyrrhizus angulatus, Richard.

From Central America rendered spontaneous in many tropical countries. A climber, the horizontal starchy roots of which attain a length of eight feet, and a thickness of many inches. It requires rich soil. The root is edible, though inferior to Yam. From the stems a tough fibre is obtained. The plant proved hardy at Sydney.

Paliurus ramosissimus, Poiret. (P. Aubletia, Schultes.) China and Japan. A thorny tree, which could be utilised for hedging.

Paliurus Spina Christi, Miller. (P. aculeatus, Lambert.) The Christ-Thorn. From the Mediterranean Sea to Nepaul. A deciduous bush or finally tree, which can be trimmed into hedges.

Pandanus furcatus, Roxburgh.

This screw Pine occurs in India, up to heights of 4000 feet, according to Mr. S. Kurz; hence it will likely bear our clime, and give us a stately plant for scenic group-planting. P. pedunculatus (R. Br.) occurs in East Australia as far south as $32^{\circ}$, and the same or an allied tall species luxuriates in Howe's Island.

Panicum amarum, Elliot.

North America. A perennial species, fit to be grown on drifting coast-sand.

Panicum barbinode, Trinius.

Brazil. Valuable as a fodder-grass.

Panicum brizanthum, Hochstetter.

From Abyssinia to Nepal. A large-grained perennial Milletgrass.

Panicum Crus-Galli, Linné.

The Barnyard or Cockshin Grass. Occurring now in all warm countries, but probably of Oriental origin, as it seems not recorded in our ancient classic literature. A rich but annual grass of ready spontaneous dispersion. P. colonum, L., and P. Crus-Corvi, L., are varieties of it. Regarded by $\mathbf{R}$. Brown as indigenous to Eastern and Northern Australia, where many other excellent fodder-species occur, some perennial. It will succeed also on somewhat saline soil, particularly on brackish water-courses, also in moor-land. 
Panicum decompositum, R. Brown. (P. laevinode, Lindley.) The Australian Millet. One of the most spacious of native nutritious grasses. The aborigines convert the small milletlike grains into cakes. This grass will thrive on poor soil.

Panicum fluitans, Retzius.

Tropical Asia and Africa. This grass, like P. spinescens (R. Brown), of East Australia, ought to be naturalised along lakes, lagoons and rivers, particularly for the benefit of water-fowl.

Panicum frumentaceum, Roxburgh.

The Shamalo or Deccan Grass. Probably introduced from tropical Africa into South Asia. It serves as a fodder-grass and produces also a kind of Millet.

To this species is allied P. sarmentosum, Roxb., from Sumatra, which is now likewise much cultivated in tropical countries. It is perennial.

Panicum Italicum, Linné.

This grass, notwithstanding its specific name, is of Indian origin, but appears to be likewise a native of North Australia. It is annual and worthy to be cultivated as a tender green-fodder, attaining a height of five feet. It keeps weeds down. The abundantly-produced grain is not only one of the best for poultry, but that of some varieties can also be utilised as Millet. P. Germanicum, Roth., is a form of this species.

Panicum Koenigii, Sprengel. ( $P$. Helopus, Trin.)

India. A good fodder-grass.

Panicum latissimum, Mikan.

Brazil. A highly-ornamental grass. Leaves extremely broad but hard; panicle very rich.

Panicum maximum, Jacquin.* ( $P$. jumentorum, Persoon.) The Guinea-Grass. Tropical Africa; elsewhere not indigenous. This perennial grass attains a height of eight feet in tropical countries. It is highly nutritious and quite adapted for the warmer parts of our colonial territory.

Panicum miliaceum, Linné.* ( $P$. miliare, Lam.)

The true Millet. South Asia and North Australia, but cultivated in Southern Europe already at Hippocrates' and Theophrastos' time. Annual, attaining a height of four feet. Several varieties occur, one with black grains. They all need a rich but friable soil. It is one of the best of all grains for poultry, but furnishes also a palatable and nutritious tablefood. It ripens still in Middle Europe.

Panicum pilosum, Swartz.

Tropical America. A perennial fodder-grass. 
Panicum repens, Linné.

At the Mediterranean Sea, also in South Asia and] North Australia. Regarded fby the Cingalese as a good foddergrass. It is perennial and well-suited for naturalisation on moist soil or river-banks or swamps.

Panicum prostratum, Lamarck. ( $P$. setigerum, Retz.) Egypt, South Asia, North Australia, perhaps also indigenous to tropical America. Perennial. Recommendable for pastures.

Panicum sanguinale, Linné.

From South Europe and Southern Asia spread through all countries with a warm climate, but apparently also indigenous in East Australia. It readily disseminates itself on barren ground, and is likely to add to the value of our desert-pastures, although it is annual. Stock relish this grass. P. ciliare (L.) and P. glabrum (Gaudin) are allied species.

Panicum spectabile, Nees.*

The Coapim of Angola. From West Africa transferred to many other tropical countries. A rather succulent very fattening grass, attaining a height of about four feet.-It may be assumed, that hitherto about 300 well-defined species of Panicum are known, chiefly tropical and sub-tropical, thus very few extending naturally to Europe, or the United States of North America, or Japan, or the southern part of Australia. Though mostly from the hot zones these grasses endure in many instances our clime, and some of them would prove great acquisitions, particularly the perennial species. Numerous good kinds occur in Queensland and North Australia spontaneously. Panicum is the genus richest in species among grasses.

Panicum turgidum, Forskael.

Egypt, where this Millet yields a bread-grain.

Panicum virgatum, Linné.

North America, South Asia and North Australia. A tall perennial species, with a wide nutritious panicle.

Papaver somniferum, Linné.*

The Opium-Poppy. Orient. The capsules of this tall annual, so showy for its flowers, are used for medicinal purposes; from the minute but exceedingly numerous seeds oil of a harmless and most palatable kind can be pressed remuneratively; but a still more important use of the plant is that for the preparation of Opium, of which a quantity valued in the Customs returns at $£ 94,455$ was imported during 1871 into Victoria, and this does not provide for a 
large portion of the Morphia used in medicine. Both the black and pale seeded varieties can be used for the production of Opium. The return of Poppy-culture, whether for opium or for oil, is within a few months. Our milder and somewhat humid open forest-tracts proved most productive for obtaining Opium from this plant; but it can be reared also in colder localities, good Opium, rich in Morphia, having even been obtained in Middle Europe and the Northern United States, the summers there being sufficiently long to ripen the Poppy with a well-elaborated sap. The Morphia contents in Opium from Gipps Land was at an average somewhat over 10 per cent. Opium was prepared in our Botanic Gardens for the Exhibition of 1866 ; but particularly Mr. J. Bosisto and Mr. $J$. Hood have given to this branch of rural industry here commercial dimensions. The Smyrna variety is particularly desirable for Opium; it enables the cultivator to get from $40 \mathrm{lbs}$. to $75 \mathrm{lbs}$. of Opium from an acre, generally worth $30 \mathrm{~s}$. to $35 \mathrm{~s}$. per pound. The ground for Poppy-culture must be naturally rich, or otherwise be well manured; dressing with ashes increases the fecundity of the plant. The seed, about 9 lbs. to an acre, is generally sown broadcast, mixed with sand. In the most favourable places as many as three crops are obtained during a season. The collecting of the Opium, which consists merely of the indurating sap of the seedvessels, is commenced a few days after the lapse of the petals. Superficial, horizontal or diagonal incisions are made into the capsules as they successively advance to maturity. This operation is best performed in the afternoons and evenings, and requires no laborious toil. The milky Opium-sap thus directed outward, is scraped off next morning into a shallow cup, and allowed to dry on a place away from sunlight; it may also be placed on Poppy-leaves. From one to six successive incisions are made to exhaust the sap, according to season, weather, locality or the knife-like instrument employed. In the Department of Somme (France) alone Opium to the value of $£ 70,000$ annually is produced, and Poppyseed to the value of $£ 170,000$. Our seasons here, as a rule, are favourable for collecting Opium, and thus this culture is here rendered less precarious than in many other countries. Our Opium has proved as good as the best Smyrna kinds. The petals are dried for packing the Opium. The main value of Opium depends on its contents of Morphia, for which the genus Papaver, as far as hitherto known, remains the sole source. But not less than eleven alkaloids have been revealed in Opium by the progressive strides of organic chemistry: Codein, Metamorphin, Morphia or Morphin, Narcein, Narcotin, Opianin, Papaverin, Porphyroxin, 
Pseudo-morphin and Thebain. It contains besides an indifferent bitter principle: Meconin and Meconic Acid (vide "Wittstein's Chemische Analyse von Pflanzentheilen"). Various species of Papaver produce more or less Opium and Morphia.

Pappea Capensis, Ecklon and Zeyher.

South Africa. The fruit of this tree is of the size of a cherry, savoury and edible.

Pappophorum commune, F. v. Mueller.

Widely dispersed over the continent of Australia, also in some parts of Asia and Africa. Perennial ; regarded as a very fattening pasture-grass, and available for arid localities.

Parinarium Nonda, F. von Mueller.

The Nonda-tree of North-East Australia. It may prove hardy in East Gipps Land, and may live perhaps in the dry and hot air of our deserts, where it deserves trial-culture for the sake of its edible mealy plum-like fruit. A few other species with esculent drupes occur in different tropical countries.

Parkinsonia aculeata, Linné.

From California to Monte Video. A thorny shrub, clearly adapted for the warmer parts of Victoria, where it might be utilised with the following plant for evergreen hedges. The flowers are handsome.

Parkinsonia Africana, Sonder.

South Africa. A tall bush. A third species, P. microphylla, Torr., occurs on the Colorado.

Parthenium integrifolium, Linné.

North America. The flowering tops of this perennial bitter herb have come into use as a febrifuge (Houlton).

Parrotia Jacquemontiana, Decaisne.

North Western Himalayas, from about 3000 to 8500 feet elevation. This deciduous-leaved small tree merits introduction. Its tough and pliable twigs are used for basketwork and preferentially for the twig-bridges, the latter up to 300 feet long; hence this tree could be used here for a variety of economic purposes (Stewart and Brandis). P. Persica (C. A. Meyer) occurs on the Caspian Sea.

Paspalum ciliatum, Humboldt.

Tropical South_America. A perennial and lauded cereal grass.

Paspalum dilatatum, Poiret.

Extra-tropical South America. Perennial, of excellent quality for fodder. Mr. Bacchus found it hardy here up to a height of 2000 feet. 


\section{Paspalum distichum, Burmann.}

From India to South-Eastern Australia. A creeping swampgrass, forming extensive cushions. It keeps beautifully green throughout the year, affords a sufficiently tender blade for feed, and is exquisitely adapted to cover silt or bare slopes on banks of ponds or rivers, where it grows grandly; moderate submersion does not destroy it, but frost injures it.

\section{Paspalum scrobiculatum, Linné.}

Through the tropics of the Eastern Hemisphere widely dispersed, extending to South East Australia. A valuable pasture-grass. A superior variety is cultivated in Indian for a grain-crop. This grass furnishes a good ingredient to hay. The stem sometimes attains a height of eight feet. Rosenthal pronounces it pernicious, perhaps when long and exclusive use is made of this grass, under which circumstances also the Rye-grass will become injurious.

\section{Paspalum stoloniferum, Bosc.}

Central America. A fodder-grass of considerable value.

Passiflora alata, Aiton.

Peru and Brazil. This Passion-flower and all the following (and probably other species) furnish Granadilla fruits.

Passiflora coccinea, Aublet.

From Guiana to Brazil.

Passiflora coerulea, Linné.

South Brazil and Uruguay. One of the hardiest of all Passion-flowers, and with many others well-adapted for covering bowers, rookeries and similar structures. Many of the Equatorial species come from mountainous regions and may thus endure our lowland clime.

Passiflora edulis, Sims.

Southern Brazil.

Passiflora filamentosa, Willdenow.

Southern Brazil.

Passiflora incarnata, Linné.

North America from Virginia and Kentucky southward. -The fruits are called Maypops.

Passiflora laurifolia, Linné. (P. tinifolia, Jussieu.)

The Water-Lemon. From West India to Brazil.

Passiflora ligularis, Jussieu.

From Mexico to Bolivia. 
Passiflora lutea, Linné.

North America from Pennsylvania and Illinois southward. Berries small.

Passiflora macrocarpa, Masters.

Brazil and Peru. Mr. Walter Hill reports having obtained fruits of eight pounds weight at the Brisbane Botanic Garden.

Passiflora maliformis, Linné.

From West India to Brazil.

Passiflora quadrangularis, Linné.

Brazil. One of the most commonly cultivated Granadillas.

Passiflora serrata, Linné.

From West India to Brazil.

Passiflora suberosa, Linné. ( $P$. pallida, Linné.)

From Florida to Brazil. A careful investigator, Dr. Maxw. Masters, has recently defined about 200 species of Passionflowers.

Peireskia aculeata, Miller.

West India. The Barbadoes Gooseberry. A tall shrub, adapted for hedges in localities free of frost. The Cochineal insect can be reared also on this plant. The berries are edible. Several other species exist in tropical America, among which P. Bleo (Humb.) is particularly handsome, but they may not all be sufficiently hardy for utilitarian purposes in our clime. Otherwise the Bleo is used for salad.

Peireskia portulacifolia, Haworth.

West India. This attains the size of a fair tree.

Pelargonium odoratissimum, Aiton.

South Asia. A perennial trailing herb, from the leaves of which a fragrant oil can be distilled. The same remark applies to the shrubby P. Radula and P. capitatum (Dr. Rosenthal).

Pennisetum thyphoideum, 'Richard.* (Penicillaria spicata, Willdenow; Paricum coeruleum, Miller.)

Tropical Asia, Nubia and Egypt. The Bajree. An annual, ripening its millet crop in about three months in warm countries. The stems are thick and reach a height of six feet. This grass requires a rich and loose soil, and on such it will yield upwards of a hundred fold. It furnishes also a good hay, and is also valuable as green-fodder. Some of the many other species of Pennisetum are doubtless of pastoral value. A plant allied to $\mathbf{P}$. thyphoideum occurs in China: namely, P. cereale (Trin.). This affords also millet or corn for cakes. 
Pentzia virgata, Lessing.

South Africa. A small bush, recommended to be established in our deserts for sheep-fodder. Several other species occur in South Africa.

Periandra dulcis, Martius.

Sub-tropical Brazil. The sweet root yields liquorice.

Perilla arguta, Bentham.

Japan. An annual herb. An infusion of this plant is used to impart to table-vegetables and other substances a deep red colour. P. ocimoides (L.), of Upper India, serves probably. similar purposes.

Persea gratissima, Gaertner.

From Mexico to Peru and Brazil in forest-tracts near the coast. The Avocado-Pear. Suggestively mentioned here as likely available for East Gipps Land, French Island and other mild localities of our country, inasmuch as it has become naturalised in Madeira, the Azores and Canary Islands. A noble evergreen spreading tree. The pulp of the large pear-shaped fruit is of delicious taste and flavour.

Persea Teneriffæ, Poiret (sub Lauro). (P. Indica, Sprengel.) Madeira, Azores and Canary Islands. This magnificent tree produces a very beautiful hard mahogany-like wood, especially sought for superior furniture and turners' work. One of the most hardy trees of the large order of Laurinæ.

Peucedanum cachrydifolium, Ledebour.

Persia. A valuable fodder-herb (Dr. Rosenthal).

Peucedanum graveolens, Bentham. (Anethum graveolens, Linné.)

The Dill. South Europe, North Africa, Orient. Annual. The well-known aromatic fruitlets used as a condiment. $P$. Sowa, Benth. (Anethum Sowa, Roxb.) is a closely-allied Indian annual herb.

Peucedanum officinale, Linné.

The Sulphur-Root. Middle and South Europe, North Africa, Middle Asia. Perennial. The root is used in veterinary medicine. It contains like that of the following species the crystalline Peucedanin.

Peucedanum Ostruthium, Koch. (Imperatoria Ostruthium, Linné.)

Mountains of Middle Europe. A perennial herb, which could be grown in our Alps. The acid aromatic root is used in medicine, particularly in veterinary practice. It is required for the preparation of some kinds of Swiss Cheese. P. Cervaria (Cuss.) and P. Oreoselinum (Moench) are also occasionally drawn into medicinal use. 
Peucedanum sativum, Bentham. (Pastinaca sativa, Linné.) The Parsnip. Europe, North and Middle Asia. Biennial. The root palatable and nutritious. A somewhat calcareous soil is favourable for the best development of this plant. The culture is that of the carrot; for fodder, the root surpasses that of the latter in augmenting milk (Langethal).

Peucedanum Sekakul, Bentham.

Egypt and Syria. Biennial. The root is edible.

Peumus Boldus, Molina.

The Boldo of Chili. A small ornamental evergreen tree, with exceedingly hard wood, which is utilised for many kinds of implements. The bark furnishes dye-material. The fruits are of aromatic and sweet taste (Dr. Philippi).

Phalaris Canariensis, Linné.

The Canary-Grass. An annual grass from the Canary Islands, now widely dispersed as a spontaneous plant over the warmer zones of the globe. Thus it has also become naturalised in Australia. It is grown for its seeds, which form one of the best kinds of fodder for many sorts of small cage-birds. The flour is utilised in certain processes of cotton-manufacture, and liked for some kinds of cakes. The soil for the culture of the Canary-grass must be friable and not too poor. It is an exhaustive crop. As allied annual species of similar use, but mostly of less yield, may be enumerated: P. brachystachys (Link.) from Italy, P. minor (Retz) and P. truncata (Guss.) from various countries at the Mediterranean Sea. Other species, including some from Asia, are deserving of trial; but the perennial British P. arundinacea (L.), is too harsh to serve for wholesome fodder, nor does it furnish Canary-seed.

Phaseolus adenanthus, G. Meyer. (P. Truxillensis, Humboldt; $P$. rostratus, Wallich.)

Almost cosmopolitan within the tropics, where irrespective of navigation and other traffic it becomes dispersed by migrating birds; truly spontaneous also in tropical Australia. A perennial herb with large flowers, resembling those of Vigna vexillata (Benth.) Cultivated for its seeds, which are rather small, but copiously produced. A variety with edible roots occurs.

Phaseolus coccineus, Kniphof. ${ }^{*}(P$. multiflorus, Willdenow.)

The Turkish Bean or Scarlet-Runner. A native of the Orient, if Sprengel's identification is correct, according to which this plant was known in Arabia and Persia at Avicenna's time; but according to other opinions it is a 
native of Mexico. A twining showy perennial, as useful as the ordinary French Bean. Its seeds usually larger than those of the latter plant, purple with black dots, but sometimes also pure blue and again quite white. The flowers occur sometimes white. The root contains a narcotic poison.

Phaseolus lunatus, Linné.

Considered as a native of tropical America, but also recorded as wild from many parts of tropical Africa and Asia. Biennial according to Roxburgh. Much cultivated in the warm zone for its edible beans, which are purple or white. A yellow-flowered variety or closely-allied species is known as the Madagascar-Bean and proved hardy and productive here. P. perennis, Walt., from the United States of North America, is another allied plant.

Phaseolus Max, Linné. ( $P$. Mungo, Linné; P. radicatus, Linné.) The Green Gram. South Asia and tropical Australia. An annual very hairy plant, not much climbing. Frequently reared in India, when rice fails or where that crop cannot be produced. The seeds are but small, and the herb is not available for fodder. This plant requires no irrigation, and ripens in two and a-half to three months. The grain tastes well and is esteemed wholesome. The harvest is about thirtyfold.

Phaseolus vulgaris, Linné.*

The ordinary Kidney-Bean or French Bean or Haricot. India, from whence it came to Europe through the conquests of Alexander the Great; but apparently it is also wild in North-Western Australia. Though this common and important culinary annual is so well known, it has been deemed desirable, to refer to it here with a view of reminding, that the Kidney-Bean is nearly twice as nutritive as wheat. The meal from Beans might also find far augmented use. As constituents of the Beans should be mentioned a large proportion of starch (nearly half), then much Legumin, also some Phaseolin (which like Amygdalin can be converted into an essential oil) and Inosit-sugar. Lentils contain more Legumin but less starch, while Peas and Beans are in respect to the proportion of these two nourishing substances almost alike. The Kidney-Bean can still be cultivated in cold latitudes and at sub-alpine elevations, if the uninterrupted summer-warmth lasts for four months; otherwise it is more tender than the Pea. The soil should for field-culture be friable and somewhat limy and not sandy. Phaseolus nanus, L., the Dwarf-Bean, and P. tumidus, Savi, the Sugar-Bean or Sword-Bean or Egg-Bean, are varieties of P. vulgaris. Several other species of Phaseolus seem worthy of culinary culture. 


\section{Phleum pratense, Linné.*}

The Catstail- or Timothy-Grass. Europe, North Africa, North and Middle Asia. One of the most valuable of all perennial fodder-grasses. Its production of early springherbage is superior to that of the Cocksfoot-grass. It should enter largely into any mixture of grasses for permanent pasturage. It will live also on moist and cold clay-ground. This grass and perhaps more yet the allied Phleum alpinum, L., are deserving of an extensive transfer to our moory Alps. For hay it requires mowing in a young stage. The seed is copiously yielded and well-retained. The greatest advantage from this grass arises, according to Langethal, when it is grown along with clovers. It thrives even better on sandy meadows than on calcareous soil ; it will prosper on poorer ground than Alopecurus pratensis; the latter furnishes its full yield only in the fourth year, whereas the Phleum already in the second. The Timothy dries more quickly for hay and the seeds are gathered more easily, but it regetates later, is of harder consistence and yields less in the season after the first cut.

\section{Phœnix dactylifera, Linné.*}

The Date-Palm. North Africa, also inland; Arabia, Persia. This noble palm attains finally a height of 80 , exceptionally 120 feet. It is unisexual and of longerity :- "Trees of from 100 to 200 years old continue to produce their annual crop of dates." Though from the sap sugar or palm-wine can be obtained, and from the leaves hats, mats and similar articles can be manufactured, we here would utilise this palm beyond scenic garden-ornamentation only for its fruits. It is in the oases of our desert-tracts, swept by burning winds, where the Date-Palm would afford in time to come a real boon, although it might be grown also in the valleys of our mountains and in any part of our lowlands. Several bunches of flowers are formed in a season, each producing often as many as 200 dates. In Egypt as many as 4 cwt. of dates have been harvested in one season from a single Date-Palm. Many varieties of Dates exist, differing in shape, size and colour of the fruit; those of Gomera are large and contain no seed. The unexpanded flower-bunches can be used for palm-cabbage, the fibre of the leaf-stalks for cordage. The town Elche in Spain is surrounded by a planted forest of about 80,000 Date-Palms, and the sale of leaves for decorative purposes produces irrespective of the value of the Date-fruits a considerable income to the town, and so it is at Alicante. As far north as the Gulf of Genoa exists also a Date-forest. The ease, with which this palm grows from seeds, affords 
facility in adapted climes to imitate these examples, and we certainly ought to follow them in all parts of Australia.

Phœnix paludosa, Roxburgh.

India. A stout species, not very tall. Of value at least for decorative culture.

Phœnix pusilla, Gaertner.

India and South China. A dwarf species, likely also to be hardy here. P. farinifera (Roxb.) appears to be identical. It is adapted for sandy and otherwise dry and barren land, but prefers the vicinity of the sea. Berry shining black, with a sweet mealy pulp.

Phœnix reclinata, Jacquin.

South Africa, in the eastern districts. A hardy species, but not tall, often reclining. It is adapted for ornamentation. The seeds are frequently drawn into local use as a substitute for coffee.

Phœnix silvestris, Roxburgh.

India, almost on any soil or in any situation. It has proved at Melbourne a very hardy species. Its greatest height is forty feet. Berries yellowish or reddish, larger than in $\mathrm{P}$. pusilla. Where this Palm abounds much sugar is obtained from it by evaporation of the sap, which flows from incisions into the upper part of the trunk, a process not sacrificing the plant, as for twenty years the sap can thus be withdrawn. A kind of arrack is obtained by fermentation and distillation of this sap, and also from the young spikes. Each plant furnishes the juice for about 8lbs. of date-sugar annually, but in some instances much more. About 50,000 tons of sugar are produced a year in Bengal alone from this and some other palms. The leaves are used for mats.

Phœnix spinosa, Thonning.

Tropical Africa, ascending mountain-regions, thus perhaps hardy here with us. Dr. Kirk found the green bushes, if immersed in water for half a day, suddenly to assume a scarlet hue, and then the astringent pulp to become edible and sweet.

Phormium tenax, J. R. and G. Forster.* The Flax-lily of New Zealand, where it occurs as far south as $46^{\circ} 30^{\prime}$, occurring also in the Chatham Islands and Norfolk Island, though not on Lord Howe's Island. It seems important that this valuable plant should here be brought universally under culture, particularly on any inferior spare ground or on the sea-beaches or any rocky declivity, where it may be left unprotected to itself, as no pastoral animal will touch it. It is evident that the natural upgrowth will soon 
be inadequate to the demand for the plant. Merely torn into shreds the leaves serve at once in gardens and vineyards as cordage, and for this purpose, irrespective of its showy aspect, the Phormium has been distributed from our Botanic Garden since the last eighteen years. From the divided roots any plantation can gradually be increased, or this can be done more extensively still by sowing the seeds. In all likelihood the plant would thrive and become naturalised in the Auckland and Campbell's Group, in Kerguelen's Land, the Falkland Islands, the Shetland Islands and many continental places of both hemispheres. Among the varieties three are better characterised than the rest: the Tehore, the Swamp and the Hill variety. The first and the last mentioned produce a fibre fine and soft, yet strong, and the plants attain a height of only about five feet, whereas the Swampvariety grows to double that height, producing a larger yield of a coarser fibre, which is chiefly used for rope or paper making. As might be expected, the richer the soil the more vigorous the growth of the plant; it likes moreover now and then to be overflown by fresh or brackish water, but it will not live if permanently sunk into wet. In swampy ground trenches should be dug to divert the surplus of humidity. Fibre free from gum-resin properly dressed withstands moisture as well as the best Manila rope. Carefully prepared the fibre can also be spun into various textile durable fabrics, either by itself or mixed with cotton, wool or flax. In October, 1872, the sale of Phormium-fibre in London was 11,500 bales, ranging in price from $£ 19$ to $£ 31$. The tow can also be converted into paper, distinguished for its strength and whiteness. The London price of Phormium-fibre for this purpose is from $£ 10$ to $£ 20$ per ton.

For further details on the utilisation of this plant the elaborate reports of the New Zealand Commission for Phormium should be consulted. One of the dwarf varieties is Phormium Colensoi (J. Hook).

Phyllocladus rhomboidalis, Richard.

Celery-Pine of Tasmania. A stately tree up to sixty feet high, with a stem of two to six feet in diameter. The timber is valuable for ships' masts. It will only grow to advantage in deep forest-valleys.

Phyllocladus trichomanoides, Don.

Celery-Pine of New Zealand, northern island; it is also called Pitch-Pine by the colonists-native name, Tanekaha. This tree attains a height of seventy feet, with a straight stem of three feet in diameter, and furnishes a pale close-grained timber, strong, heavy, and remarkably durahle according to 
Professor Kirk greatly valued for mine-props, struts, caps, sleepers, water-tanks, bridge-planks and piles and spars; the Maories employ the bark for dyeing red and black.

Physalis Alkekengi, Linné.

The Strawberry-Tomato or Winter-Cherry. Middle and South Europe, North Africa, Middle Asia, extending to Japan, said to have come originally from Persia. A perennial herb. The berry, which is red and of a not unpleasant taste, has some medicinal value. The leaves contain a bitter principle: Physalin.

Physalis angulata, Linné.

In many tropical countries, extending as a native plant to the northern parts of the United States and to Japan. An annual herb. Yellowish; the berries edible. P. minima, L. (P. parviflora, R. Br.), appears to be a variety and extends also into tropical Australia.

Physalis Peruviana, Linné.

Temperate and tropical America, widely naturalised in many countries of the warmer zones. With double inaptness called the Cape Gooseberry. A perennial herb; but for producing its fruit well, it requires early renovation. The acidulous berries can be used as well as a table-fruit as for preserves. Doubtless several other kinds of Physalis can be utilised in the same manner. In colder countries the P. Peruviana becomes annual.

Pimpinella Anisum, Linné.

The Anise-plant. Greece, Egypt, Persia. An annual. The seed-like fruits enter into various medicines and condiments, and are also required for the distillation of oil, rich in Anethol. The herbage left after obtaining the seeds serves for fodder.

Pimpinella Saxifraga, Linné.

Europe, North and. Middle Asia. A perennial herb; its root used in medicine; a peculiar volatile oil can be distilled from the root. P. magna (L.) is a closely allied species, and $\mathrm{P}$. nigra (W.) is a variety. The root of the last is particularly powerful.

Pimpinella Sisarum, Bentham. (Sium Sisarum, Linné). East Asia. A perennial herb. The bunches of small tubers afford an excellent culinary vegetable. The taste is sweet and somewhat celery-like. The roots endure frost.

Pinus Abies, Du Roi.* (Pinus Picea, Linné.) Silver-Fir, Tanne. In Middle Europe up to $50^{\circ} \mathrm{N}$. latitude, forming dense forests. A fine tree, already the charm of the ancients, attaining 200 feet in height, and twenty feet in cir- 
cumference of stem, reaching the age of 300 years. It furnishes a most valuable timber for building as well as furniture, and in respect to lightness, toughness, and elasticity it is even more esteemed than the Norway Spruce, but is not so good for fuel or for charcoal. It also yields a fine white resin and the Strassburg turpentine, similar to the Venetian.-Beside the above normal form, the following two main varieties occur:--P. Abies var. Cephalonica, Parlatore (P. Cephalonica, Endl.). Greece, 3000 to 4000 feet above the sea. A tree sixty feet high, with a stem circumference of ten feet. The wood is very hard and durable, and much esteemed for building. General Napier mentions that in pulling down some old houses at Argostoli, which had been built 150 to 300 years, all the wood-work of this Fir was found as hard as Oak and perfectly sound. P. Abies var. Nordmanniana, Parlatore (P. Nordmanniana, Steven). Crimea and Circassia, 6000 feet above the sea. This is one of the most imposing Firs, attaining a height of 100 feet, with a perfectly straight stem. It furnishes a valuable building-timber. The Silver-Fir is desirable for our mountain-forests.

Pinus alba, Aiton.

White Spruce. From Canada to Carolina, up to the highest mountains. It resembles P. Picea, but is smaller, at most fifty feet high. Eligible for our alpine country.

Pinus Alcocquiana, Parlatore.

Japan, at an elevation of 6000 to 7000 feet. A fine tree, 120 feet high, with very small blue-green leaves; the wood is used for light household furniture.

Pinus amabilis, Douglas.

Californian Silver-Fir. North California, at an elevation of 4000 feet. A handsome Fir, 200 feet high, circumference of stem twenty-four feet; the stem is naked up to 100 feet.

Pinus Australis, Michaux.*

Southern or Swamp Pine, also called Georgia, Yellow Pitch or Broom Pine. In the Southern States of North America. The tree attains a height of seventy feet. It furnishes a good timber for furniture and building. It is this tree, which forms chiefly the extensive Pine-barrens of the United States, and yields largely the American turpentine, as well as resin, pitch and tar. Porcher observes that the tree shoots up devoid of branches for sometimes as much as sixty feet, and he calls it "one of the greatest gifts of God to man." The emanations from Pines, particularly the very resinous species, are antimalarian and antiseptic, as proved by residences near Pineforests, and by the use of hospital buildings constructed of Pine-wood. 
Pinus Ayacahuite, Ehrenberg. (P. Loudoniana, Gordon.) In Mexico, at an elevation of 8000 to 12,000 feet. An excellent Pine, 100 to 150 feet high, with a stem-diameter of three to four feet. Yielding a much-esteemed white or sometimes reddish timber.

Pinus balsamea, Linné.

Balsam-Fir, Balm of Gilead Fir. Canada, Nova Scotia, New England. An elegant tree, forty feet high, which with Pinus Fraseri yields the Canada-Balsam, the well-known oleo-resin. The timber is light, soft and useful for furniture. It thrives best in cold swampy places. Eligible for our alps.

Pinus bracteata, D. Don.

Southern California, up to 6000 feet. A very handsome tree, attaining 150 feet in height, with a slender, perfectly straight stem, not more than two feet in circumference. The resin is used for incense.

Pinus Brunoniana, Wallich. ( $P$. dumosa, D. Don.) Himalaya, descending to 8000 and ascending to 10,500 feet. Attains a height of 120 feet, and the stem a circumference of 28 feet (J. D. Hooker). Particularly eligible for our alps. The timber is pale and soft and does not stand exposure well.

Pinus Canadensis, Linné.

Hemlock-Spruce. In Canada and over a great part of the United States, on high mountains. A very ornamental tree, 100 feet high, with a white cross-grained and inferior wood. The tree, however, is extremely valuable on account of its bark, which is much esteemed as a tanning material; it is stripped off during the summer months. The young shoots are used in making, spruce-beer.

Pinus Canariensis, C. Smith.*

Canary-Pine. Canary Islands, forming large forests at an elevation of 5000 to 6000 feet. A tree seventy feet high, with a resinous durable very heavy wood, not readily attacked by insects. It thrives well in Victoria, and shows celerity of growth.

Pinus Cedrus, Linné.

Cedar of Lebanon. Together with the Atlas-variety on the mountains of Lebanon and Taurus, also in North Africa. The tree grows to a height of 100 feet, and attains a very great age; the wood is of a light reddish colour, soft, easy to work, and much esteemed for its durability.

Pinus Cedrus, var. Deodara.*

Deodar-Cedar. On the Himalaya mountains, 3000 to 12,000 above the sea-level. A majestic tree, reaching a height of 
more than 200 feet and sometimes 30 feet in circumference of stem. The wood is of a light-yellow colour, very closegrained and resinous, strongly and agreeably scented, light, extremely durable, well resisting the vicissitudes of a variable clime, and furnishes one of the best building-timbers known. Pillars of Kashmir mosques of this wood are found sound after 400 years, and bridges of still greater antiquity are in existence. White ants hardly ever attack the heartwood. Boats built of this wood last forty years. It is also extensively used for canal-edges and for railways. The tree should not be felled too young. It also yields a good deal of resin and turpentine. A humid clime very much accelerates the growth of this Pine, which in our forest-ranges would come best and quickest to its development.

Pinus Cembra, Linné.

On the European Alps, also in Siberia and Tartary. The tree attains a height of 120 feet, the stem upwards of four feet in diameter; the wood is of a yellow colour, very soft and resinous, of an extremely fine texture and is extensively used for carving and cabinet work. The seeds are edible, and when pressed yield a great quantity of oil. A good turpentine is also obtained from this Pine.

Pinus cembroides, Zuccarini. (P. Laveana, Schiede and Deppe.)

Mexican Swamp-Pine. A small tree, thirty feet high, growing at an elevation of 8000 to 10,000 feet. The timber is not of much use, but the seeds are edible and have a very agreeable taste.

Pinus Cilicica, Antoine and Kotschy.

Cilician Silver-Fir. Asia Minor. 4000 to 6500 feet above sea-level. A handsome tree of pyramidal growth, 160 feet high. The wood is very soft, and used extensively for the roofs of houses, as it does not warp.

Pinus contorta, Douglass. (P. Bolandri, Parlatore.)

On high damp ranges in California, attaining fifty feet in height, also abundant on the mountains of Colorado, and very eligible for clothing rocky hill-sides (Meehan). In California it forms dense thickets along the coast, and is in this respect as valuable as $\mathrm{P}$. Laricio, P. Pinaster, and P. Haleppensis in Europe, as a shelter-tree in stormy localities.

Pinus Coulteri, D. Don.

California, on the eastern slope of the coast range, at an elevation of 3000 to 4000 feet. A Pine of quick growth, attaining a height of about 100 feet, with a trunk up to four feet in diameter; it has the largest cones of all Pines. 
Pinus densiflora, Siebold and Zuccarini.

Japan, in the interior of Nipon, where it forms, along with P. Massoniana, extensive forests at 1000 to 2000 feet above sea-level. The timber is excellent for building.

Pinus Douglasii, Sabine.*

Oregon-Pine, called also the Yeilow Pine of Puget Sound, where it yields the principal timber for export, and is therefore of great commercial value in the lumber-trade. The maximum height known is 400 feet, the greatest diameter of the stem 14 feet. The timber is fine and clear-grained, splendid for masts and spars, also for flooring, being for that purpose regarded as the best of California (Bolander). It is the strongest wood on the North Pacific coast, both in horizontal strain and perpendicular pressure. Sub-alpine localities here should be extensively planted with this famous tree. It requires deep and rich soil, but likes shelter ; its growth is at the rate of the Larch; it passes in various localities as Black and Red Spruce. P. Lambertiana yields also much of the flooring-wood in California. Wood firm, heavy and solid. Both in clayey and light. soil it attains fifty feet in about eighteen years; it requires however a moist forest-clime for rapid growth.

Pinus excelsa, Wallich.*

The Lofty or Bootan Pine. Himalaya, forming large forests at from 5000 to 12,500 feet elevation, also in Macedonia and MTontenegro. A fine tree, 150 feet high, furnishing a valuable, close-grained, resinous, soft and easily workable wood, ranking among Himalayan Pine-woods for durability next to Deodar-timber (Stewart and Brandis). It also furnishes a good quantity of turpentine.

Pinus firma, Antoine.

North Japan, at 2000 to 4000 feet above the sea-level. A lofty tree of the habit of the Silver-Fir. The timber is white, soft and fine-grained, employed particularly by coopers and upholsterers.

Pinus flexilis, James.

The White Pine of the Rocky Mountains, from New Mexico to British Columbia, ascending to 12,000 feet. A valuable Fir for cold regions. It attains a height of 100 feet. Wood pale and compact.

Pinus Fortunei, Parlatore.

China, in the neighbourhood of Foo-Chow-Foo. A splendid tree, seventy feet high, somewhat similar in habit to $P$. Cedrus. 
Pinus Fraseri, Pursh.

Double Balsam-Fir. On high mountains of Carolina and Pennsylvania. This tree, which gets about twenty feet high, yields with $\mathrm{P}$. balsamea Canada-Balsam.

Pinus Gerardiana, Wallich.

Nepal Nut-Pine. In the north-eastern parts of the Himalaya at an elevation of 10,000 to 12,000 feet, forming extensive forests. The tree gets fifty feet high, with a comparatively short stem, and produces very sweet edible seeds, also turpentine. In reference to the nut-like seeds, the proverb prevails at Kunawar-"One tree a man's life in winter."

Pinus glabra, Walter.

Carolina. Allied to P. mitis. It attains, according to Chapman, a height of sixty feet. Porcher compares the wood to that of P. Strobus.

Pinus grandis, Douglas.

Great Silver-Fir of North California. A splendid Fir, 200 feet high and upwards, growing best in moist valleys of high ranges; the wood is white and soft.

Pinus Griffithii, Parlatore. (Larix Griffithii, J. Hooker and Thomson).

The Himalayan Larch. Descends to 8000 feet and ascends to 12,000 feet. Timber pale, soft, without distinct heartwood, one of the most durable of all Pine-timbers (Stewart and Brandis). P. Ledebourii, Endlicher, is the Siberian Larch.

Pinus Haleppensis, Miller.

Aleppo-Pine. South Europe and North Africa. This wellknown Pine attains a height of eighty feet, with a stem of from four to five feet in diameter. The timber of young trees is white, of older trees of a dark colour; it is principally esteemed for ship-building, but also used for furniture. The tree yields a kind of Venetian turpentine, as well as a valuable tar. Although ascending mountains in South Europe to the height of 4000 feet, it thrives best in loose coast-sands, where in ten years it will attain to twenty-five feet, and finally will become a larger tree than on firm lands. We find the Haleppo-Fir one of our best avenue-trees, as here first proved by the writer. P. maritima is a variety of this species. Content with the poorest and driest localities and rapid of growth.

Pinus Hartwegii, Lindley.

Mexico, 9000 to 13,000 feet above sea-level. A Pine fifty feet in height, with a very durable wood of a reddish colour; it yields a large quantity of resin. 
Pinus Hudsonica, Poiret. (P. Banksiana, Lamb.)

Grey Pine. North America, up to $64^{\circ} \mathrm{N}$. latitude. Height of tree forty feet, in the cold north only a shrub. The wood is light, tough, and easily worked.

Pinus Jeffreyi, Murray.

North California, on a sterile sandy soil. A noble Pine, 150 feet high; stem four feet thick.

Pinus Jezoensis, Antoine and Endlicher.

Japan. A large tree, with light, soft, smooth timber, used principally for household utensils.

Pinus Kæmpferi, Lambert.

Chinese Larch; also called Golden Pine. China. This is the handsomest of all the Larches. It is of quick growth, and attains a height of 150 feet. The leaves, which are of a vivid green during spring and summer, turn to a golden yellow in autumn. The wood is very hard and durable.

Pinus Koraiensis, Siebold and Zuccarini.

China and Japan. A handsome tree, thirty to forty feet high, producing edible seeds.

Pinus Lambertiana, Douglas.*

Giant or Sugar Pine. North-West coast of America, mostly in great altitudes. A lofty tree, of rapid growth, upwards of 300 feet high, with a straight naked stem of from twenty to sixty feet in circumference. It thrives best in sandy soil, and produces a soft, white, straight-grained wood, which for inside work is esteemed above any other Pine in California, and furnished in large quantities. The tree yields an abundance of remarkably clear and pure resin, of sweet taste, used instead of sugar by the natives. The cones are eighteen inches long; the seeds are edible, and used as food by the natives. Would come best to perfection in the humid regions of our higher mountains. The timber serves also for flooring.

Pinus Laricio, Poiret.*

Corsican Pine. South Europe. It attains a height of 120 feet. The wood is white, towards the centre dark, very resinous, coarse-grained, elastic and durable, and much esteemed for building, especially for waterworks. There are three main varieties of this Pine, viz.:-P. L. Poiretiana, in Italy; P. L. Austriaca, in Austria; P. L. Pallasiana, on the borders of the Black Sea. The tree grows best in calcareous soil, but also in poor sandy soil, where, however, the timber is not so large nor so good. It yields all the products of $\mathrm{P}$. silvestris, but in greater quantities, being perhaps the most resinous of all Pines. 
Pinus Larix, Linné.

Common Larch; deciduous. On the European Alps, up to 7000 feet. It attains a height of 100 feet, sometimes rising even up to 160 feet, and produces a valuable timber of great durability, which is used for land and water buildings, and much prized for ship-building. . The bark is used for tanning and dyeing. The tree is of great importance for its yield of the Venetian turpentine, which is obtained by boring holes into it in spring; these fill during the summer, supplying from half to three-quarters of a pint of turpentine. In Piedmont, where they tap the tree in different places and let the liquid continually run, it is said that from seven to eight pints may be obtained in a year, but the wood suffers through this operation. P. L. var. Rossica, Russian Larch, grows principally on the Altai Mountains, from 2500 to 5500 feet above sea-level; it attains a height of eighty feet. The species would be important for our upland country.

Pinus leiophylla, Schiede and Deppe.

7000 to 11,000 feet up on the mountains of Mexico. A tree ninety feet high. The wood is excessively hard.

Pinus leptolepis, Siebold and Zuccarini.

Japan Larch. In Japan, between $35^{\circ}$ and $48^{\circ} \mathrm{N}$. latitude, up to an elevation of 9000 feet. The timber is highly valued by the Japanese.

Pinus longifolia, Roxburgh.*

Emodi-Pine or Cheer-Pine. On the Himalaya Mountains, from 2000 to 9000 feet. A handsome tree with a branchless stem of fifty feet, the whole tree attaining a maximum height of somewhat over 100 feet, the girth of the stem twelve feet. The wood is resinous, and the red variety useful for building; it yields a quantity of tar and turpentine. The tree stands exposure and heat well.

Pinus Massoniana, Lambert. (P. Sinensis, Lamb.) China and Japan. This Pine attains a height of sixty feet, and supplies a resinous, tough and durable wood, used for buildings and furniture. The roots, when burned with the oil of Brassica Orientalis, furnish the Chinese Lampblack.

Pinus Menziesii, Douglas.

North-West America. A very handsome tree, which grows to a height of seventy feet, and furnishes a valuable timber; it thrives best in moist ground.

Pinus Mertensiana, Bongard.

Californian Hemlock-Spruce. North-West America. The wood is white and very soft, but is often used for building. 
The tree is from 100 to 150 feet high, witl a stem of four to six feet in diameter.

Pinus mitis, Michaux.

Yellow Pine of North America. In dry sandy soil, attaining a height of sixty feet. Wood durable, fine-grained, moderately resinous, valuable for flooring.

Pinus monophylla, Torrey. (P. edulis, Engelmann.)

Stone or Nut Pine of California, on the Sierra Nevada and Cascade Mountains, 6500 feet. It thrives best in dry limestone soil. The seeds are edible, of an almond-like taste, and consumed in quantity by the natives. Height of tree generally about thirty-five feet, but occasionally as much as eighty feet; stem not of great thickness.

Pinus montana, Du Roi. (P. Pumilio, Hænke.)

On the Alps and Carpathians up to the highest points, covering large tracts, and thriving on the poorest soil. The tree, which grows about twenty-five feet high, in favourable localities fifty, yields much oil of turpentine. The wood is used for carving and for firewood. Only available to advantage for our highlands.

Pinus Montezumæ, Lambert. ( $P$. Devoniana, Lindley.) (P. Grenvillece, Gordon.)

Mexico. A handsome Pine, eighty feet high; wood white, soft and resinous.

Pinus monticola, Douglas.

California, at an elevation of 7000 feet. It thrives best in poor soil of granite formation, and attains the height of 200 feet, with a stem of one and a-half to four feet thick. The wood is white, close-grained.

Pinus muricata, D. Don.

Bishop's-Pine. California. Found up to 7500 feet. This Pine grows to about forty feet.

Pinus nigra, Aiton.

Black Spruce. North-East America. Occurring extensively between $44^{\circ}$ and $53^{\circ} \mathrm{N}$. latitude. This tree, which is termed Double Spruce by the Canadians, attains a height of seventy feet, and furnishes a light elastic timber of pale colour, excellent for yards of ships. The young shoots are used for making spruce-beer, and the small roots serve as cords. It likes swampy forest-land.

Pinus nobilis, Douglas.

Noble White Fir. North-West Coast of America, on the Columbia-River and the mountains of North California, 
where it forms extensive forests at 6000 to 8000 feet. A majestic tree, 150 to 200 feet high, with regular horizontal branches.

\section{Pinus' orientalis, Linné.}

Sapindus-Fir. In A sia Minor, at 4000 feet. The tree rises to about eighty feet, and resembles somewhat the Norway Spruce. The wood is exceedingly tough and durable.

Pinus parviflora, Siebold.

In Japan. It only gets about twenty-five feet high; but is much used as an avenue-tree. Wood for fine furniture and boat-building.

Pinus Pattoniana, Parlatore.

California, 5000 to 6000 feet above sea-level. A very fine Fir, 300 feet high, with a perfectly straight stem. The wood is hard, of a reddish colour, with handsome veins; but poor in resin.

Pinus patula, Schiede and Deppe.

In Mexico, at an elevation of 8000 to 9000 feet. A graceful Pine, eighty feet high.

Pinus pendula, Solander. ( $P$. microcarpa, Lambert.)

Small-coned American Larch, Black Larch, or Tamarack. Frequent in Vermont and New Hampshire. A Pine of pyramidal growth, 100 feet high. The timber is pale, heavy, resinous, and as highly valued as that of the Common Larch.

Pinus picea, Du Roi.* (P. Abies, Linné.)

Norway Spruce, Fichte. Middle and Northern Europe and Northern Asia, rising from the plains to an elevation of 4500 feet, and forming extensive forests. The tree attains a height of 150 feet or even more, and furnishes an excellent timber for building and furniture, commonly known under the name of White Deal. It also produces the Burgundy Pitch in quantity, while the bark is used for tanning. Though enduring our dry summers, this Spruce would have to be restricted for timber purposes to the damp mountains.

Pinus Pinaster, Solander.*

Cluster-Pine. On the shores of the Mediterranean. The tree is of quick growth, and rises up to sixty feet in height. The wood is soft and resinous; it yields largely the French turpentine. Among the best Pines for consolidation of sandy coast-land, and converting rolling sands into pasture and agricultural land. For ease of rearing and rapidity of growth one of the most important of all Pines. 
Pinus Pinceana, Gordon.

Mexico, up to 9000 feet above sea-level. A very remarkable Pine, having drooping branches like the Weeping Willow, sixty feet high. Most desirable for cemeteries.

Pinus Pindrow, Royle.

In great abundance on the spurs of the Himalaya mountains, 8000 to 12000 feet above the sea-level. A fine straightstemmed tree, 100 feet high; cones purple.

Pinus Pinea, Linné.*

Stone-Pine. Frequent in the countries bordering on the Mediterranean. Height of tree, sixty feet. The wood is whitish, light, but full of resin, and much used for buildings, furniture and ships. The seeds are edible, somewhat resembling almonds, but of a resinous though not disagreeable taste; they should be left in the cones until they are about to be used, as otherwise they speedily become rancid; they only ripen in their third year. This Pine grows as easily and almost as quickly as the Cluster-Pine.

Pinus Pinsapo, Boissier.

Spanish Fir. In Spain, on the Sierra Nevada, 4000 to 6000 feet. A tree sixty feet high, with branches from the ground. The timber is similar to that of the Silver-Fir.

Pinus ponderosa, Douglas.* ( $P$. Benthamiana, Hartweg.)

Yellow or Pitch Pine of the mountains of North-West America. Height of tree up to 225 feet, with a stem of 24 feet in circumference, of comparatively quick growth. The wood is heavy, and for general purposes preferred to that of any other Pine. Has proved well-adapted even for dry localities in Victoria.

Pinus Pseudo-Strobus, Lindley.*

In Mexico. This tree is superior in appearance to any other Mexican Pine; height eighty feet.

Pinus Pyrenaica, Lapeyrouse.

In the South of Spain and on the Pyrenees. A fine ornamental tree of quick growth, eighty feet high; the wood is pale and dry, poor in resin.

Pinus radiata, Don.* (P. insignis, Douglas.)

California. A splendid Pine, fully 100 feet high, with a straight stem two to four feet in diameter. It is of remarkably rapid growth, a seedling one year old being strong enough for final transplantation; it has been noticed to grow fully five feet in a year, in light soil near Melbourne. In the United Kingdom it suffers greatly from the attacks of the Pine-beetle, Hylurgus piniperda (Lawson). The wood is tough, and much sought for boat-building and various utensils. This tree can be utilised for obtaining tar and pitch. It bears exposure to the sea at the very edge of the coast. 
Pinus religiosa, Humboldt.

Oyamel-Fir. Mexico, 4000 to 9000 feet above the sea-level. A magnificent tree with silvery leaves, growing 100 feet high; stem six feet in diameter; the wood is particularly well fit for shingles and laths.

Pinus resinosa, Solander.

Red Pine. North America, principally Canada and Nova Scotia. It gets eighty feet high and two feet in diameter; the wood is red, fine-grained, heavy and durable, very resinous, and is used for ship-building.

Pinus rigida, Miller.*

American Pitch-Pine. From New England to Virginia. It grows to a height of eighty feet; the timber from light gravelly or rocky soil heavy and resinous, from damp alluvial soil light and soft ; used for building ; but the tree is principally important for its yield of turpentine, resin, pitch and tar. The tree is suitable for sea-shores; it will also grow in the driest localities, nor is it readily susceptible to injury from fire.

Pinus rubra, Lambert.

Hudson's Pine, Red Spruce. Nova Scotia, Newfoundland and other northern parts of the American Continent. A straight slender tree, seventy feet high; the wood is of a reddish colour and highly esteemed.

Pinus Sabiniana, Douglas.*

Californian Nut-Pine or White Pine. Most frequent on the western slopes of the Rocky Mountains, intermixed with other trees; 150 feet high; stem three to five feet in diameter. The wood is pale and soft; the clustered heary cones attain a length of one foot. The seeds are edible. Proves in dry localities of Victoria to be of quick growth.

Pinus serotina, Michaux.

Pond-Pine. Southern States of North America, in black morassy soil, principally near the sea-coast. It is fifty feet high, stem eighteen inches in diameter. The wood is soft.

Pinus Sibirica, Turczaninow. (P. Pichta, Fischer.)

Siberian Pitch-Fir. On the Altai Mountains; it reaches a height of fifty feet.

Pinus silvestris, Linné.*

Scotch Fir, Foehre. Middle and Northern Europe, up to $70^{\circ} \mathrm{N}$. latitude, and North Asia, thriving best in sandy soil. A very valuable tree, fully one hundred feet high, growing to the age of about 120 years. The Red Baltic, Norway or Riga deals are obtained from this Pine, as well as a large portion of the European Pine-tar. Proves well-adapted 
even for the drier parts of Victoria.-The leaves of Pines can be well converted into material for pillows and mattresses, with the great recommendation of healthiness for such a purpose.

Pinus Smithiana, Lambert. ( $P$. Khutrow, Royle.)

In the Himalayan Mountains at elevations from 6000 to 11,000 feet. Attains a height of 150 feet, and the stem a girth of 15 feet. The wood is pale, even and straightgrained, but only durable under shelter.

\section{Pinus Strobus, Linné.*}

Weymouth-Pine or American White Pine. North-Eastern America, growing on any soil, but particularly adapted for deep rich soil in mountain-valleys ; known to reach a height of 270 feet, with a stem of 8 feet diameter. The wood is soft, white, light, free of knots, almost without resin, easy to work, and much esteemed for masts, flooring, oars, \&c. It yields American turpentine and gallipot.

\section{Pinus Tæda, Linné.}

Frankincense- or Loblolly-Pine. Florida and Virginia, in sandy soil, attaining a height of eighty feet; the timber is used for pumps, \&c. It also yields turpentine in good quantity, though of inferior quality. The tree likes the regions near the coast, hence can be utilised for raising Firforests on sea-sand.

Pinus tenuifolia, Bentham.

Mexico, at an elevation of 5000 feet, forming dense forests. Height of tree, 100 feet, stem up to five feet in diameter.

Pinus Teocote, Chamisso and Schlechtendal.

Okote or Torch-Pine. Mexico, 5000 to 8000 feet above the sea-level. Tree 100 feet high, stem three to four feet in diameter; the wood is resinous and durable.

Pinus Tsuga, Antoine.

In the Northern provinces of Japan, 6000 to 9000 feet above the sea. The tree gets only twenty-five feet high; its timber is highly esteemed for superior furniture, especially by turners.

Pinus Webbiana, Wallich.

King-Pine, Dye-Pine. On the Himalaya Mountains, at an elevation of from 7000 to 13,000 feet. A splendid Fir, reaching a height of 150 feet, the stem a circumference up to thirty feet. In compact forests the bare trunk is very short. The wood is of a pale colour, soft, coarse-grained, and very resinous; the natives extract a splendid violet dye from the cones. 
Pipturus propinquus, Weddell.

Insular India, South Sea Islands and warmer parts of East Australia. This bush is higher and rather more hardy than Boehmeria nivea; but in fibre it is similar to that plant. $\mathbf{P}$. velutinus (Wedd.) is closely allied. The few other species serve probably as well for fibre.

Pircunia dioica, Moquin.

Southern Brazil and La Plata States. A deciduous tree, for shady avenues grown in South Europe, as well as in many tropical countries, tested by the writer to be hardy in our lowlands. It is comparatively quick of growth.

Pisonia aculeata, Linné.

Tropical and sub-tropical countries of both hemispheres, extending as a native plant into New South Wales. This rambling prickly bush can be chosen for hedge-copses.

Pistacia Lentiscus, Linné.

The Mastic-tree. Mediterranean regions. A tall evergreen bush, exuding the Mastic-resin mostly through incisions into its bark. In Morocco it is extensively used for hedges.

Pistacia Terebinthus, Linné.

Countries around the Mediterranean Sea. A tall bush or small tree with deciduous foliage. The fragrant Cyprian or Chio Turpentine exudes from the stem of this species.

Pistacia vera, Linné.

Indigenous in the Orient, as far as Persia. A deciduous tree, thirty feet high, yielding the Pistacia-nuts of commerce, remarkable for their green almond-like kernels. The likewise deciduous P. Atlantica (Desfontaines) and the evergreen South European P. Lentiscus (L.), furnishing the Mastic, grow rarely to the size of large trees.

Pisum sativum, Linné.*

The Common Pea. Mediterranean countries and Western Asia. This annual of daily use could hardly be left disregarded on this occasion. Suffice it to say, that the herbage as a nutritious fodder deserves more attention than it receives. The green fruit contains Inosit-sugar and Cholestrinfat. For field-culture a sandy calcareous loam should be chosen for this plant, to ensure rich and safe harvests. A second species, P. Aucheri (Jaub. and Spach.), which is perennial, occurs in alpine elevations on the Táurus.

Pittosporum tenuifolium, Banks and Solander.

New Zealand. This with P. eugenioides has proved exquisite for tall garden-hedges, for which these and several other species were first brought into notice by the writer. Our 
native $P$. undulatum is rather adapted for copses, and deserves cultivation also for the sake of its fragrant flowers, from which an essential oil can be distilled.

Planera aquatica, Gmelin.

North America. An elm-like tree, which can be chosen for plantations in wet localities. The wood is hard and strong.

Platanus occidentalis, Linné.

The true Plane-tree of the east part of North America. More eligible as an avenue-tree than as a timber-tree; diameter of stem at times fourteen feet; wood dull red, not readily attacked by insects. It has been successfully planted in morassy places, to cope with miasmatic effluvia.

\section{Platanus orientalis, Linné.}

The Plane-tree of South Europe and Middle Asia. One of the grandest trees for lining roads and for street-planting, deciduous like the other Planes, rather quick of growth, and not requiring much water; attains a height of ninety feet. It resists, in large towns such as London, the smoke better than any other tree, growing even under such disadvantage vigorously. The wood is well adapted for furniture and other kinds of cabinet-work.

Platanus racemosa, Nuttall.

The Californian Plane-tree. A good promenade-tree, which, according to Professor Bolander, grows more rapidly and more compact than P. occidentalis. Wood harder and thus more durable than that of $\mathrm{P}$. occidentalis, also less liable to warp.

Plectocomia Himalaiana, Griffith.

Sikkim, up to 7000 feet. This Rattan-Palm requires moist forest-land. Its canes are not durable, but this palm is an object worthy of scenic horticulture and would prove the hardiest among its congeners.

Plectronia ventosa, Linné.

South Africa. A hedge-bush, like P. ciliata (Sonder) and P. spinosa (Klotzsch).

Poa Abyssinica, Jacquin.

The Teff of Abyssinia. An annual grass. The grain there extensively drawn into use for bread of an agreeable acidulous taste.

Poa airoides, Koeler. (Catabrosa aquatica, Beauvois.) Europe, North Africa, North and Middle Asia, North America. The Water Whorl-grass. A creeping grass, suitable for soil subject to inundation. 
Poa alpina, Linné.

Alpine and Arctic Europe, Asia and North America. Deserves to be transferred to our snowy mountains as a nutritious perennial pasture-grass. P. Sudetica (Haenke) and P. hybrida (Gaudin) are mentioned also as excellent alpine grasses.

Poa angustifolia, Linné.

Europe, North Asia, North America. A perennial pasturegrass, allied to P. nemoralis. An excellent grass for moist meadows and river-banks. Poa fertilis (Host.) may be a mere variety of this species.

Poa aquatica, Linné. (Glyceria aquatica, Smith.)

Europe, North and Middle Asia, North America. This conspicuous Water-grass attains a height of six feet. It is perennial, and deserves naturalisation in our swamps. It produces a large bulk of foliage, and may be disseminated for fodder purposes.

Poa Brownii, Kunth. (Eragrostis Brownii, Nees.)

Tropical and Eastern extra-tropical Australia, extending rather widely through our colony. It is here mentioned as a valuable perennial species, keeping beautifully green in our driest summer, even on poor soil. The section Eragrostis of the genus Poa contains numerous species in the hotter parts of the globe. Of these many would doubtless be hardy here and prove of pastoral value.

Poa Canadensis, Beauvois.

The Rattlesnake-grass of South-East America. A valuable swamp-grass.

Poa cynosuroides, Retz.

North-Eastern Africa, South Asia. A harsh perennial grass, not serviceable for fodder, but mentioned by Royle as a fibreplant of North-Western India, where it is valued as a material for ropes. In this respect it many not surpass the rough tufty variety of our own Poa caespitosa, F., so common on our river-banks, from the leaves of which excellent nets are made by the natives.

Poa digitata, R. Brown.

South-Eastern and Central Australia. Valuable for fixing wet river-banks and slopes. It forms large stools. Cattle and horses relish it.

Poa distans, Linné.

Europe, North Africa, Middle and Northern Asia, North America. Perennial. It is one of the limited number of tender grasses, suited for moist saline soil, and thus affords pasturage on coast marshes. 
Poa fertilis, Host. (P. serotina, Ehrhart.)

Europe, North Asia, North America. Perennial ; important for wet meadows, even with sandy sub-soil. Its foliage is tender, tasty and nourishing. In mixtures of grasses it keeps up the growth late into the autumn.

Poa fluitans, Scopoli. (Glyceria fluitans, R. Brown.) Europe, North Africa, Middle and North Asia, North America. The Manna-grass. Perennial. Excellent for stagnant water and slow-flowing streams. The foliage is tender. The seeds are sweet and palatable, and are in many countries used for porridge.

Poa maritima, Hudson.

Europe, North Africa, North Asia, North America. Its long creeping roots help to bind the coast-sand. This grass can also be depastured.

Poa nemoralis, Linné.

Europe, North and Middle Asia, North America. This perennial grass can be grown on shady forest-land, as the name implies, but it accommodates itself also to open places, and will grow even among rocks. It endures alpine winters. According to Lawson no better grass exists for displacing weeds on pleasure-lawns; the same may be said of Poa compressa, $\mathbf{L}$.

Poa pratensis, Linné.

The ordinary English Meadow-grass. A perennial species, fit for any meadows, thriving early, and able to live also in alpine localities. Better adapted for pasture than hay. It is suitable for moor-land, when such is laid dry; although it shoots only once in the season into flower, yet it forms a nutritious fodder, even on comparatively poor soil. It resists drought. It forms excellent sward, and with advantage can be used for intermixing it with other pasture-grasses.

Poa trivialis, Linné.*

Europe, North Africa, Middle and Northern Asia. Also a good perennial grass for mixture on pasture-land. One of the best grasses for sowing on ground recently laid dry. Sinclair regarded the produce of this Poa as superior to many other kinds, and noticed the marked partiality which horses, oxen and sheep evince towards it. To thrive well it wants rather moist and rich soil and sheltered places. It is a later grass than $\mathrm{P}$. pratensis, is well adapted for hay and gives good after-growth (Langethal).

These few species of Poa have been singled out as recommendable, because they are well tested. Future experiments beyond Europe will add others to lists of recommendations like this. 
Podachænium alatum, Bentham. (Ferdinanda eminens, Lagasca.)

Central America, up to heights of 8000 feet. A tall shrub, for the grandeur of its foliage in requisition for scenic effects.

Podophyllum peltatum, Linné.*

North America. A perennial forest-herb, not without importance for medicinal purposes. The root contains the bitter alkaloid Berberin. Podophyllum Emodi (Wall.), occurring in the Indian mountains at a height from 6000 to 14,000 feet, can probably be used like the American species. The berries of both are edible, though the root and leaves are poisonous.

Pogostemon Patchouli, Pellet.

Mountains of India. A perennial herb, famed for its powerful scent arising from a volatile oil. P. parviflorus (Benth.) and P. Heyneanus (Benth.) belong to this species.

Polygala crotalaroides, Hamilton.

Temperate Himalaya. Praised as an ophidian alexipharmic.

To several other species both of the eastern and western hemispheres similar properties are ascribed, but we are almost entirely without any reliable medical testimony on these and many other vegetable antidotes against snakepoison.

Polygala Senega, Linné.

North America. A perennial herb. The root is of medicinal value.

Polygaster Sampadarius, Fries.

South-Eastern Asia. One of the most palatable of all truffles.

Polygonum tinctorium, Loureiro.

Japan and China. An annual herb, deserving attention and local trials here, as yielding a kind of Indigo. Its growth would be vigorous.

Populus alba, Linné.

The Abele or White Poplar of Europe and Middle Asia, growing in the Himalayas up to 10,000 feet, ceasing at 4000 feet. Height ninety feet. It proved here an excellent avenue-tree, even in comparatively waterless situations, and gives by the partial whiteness of its foliage a pleasing effect in any plantation. The wood is pale with a reddish tinge, brown near the centre, soft and light, it can be used for flooring; it is particularly sought for trays, bowls, bellows and shoe-soles; also according to Porcher for wooden structures under water. "Sparterie" for plaiting is obtained from the wood-shavings. The wood of this and some 
other Poplars is easily converted into paper-pulp, which again is cheaply bleached. Lines of Poplars along foreststreams prevent the progress of wood-conflagrations. The roots of Poplars spread widely. P. canescens $(\mathrm{Sm}$.$) , the$ Grey Poplar, is either a variety of the Abele or its hybrid with the Aspen, and yields a better timber for carpenters and millwrights.

Populus balsamifera, Linné.

The Tacamahac or Balsam-Poplar of the colder, but not the coldest parts of North America, also in Siberia and the Himalayan Mountains, where it ranges from 8000 to 14,000 feet. It attains a height of eighty feet. The tree may be lopped for cattle-fodder (Stewart and Brandis). Mr. Meehan says that it will grow near the ocean's brink. Its variety is P. candicans (Ait.).

Populus eiliata, Wallich.

Himalaya, from 4000 to 10,000 feet. Height up to 70 feet with a straight trunk, which attains ten feet in girth.

Populus Euphratica, Olivier.

From Algeria, dispersed to the Himalayas and Songaria, up to 13,500 feet. Height up to fifty feet. Wood harder than that of most Poplars, the inner wood turning black in old trees; it is used for planking and boat-building (Stewart and Brandis), also for beams, rafters, boxes, panneling, turnery. Cattle will browse on the leaves. This is the Willow of the 137th Psalm.

Populus grandidentata, Michaux.

North America. Sixty feet high. The Soft Aspen. P. angulata (Ait.) is another large Poplar of North-Eastern America.

Populus heterophylla, Linné.

The Downy Poplar of North America. Height sixty feet.

Populus monilifera, Aiton. (P. Canadensis, Desfontaines.) The Cottonwood-tree of North America. Height 100 feet. One of the best Poplars for the production of timber. It is recommended to obtain for planting along streets or near dwellings cuttings from male trees only, as the minute downy seeds of the female trees are copiously wafted through the air, and have irritant effects on the respiratory organs. Of quick and luxuriant growth, thriving even in arid and exposed places.

Populus nigra, Linné.

The European Black Poplar, extending spontaneously to China; in the Himalayas up to 12,500 feet. The spreading variety one of the best of trees for lining roads. Wood 
similar to that of $\mathrm{P}$. alba. It includes $\mathrm{P}$. dilatata (Ait.) or as a contracted variety, P. fastigiata (Desf.), the LombardyPoplar. Greatest height 150 feet. Growth rapid, like that of all other Poplars. Wood soft, light and of loose texture, used by joiners, coopers and turners; also for matches ; furnishing also superior charcoal for gunpowder. Bark employed in tanning. The tree requires damp soil.

Populus tremula, Linné.

The European Aspen. Height eighty feet. It extends to Japan, where also a peculiar species, P. Sieboldii (Miq.), exists. The Aspen-wood is white and tender, and in use by coopers and joiners. Like the wood of other Poplars, much sought for paper-mills as an admixture to the pulp.

Populus tremuloides, Michaux.

The North-American Aspen. Height fifty feet. It extends west to California, where a particular species, P. trichocarpa (Torrey), occurs. All Poplars might be planted like all Willows, in our gullies, to intercept forest-fires, also generally on river-banks.

Prangos pabularia, Lindley.

Plateaux of Mongolia and Thibet. A perennial fodder-herb, much relished by sheep, eligible for cold and arid localities, and deserving naturalisation on our alpine pasture-grounds. Other perennial species exist near the Mediterranean Sea, on the Atlas, the Caucasus and the Indian Highlands. P. pabularia is regarded by some as the Silphium of Arrianus.

Pringlea antiscorbutica, W. Anderson and R. Brown.* The Cabbage or Horse-Radish of Kerguelen's Island. The perennial long roots taste somewhat like Horse-Radish. The leaves in never-ceasing growth are crowded cabbage-like into heads, beneatl which the annual flower-stalks arise. The plant ascends mountains in its native island to the height of 1400 feet, but luxuriates most on the sea-border. To Arctic and other Antarctic countries it would be a boon. Probably it would live not only on our shores, but also on our Alps. Whalers might bring us the roots and seeds of this remark. able plant, which seems to have never entered into culture yet. Not even its flowers in a perfect state are known. The plant was used by the celebrated Captain Cook and all subsequent navigators, touching at yonder remote spot, as Cabbage, and it proved to possess powerful properties against scurvy. Dr. Hooker observes, that Pringlea can sectionally be referred to Cochlearia. The whole plant is rich in a pungent volatile oil. Through culture important new culinary varieties may likely be raised from this plant The taste of this vegetable in its natural growth is like mustard 
and cress, and the Kerguelen's Land Cabbage, when boiled, proved a wholesome and agreeable substitute for the ordinary Cabbage.

Priva lævis, Jussieu.

Chili and the Argentine Republic. A perennial herb, the small tubers of which can be used for food (Philippi).

Prosopis dulcis, Kunth.

From Mexico to the southern parts of the La Plata States. A thorny shrub, growing finally to a tree, adapted for livefences. This is one of the species yielding the sweetish Algaroba-pods for cattle-fodder, and utilised even in some instances for human food. Mere varieties according to Bentham are: P. horrida, P. juliflora, P. siliquastrum, P. glandulosa. The latter variety exudes a gum not unlike Gum Arabic, and this is obtained so copiously, that children could earn two to three dollars a day in Texas while gathering it, latterly about 40,000 lbs. being bought by druggists there. The tree attains a height of thirty feet, and its wood is excessively hard. The pods of several species are rich in tannin. A short communication on the American Algaroba-trees was presented to our Parliament by the writer in 1871.

Prosopis pubescens, Bentham.

Texas, California, New Mexico. Likely available for hedges, with other species of other countries.

Prosopis spicigera, Linné.

India, extending to Persia. A thorny tree, also with edible pods, possibly hardy here. It attains a height of sixty feet, but is of slow growth. Serves for hedge-lines. It can be chosen for desert-land (Kurz).

Prosopis Stephaniana, Kunth.

Syria and Persia. A shrubby species for hedge-growth.

Prunus Americana, Marshall. (P. nigra, Aiton).

Canada, Eastern United States of America. A thorny tree, furnishing the Yellow and Red Plum of North America. The fruit is roundish and rather small, but of pleasant taste.

Prunus Amygdalus, J. Hooker. (Amygdalus communis, Linné.)

The Almond-tree. Countries around the Mediterranean Sea and Orient; really indigenous on the Anti-Lebanon, in Kurdestan, Turkestan, and perhaps on the Caucasus (Stewart). Both the sweet and bitter Almond are derived from this species. Their uses, and the value of the highly palatable oil, obtained by pressure from them, are well 
known. This oil can well be chosen as a means of providing a pleasant substitute for milk during sea voyages, \&c., by mixing, when required, with it half its weight of powdered gum arabic, and adding then successively, while quickly agitating in a stone mortar, about double the quantity of water. Thus a palatable and wholesome sort of cream for tea or coffee is obtained at any moment. There exist hard and soft-shelled varieties of both the sweet and bitter Almond. In time, they should form an important article of our exports. Almonds can even be grown on sea shores. The crystalline Amygdalin can best be prepared from bitter Almonds, through removing the oil by pressure, then subjecting them to distillation with alcohol, and finally precipitating with ether. The volatile bitter Almond-oil-a very dangerous substance-is obtained by aqueous distillation. Dissolved in alcohol, it forms the Essence of Almonds. This can also be prepared from peach-kernels.

\section{Prunus Caroliniana, Aiton.}

Southern States of North America. Porcher regards it as one of the most beautiful and manageable evergreens of those States. It can be cut into any shape, and is much employed for quick and dense hedges. It can be grown on coast-land.

Prunus Chisasa, Michaux.

North America, west of the Mississippi. On the prairies it is only three to four feet high. Fruit spherical, red, rather small, with a tender usually agreeable pulp. Other species with edible fruit occur in North America, such as P. pumila, L., P. Pennsylvanica (L.), P. Virginiana (L.), P. serotina (Ehrh.), but their fruits are too small to render these plants of importance for orchard-culture, though they may also become enlarged by artificial treatment.

Prunus ilicifolia, Nuttall.

California. In deep rich soil, valuable for evergreen hedges of intricate growth.

Prunus Mahaleb, Linné.

Middle and South Europe. It deserves some attention on account of its scented seeds and also odorous wood, the latter used in turnery for pipes and other articles. The flowers are in use for perfumes.

Prunus maritima, Wangenheim.

The Beach-Plum of North America. A shrubby species, of service not only for covering coast-sands, but also for its fruit, which is crimson or purple, globular and measuring from a-half to one inch. It is not necessary to enter here any notes on the generally known species of Prunus, which have engaged already for years the keen attention of many 
orchard-cultivators also in this colony. Thus we possess in this country numerous though not all the best varieties, of the Cherry, P. avium (L.) and P. Cerasus (L.), of the Plum, P. domestica (L.), of the Apricot, P. Armeniaca (L.) and of the Cherry-Plum, P. myrobalana (L.), the latter Canadian, the others European and Oriental. Information on these and other varieties, to which we have added independently also here, may be sought in "Hogg's Fruit Manual." The Almond (Amygdalus communis, L.) and the Peach (Amygdalus Persica, L.) belong also generically to Prunus, as indicated in 1812 by Stokes ("Bot. Mat. Med.," iii., 101) and in 1813 by F. G. Hayne ("Arznei-Gewächse," iv., 38) and finally settled by J. D. Hooker (Benth. and Hook., gen. pl. i., 610), for which therefore now the names P. Amygdalus and P. Persica should be adopted. The latter came originally from China, while P. Armenica seems indigenous to the Caucasian regions, and perhaps the Himalayas, and P. Cerasus originated from West Asia.

\section{Prunus spinosa, Linné.}

The Sloe or Blackthorn. Wild in many parts of Europe. With its flowers it is one of the earliest plants to announce the spring. Its tendency to throw out suckers renders the bush less adapted for hedges of gardens than of fields, but these suckers furnish material for walking-sticks. The small fruits can be made into preserves. P. insititia (L.), the Bullace, with larger and sometimes yellow fruits, extends, as a variety, to North Africa and Middle Asia. Dr. Hooker and other phytographers consider P. domestica not specifically distinct from P. spinosa. Of medical value are P. LauroCerasus (L.), the evergreen Cherry-Laurel from the Orient, and P. Padus (L.), the deciduous Bird's Cherry, which extends from Europe to North Africa and West Asia. These and most other species contain in their foliage and in some other parts Amygdalin. Perhaps some of the species from Eastern Asia, California and tropical America are eligible for improving their fruit through horticultural skill. The Sloe and others might with advantage be naturalised on our foreststreams.

\section{Prunus Virginiana, Linné.}

The Choke Cherry-tree of the United States. In a mild clime and fertile soil this tree attains a height of 100 feet and a stem of sixteen feet in circumference. The wood is compact, fine-grained, and not liable to warp when perfectly seasoned, of a dull, light-red tint deepening with age. The fruit finally loses its austerity. 
Psamma arenaria, Roemer and Schultes. (P. littoralis, Beauvois, Calamagrostis arenaria, Roth.)

The Moram or Marrem or Bent Grass. Sand-coasts of Europe, North Africa and Middle North America. One of the most important of reedy grasses, with long creeping roots, for binding and moving drift-sands on the sea-shore, for the consolidation of which in Europe chiefly this tall grass and Elymus arenarius are employed. Psamma Baltica ( $R$. and S.) from the Baltic and North Sea, serves the same purpose. Both can also be used in the manner of Sparta for paper material, for tying and for mats. Like Elymus arenarius it is not touched by pastoral animals. It collects the sand-heaps at the tops of ridges, while the Elymus fastens their sides.

Psidium acidum, Martius.

Higher regions on the Amazon River. A tree thirty feet high ; its Guava-fruit pale-yellow and of apple size.

Psidium Araca, Raddi.

From West India and Guiana to Peru and Southern Brazil, where it is found in dry high-lying places. This is one of the edible Guavas, recorded already by Piso and Marcgrav. The greenish-yellow berry is of exquisite taste.

Psidium arboreum, Vellozo.

Brazil; province Rio de Janeiro. This Guava-fruit measures about one inch, and is of excellent flavour.

Psidium Cattleyanum, Sabine.*

The Purple Guava. Brazil and Uruguay. One of the hardiest of the Guava-bushes, attaining finally a height of twenty feet. The purple berries are seldom above an inch long, but of delicious flavour and taste, resembling thus far strawberries. P. buxifolium (Nutt.) of Florida, seems nearly related to this species.

Psidium chrysophyllum, F. v. Mueller. (Abbevillea chrysophylla, Berg.)

The Guabiroba do mato of South Brazil. This tree attains also a height of about thirty feet. The fruit generally not larger than a cherry. Perhaps other species of the section Abbevillea would be hardy here and worthy of cultivation.

Psidium cinereum, Martius.

Brazil; provinces Minas Geraes and Sao Paulo. Also yielding an edible fruit.

Psidium cordatum, Sims.

The Spice Guava. West India. This one attains the height of a tree. Its fruit edible. 
Psidium cuneatum, Cambessedes.

Brazil, province Minas Geraes. Fruit greenish, of the size of a Mirabelle Plum.

Psidium grandifolium, Martius.

Brazil; provinces Rio Grande do Sul, Parana, Sao Paulo, Minas Geraes, where the climate is similar to Southern Queensland. A shrub of rather dwarf growth. The berries edible, size of a walnut.

Psidium Guayava, Raddi.* ( $P$. pomiferum, Linné; $P$. pyriferum, Linné.)

The large Yellow Guava. From West India and Mexico to South Brazil. For this handsome evergreen and useful bush universal attention should be secured anywhere in our warm lowlands, for the sake of its aromatic wholesome berries, which will attain the size of a hen's egg and can be converted into a delicious jelly. The pulp is generally cream-coloured or reddish, but varies in the many varieties which have arisen in culture, some of them bearing all the year round. Propagation is easy from suckers, cuttings, or seeds. Many other berry-bearing Myrtaceæ (of the genera Psidium, Myrtus, Myrcia, Marliera, Calyptranthes, Eugenia) furnish edible fruits in Brazil and other tropical countries, but we are not aware of their degrees of hardiness. Berg enumerates as esculent more than half a hundred for Brazil alone, of which the species of Campomanesia may safely be transferred to Psidium.

Psidium incanescens, Martius.

Brazil, from Minas Geraes to Rio Grande do Sul. This Guava-bush attains a height of eight feet. Berry edible.

Psidium lineatifolium, Persoon.

Mountains of Brazil. Berry about one inch diameter.

Psidium malifolium, F. v. Mueller. (Campomanesia malifolia, Berg.)

Uruguay. Berry about one inch diameter.

Psidium polycarpon, Al. Anderson.*

From Guiana to Brazil, also in Trinidad. A comparatively small shrub, bearing prolifically and almost continuously its yellow berries, which are of the size of a large cherry and of exquisite taste.

Psidium rufum, Martius.

Brazil, in the province Minas Geraes, on sub-alpine heights. This Guava-bush gains finally a height of ten feet, and is likely the hardiest of all the species producing palatable fruit. 
Pterocarpus Indicus, Roxburgh.

The Lingo of China and India. A tree of considerable dimensions, famed for its flame-red wood. It furnishes also a kind of dragon-blood resin.

Pterocarpus Marsupium, Roxburgh.

India, ascending in Ceylon and the Circars to at least 3000 feet altitude; hence this tree would doubtless grow without protection in those tracts of our colony, which are free of frost. It exudes the best medicinal kino, which contains about 75 per cent. of tannic acid. The foliage is deciduous. P. santalinus (Linné fil.), which provides the Saunders or red sandal-wood, is also indigenous to the mountains of India.

Pterocarya fraxinifolia, Kunth.

From Central Asiatic Russia to Persia. A kind of Walnuttree, which with P. stenoptera (Cas. de Cand.) on Dr. Hance's recommendation, should be adopted as trees for both ornament and timber, and so perhaps also the Japanese species.

Ptychosperma Alexandræ, F. v. Mueller.

The Alexandra-Palm. Queensland, as well in tropical as extra-tropical latitudes. The tallest of Australian Palms, and one of the noblest forms in the whole empire of vegetation. It exceeds 100 feet in height, and is likely destined to grace any shady moist grove free from frost in this and other countries, as it seems less tender than most palms. The demand for seeds has already been enormous.

Ptychosperma Cunninghami, Hermann Wendland.

East Australia, as far south as Illawarra; thus one of the most southern of all Palms. This also is a very high species, destined to take here a prominent position in decorative plantations. Several species occur in Fiji and other islands of the Pacific Ocean, and again others might be obtained from India, but they are probably not so hardy as ours. Though strictly speaking of no industrial value, these Palms are important for horticultural trade, and are objects eminently fitted for experiments in acclimation.

Ptychosperma disticha, Miquel. (Areca disticha, Griffith.) Assam, up to 4000 feet.

Ptychosperma elegans, Blume. (P. Seaforthia, Miquel; Seaforthia elegans, R. Brown.)

Littoral forests of tropical Australia. Also a lofty magnificent Feather-Palm. Its leaflets are erose. It may prove hardy.

Pueraria tuberosa, Candolle.

South Asia, up to 4000 feet. A tall woody twiner. Its large tubers are edible and might improve by culture. 
Punica Granatum, Linné.

The Pomegranate. North Africa and West Asia, in the Himalayas up to 6000 feet. Well-known for its showy habit, rich coloured flowers, peculiar fruit, and medicinal astringency, but much overlooked regarding its value as a hedge-plant.

Pycnanthemum incanum, Michaux.

North America. A perennial herb, in odour resembling both Pennyroyal and Spearmint. It likes to grow on rocky woodland, and on such it might be easily naturalised.

Pycnanthemum montanum, Michaux.

The Mountain-Mint of North America. A perennial herb of pleasant aromatic mint-like taste. These two particular species have been chosen from several North American kinds to demonstrate, that we may add by their introduction to the variety of our odorous garden-herbs. They may also be subjected with advantage to distillation.

Pyrularia edulis, Meissner.

Nepal, Khasia, Sikkim. A large umbrageous tree. The drupaceous fruit is used by the inhabitants for food. A few other species occur in Upper India, one on the high mountains of Ceylon and one in North America. The latter, P. pubera (Mich.) can be utilised for the oil of its nuts.

Pyrus coronaria, Linné.

The Crab-Apple of North America. This showy species is mentioned here as worthy of trial-culture, since it is likely that it would serve well as stock for grafting. It seems unnecessary to refer here to any of the forms of Pyrus communis (L.), P. Malus (L.), P. Cydonia (L.) and P. Germanica (J. Hooker.) (Mespilus Germanica, L.), but it may passingly be observed, that curious fruits have been produced latterly in North America by the hybridisation of the Apple with the Pear. A bitter Glycosid, namely Phlorrhizin, is obtainable from the bark of apple and pear trees, particularly from that of the root, while a volatile alkaloid, namely Trimethylamin, can be prepared from the flowers.

Pyrus Japonica, Thunberg.

Japan. One of the prettiest of small hedge-bushes. Under favourable circumstances it will produce its quince-like fruit.

Pyrus nivalis, Jacquin.

The Snow-Pear. Middle and South Europe. This would be adapted for orchards in our higher mountain-regions. The fruit becomes soft and edible through exposure to snow. P. amygdaliformis (Villars) is probably the wild state of this tree. 
Pyrus salicifolia, Linné.

Greece, Turkey, Persia, South-West Russia. Though its fruit, which slowly mollifies, is edible, this tree is mainly utilised as a superior stock for grafting.

Quercus Ægilops, Linné.

South Europe, also Syria. A nearly evergreen tree of the size of the British Oak. The cups, known as Valonia, used for tanning and dyeing; the unripe acorns, as Camata or Camatena, for the same purpose. The ripe acorns are eaten raw or boiled. The wood is capital for furniture.

Quercus agrifolia, Nee.

California and Mexico. One of the most magnificent among evergreen Oaks, with dense, widely-spreading foliage.

Quercus alba, Linné.*

The White or Quebec Oak. A most valuable timber-tree, 100 feet high; diameter of stem seven feet. Wood in use by shipbuilders, wheelwrights, coopers and other artisans.

Quercus annulata, Smith.

A large evergreen Oak of Nepal, which provides a very good timber. It does not ascend quite so high as Q. incana. Q. spicata (Smith), another very large Himalayan Oak, ascends only to 5000 feet; it is known also from Borneo, Java and Sumatra.

Quercus aquatica, Walter.

North America. Height of tree sixty feet; it furnishes a superior bark for tanning, also wood for ship-building.

Quercus Castanea, Nee.

The Mexican Chestnut-Oak. It furnishes also edible acorns.

Quercus Cerris, Linné.

South Europe, South-West Asia. Of the height of the English Oak, in suitable localities of quick growth. The foliage deciduous, or also evergreen. The wood available for wheelwrights, cabinetmakers, turners, coopers; also for building purposes. Structure of the wood similar to that of the British Oak; the sapwood larger, the heartwood of a more saturated brown, and the large rays more numerous, giving it a most varied and beautiful wainscot grain (Brandis).

Quercus Chinensis, Bunge.

North China. One of the hardiest among the evergreen Oaks. 
Quercus coccifera, Linné.

The deciduous Kermes-Oak of South Europe, North Africa. and South-West Asia. So called from the red dye furnished by the Coccus ilicis from this Oak. It also supplies tanners' bark. The huge and ancient Abraham's Oak belongs to this species.

Quercus coccinea, Wangenheim.

The Black Oak of North America. Height 100 feet; stemdiameter five feet. Foliage deciduous. The yellow dye known as Quercitron comes from this tree. It is much more powerful than that of Woad (Bancroft). With alumina the tinge of the bark is bright yellow, witl oxyde of tin it is orange, with oxyd of iron it is drab (Porcher). Q. tinctoria (Bartram) is a variety. The bark of the variety called Scarlet Oak is practically far inferior in value to that of the Black Oak (Meehan). Bark rich in tannic acid.

Quercus cornea, Loureiro.

China. An evergreen tree, forty feet high. A corns used for food.

Quercus densiflora, Hooker and Arnott.

Californian Chestnut-Oak. A large evergreen tree of beautiful outline, dense foliage and compact growth. Bark very valuable for tanning; wood however subject to rapid decay (Prof. Bolander). Quercus Douglasi is another tall Oak of California.

Quercus dilatata, Lindley.

From the Himalayas to Afghanistan, at elevations from 4500 to 10,000 feet. Height up to 100 feet; crown very shady, lopped for sheep-fodder. The hard, heavy and durable wood much used for building-purposes and implements (Madden).

uercus falcata, Michaux.

North America. A tree attaining a height of eighty feet, with a stem four feet in diameter. Foliage deciduous. It lives in dry sandy ground and can also be utilised for seacoasts. Produces an excellent tanner's bark and also galls for superior ink.

Quercus Garryana, Douglas.

North-West America, along the coast between the 38th and 50th degrees. A gigantic tree, 100 feet high or more, with a stem 6 feet in diameter. The timber is remarkably pale for an Oak, hard and fine-grained, of great strength and durability, well-suited for almost every kind of construction for which the White or the European Oak is employed. The acorns, being sweet and agreeable, form an excellent mast for hogs. 
Quercus Ilex, Linné.

The Holly-Oak of South Europe; extending also to Algeria and to the Himalayas, which it ascends up to about 10,000 feet. Height of tree fifty feet. Wood in use for shipbuilding, bark for tanning. From varieties of this tree are obtained the sweet and nourishing Ballota and Chestnut acorns.

Quercus incana, Roxburgh.

Himalayas, at elevations between 3000 and 8000 feet. A beautiful evergreen tree of great dimensions. Mr. Simmonds reminds us that a silkworm (Antheraea Roylei) producing large cocoons, lives on this Oak. In its native localities $\mathbf{Q}$. lanuginosa (D. Don) is associated with it. Q. lamellosa (Smith), of the same region, attains a height of 120 feet, with a straight trunk of 60 feet and 15 feet in girth (Brandis).

Quercus infectoria, Oliver.

Around the Mediterranean Sea. Only a small tree, with deciduous foliage. Chiefly from this tree the galls of commerce are obtained. A variety, Q. Lusitanica (Webb), or Q. Mirbeckii (Durieu), attains a height of 120 feet, with a stemgirth of twenty feet. Some states of this are almost evergreen.

Quercus lancifolia, Roxburgh.

A tall timber-tree of the Himalayas. Wood valued for its durability.

Quercus lobata, Nee.

California. The acorns of this Oak used to form a large proportion of the winter-food of the aboriginal inhabitants of North California.

Quercus Iyrata, Walter.

The Overcup-Oak of the South-Eastern States of North America, extending from South Illinois to Florida and Louisiana. A tree of majestic size, eighty feet high, with a stem four feet in diameter. Lately recommended as one of the most valuable for timber-cultivation, especially for wet ground.

Quercus macrocarpa, Michaux.*

The Bur-Oak of North America. Tree seventy feet high. The timber nearly as good as that of the White Oak.

Quercus palustris, Du Roi.

The Pin-Oak or Marsh-Oak of North America. Height eighty feet; of quick growth. The wood, though not finegrained, is strong and tough. 


\section{Quercus Phellos, Linné.}

The Willow-Oak of the Eastern States of North America. The acorns available for food, like those of several other species, for instance, Q. glabra (Thunb.) of Japan. The comparative value of the very numerous cis- and transatlantic Oaks, but little as yet understood, either for avenue purposes or timber-plantations, should be tested with care in botanic gardens. Even recently Oaks have been discovered on the mountains of New Guinea.

\section{Quercus Prinus, Linné.}

The North American Swamp-Oak. A tree ninety feet high, available for wet localities. Foliage deciduous. Wood strong and elastic, of fine grain; according to Porcher, it is easy to split and not hard. A red dye is produced from the bark.

\section{Quercus Robur, Linné.*}

The British Oak. Extending through a great part of Europe and Western Asia, attaining a great age and an enormous size. Extreme height 120 feet. Two varieties are distinguished:-1. Q. sessiliflora (Salisbury). The DurmastOak, with a darker, heavier timber, more elastic, less fissile. This tree is also the quickest of the two in growth, and lives on poorer soil. Its bark is also richer in medicinal, dyeing, and tanning principles. 2. Q. pedunculata (Ehrh.). This variety supplies most of the oak-timber in Britain for shipbuilding, and is the best for bending under steam. It is also preferred for joiners' work. In Britain it is attacked by Scolytus multistriatus. The long-continued adherence of dead leaves in the cool and here most verdant season renders this Oak not so well adapted for pleasure-grounds as many other, particularly evergreen Oaks.

Quercus rubra, Linné.

The Red Oak of North America. Height 100 feet; diameter of stem four feet. The wood is not of value, but the bark is rich in tannin. Autumnal tint of foliage beautifully red. The acorns, which are produced in great abundance, are relished by animals.

\section{Quercus semecarpifolia, Smith.}

In the Himalayas, up to 10,000 feet. The largest of the Oaks of India, upwards of 100 feet high, with a stem up to 18 feet in girth. Leafless for a short time. It furnishes a hard and heavy timber of fair quality.

Quercus serrata, Thunberg.

One of the twenty-three known Japan Oaks; extending to China and Nepal. A good avenue-tree, though deciduous. 
It yields the best food for the Oak Silkworm (Bombyx Yamamai).

Quercus Sideroxylon, Humboldt.

Mountains of Mexico, at 8000 feet elevation. An Oak of great size, of compact timber, almost imperishable in water. Q. lanceolata, Q. chrysophylla, Q. reticulata, Q. laurina, Q. obtusata, Q. glaucescens, Q. Xalapensis (Humb.) and Q. acutifolia (Nee) are among the many other highly important timber Oaks of the cooler regions of Mexico. No printed records seem extant concerning the technology of the numerous Mexican Oaks, though doubtless their respective value is well known to local artisans.

Quercus Skinneri, Bentham.

Mexico. The acorns of this Oak measure nearly six inches in circumference, and are available for various domestic animals.

Quercus squamata, Roxburgh.

One of the tallest of the Himalayan Oaks. Wood lasting.

Quercus stellata, Wangenheim.

The Post-Oak of North-East America. Content with poor and even sandy soil, but not a large tree. For its very durable and dense wood it is much in requisition there $\mathrm{e}^{\prime}$ for posts, and particularly highly-prized for ship-building.

Quercus Suber, Linné.*

The Cork-Oak of South Europe and North Africa; evergreen. It attains an age of fully 200 years. After about twenty years it can be stripped of its bark every six or seven years; but the best cork is obtained from trees over forty years old. Height of tree about forty feet. Acorns of a sweetish taste. Mr. Robinson found that young Cork-Oaks, obtained from the writer, made a growth of four feet in a year in the humid. Western Port district. The bark of Q. Pseudo-Suber (Sant.) is inferior for cork, but the closely-allied Q. occidentalis (Gay), which is hardier than Q. Suber, produces a superior corkbark.

Quercus Sundaica, Blume.

One of the Oaks from the mountains of Java, where several other valuable timber Oaks exist. The existence of Oaks on the higher mountains of New Guinea has been demonstrated by Dr. Beccari; hence, in all probability, additional valuable evergreen species will be obtainable for our arboreta from thence.

Quercus Toza, Bosc.

South Europe. One of the handsomest Oaks, and one of the quickest of growth. Will live in sandy soil. It furnishes superior tanners' bark. 


\section{Quercus virens, Linné.*}

The Live-Oak of North America. Evergreen, fifty feet high, with a stem of sometimes nine feet in diameter. Supplies a most valuable timber for ship-building; it is heavy, compact, fine-grainea ; it is moreover the strongest and most durable of all American Oaks. Like Q. obtusiloba (Mich.), it lives also on sea-shores, helping to bind the sand, but it is then not of tall stature. Of many of the 300 Oaks of both the western and eastern portions of the northern hemisphere, the properties remain unrecorded and perhaps unexamined; but it would be important to introduce as many kinds as possible for local test-growth. The acorns, when packed in dry moss, retain their vitality for some months. The species with deciduous foliage are not desirable for massive ornamental planting, because in this clime they shed their dead leaves tardily during the very time of our greatest verdure.

Quillaja saponaria, Molina.

Chili. A colossal tree. The bark is rich in Saponin, and thus valuable for dressing wool and silk.

Rafnia amplexicaulis; Thunberg.

South Africa. The root of this bush is sweet like liquorice, and is administered in medicine. Rafnia perfoliata (E. Meyer), also from South Africa, furnishes likewise a medicinal root.

Raphanus sativus, Linné.

South Asia, up to 16,000 feet in the Himalayas, eastward to Japan. The Radish. R. caudatus (L.), the Radish with long edible pods, is regarded by Dr. Th. Anderson as a mere variety, and he thinks that all are sprung from the ordinary R. Raphanistrum (L.) of Europe. All Radishes succeed best in a calcareous soil, or aided by manure rich in lime.

Reseda Luteola, Linné.

The Weld. Middle and South Europe, Middle Asia, North Africa. A herb of one or two years' duration. Likes calcareous soil. A yellow dye (Luteolin) pervades the whole plant. The plant must be cut before the fruit commences to develop, otherwise the pigment will much diminish.

Reseda odorata, Linné.

The true Mignonette. North Africa and Syria. A herb of one or very few years' duration. The delicate scent can best be concentrated and removed by enfleurage.

Rhagodia Billardieri, R. Brown.

Extra-tropical Australia. An important bush for binding moving sand on sea-shores. A herb of this order, Atriplex 
crystallinum (J. Hooker), should be encouraged in its growth at the very edge of tides or sand-shores, where with Cakile maritima, Mesembrianthemum australe, and M. æquilaterale, it will form one of the most effectual first impediments to the influx of sea-sand.

Rhamnus catharticus, Linné.

The Buckthorn. Middle and South Europe, North Africa, Middle Asia. It can be utilised as a hedge-plant. The berries are of medicinal value, as indicated by the specific name. The foliage and bark can be employed for the preparation of a green dye.

Rhamnus chlorophorus, Lindley.

China. From the bark a superior green pigment is prepared. R. utilis, from the same country, serves for the like purpose. This kind of dye is particularly used for silk, and known as Lokao.

Rhamnus Græcus, Reuter.

Greece. From this shrub, and to no less extent from the allied R. prunifolius (Sibth.), are the green dye-berries collected in Greece, according to Dr. Heldreich. These shrubs grow on stony mountains up to 2500 feet.

Rhamnus infectorius, Linné.

On the Mediterranean Sea and in the countries near to it. The berry-like fruits of this shrub are known in commerce as Graines d'Avignon and Graines de Perse, and produce a valuable green dye. Other species seem to supply a similar dye-material, for instance $R$. saxatilis (L.), R. amygdalinus (Desf.), R. oleoides (L.), R. tinctorius (W. and K.)

Rhapis flabelliformis, Linné fil.

China and Japan. This exceedingly slender Palm attains only a height of a few feet. The stems can be used for various small implements. It is one of the best plants for table decoration.

Rhaponticum acaule, Candolle.

On the Mediterranean Sea. A perennial herb. The root is edible.

Rheum australe, Don.* (R. Emodi, Wall.; $R$. Webbianum, Royle.)

Himalayan regions up to 16,000 feet. From this species at least a portion of the medicinal Rhubarb is obtained; most likely several species furnish Rhubarb-root, and its quality depends probably much on the climatic region and the geologic formation, in which the plant grows. Should we wish to cultivate any species here for superior medicinal roots, then clearly localities in our higher and drier alpine tracts 
should be chosen for the purpose. Hayne regards the presence of much yellowish pigment in the seed-shell as indicating a good medicinal Rhubarb-plant. As much as five lbs. of the dried drug are obtained from a single plant, several years old. An important orange-red crystalline substance, Emodin, allied to Crysophanic acid, occurs in genuine Rhubarb.

Rheum officinale, Baillon.*

Western China and Eastern Thibet on the high tableland. It furnishes the most of the true Turkey Rhubarb, not merely from the root, but also from the woody stem. Suited for our Alps.

Rheum Rhaponticum, Linné.

From the Volga to Central Asia. This species together with R. Tataricum (L. fil.), R. undulatum (L.) and a few others, all Asiatic (one extending to Japan), provide their acidulous leaf-stalks and unexpanded flower-mass for culinary purposes. Rhubarb-leaves can also be used in the manner of Spinage. R. palmatum (L.) often considered to yield the best Rhubarbroot, is an insular plant of North-Eastern Asia, but may in the alpine deserts far inland become a source of the genuine root, so long ascribed to it. That is the only one with deeply-jagged leaves.

Rhododendron maximum, Linné.

North-East America. Attains a height of twenty feet. Irrespective of its being a fine acquisition for any gardencopses, this bush seems of industrial importance, because $\mathrm{Mr}$. C. Forster asserts that the wood of this and the allied Kalmia latifolia (L.) is equalled only by the best boxwood. This may give a clue to other substitutes for that scarce commodity, needed so extensively by the wood-engraver.

Rhus caustica, Hooker and Arnott.

Chili, where it is called the Litre. A small or middle-sized tree, the very hard wood of which is used for wheel-teeth, axletrees and select furniture. The plant seems neither caustic nor otherwise poisonous (Dr. Philippi).

Rhus copallina, Linné.

North America, extending to Canada. A comparatively dwarf species. This can also be used for tanning. A resin for varnishes is also obtained from this shrub.

Rhus coriaria, Linné.*

The Tanner's Sumach. Countries around the Mediterranean Sea. The foliage of this shrub or small tree, reduced to powder, forms the Sumach of commerce. Many localities in our colony are particularly well adapted for the growth of 
this bush. It is remarkably rich in tannic acid, yielding as much as 30 per cent., and extensively used for the production of a superior Corduan-or Maraquin-leather. The cultivation presents no difficulty. Sumach can also be used for ink and various, particularly black dyes. Under favourable circumstances as much as a ton of Sumach is obtained from an acre.

Rhus Cotinus, Linné.

The Scotino. Countries of the Mediterranean Sea, extending to the Himalayas. The wood of this bush furnishes a yellow pigment. The Scotino, so invaluable as a material for yellow and black dye, and as a superior tanning substance, consists of the ground foliage of this plant.

Rhus glabra, Linné.

North America, extending to $54^{\circ} \mathrm{N}$. latitude. This Sumach shrub will grow on rocky and sterile soil. It produces a kind of gall, and can also be used as a good substitute for the ordinary Sumach. This species can be easily multiplied from suckers. It will live on poor soil. American Sumachs contain generally from 15 to 20 per cent. tannin.

Rhus lucida, Linné.

South Africa. This shrub proved here of particular adaptability for forming hedges. About half a hundred South African species are known, of which probably some could be utilised like ordinary Sumach, but hitherto we have remained unacquainted with the nature and degree of any of their tanning and colouring principles.

Rhus semialata, Murray.

China and Japan, extending to the Himalayas. Attains a height of forty feet. This shrub produces a kind of nutgalls.

Rhus succedanea, Linné.

The Japan Wax-tree, the produce of which has found its way into the English market.

Rhus typhina, Linné.

The Staghorn-Sumach. North America, extending to Canada. This species will grow to a tree of thirty feet high. Its wood is of an orange tinge. Through incisions into the bark a kind of Copal is obtained. The leaves can be used like ordinary Sumach. This bush can be reared on inferior land.

Rhus vernicifera, Candolle.

Extends from Nepal to Japan. It forms a tree of fair size, and yields the Japan varnish. It ascends in India to 7000 feet, but Stewart and Brandis are doubtful whether the Japan species (R. Vernix, L.) is really identical with the Indian. 
Ribes aureum, Pursh.

Arkansas, Missouri, Oregon. This favourite bush of our shrubberies would likely on our forest-streams produce its pleasant berries, which turn from yellow to brown or black. Mr. Meehan mentions a variety or allied species from Utah, with berries larger than those of the black currant; they are quite a good table-fruit, and of all shades from orange to black. Allied to this is R. tenuiflorum (Lindl.), of California and the nearest States, with fruits of the size of red currants, of agreeable flavour, and either dark-purple or yellow colour.

Ribes divaricatum, Douglas.

California and Oregon. One of the Gooseberries of those countries. Berries smooth, black, about one-third of an inch in diameter, pleasant to the taste. Culture might improve this and many of the other species. R. Nuttalli ( $R$. villosum Nutt., not of Gay, nor of Wallich), is an allied plant also from California.

Ribes Floridum, L'Heritier.

The Black Currant of North America. The berries resemble in odour and taste those of $\mathrm{R}$. nigrum. Allied to this is R. Hudsonianum (Rich.), from the colder parts of North America.

Ribes Griffithi, J. Hooker and T. Thomson.

Himalaya, at the height of 10,000 to 13,000 feet. Allied to R. rubrum, bearing similar but larger berries of somewhat austere taste. The naturalisation of this Currant-bush on our highest alps may prove of advantage. R. laciniatum (H. and T.) is likewise a Himalayan species with red berries, and so R. glaciale (Wall). Furthermore R. villosum Wall., (R. leptostachyum, Decaisne) comes from the Indian highlands and seems worthy of introduction.

Ribes Grossularia, Linné.

The ordinary Gooseberry. Europe, North Africa, Western Asia, on the Himalayan mountains up to a height of 12,000 feet. This bush, familiar to every one, is mentioned here merely to indicate the desirability of naturalising it in our alpine regions, where no fruits equal to it in value exist.

Ribes hirtellum, Michaux.

The commonest smooth Gooseberry of North America. It likes moist ground.

Ribes nigrum, Linné.

The Black Currant. Middle and Northern Asia, Europe, North America, ascending the Himalayan and Thibet mountains to a height of 12,000 feet. Commonly cultivated 
already in the cooler parts of Victoria, but also particularly fit to be dispersed through our forests and over our alps.

Ribes niveum, Lindl.

One of the Oregon Gooseberry-bushes. Berries small, black, of a somewhat acid taste and rich vinous flavour.

Ribes rotundifolium, Michaux.

North America. Yields part of the smooth Goosebervies of the United States. The fruit is small, but of delicious taste. Unlike the ordinary Gooseberry, not subject to mildew.

Ribes rubrum, Linné.

The ordinary Red Currant. Europe, North America, North and Middle Asia, in the Himalayan mountains ceasing where R. Griffithi commences to appear. One of the best fruitplants for jellies and preserves that could be chosen for the colder mountain altitudes of our colony. The root-bark contains Phlorrhizin. Perhaps other species than those recorded here, among them some from the Andes, may yet deserve introduction, irrespective of their showiness, for their fruits.

Ricinus communis, Linné.*

The Castor-oil plant. Indigenous to the tropical and subtropical zones of Asia and Africa. A shrubby very decorative plant, attaining the size of a small tree. It was well known to the Egyptians 4000 years ago, and is also mentioned already in the writings of Herodotus, Hippocrates, Dioscorides, Theophrastos, Plinius and other ancient physicians, philosophers and naturalists. The easy and rapid growth, the copious seeding and the early return of produce render this important plant of high value in a clime like ours, more particularly as it will thrive on almost any soil, and can thus be raised even on arid places, without being scorched by hot winds. It may thus become an important plant also for culture in our desert-tracts, and is evidently destined to be one of our most eligible oil-plants for technical uses, particularly for lubricating machinery, irrespective of the value of its oil for medicinal purpose. The seeds contain about 50 per cent. oil. To obtain the best medicinal oil, hydraulic pressure should be employed, and the seeds not be subjected to heat; the seed-coat should also be removed prior to the extracting process being proceeded with. A screwpress suffices however for ordinary supply to obtain the oil. By decantation and some process of filtration it is purified. For obtaining oil to be used for lubrication of machinery or other technological purposes, the seeds may be pressed and prepared by various methods under application of heat and access of 
water. Castor-oil is usually bleached simply by exposure to solar light, but this procedure lessens to some extent the laxative properties of the oil. It dissolves completely in waterless alcohol and in ether, and will become dissolved also in spirit of high strength, to the extent of three-fifths of the weight of the latter. Solutions of this kind may become valuable for various technic purposes, and afford some tests for the pureness of the oil. If pressed under heat it will depose margaritin. Heated in a retort about one-third of the oil will distil over, and a substance resembling india-rubber remains, which saponises with alkalies. Other educts are at the same time obtained, which will likely become of industrial value. These facts are briefly mentioned here merely to explain, that the value of this easily produced oil is far more varied than is generally supposed, and this remark applies with equal force to many other chemical compounds from vegetable sources, briefly alluded to in this present enumerative treatise. The seeds contain also a peculiar alkaloid: Ricinin. The solid chemic compound of Castor-oil is the crystalline Isocetin-acid (a Glycerid). The oil contains also a non-crystalline acid peculiar to it (Ricin-acid). For the production of a particular kind of silk the Ricinusplant is also important, inasmuch as the hardy Bombyx Arrindi requires for food the leaves of this bush. The value of Castor-oil imported in 1871 into Victoria was according to the Customs returns not less than £23,755. Even a few of the seeds if swallowed will produce poisonous effects.

Robinia Pseudacacia, Linné.

The North-American Locust-A cacia. Height to ninety feet. The strong hard and durable wood is for a variety of purposes in use, and particularly eligible for tree-nails, axle-trees, turnery. The natives used the wood for their bows. Tree of rapid growth, and attains an age of several hundred years. It may be planted closely for timber-belts and hedge-shelter on farm-lands. It is one of the best trees for renovating exhausted land and for improving poor soil. The roots are poisonous. The allied $R$. viscosa attains a height of forty feet. No less than four arborescent Robinias are recorded from Juan Fernandez.

Roccella tinctoria, Candolle.

Canary Islands, Azores, also in Middle and South Europe and North Africa. This Lichen furnishes the Litmus, Orseille or Orchil for dyes and chemical tests. It is a question of interest, whether it could be trans-located and naturalised on the cliffs also of our shores. Other dye-lichens might perhaps still more easily be naturalised; for instance, Lecanora 
tartarea, L. parella, Pertusaria communis, Parmelia sordida, Isidium corallinum and some others, which furnish the Cudbear or Persio.

Rosa centifolia, Linné.

The Cabbage-Rose. Indigenous on the Caucasus and seemingly also in other parts of the Orient. Much grown in South Europe and South Asia for the distillation of Rosewater and Oil or Attar of Roses. From 12,000 to 16,000 Roses, or from $250 \mathrm{lbs}$. to $300 \mathrm{lbs}$. of Rose-petals are required according to some calculations for producing a single ounce of Attar through ordinary distillation. The flowers require to be cut just before expansion; the calyx is separated and rejected; the remaining portions of the flowers are then subjected to aqueous distillation, and the saturated Rose-water so obtained is repeatedly used for renewed distillation, when from the overcharged water the oil separates on a cold place and floats on the surface. But some other methods exist for producing the oil, for instance it may be got by distilling the rosebuds without water at the heat of a saltwater bath. The odour may also be withdrawn by alcoholic distillation from the Roses, or be extracted by the "enfleurage" process. The latter is effected by placing the flowers, collected while the weather is warm, into shallow frames covered with a glass plate, on the inner side of which a pure fatty substance has been thinly spread. The odour of the flowers is absorbed by the adipose or oleous substance, though the blossoms do not come with it in direct contact; fresh flowers are supplied daily for weeks. The scent is finally withdrawn from its matrix by maceration with pure alcohol. Mr. Jos. Bosisto's method for obtaining the most delicate and precious volatile oils will likely be applicable also to the Rose, and prove more advantageous both in labour and gain than any other process. Purified Eucalyptus-oil can be used for diluting Rose-oil, when it is required for the preparation of scented soap.

Rosa Damascena, Miller.

Orient. Allied to the preceding species, and also largely used for the production of Essential Oil of Roses.

Rosa Gallica, Linné.

The French or Dutch Rose. Middle and South Europe, Orient. The intensely coloured buds of this species are particularly chosen for drying. These however may be got also from other kinds of Roses.

Rosa Indica, Linné.

Noisette Rose. From Upper India to China and Japan. Some Roses of the sweetest scent are derived from this species. 
Rosa lævigata, Michaux. (R. Sinica, Aiton.)

The Cherokee-Rose. China and Japan. Considered one of the best Hedge-roses, and for that purpose much employed in North America. It serves also well for bowers. Allied to the foregoing species.

Rosa moschata, Miller.

North Africa and South Asia as far east as Japan. From the flowers of this extremely tall climbing species also essential oil is obtained. The Attar thus derived from Roses of not only different varieties but even distinct species must necessarily be of various quality.

Rosa sempervirens, Linné.

From South Europe through Southern Asia to Japan. One of the best Rose-bushes for covering walls, fences and similar structures. Also the flowers of this species can be utilised for Rose-oil.

Rosa setigera, Michaux.

North America, where it is the only climbing Rose-bush. It deserves introduction on account of its extremely rapid growth, ten feet to twenty feet in a season. Its flowers however are nearly inodorous.

Other original species of Roses deserve our attention, Dr. J. Hooker admitting about thirty, all from the Northern Hemisphere. But on the snow-clad unascended mountains of Borneo, Sumatra, New Guinea, and Africa south of the Equator yet perhaps new Roses may be discovered, as they have been traced south to Abyssinia already.

Rosa spinosissima, Linné.

Europe, North Africa, Middle and North Asia. Adapted for holding coasts-sands ; unapproachable to pasture animals, and not spreading like the Sweet Briar, R. rubiginosa (L.) into culture-land or pastures.

Rosmarinus officinalis, Linné.

The Rosemary. Countries around the Mediterranean Sea. This well-known bush is mentioned here as a medicinal plant, from which a distilled oil is rather copiously obtainable. One of our best plants for large garden-edgings. The oil enters into certain compositions of perfumery.

Royenia Pseudebenus, E. Meyer.

South Africa. Only a small tree, but its wood jet-black, hard and durable, thus in Capeland and Caffraria called ebony. R. pubescens (Willd.), according to Dr. Pappe, furnishes there a wood adapted for xylography; this may give a clue to the adaptability of many other kinds of woods in the large order of Ebenaceæ as substitutes for the Turkish boxwood. 
Rubia cordifolia, Linné. (R. Mungista, Roxburgh.)

From the Indian Highlands through China and Siberia to Japan; also occurring in various parts of Africa, as far south as Caffraria and Natal. This perennial plant produces a kind of Madder. Probably other species yield likewise dye-roots. The genus is represented widely over the globe, but as far as known not in Australia.

Rubia peregrina, Linné.

Middle and South Europe, South-West Asia. This perennial species yields also Madder-root. Several other kinds deserve comparative test-culture.

Rubia tinctorum, Linné.

The Madder. Countries around the Mediterranean Sea. A perennial herb of extremely easy culture. Soil fit for Barley suits also for Madder. Its culture opens any deep subsoil and suffocates weeds, but requires much manure, leaving however then the land enriched. Any stagnant water in the soil must be avoided, if Madder is to succeed. The harvest is in the second or third year. It can be raised from seeds or planted from offshoots. The roots merely dried and pounded form the dye. The chemical contents are numerous; in the herb-Rubichloric and Rubitannic acid; in the root-Alizarin, Purpurin, Rubiacin, Rubian, Ruberythrin acid, and three distinct resins; also Chlorogenin, Xanthin, and Rubichloric acid. On the five first depend the pigments produced from the root. Madder is one of the requisites for Alizarin Ink.

\section{Rubus Canadensis, Linné**}

The Dewberry of North America. A shrub of trailing habit. Fruit black, of excellent taste, ripening earlier than that of R. villosus (Ait.), which constitutes the High Blackberry of the United States, with large fruits.

Rubus Chamæmorus, Linné.

The Cloudberry. North Europe, North Asia, North America, particularly in the frigid zone. A perennial but herbaceous plant; a pigmy amongst its congeners. Nevertheless it is recommended for introduction to our spongy mossy alpine moors, on account of its grateful amber-coloured or red fruit. All the species can readily be raised from seeds. R. Articus (L.), also with edible fruit, is in the high north usually its companion. Near to us we have a similar little herb, living for a great part of the year in snow, namely R. Gunnianus (Hook.). It occurs on the alpine heights of Tasmania, from whence it might be easily transferred to our snowy mountains and those of New Zealand. The fruit of R. Gunnianus is red and juicy, but not always well developed. 
Rubus cuneifolius, Pursh.

The Sand-Blackberry. North America. A dwarf shrub. The fruit is of agreeable taste.

Rubus deliciosus, Torrey.

On the sources of the Missouri. An erect shrub. Fruit raspberry-like, large and grateful. An exceedingly handsome species.

Rubus fruticosus, Linné.*

The ordinary Blackberry or Bramble. All Europe, North and Sonth Africa, Middle and Northern Asia. This shrub bears well in our clime. In some countries it is a favourite plant for hedges. It likes above all calcareous soil, though it is content with almost any, and deserves to be naturalised on the rivulets of our ranges. $R$. corylifolius (Sm.), $R$. suberectus (Andr.) and R. leucostachys ( $\mathrm{Sm}$.) are varieties like many other named kinds of European Blackberries, or perhaps belong to the closely allied R. caesius (L.), the English Dewberry; or in some instances hybrid forms may have arisen from the two, although the generality of these various Blackberry-bushes bear their fruit freely enough.

Rubus geoides, Smith.

Falkland Islands, Fuegia, Patagonia and Chiloe. A herbaceous kind of Raspberry-plant with greenish-yellow fruits, resembling the Cloudberry, and of a very agreeable taste. Best adapted for our Alps.

Rubus Idaeus, Linné.*

The ordinary Raspberry. Europe, Northern and West Asia. It is mentioned here to point out the desirability of naturalising the plant in our mountains and on river-banks. It would live also on our highest alps, where the native Raspberry (R. parvifolius, L.) produces much finer fruits than in our lowlands. The fruits contain Stereopten. Leaves a substitute for tea.

Rubus lasiocarpus, Smith.

India, reaching in the Himalayas an elevation of 8000 feet, in Ceylon of 6000 feet. The black fruit is very palatable. $R$. biflorus (Hamilton) ascends with $R$. rosifolius to 10,000 feet; its fruit either red or orange is sweet (J. D. Hooker).

Rubus macropetalus, Douglas.*

California and Oregon. An unisexual shrub. Fruit black, oval-cylindric, particularly sweet.

Rubus occidentalis, Linné**

The Black Raspberry or Thimbleberry. North America. A species with woody stems and nice fruits, with a glaucous bloom, well flavoured and large. It ripens early. 


\section{Rubus odoratus, Linné.*}

North America. A kind of Raspberry. A handsome species on account of its large purple flowers. Berry edible. Culture would doubtless enhance the value of the fruits of many of these Rubi. Hybridising might be tried.

Rubus rosifolius, Smith.

Tropical and sub-tropical regions of Africa and Asia, also throughout the littoral forests of East-Australia. This shrub bears in woody regions an abundance of fruits of large size, and these early and long in the season.

Rubus rugosus, Smith.

South-Asia. The fruit, which ripens here all the year round, is nearly twice the size of the ordinary Blackberry.

Rubus strigosus, Michaux.

North America. Closely allied to the European Raspberry.

Its fruits large, also of excellent taste. It would lead too far to enumerate other kinds of Rubus, although about a hundred genuine species occur, which render the genus one of very wide dispersion over the globe.

Rubus trivialis, Michaux.*

Southern States of North America. Another shrubby species with good edible fruits, which are large and black. The plant will thrive in dry sandy soil. Like many other species rich in tannic acid.

Rumex Acetosa, Linné.

The Kitchen Sorrel. Europe, Middle and North Asia to Japan, also in the frigid zone of North America. A perennial herb. The tender varieties, particularly the Spanish one, serve as pleasant aciduous vegetables, but must be used in moderation, as their acidity like that of the species of Oxalis (Wood-sorrel) depends on binoxylate of potash. The South African R. luxurians (L.) serves likewise as culinary Sorrel.

Rumex Patientia, Linné.

Middle and South Europe, Middle Asia. Biennial. The young leaves furnish a palatable Sorrel, like Spinage. In cold climes it pushes forth its leaves before the frost is hardly gone, and thus comes in as one of the first vegetables of the season.

Rumex scutatus, Linné.

The French Sorrel. Middle and South Europe, North Africa, Orient. Also perennial, and superior to the foregoing as a culinary plant. They all are of use against scurvy and most easily reared. 
Rumex vesicarius, Linné.

South Europe, Middle Asia, North Africa. An annual herb of similar utility as the two former ones.

Ruscus aculeatus, Linné.

Middle and South Europe, North Africa, South-West Asia. This odd plant is the only shrubby species of the genus. It serves for forming garden-hedges. The young shoots of this and others are edible.

Ruta graveolens, Linné.

The Rue. Mediterranean countries and the Orient. The foliage of this acrid and odorous shrub, simply dried, constitutes the Rue-herb of medicine. The allied R. silvestris (Mill.) is still more powerful in its effect. These plants and others of the genus contain a peculiar volatile oil and a glycosid (Rutin).

Sabal Adansoni, Guernsent.

Dwarf Palmetto. South Carolina, Georgia and Florida. A stemless Fan-Palm, with the two following and Chamaerops Hystrix attaining the most northerly positions of any American Palms. According to Count de Saporta it resists a temperature as low as $17^{\circ} \mathrm{F}$. This Palm does well in marshy places.

Sabal Palmetto, Roemer and Schultes.*

Extends from Florida to North Carolina. The stem attains a height of forty feet. This noble Palm ought to grow on our sandy coast-tracts, as in such it delights to live.

Sabal serrulata, Roemer and Schultes.

South Carolina, Georgia and Florida. The stem grows to eight feet high; particularly weli-adapted for sea-coasts. The leaves can be used for cabbage-tree hats and other purposes, for which palm-leaves are sought. The fibrous spongy parts of the stem serve as brushes.

Sabal umbraculifera, Martius.

West India. Attains, according to Grisebach, a height of eighty feet. Though naturally a tropical Savannah-Palm, it has proved even hardier than the Orange. Another equally tall Antillan-Palm is S. glaucescens (Loddiges).

Sabbatia angularis, Pursh.

North-East America. This biennial pretty herh is lauded as a substitute for Gentian by American physicians, and might with other congeners be grown in medicinal gardens, though its naturalisation would not be desirable, as stock avoid the bitter gentianaceous plants. 
Saccharum officinarum, Linné.

The Sugar-Cane. India, China, South Sea Islands, not indigenous in any part of America or Australia. Sugarcane having been cultivated in Spain and other countries on the Mediterranean Sea, it will be worthy of further trial, whether in the warmest parts of our colony under similar climatic conditions sugar from cane can be produced to advantage. Though the plant will live unprotected in the vicinity of Melbourne, it thrives there not sufficiently for remunerative culture. But it may be otherwise in East Gipps Land or along the Murray River and its lower tributaries. In the United States the profitable culture of cane ceases at $32^{\circ}$ north latitude, in China it extends only to the $30^{\circ}$ north latitude. In the last-mentioned country the culture of Sugar-cane dates from the remotest antiquity; moreover we have from thence a particular kind, S. Sinense (Roxb.), which is hardier and bears drought better than the ordinary cane; this kind needs renewal only every second or third year, and ripens in seven months, if planted early in spring, but if planted in autumn and left standing for fully a year the return of sugar is larger. Moderate vicinity to the sea is favourable for the growth of canes. Prolific yields have been secured in East Australia as far south as $28^{\circ}$.

The multiplication of all sorts of Sugar-cane is usually effected from top-cuttings, but this cannot be carried on from the same original stook for an indefinite period without deterioration; and as seeds hardly ever ripen on the canes, new plants must from time to time be brought from the distance. Thus New Caledonia has latterly supplied its wild-growing splendid varieties for replanting many sugar-fields in Mauritius. The Bourbon variety is praised as one of the richest for sugar: the Batavian variety $\mathrm{S}$. violaceum (Tussac), is content with less fertile soil. Many other varieties are known. Excessive rains produce a rank luxuriance of the canes at the expense of the saccharine principle. Rich manuring is necessary to attain good crops, unless in the best of virgin soil. The lower leaves of the stem must successively be removed, also superabundant suckers, to promote the growth upwards, and to provide ventilation and light. Out of the remnants of Sugar-cane molasses, rum and taffia can be prepared. The average yield of Sugar varies from 1 ton 6 cwt. to 3 tons for the acre. For fuller information the valuable local work of Mr. A. McKay, "The Sugar-cane in Australia," should be consulted. The stately S. spontaneum (L.), which extends from India to Egypt, is available for scenic culture. It attains a height of fifteen feet. Other tall kinds of Saccharum occur in South Asia. 
Sagittaria lancifolia, Linné.

From Virginia to the Antilles. This very handsome aquaticplant can doubtless be utilised like the following species. It attains a height of five feet.

Sagittaria obtusa, Muehlenberg. (S. latifolia, Willdenow). North America, where it replaces the closely-allied S. sagittifolia. A few other conspicuous species are worthy of introduction.

Sagittaria sagittifolia, Linné.

Europe, North and Middle Asia, east to Japan. One of the most showy of all hardy water-plants ; still not alone on that account deserving naturalisation, but also because its root is edible. If once established this plant maintains its ground well, and might occupy spots neither arable nor otherwise utilised.

Salix alba, Linné.

The Huntingdon or Silky Willow of Europe, originally probably from Middle Asia. Available for wet places not otherwise utilised. Height eighty feet, circumference of stem twenty feet; wood light and elastic, available for carpenter's work and implements, bark for tanning. The Golden Osier, Salix vitellina (L.) is a variety. The shoots are used for hoops and wickerwork. With other large Willows and Poplars one of the best scavengers for back yards, where drainage cannot readily be applied; highly valuable also for forming lines along narrow watercourses or valleys in forests, to stay bush-fires. The charcoal excellent for gunpowder. The wood in demand for matches.

Salix Babylonica, Tournefort.

The Weeping Willow, indigenous in West Asia as far as Japan, sparingly wild, according to Stewart, in the Himalayas, probably also in Persia, Kurdistan and China. One of the most grateful of all trees for the facility of its culture, rapidity of growth, and fitness for embellishments, also as one of the quickest growing and most easily reared of all shade-trees. Dr. C. Koch distinguishes another Weeping Willow as $\mathrm{S}$. elegantis sima from Japan. Important for consolidating river-banks.

Salix Capensis, Thunberg. (S. Gariepina, Burchell.)

South Africa. This Willow might be introduced on account of its resemblance to the ordinary Weeping Willow. S. daphnoides (Vill.) of Europe and Asia, S. petiolaris (Smith), S. cordata (Muehlenb.), S. tristis (Ait.), of North America, are among the best for binding sand. S. longifolia (Muehlenb.), also North American, is among those which form long flexible withes. 
Salix caprea, Linné.

Europe, North and Middle Asia. The British Sallow or Hedge Willow; grows also to a tree; wood useful for handles and other implements, the shoots for hoops. It is largely employed for the coal for gunpowder. Bark for tanning, particularly glove-leather. The flowers are eagerly sought by bees. It is the earliest flowering Willow.

Salix cordata, Muehlenberg.

One of the Osiers of North America.

Salix daphnoides, Villars.

Middle Europe and Northern Asia, as far as the Amoor, ascending to 15,000 feet in the Himalayas. A tree of sixty feet in height, of remarkable rapidity of growth, attaining twelve feet in four years. It is much chosen to fix the ground at railway embankments, on sandy ridges and slopes, for which purpose its long-spreading and strong roots render it particularly fit. The twigs can be used for baskets and wickerwork and twig-bridges (Stewart and Brandis). The foliage furnishes cattle-fodder. The tree is comparatively rich in Salicine, like S. pentandra (L.)

Salix fragilis, Linné.

The Crack-Willow. Indigenous in South-Western Asia. Height ninety feet, stem to twenty feet in girth. A variety of this species is the Bedford-Willow, Salix Russelliana (Smith), which yields a light elastic tough timber, more tannin in its bark than oak, and more Salicine (a substitute for quinine and most valuable as an anti-rheumatic remedy) than most congeners. One of the dwarf American Willows, perhaps S. tristis (Aiton) has been traced on the coastsands of California to send out root-like stems up to 120 feet length.

Salix Humboldtiana, Willdenow.

Through a great part of South America. This Willow is of pyramidal habit, attains a height of fifty feet and more. The wood is much in use for yokes and other implements. Many kinds of Willow can be grown for consolidating shifting sand ridges.

Salix lucida, Muehlenberg. One of the Osiers of North America.

Salix nigra, Marshall. (S. Purstiana, Sprengel.)

The Black Willow of North America. It attains a height of twenty-five feet. The Black Willow is one used for basket-work, although it is surpassed in excellence by some other species, and is more important as a timber-Willow. Mr. W. Scaling, of Basford, includes it among the sorts, 
which he recommends in his valuable publication "The Willow" (London, 1871).

\section{Salix purpurea, Linné.*}

Of wide range in Europe and West Asia. One of the Osiers. In deep moist soil, not readily otherwise utilised, it will yield annually four to five tons of the best of rods, qualified for the finest work. Impenetrable, not readily inflammable screens twenty-five feet high can be reared from it in five years. In localities exposed to storm willow-screens fully forty feet high can be raised. It is invaluable also for the reclamation of land along water-courses. Rich in Salicine. From Mr. Scaling's treatise on the Willow, resting on unrivalled experience, it will be observed, that he anew urges the adoption of the Bitter Willow (also called the RoseWillow or the Whipcord-Willow), S. purpurea (L.), for game-proof hedges, this species scarcely ever being touched by cattle, rabbits and other herbivorous animals. Not only for this reason, but also for its very rapid growth and remunerative yield of the very best of basket-material he recommends it for field-hedges. Cuttings are planted only half a foot apart, and must be entirely pushed into the ground. The annual produce from such a hedge is worth $4 \mathrm{~s}$. to $5 \mathrm{~s}$. for the chain. For additional strength the shoots can be interwoven. In rich bottoms they will grow from seven feet to thirteen feet in a year. The supply of basketmaterial from this species has fallen very far short of the demand in England. The plant grows vigorously on light soil or warp-land, but not on clay. S. rubra (Huds.), is also admirably adapted for hedges. The real Osier, S. viminalis (L.), is distinguished by basket-makers as the soft-wooded Willow, and is the best for rods requiring two years' age, and also the most eligible for hoops, but inferior to several other species for basket-manufacture. S. triandra (L) is a prominent representative of the hard-wooded basket-Willows, and comprises some of the finest varieties in use of the manufacturers. A crop in the third year after planting from an acre weighs about 12 tons, worth $£ 3$ for the ton. S. fragilis (L.) and S. alba (L.) are more important as timberWillows, and for growing hoop-shoots. Their rapidity of growth recommends them also for shelter-plantations, to which advantage may be added their uninflammability and their easy propagation; the latter quality they share with most Willows. Mr. Scaling's renewed advocacy for the formation of Willow-plantations comes with so much force, that his advice is here given though condensed in a few words. Osier-plantations come into full bearing already in 
the third year; they bear for ten years and then slowly decline. The raw-produce from an acre in a year averages 6 tons to $7 \frac{1}{2}$ tons, ranging in price from $£ 210$ s. to $£ 310$ s. for the ton (unpeeled). Although 7000 acres are devoted in Britain to the culture of basket-Willows (exclusive of spinneys and plantations for the farmers' own use), yet in 1866 there had to be imported from the continent 4400 tons of Willow-branches, at a value of $£ 44,000$, while besides the value of the made baskets imported in that year was equal to the above sum. Land comparatively valueless for root- or grain-crops can be used very remuneratively for Osierplantations. The soft-wooded Willows like to grow in damper ground than the hard-wooded species. The best peeled Willow-branches fetch as much as $£ 25$ for the ton. Peeling is best effected by steam, by which means the material is also increased in durability. No basket-Willow will thrive in stagnant water. Osier-plantations in humid places should therefore be drained. The cuttings are best taken from branches one or two years old, and are to be planted as close as one foot by one and a half foot. No part of the cutting must remain uncovered, in order that only straight shoots may be obtained; manuring and ploughing between the rows is thus also facilitated, after the crop has been gathered, and this, according to the approved Belgian method, must be done by cutting the shoots close to the ground after the fall of the leaves.

Salix rubra, Hudson.*

Throughout Europe, also in West Asia and North Africa; it is much chosen for osier-beds. When cut down, it will make shoots eight feet long in a season. Porcher regards it as one of the most valuable species for work in which unpeeled rods are used.

Salix tetrasperma, Roxburgh.

Mountains of India, from 2000 to 7000 feet. Height of tree forty feet. This thick-stemmed Willow is worthy of a place on the banks of our watercourses. The twigs can be worked into baskets, the wood serves for gunpowder, the foliage for cattle-food.

\section{Salix triandra, Linné* (S. amygdalina, Linné).}

The Almond-Willow, through nearly all Europe and extratropical Asia. Height of tree thirty feet. Shoots nine feet long, for hoops and white basket-work, being pliant and durable. The bark contains a good deal of Salicine. S. lanceolata (Smith) is a hybrid between S. triandra and $\mathrm{S}$. viminalis, according to Andersson. 


\section{Salix viminalis, Linné.*}

The common Osier of Europe and North and West Asia; attains the height of thirty feet. One of the best for wickerwork and hoops; when cut it shoots up to a length of twelve feet. It would lead too far to enumerate even the more important Willows all on this occasion. Professor Andersson, of Stockholm, admits 158 species. Besides these, numerous hybrids exist. Many of the taller of these Willows could here be grown to advantage.

Salvia officinalis, Linné.

The Garden Sage. Countries at the Mediterranean Sea. A somewhat shrubby plant of medicinal value, pervaded by essential oil. Prefers calcareous soil. Among nearly half a thousand species of this genus some are gorgeously ornamental.

Sambucus Canadensis, Linné.

North-East America. The berries of this half-woody Elder are used as well as those of Phytolacca decandra for colouring vinous liquids. S. xanthocarpa (F. v. Mueller) is a large Elder-tree of extra-tropic East Australia.

Sambucus nigra, Linné.

The ordinary Elder. Europe, North Africa, Middle Asia. The flowers are of medicinal value, and an essential oil can be obtained from them. The wood can be utilised for shoepegs and other purposes of artisans. The berries are used for colouring port-wine and for other purposes of dye.

Sanguinaria Canadensis, Linné.

North-East America. A perennial herb. The root important as a therapeutic agent, contains also dye-principles.

Sanguisorba minor, Scopoli. (Poterium Sanguisorba, Linné.) The Salad Burnet. Europe, North Africa, North and Middle Asia. A perennial, easily disseminated and naturalised herb, particularly adapted for calcareous soils. Serves as salad and particularly as a sheep-fodder.

Sanseviera Zeilanici, Willdenow.

India. This thick-leaved liliaceous plant should not be passed in this enumeration, as it has proved hardy in places free of frost. Four pounds of leaves give about one pound of fibre, which unites with softness and silky lustre extraordinary strength and tenacity, serving in its native country for bowstrings. The plant might be left to itself in rocky unutilised places. Several allied species exist.

Santalum album, Linné.*

India, ascending to the temperate elevations of Mysore. A small or middle-sized tree, famed for its fragrant wood and 
roots. In the drier and stony parts of ranges the greatest fragrance of the wood is generated. S. Freycenetianum (Gaudichaud) produces sandal-wood on the mountains of the Sandwich Islands, up to 3000 feet. Several other species occur in Polynesia. The precious sandal-oil is obtained by slow distillation from the heartwood and root, the yield being about two and a-half per cent.

Santalum cygnorum, Miquel.

South-Western Australia, where this tree yields scented sandal-wood.

Santalum Preissianum, Miquel. (S. acuminatum, A. de Candolle.)

The Quandong. Desert-country of extra-tropical Australia. The fruits of this small tree are called Native Peaches. As both the succulent outer part and kernel are edible, it is advisable to raise the plant in desert-tracts, where the species does not occur, since moreover it becomes gradually sacrificed on many native places by pasture operations.

\section{Santalum Yasi, Seemann.}

The Sandal-tree of the Fiji Islands, where it grows on dry and rocky hills. It is likely to prove hardy here, and deserves with a few other species from the South Sea Islands, yielding scented wood, test-culture in the warmest parts of our colony.

\section{Santolina cyparissias, Linné.}

Countries at the Mediterranean Sea. A very aromatic and handsome bush, of medicinal value. There are several allied species.

\section{Saponaria officinalis, Linné.}

The Soapwort or Fuller's Herb. Europe, North and Middle Asia. A perennial herb of some technologic interest, as the root can be employed with advantage in some final processes of washing silk and wool, to which it imparts a peculiar gloss and dazzling whiteness, without injuring in the least the most sensitive colours. Experiments instituted in the laboratory of the Botanic Garden of Melbourne render it highly probable that Saponin, which produces the froth from the Soapwort, is also present in the bark and root of Acacia (Albizzia) lophanta (W.) At all events a substance closely resembling Saponin was unexpectedly detected (in the course of other investigations entrusted to Mr. Rummel) in the bark of this Acacia, and this substance occurred in so large a proportion as to constitute 10 per cent. of the dry bark. 


\section{Sassafras officinale, Hayne.}

The deciduous Sassafras-tree, indigenous from Canada to Florida, in dry open woods. Height fifty feet. It furnishes the medicinal Sassafras bark and wood, and from this again an essential oil is attainable. The deciduous and often jagged leaves are remarkable among those of Lauraceæ.

Satureja hortensis, Linné.

The Summer Savory. Countries around the Mediterranean Sea. An annual scent-herb, from which an essential aromatic oil can be distilled. The culture of this and allied plants is easy in the extreme.

Satureja montana, Linné.

The Winter Savory. On arid hilly places at and near the Mediterranean Sea. A perennial somewhat shrubby herb, frequently used as a culinary condiment along with or in place of the foregoing species, although it is scarcely equal to it in fragrance.

Satureja Thymbra, Linné.

Countries at or near the Mediterranean Sea. A small evergreen bush, with the flavour almost of thyme. The likewise odorous S. Graeca (L.) and S. Juliana (L.) have been transferred by Bentham to the closely cognate genus Micromeria; they are in use since Dioscorides' time, though not representing, as long supposed, the Hyssop of that ancient physician.

Saussurea Lappa, Bentham. (Haplotaxis Lappa, Decaisne.) Cashmere. The aromatic root of this perennial species is of medicinal value, and by some considered to be the Costus of the ancients.

Saxono-Gothæa conspicua, Lindley.

The Mahin of Southern Chili. A middle-sized tree, with fine-grained yellowish timber.

Scandix grandiflora, Linné.

Countries around the Mediterranean Sea. An annual herb, much liked there as a salad for its pleasant aromatic taste.

Schizostachyum Blumei, Nees.

Java, at an elevation of about 3000 feet. A lofty Bamboo. A few other species, less elevated, occur in China, the South Sea and Philippine Islands and Madagascar. The genus might well be united with Melocanna. The Bamboos being brought once more thus before us, it may be deemed advisable to place together into one brief list all other kinds which are recorded either as very tall or as particularly hardy. Accordingly, from MajorGeneral Munro's admirable monography ("Linnean Trans- 
actions," 1868), the succeeding enumeration is compiled, and from that masterly essay, resting on very many years' close study of the richest collections, a few prefatory remarks are likewise offered, to vindicate the wish of the writer of seeing these noble and graceful forms of vegetation largely transferred to every part of Australia, where they would impress a grand tropical feature on the landscapes. Even in our far southern latitudes Bamboos from the Indian lowlands have proved to resist our occasional night-frosts of the low country. But in colder places the many sub-alpine species could be reared. Be it remembered that Chusquea aristata advances to an elevation of 15,000 feet on the Andes of Quito, indeed to near the zone of perpetual ice. Arundinaria falcata, A. racemosa and $\mathrm{A}$. spathiflora live on the Indian highlands, at a zone between 10,000 and 11,000 feet, where they are annually beaten down by snow. We may further recognise the great importance of these plants, when we reflect on their manifest industrial uses, or when we consider their grandeur for picturesque scenery, or when we observe their resistance to storms or heat, or when we watch the marvellous rapidity in which many develop themselves. Their seeds, thougl generally only in long intervals produced, are valued in many instances higher than rice. The ordinary great Bamboo of India is known to grow forty feet in forty days, when bathed in the moist heat of the jungles. The Bourbon Bamboo forms an impenetrable sub-alpine belt of extraordinary magnificence in yonder island. One of the Tenasserim Bambusas rises to 150 feet, witl a diameter of the mast-like cane sometimes measuring fully one foot. The great West Indian Arthrostylidium is sometimes nearly as high and quite as columnar in its form, while the Dendrocalamus at Pulo Geum is equally colossal. The Platonia Bamboo of the highest wooded mountains of Parama sends forth leaves fifteen feet in length and one foot in width. Arundinaria macrosperma as far north as Philadelphia rises still in favourable spots to a height of nearly forty feet. Through perforating with artistic care the huge canes of various Bamboos musical sounds can be melodiously produced when the air wafts through the groves, and this singular fact may possibly be turned to practice for checking the devastations from birds on many a cultured spot. Altogether twenty genera with 170 well-marked species are circumscribed by General Munro's consummate care; but how may these treasures yet be enriched, when once the snowy mountains of New Guinea through Bamboo jungles become ascended, or when the alps on the sources of the Nile, which Ptolemæus and Julius Cæsar already longed to ascend, have become the 
territory also of phytologic researches, not to speak of many other tropical regions as yet left unexplored. Europe possesses no Bamboo; Australia as far as hitherto ascertained only one (in the interior of Arnhem's Land). Almost all Bamboos are local, and there seems really no exception to the fact, that none are indigenous to both hemispheres, all true Bambusas being Oriental. Observations on the growth of many Bamboos in Italy are recently offered by Chevalier Fenzi.

The introduction of these exquisite plants is one of the easiest imaginable, either from seeds or the living roots. The consuls at distant ports, the missionaries, the mercantile and navigating gentlemen abroad, and so particularly also any travellers, could all easily aid in transferring the various Bamboos from one country to the other--from hemisphere to hemisphere. Most plants of this kind here with us, once well established in strength under glass, can be trusted out to permanent locations with perfect and lasting safety at the commencement of the warm season. Indeed, Bamboos are hardier than most intra-tropical plants, and the majority of them are not the denizens of the hottest tropical lowlands, but delight in the cooler air of mountain regions. In selecting the following array from General Munro's monography, it must be noted, that it comprises only a limited number, and that among those, which are already to some extent known, but as yet cannot be defined with precision in their generic and specific relation, evidently some occur which in elegance, grace and utility surpass even many of those now specially mentioned:-

Arundinaria Japonica, S. and Z. Japan. Height to twelve feet.

Arundinaria verticillata, Nees. Brazil. Height to fifteen feet.

Arundinaria debilis, Thwaites. Ceylon; ascends to 8000 feet. A tall species.

Arundinaria acuminata, Munro. Mexico. Height to twenty feet.

Arundinaria tesselata, Munro. South Africa; ascends to 6500 feet. Height to twenty feet.

Arundinaria callosa, Munro. Himalaya; ascends to 6000 feet. Height to twelve feet.

Arundinaria Khasiana, Munro. Himalaya; ascends to 6000 feet. Height to twelve feet.

Arundinaria Hookeriana, Munro. Sikkim; ascends to 7000 feet. Height to fifteen feet. 
Arundinaria suberecta, Munro. Himalaya; ascends to 4500 feet. Height to fifteen feet.

Thamnocalamus Falconeri, J. Hook. Himalaya; ascends to 8000 feet. Tall.

Thamnocalamus spathiflorus, Munro. Himalaya; ascends to 11,000 feet. Tall.

Phyllostachys bambusoides, S. and Z. Himalaya, China and Japan. Height to twelve feet.

Phyllostachys nigra, Munro. China, Japan. Height to twenty-five feet.

Arthrostylidium longiflorum, Munro. Venezuela; ascends to 6000 feet.

Arthrostylidium Schomburgkii, Munro. Guiana; ascends to 6000 feet. Height to sixty feet.

Arthrostylidium excelsum, Griseb. West India. Height to eighty feet, diameter one foot.

Arthrostylidium racemiflorum, Steudel. Mexico; ascends to 7500 feet. Height to thirty feet.

Aulonemia Queso, Goudot. New Granada, Venezuela, in cool regions. Tall, climbing.

Merostachys ternata, Nees. South Brazil. Height to twenty feet.

Merostachys Clausseni, Munro. South Brazil. Height to eighty feet.

Merostachys Kunthii, Ruprecht. South Brazil. Height to thirty feet.

Chusquec simpliciflora, Munro. Panama. Height to eighty feet. Scandent.

Chusquea abietifolia, Griseb. West India. Tall, scandent.

Chusquea Culcou, E. Desv. Chili. Height to twenty feet. Straight.

Chusquea uniflora, Steudel. Central America. Height to twenty feet.

Chusquea Galleottiana, Ruprecht. Mexico; ascends to 8000 feet.

Chusquea montana, Philippi. Chili Andes. Height to ten feet.

Chusquea Dombeyana, Kunth. Peru; ascends to 6000 feet. Height to ten feet.

Chusquea Fendleri, Munro. Central America; ascends to 12,000 feet.

Chusquea scandens, Kunth. Colder Central America. Climbing, tall.

Chusquea Quila, Kunth. Chili. Tall.

Chusquea tenuiflora, Philippi. Chili. Height to twelve feet. Chusquea Gaudichaudiana, Kunth. South Brazil. Very tall. Chusquea capituliflora, Trinius. South Brazil. Very tall. 
Platonia nobilis, Munro. New Granada, colder region.

Nastus Borbonicus, Gmel. Bourbon, Sumatra; ascends to 4000 feet. Height to fifty feet.

Guadua Tagoara, Kunth. South Brazil; ascends to 2000 feet. Height to thirty feet.

Guadua macrostachya, Rupr. Guiana to Brazil. Height to thirty feet.

Guadua capitata, Munro. South Brazil. Height to twenty feet.

Guadua virgata, Rupr. South Brazil. Height to twentyfive feet.

Guadua refracta, Munro. Brazil. Height to thirty feet.

Guadua paniculata, Munro. Brazil. Height to thirty feet.

Bambusa Tulda, Roxb. Bengal to Burmah. Height to seventy feet.

Bambusa nutans, Wall. Himalaya; ascends to 7000 feet.

Bambusa tuldoides, Munro. China, Hong Kong, Formosa.

Bambusa pallida, Munro. Bengal to Khasia; ascends to 3500 feet. Height to fifty feet.

Bambusa polymorpha, Munro. Burmah, in the Teak-region. Height to eighty feet.

Bambusa Balcooa, Roxb. Bengal to Assam. Height to seventy feet.

Bambusa flexuosa, Munro. China. Height to twelve feet.

Bambusa Beecheyana, Munro. China. Height to twenty feet.

Bambusa marginata, Munro. Tenasserim; ascends to 5000 feet. Tall, scandent.

Bambusa regia, Th. Thomson. Tenasserim. Height to forty feet.

Bambusa Brandisii, Munro. Tenasserim; ascends to 4000 feet. . Height to 120 feet, circumference 2 feet.

Gigantochloa heterostachya, Munro. Malacca. Height to thirty feet.

Oxytenanthera Abyssinica, Munro. Abyssinia to Angola; ascends to 4000 feet. Height to fifty feet.

Oxytenanthera albo-ciliata, Munro. Pegu, Moulmein. Tall, scandent.

Cephalostachyum capitatum, Munro. Himalaya; ascends to 6000 feet. Height to thirty feet.

Cephalostachyum pallidum, Munro. Himalaya; ascends to 5000 feet. Tall.

Cephalostachyum pergracile, Munro. Burmah. Height to forty feet.

Pseudostachyum polymorpluum, Munro. Himalaya; ascends to 6000 feet. Very tall.

Teinostachyum Griffithi, Munro. Burmah. Tall and slender. 
Beesha stridula, Munro. Ceylon.

Beesha capitata, Munro. Madagascar. Height to fifty feet. Dendrocalamus sericeus, Munro. Behar; ascends to 4000 feet. Tall.

Dendrocalamus flagellifer, Munro. Malacca. Very tall.

Dendrocalamus Hookeri, Munro. Himalaya; ascends to 6000 feet. Height to fifty feet.

Dendrocalamus Hamiltoni, Nees. Himalaya; ascends to 6000 feet. Height to sixty feet.

Dinochloa Tjankorreh, Buehse. Java, Philippines; ascends to 4000 feet. Climbing.

Schizostachyum brachycladum, Kurz.

Sunda Islands and Moluccas. Stems to forty feet high, very hollow. The short branches give to this Bamboo a peculiar habit. One variety has splendidly yellow stems.

Schizostachyum elegantissimum, Kurz.

Java, at elevations from 3000 to 6000 feet. Unlike all other Bamboos, this bears flowers at an age of three years, and is therefore of special importance for scenic effect. Height up to twenty-five feet, stems stout. It requires, like many allied plants, renewal after flowering.

Schizostachyum Hasskarlianum, Kurz.

Java. This and S. serpentinum afford the best kinds of Bamboo vegetables for cookery, the young shoots, when bursting out of the ground, being used for the purpose. Kurz mentions as culinary "Rebong" Bamboos :-Gigantochloa aspera, G. robusta, G. maxima, G. atter. For ornamental culture the same meritorious writer singles out Schizostachyum brachycladum, the varieties of Bambusa vulgaris with gaudy, glossy colouring of the stems, in contrast with the black-stemmed species of Phyllostachys from China and Japan.

Schizostachyum irratum, Steudel.

Sunda Islands and Moluccas. Stems to thirty feet high, remarkably slender.

Schizostachyum Zollingeri, Steudel.

Hills of Java. Much cultivated. Height up to thirty-five feet, stems slender.

Schoenocaulon officinale, A. Gray. (Asa-Graya officinalis,

Lindley; Sabadilla officinalis, Brandt and Dierbach.)

Mountains of Mexico. A bulbous-rooted herb with leafless stem, thus far specially distinct from any Veratrum. It furnishes the Sabadilla-seeds and yields two alkaloids: Veratrin and Sabadillin; a resinous substance: Helonin; also Sabadillic and Veratric acid. The generic names adopted for this plant by Lindley and by Dierbach are coetaneous. 
Sciadopitys verticillata, Siebold.

The lofty and curious Umbrella-Fir of Japan, 140 feet high.

Resists severe frosts. Wood white and compact.

Scilla esculenta, Ker. (Camassia esculenta, Lindley.)

The Quamash. In the western extra-tropic parts of North America, on moist prairies. The onion-like bulbs in a roasted state form a considerable portion of the vegetable food, on which the aboriginal tribes of that part of the globe are living. It is a pretty plant, and might be naturalised here on our moist meadows.

Sclerachne cyathopoda, F. v. Mueller.

Tropical Australia. A perennial grass, valuable according to Mr. P. O'Shanesy for green feed, yielding a large return.

Scorzonera crocifolia, Sibthorp.

Greece. A perennial herb; the leaves, according to Dr. Heldreich, used there for a favourite salad and spinage.

\section{Scorzonera deliciosa, Gusson.*}

Sicily. One of the purple-flowered species; equal, if not superior, in its culinary use to the allied Salsify.

\section{Scorzonera Hispanica, Linné.*}

Middle and South Europe, Orient. The perennial root of this yellow-flowered herb furnishes not only a wholesome and palatable food, but also serves as a therapeutic remedy much like dandelion. Long boiling destroys its medicinal value. Some other kinds of Scorzonera may perhaps be drawn into similar use, there being many Asiatic species.

Scorzonera tuberosa, Pallas.

At the Volga and in Syria. Also this species yields an edible root, and so perhaps the Chinese Sc. albicaulis (Bunge), the Persian Sc. Scowitzii (Cand.), the North African Sc. undulata (Vahl), the Greek Sc. ramosa (Sibth.), the Russian Sc. Astrachanica (Cand.), the Turkish Sc. semicana (Cand.), the Iberian Sc. lanata (Bieberst.). At all events careful culture may render them valuable esculents.

Scutia Indica, Brogniart.

South Asia. This, on Dr. Cleghorn's recommendation, might be introduced as a thorny hedge-shrub.

Sebæa ovata, R. Brown.

Extra-tropic Australia and New Zealand. This neat little annual herb can be utilised for its bitter tonic principle (Gentian-bitter). S. albidiflora (F. v. M.) is an allied species from somewhat saline ground. These plants disseminate themselves most readily. 


\section{Secale cereale, Linné.*}

The Rye. Orient, but perhaps wild only in the country between the Caspian and Black Seas. Mentioned here as the hardiest of all grain-plants for our highest alpine regions. There are annual and biennial varieties, while a few allied species, hitherto not generally used for fodder or cereal culture, are perennial. The Rye, though not so nutritious as wheat, furnishes a most wholesome well-flavoured bread, which keeps for many days, and is most extensively used in Middle and North Europe and Asia. The grain moreover can be reared in poor soil and cold climates, where wheat will no longer thrive. In produce of grain Rye is not inferior to wheat in colder countries, while the yield of straw is larger, and the culture less exhaustive. It is a hardy cereal, not readily subject to disease, and can be grown on some kinds of peaty or sandy or moory ground. The sowing must not be effected at a period of much wetness. Wide sand-tracts would be uninhabitabe, if it were not for the facility to provide human sustenance from this grateful corn. It dislikes moist ground. Sandy soil gives the best grain. It is a very remarkable fact, that since ages in some tracts of Europe, Rye has been prolifically cultivated from year to year without interruption. In this respect Rye stands favourably alone among alimentary plants. It furnishes in cold countries also the earliest green-fodder, and the return is large. Dr. Sonder observed in cultivated turf-heaths with much humus, that the spikelets produce three or even four fertile florets, and thus each spike will yield up to eighty beautiful seeds. Langethal recommends for argillaceous soils a mixture of early varieties of wheat and rye, the united crops furnishing grain for excellent bread. When the Rye-grain becomes attacked by Cordyceps purpurea (Fr.), or very similar species of fungi, then it becomes dangerously unwholesome, but then also a very important medicinal substance, namely Ergot, is obtained. The biennial Wallachian variety of Rye can be mown or clepastured prior to the season of its forming grain. In alpine regions Wallachian Rye is sown with pine-seeds, for shelter of the pine-seedlings in the first year.

Secale creticum, Linné.

Though probably only a variety of S. cereale (L.), it deserves specially to be mentioned as furnishing a bread of peculiar taste.

Sechium edule, Swartz.

West India. The Chocho or Chayota. The large root of this climber can be consumed as a culinary vegetable, while the good-sized fruits are also edible. The plant comes in climates like ours to perfection. 
Selinum anesorrhizum, F. v. Muller. (Anesorrhiza Capensis, Ch. and Schl.)

South Africa. The root of this biennial herb is edible. A. montana (Eckl. and Zeylı.), a closely allied plant, yields likewise an edible root, and so it is with a few other species of the section Anesorrhiza.

Selinum Monnieri, Linné.

From East Asia now extending to South Europe, preferring moist places. An annual herb, praised by the Chinese as valuable for medicinal purposes.

Sequoia sempervirens, Endlicher.* (Taxodium sempervirens, Lambert.)

Red-Wood or Bastard-Cedar of North-West America, chiefly California. A splendid tree, 360 feet high, occasionally with a diameter of the stem of fifty-five feet. The wood is reddish, close-veined, but light and brittle. One of the most colossal trees of the globe. Its growth is about thirty-two feet in sixteen years. Often found on metamorphic sandstone.

Sequoia Wellingtonia, Seemann.* (Wellingtonia giganitea, Lindley.)

Mammoth-tree. California, up to 5000 feet above the sea. This, the biggest of all trees, attains a stem of 320 feet in length and 112 feet in circumference, the oldest trees being estimated at 1100 years. The total height of a tree will occasionally be 450 feet. A stem broken at 300 feet had yet a diameter of eighteen feet. The wood is soft and white when felled, afterwards it turns red. Traditional accounts seem to have overrated the height of the Mammoth-tree. In the Calaveras-grove two of the largest trees, which may have been the tallest of all, were destroyed; the two highest now existing there are respectively 325 and 319 feet high, with a circumference of forty-five and forty feet at six feet from the ground. At the Mariposa-grove the highest really measured trees are 272,270 and 260 feet high, but one of these has the enormous circumference of sixty-seven feet at six feet from the ground, while another, the height of which is not recorded, is ninety-three feet in girth at the ground and sixty-four feet at eleven feet from it; the branches of this individual tree are as thick as the stems of large Elms. The height of the Calaveras-grove is 4760 feet above sea-level. Both Sequoias produce shoots from the root after the stem is cut away.

Sesamum Indicum, Linné.

The Gingili. Southern Asia, extending eastwards to Japan. This annual herb is cultivated as far as $42^{\circ}$ north latitude. The oil, fresh expressed from the seeds, is the best for table use ; free of any unpleasant taste. In Greece the seeds are 
often sprinkled over cakes. One of the advantages of the culture of this plant consists in its quick return of produce. The soot of the oil is used for China-ink.

Sesbania aculeata, Persoon.

The Danchi. Intra-tropical and sub-tropical Asia, Africa and Australia. This tall annual plant has proved adapted for our desert-regions. It yields a tough fibre for ropes, nets and cordage, valued at from $£ 30$ to $£ 40$ for the ton. Several congeneric plants can be equally well utilised.

Sesbania cannabina, Persoon.

South Asia. An annual herb of easy growth in wet localities, requiring less attention in weeding and otherwise than the Jute-plant. The crop for fibre ripens in about five months.

Sesleria coerulea, Arduino.*

Most parts of Europe. Of this perennial grass Langethal observes, that it is for dry and loose limestone what Elymus arenarius is for loose sand. It stands well depasturing by sheep and is one of the earliest grasses in the season. S. dactyloides, Nuttall (Buchloa dactyloides, Torrey), is the Buffalograss of Kansas.

Sesuvium Portulacastrum, Linné.

All around the globe on the shores of tropical and some subtropical countries, occurring naturally as far south as Port Jackson. A perennial creeping herb, fit to fix the sandy silt on the edges of sea-coasts.

Shepherdia argentea, Nuttall.

The Buffalo-Berry. From the Missouri to Hudson's Bay. This bush bears red acidulous edible berries.

Shorea robusta, Gaertner.

The Sal-tree. India, up to 3000 feet. It attains as a maximum a height of 150 and a girth of 25 feet. One of the most famed of Indian timber-trees. It could likely be grown in the warm forest-valleys of East Gipps Land. Drs. Stewart and Brandis found it on sandstone, conglomerate, gravelly and shingly ground, where loose water-transmitting soils are mixed with a large portion of vegetable mould. The climatic conditions within a Sal-area may be expressed as:-Mean annual rainfall, 40 to 100 inches; mean temperature, in the cool season $55^{\circ}$ to $77^{\circ}$, in the hot season $77^{\circ}$ to $85^{\circ} \mathrm{F}$. Sal will stand the occasional sinking of the temperature below freezingpoint. The heart-wood is dark-brown, coarse-grained, hard, very heavy, strong, tough, with fibrous cross-structure, the fibres interlaced. For buildings, river-boats and railwaysleepers it is the most important timber of North India. It exudes a pale, aromatic, Dammar-like resin. 


\section{Shorea Talura, Roxburgh. (S. laccifera, Heyne.)}

India, abounding in Mysore, where South European fruits prosper. On this tree also the Lac-insect lives. It furnishes a peculiar Dammar.

Sison Amomum, Linné.

Middle and South Europe. A herb of one or two years' duration. It grows best on soil rich in lime. The seeds can be used for condiment.

Smilax officinalis, Humboldt.

New Granada and other parts of Central America. This climbing shrub produces at least a portion of the Columbian Sarsaparilla.

Smilax medica, Chamisso and Schlechtendal.

Mexico. This plant produces mainly the Sarsaparilla-root of that country.

Smilax papyracea, Duhamel.

Guiana to Brazil. The origin of the principal supply of Brazilian Sarsaparilla is ascribed to this species, although sereral others of this genus, largely represented in Brazil, may yield the medicinal root also. In our fern-tree gullies these plants would likely succeed in establishing themselves. Smilax Australis (R. Br.), extends from the tropical coastparts of Australia to East Gipps Land. Neither this, nor the East Australian S. glycyphylla (Smith) nor the New Zealand Ripogonum scandens (Forst.) hare ever been subjected to accurate therapeutic tests, and the same may be said of numerous other Smilaces, scattered through the warmer countries of the globe. The Italian Sarsaparilla, which is derived from the Mediterranean S. aspera (L.), has been introduced into medicine.

Smilax rotundifolia, Linné.

Eastern States of North America and Canada. A prickly climber with deciduous foliage. An immense local use is made of the roots for the bowls of tobacco-pipes, clay pipes being there almost unknown. It is estimated that nearly three millions of these briar-root pipes are now made a-year. The reed-portion of these pipes is generally prepared from Alnus serrulata (Meehan).

\section{Smyrnium Olusatrum, Linné.}

The Alisander. Middle and South Europe, North Africa, Western Asia. A biennial herb, which raw or boiled can be utilised in the manner of Celery. The roots and the fruitlets serve medicinal purposes. 


\section{Solanum Æthiopicum, Linné.}

Tropical Africa. Cultivated there and elsewhere on account of its edible berries, which are large, red, globular and uneven. The plant is annual.

Solanum Dulcamara, Linné.

Middle and South Europe, North Africa, Middle Asia. A trailing half-shrub, with deciduous leaves. The stems are used in medicine, and contain two alkaloids: Dulcamarin and Solanin.

Solanum edule, Schumacher and Thonning.

Guinea. The berry is of the size of an apple, yellow and edible.

Solanum Fendleri, Asa Gray.

New Mexico. A new kind of Potato, enduring a temperature of zero. Mr. Meehan's endeavours to obtain good-sized tubers have as yet not been successful. The following plants are also spoken of by Dr. Rosenthal and others as new kinds of Potato, perhaps to be developed through cultivation: S. demissum (Lindley), S. cardiophyllum (Lindley), S. utile (Klotzsch), S. verrucosum (Schlechtendal), S. Bulbocastanum (Dunal), S. stoloniferum (Schlechtendal), all from Mexico and some from elevations 10,000 feet high; S. Maglia (Molina) from Chili and S. immite (Dunal) from Peru.

Solanum Gilo, Raddi.

Tropical America; much cultivated there for the sake of its large spherical orange-coloured berries, which are eatable.

Solanum Guinense, La Marck.

Within the tropics of both hemispheres. The berries of this shrub serve as a dye of various shades, particularly violet, for silk.

Solanum indigoferum, St. Hilaire.

Southern Brazil. A dye-shrub, deserving here trial-culture.

Solanum Lycopersicum, Linné. (Lycopersicum esculentum, Mill.)

The Tomato. South America. Annual. Several varieties exist, differing in shape and colour of the berries. It is one of the most eligible plants with esculent fruits for naturalisation in our desert-country. As well known, the Tomato is adapted for various culinary purposes.

Solanum macrocarpum, Linné.

Mauritius and Madagascar. A perennial herb. The berries are of the size of an apple, globular and yellow. S. Thonningi (F. Jacq.), from Guinea, is a nearly-related plant. S. calycinum (Moc. et Sess.), from Mexico, is also allied. 
Solanum Melongena, Linné. (S. ovigerum, Dunal; S. esculentum, Dunal.)

The Egg-plant. India and some other parts of tropical Asia. A perennial plant, usually renewed in cultivation like an annual. The egg-shaped large berries are known under the name of Aubergines or Bringals or Begoons as culinary esculents. Allied plants are: S. insanum (L.), S. longum (Roxb.), S. serpentinum (Desf.), S. undatum (Lam.), S. ferox (L.), S. pseudo-saponaceum (Blume), S. album (Lour.), which bear all large berries, considered harmless, but may not all represent well-marked species. Absolute ripeness of all such kinds of fruits is an unavoidable requisite, as otherwise even wholesome sorts may prove acrid or even poisonous. Probably many other of the exceedingly numerous species of the genus Solanum may be available for good-sized edible berries.

Solanum muricatum, L'Heritier.

The Pepino of Peru. A shrubby species with egg-shaped edible berries, which are white with purple spots, and attain a length of six inches.

Solanum Quitoense, La Marck.

Ecuador, Peru. A shrubby plant. The berries resemble in size, colour and taste small oranges, and are of a peculiar fragrance. To this the S. Plumierii (Dun.), from the West Indian Islands, is also cognate, and the S. Topiro (Kunth), from the Orinoco.

Solanum torvum, Swartz.

From West India to Peru. A shrubby species with yellow spherical berries of good size, which seem also wholesome. Other species from tropical America have shown themselves sufficiently hardy for inducing us to recommend the test-culture of such kinds of plants. Many of them are highly curious and ornamental.

\section{Solanum tuberosum, Linné.*}

The Potato. Andes of South America, particularly of Chili, but not absolutely trans-equatorial, as it extends into Columbia. It is also wild in the Aigentine territory. As a starchplant, the Potato interests us on this occasion particularly. Considering its prolific yield in our richer soil, we possess as yet too few factories for Potato-starch. The latter, by being heated with mineral acids or malt, can be converted into Dextrin and Dextro-Glucose for many purposes of the arts. Dextrin, as a substitute for gum, is also obtainable by subjecting Potato-starch in a dry state to a heat of $400^{\circ} \mathrm{F}$. Alcohol may be largely produced from the tubers. The berries and shoots contain Solanin. Baron von Liebig remarks :- "So far as its foliage is concerned, it is a lime-plant; as regards its tubers, a 
potash-plant." Langethal says:- "It surpasses in easy range of cultivation all other root-crops. Its culture suppresses weeds and opens up the soil, besides preparing the land for cereals." Seeds of the Potato-berries should be sown in adapted places by explorers of new countries. The most formidable Potato-disease of the last thirty years from the Peronospora infestans seems to have originated from the use of objectionable kinds of guano, to the introduction of which the murrain was contemporaneous.

Solanum Uporo, Dunal.

In many of the islands of the Pacific Ocean. The large red spherical berries of this shrub can be used like Tomato.

Solanum vescum, F. v. Mueller.

The Gunyang. South-East Australia. A shrub yielding edible berries, which need, however, to be fully ripe for securing absence of deleterious properties.

Solanum xanthocarpum, Schrader and Wendland.

North Africa and South Asia. A perennial herb. The berries. are of the size of a cherry, and either yellow or scarlet.

Sophora Japonica, Linné.*

A deciduous tree of China and Japan, resembling the Laburnum, up to sixty feet high; wood hard and compact, valued for turner's work. All parts of the plant purgative; the flowers rich in a yellow dye, used for silk.

Sophora tetraptera, Aiton. Var. Macnabiana, Graham.

The Pelu of Chili and Patagonia. A small tree with exceedingly hard and durable wood, much used for cog-wheels and similar structures. The wood differs much from that of S. Toramiro of the Easter Island (Dr. Philippi).

Spartina cynosuroides, Willdenow.

Eastern part of North America. A perennial grass of freshwater swamps, there often-called Prairie-grass; it can be utilised for fodder, and its value as paper-material seems equal to that of Esparto.

Spartina juncea, Willdenow.

Salt marshes of North America. A grass with creeping. roots; it can be utilised to bind moist sand on the coast. A tough fibre can readily be obtained from the leaves. S. polystachya (W.) is a stately grass, adapted for saline soil.

Spartina stricta, Roth.

Countries at the Mediterranean Sea, extending to Britain and also to North America. The twin-spiked Cord-grass. A rigid perennial with creeping roots, recommended for fixing and rendering solid any mud-flats on low shores and at the mouth of rivers; only suitable for brackish ground. 
Spartium junceum, Linné.

Countries around the Mediterranean Sea. The flowers of this bush provide a yellow dye. A textile fibre can be separated from the branches.

Spergula arvensis, Linné.

All Europe, North Africa, West Asia. This annual herb, though easily becoming a troublesome weed, is here mentioned for the desirable completeness of this enumeration. The tall variety with large seeds (S. maxima, Weihe), can be chosen with advantage for the commencement of tillage on any sandy soil, too poor for barley. It takes up the land only for about two months, if grown for green-fodder, and increases much the yield of milk. It serves also for admixture to hay (Langethal).

Spigelia Marylandica, Linné.

North America, north to Pennsylvania and Wisconsin. A perennial handsome herb, requiring as a vermifuge cautious administration. S. anthelmia (L.) is an annual plant of tropical America and possesses similar medicinal properties, in which probably other species likewise share.

Spilanthes oleracea, N. Jacquin.

The Para-Cress. South America. An annual herb of considerable pungency, used as a medicinal salad.

Spinacia oleracea, Linné.

Siberia. The ordinary Spinage. An agreeable culinary annual of rapid growth. It is of a mild aperient property. Two varieties are distinguished, the Summer and the Winter Spinage, the former less inclined to run into seed but also less hardy.

Spinacia tetrandra, Stev.

Caucasus. Also annual and unisexual like the preceding plant, with which it has equal value, though it is less known.

Spinifex hirsutus, La Billardière.

On the whole coast of extra-tropical Australia. Highly valuable for binding coast-sand with its long creeping roots.

Spinifex longifolius, R. Brown.

On the tropical and western extra-tropical coast of Australia. Available like the former.

Spinifex squarrosus, Linné.

India. Useful, like the two preceding plants. Tennent remarks, that the radiating heads become detached when the seed is matured, and are carried by the wind along the sand, over the surface of which they are impelled by their elastic spines, dropping their seeds as they roll along. The heads 
are so buoyant as to float lightly on water, and while the uppermost spiny rays are acting as sails, they are carried across narrow estuaries to continue the process of embanking beyond on any newly formed sandbars.

Spondias dulcis, G. Forster.

Fiji, Tongan and Society Islands. This noble tree is introduced into this list to indicate, that trials should locally be instituted here as regards the culture of the various good fruit-bearing species of this genus, one of which, S. pleiogyna (F. von Mueller), transgresses in East Australia the tropical circle. The lamented Dr. Seemann saw S. dulcis sixty feet ligh, and describes it as laden with fruit of agreeable appleflavour called Rewa, and attaining over 1-lb. weight.

\section{Stenotaphrum Americanum, Schranck. (S. glabrum, Trinius.)}

South Asia, Africa, warmer countries of America, not known from any part of Europe or Australia. Here called the Buffalo-grass. It is perennial, creeping and admirably adapted for binding sea-sand and river-banks, also for forming garden-edges, and for establishing a grass-sward on lawns much subjected to traffic; it is besides of some pastoral value. It was this grass, which Mr. John C. Bell reared with so much advantage for fodder on the bare rocks of the island of Ascension, and it was there where Australian Acacias took the lead to establish wood vegetation and for securing permanency of drinking-water.

Stilbocarpa polaris, Decaisne and Planchon.

Auckland's and Campbell's Islands, and seemingly also in the southern extremity of New Zealand. A herbaceous plant with long roots, which are saccharine and served some wrecked people for a lengthened period as sustenance. The plant is recommended here for further attention, as it may prove through culture a valuable addition to the stock of culinary vegetables of cold countries.

Stipa tenacissima, Linné.* (Macrochloa tenacissima, Kunth.) The Esparto or Atocha. Spain, Portugal, Greece, North Africa, ascending the Sierra Nevada to 4000 feet. This grass has become celebrated since some years, having afforded already a vast quantity of material for British paper-mills. It is tall and perennial, and may prove here a valuable acquisition, inasmuch as it lives on any kind of poor soil, occurring naturally on sand and gravel as well as on clayey or calcareous or gypseous soil, and even on the very brink of the coast. But possibly the value of grasses of our own, allied to the Atocha, may in a like manner become commercially established, and mainly with this view paper 
samples of several grass-kinds were prepared by the writer (vide "Report, Industrial Exhibition, Melbourne, 1867"). Even in the scorching heat and the arid sands of the Sahara the Atocha maintains itself, and it may thus yet be destined to play an important part in the introduced vegetation of any arid places of our desert-tracts, particularly where lime and gypsum exist. The very tenacious fibre resists decay, and is much employed for the manufacture of ropes. During 1870 the import of Esparto-ropes into England was 18,500 tons, while the raw material to the extent of about 130,000 tons was imported. Extensive culture of this grass has commenced in the south of France. It is pulled once a year, in the earlier part of the summer. The propagation can be effected from seeds, but is done usually by division of the root. Ten tons of dry Esparto, worth from $£ 4$ to $£ 5$ each, can under favourable circumstances be obtained from an acre. The supply has fallen short of the demand. Good writingpaper is made from Esparto without admixture; the process is similar to that for rags, but cleaner. The price of Espartopaper ranges from $£ 40$ to $£ 50$ for the ton. Stipa arenaria (Brot.) is a closely allied and still taller species, confined to Spain and Portugal. Consul W. P. Mark deserves great praise for having brought the Atocha into commercial and manufactural recognition.

Streblus asper, Loureiro.

South Asia. This bears a good recommendation for live fences, it being a shrub of remarkable closeness of branches.

Styrax officinale, Linné.

Countries on the Mediterranean Sea. A tall bush or small tree. The fragrant solid Storax-resin exudes from this plant, or is particularly obtained by pressure of the bark.

Swietenia Mahagoni, Linné.

The Mahogany-tree of West India, extending naturally to Florida and Mexico. The degree of endurance of this famous tree is not sufficiently ascertained. In its native mountains it ascends to 3000 feet.

Symphytum asperrimum, Sims.*

The Prickly Comfrey. Caucasus. The growth of this hardy plant may be recommended as an adjunct to Lupine-culture. The Hon. Arthur Holroyd, of Sydney, has recently devoted a special publication to this plant. He quotes on good authority the return of foliage already in the first year as 20 tons to the acre, in the second year 50 tons and every year after 80 to 120 tons on manured land. It yields a nutritive and relished forage in rapid and continuous reproduction. It is likewise recommended for green manure. Dr. 
Voelcker found much mucilage but little sugar in this plant. The massive root known to penetrate to nine feet depth sustains the plant in vigour, admitting it to be cut almost throughout the year. The propagation is easy from rootcuttings, difficult from seeds, 4000 of the former to an acre; it will thrive even in sand and tough clay, but prefers moist and even boggy land. It ought here to be naturalised along swamps, lagoons and river-banks. It can be dried for hay. Finally it is recommended as a plant for game.

Symphytum officinale, Linné.

The Comfrey. Europe, Western Asia. A perennial herb. The root is utilised in veterinary practice.

Symplocos ramosissima, Wallich.

Himalaya, up to 7500 feet. In Sikkim, according to Dr. Stewart, the yellow silkworm is reared on the leaves of this tree. Two allied species occur spontaneously in the forests of East Australia.

Synoon glandulosum, A. de Jussieu.

New South Wales and South Queensland. This evergreen tree deserves cultivation in sheltered warm forest-valleys of our colony, on account of its rose-scented wood. Some species of Dysoxylon of East Australia produce also rosewood.

Tacca pinnatifida, G. Forster.

Sand-shores of the South Sea Islands. From the tubers of this herb the main supply of the Fiji arrowroot is prepared. It is not unlikely, that this plant will endure our coast-clime. The Tacca-starch is much valued in medicine, and particularly used in cases of dysentery and diarrhœea. Its characteristics. are readily recognised under the microscope. Several other kinds of Tacca are distinguished, but their specific limits are not yet well ascertained. Dr. Seemann admits two (T. maculata and T. Brownii) for tropical Australia, one of these extending as a hill-plant to Fiji. From the leaves and flower-stalks light kinds of bonnets are plaited. A Tacca occurring in the Sandwich Islands yields a large quantity of the so-called arrowroot exported from thence. Other species (including those of Ataccia) occur in India, Madagascar, Guinea and Guiana, all deserving tests in reference to their value as starch-plants.

Tagetes glanduligera, Schranck.

South America. This vigorous annual plant is said by Dr. Prentice to be pulicifugous. 
Tamarindus Indica, Linné.

Tropical Asia and Africa. This magnificent large expansive tree extends northwards of Egypt, and was found by the writer of this list in North-Western Australia. Final girth of stem 25 feet not rare. Never leafless. Varieties occur according to Brandis with sweetish red pulp. It is indicated here not without hesitation, to suggest new trials of its acclimation on the lower Murray River and in East Gippsland. The acid pulp of the pods forms the medicinal Tamarind, rich in formic and butyric acid, irrespective of its other contents.

Tamarix dioica, Roxburgh.

India, up to 2500 feet. An important shrub for binding newly-formed river-banks even in saline soil.

Tamarix Gallica, Linné.*

South Europe, North and tropical Africa, South Asia, ascending the Himalayas to 11,000 feet. This shrub adapts itself in the most extraordinary manner to the most different localities. It will grow alike in water and the driest soil ; also in salty ground; and is one of the most grateful and tractable plants in culture; it is readily multiplied from cuttings, which strike root as easily as a willow, and push forth stems with unusual vigour. Hence it is one of the most eligible bushes for planting on coast-sand to stay its movements, or for lining embankments. Planted much in cemeteries. Here first largely sent out by the writer.

Tamarix Germanica, Linné.

Europe and West Asia, ascending to 15,000 feet in the Himalayas. Likewise available for arresting the ingress of shifting sand, particularly in moist places, also for solidifying precipitous river-banks. The allied T. elegans (Myricaria elegans, Royle) attains a height of twenty feet.

Tamarix orientalis, Forskal. (T. articulata, Vahl.)

North and Middle Africa, South Asia. A fast-growing tree, attaining a height of sixty feet, the trunk occasionally expanding to a circumference of twelve feet. Springs up freely from seeds and is also readily propagated from cuttings. Coppices well (Stewart and Brandis). The wood serves for ploughs, wheels and many implements. Dye-galls and a kind of manna are also produced by this tree. The same or an allied species extends to Japan.

Tanacetum vulgare, Linné.

The Tansy. North and Middle Europe, North Asia, NorthWestern America. A perennial herb of well-known medicinal value, which mainly depends on its volatile oil. 
Taraxacum officinale, Weber.

Dispersed over most of the temperate and cold parts of the globe, but apparently not a native of this part of Australia. This well-known plant is mentioned, as it can be brought under regular cultivation to obtain the medicinal extract from its roots. It is also considered wholesome to pasture-animals. The young leaves furnish a medicinal salad.

Tarchonanthus camphoratus, Linné.

South Africa. This bush deserves attention, being of medicinal value. As an odorous garden-plant it is also very acceptable.

Taxodium distichum, Richard.*

Virginian Swamp- or Bald-Cypress. In swampy places of North America. A large and valuable tree, one hundred feet high, with a stem circumference of sometimes forty feet; of rapid growth, with deciduous foliage like that of the larch and ginkgo. It is found fossil in the miocene formation of many parts of Europe. The wood is fine-grained, hard and durable; it yields an essential oil and a superior kind of turpentine. Useful for avenues on swampy margins of lakes or river-banks. Porcher says: This tree, lifting its giant form above the others, gives a striking feature to many of the swamps of Carolina and Georgia; they seem like watchtowers for the feathered race.

Taxodium mucronatum, Teno.

The famed Montezuma-Cypress of Mexico, 120 feet high, with a trunk 44 feet in circumference; it forms extensive forests between Chapultepec and Tescuco.

Taxus baccata, Linné.

Yew. Middle and South Europe and Asia, at 1000 to 10,000 feet elevation. Generally a shrub, sometimes a tree one hundred feet high, which furnishes a yellow or brown wood, exceedingly tough, elastic and durable, and much esteemed by turners; one of the best of all woods for bows. The tree is of very slow growth, and attains a great age, perhaps several thousand years ; some ancient ones are known with a stem of fifty feet in girth. It should be kept out of the reach of pasture-animals, as leaves and fruit are deadly poisonous.

Taxus brevifolia, Nuttall. (T. Lindleyana, Lawson.)

North-West America. Western Yew. A stately tree, serenty-five high, with a stem of five feet in circumference. Wood beautifully white or slightly yellow, as fine and closegrained as the European Yew. The Indians use it for their bows. 
Tectona grandis, Linné fil.

The Teak of South Asia. This superb timber-tree has its northern limit in Bandalkhand, at elevations of 3000 feet, ascending to 4000 feet; but then not of tall size. In Western India, according to Stewart and Brandis, frost is not uncommon in the Teak districts.

Teinostachyum attenuatum, Munro.

The hardy Bamboo of Ceylon, there growing on the mountains at elevations between 4000 to 6000 feet. It attains a height of 25 feet.

Telfairia pedata, Hooker.

Mozambique. A cucurbitaceous climber with perennial stems, attaining a length of 100 feet, with fringed lilac flowers of extraordinary beauty and with fruits attaining a weight of $60 \mathrm{lbs}$, and containing at times as many as 500 large seeds. The latter in a boiled state are eatable, or a large quantity of oil can be pressed from them. The root is fleshy. Our summers in the Murray-country are likely to bring this plant regularly into bearing. A second huge species of similar use, T. occidentalis (J. Hook.), occurs in Guinea.

Terfezia Leonis, Tulasne.

South Europe, North America. This edible Truffle, together with other species of this and other genera, is deserving of naturalisation in Australia.

Terminalia Catappa, Linné.

India, ascending mountain-regions. Few trees, as stated by Roxburgh, surpass this in elegance and beauty. We have yet to learn whether it can be naturalised here, which it especially deserves for its nuts. Several species extend in East Australia to subtropical latitudes. The seeds are almond-like, of filbert taste and wholesome. The astringent fruits of several other species form an article of trade, sought for a lasting black dye. T. parviflora (Thwaites) forms a large tree in Ceylon, at elevations up to 4000 feet.

Tetragonia expansa, Murray.

The New Zealand Spinage, occurring also on many places of the coast and in the desert-interior of Australia. Known also from New Caledonia, China, Japan and Valdivia. An annual herb, useful as a culinary vegetable, also for binding drift-sand.

Tetragonia implexicoma, J. Hooker.

Extra-tropic Australia, New Zealand, Chatham Island. A frutescent widely expanding plant, forming often large natural festoons, or trailing and climbing over rocks and 
sand, never away from the coast. As a spinage-plant it is as valuable as the succeeding species. It is well adapted for the formation of bowers in arid places; it helps also to bind sand. T. trigyna (Banks and Solander) seems identical.

Tetranthera Californica, Hooker and Arnott.* (Oreodaphne Californica, Nees.)

Oregon and California, where it is called the Mountain-Laurel or Bay-tree. On the banks of rivers attaining a height of 100 feet, throughout pervaded by a somewhat camphoric odour. Wood hard, close-grained, durable, susceptible of a high polish, easily worked, used for superior flooring, turnery and manifold other select work. The tree is easily cultivated, and of comparatively quick growth (Dr. Behr and Prof. Bolander.)

Tetranthera calophylla, Miquel. (Cylicodaphne sebifera, Blume.)

Mountains of Java and the Neilgherries. From the kernels of the berries a tallow-like fat is pressed for the manufacture of candles. The yield is comparatively large. Trial cultures with this tree might be instituted in our humid forest-valleys. T. laurifolia (Jacq.) of tropical Asia and Australia and T. japonica (Sprengel) are noted as similarly utilitarian.

Teucrium Marum, Linné.

Countries at the Mediterranean Sea. A small somewhat shrubby plant, in use for the sake of its scent, containing a peculiar Stearopten. T. Scordium (L.) from Europe and Middle Asia, T. Chamaedrys (L.), T. Polium (L.) and T. Creticum (L.) from South Europe, are occasionally drawn into medical use. All these together with many other species from various countries are pleasantly odorous.

Thapsia edulis, Bentham. (Monizia edulis, Lowe.)

On the island of Deserte Grande, near Madeira, where it is called the Carrot-tree. It might be of some use to bring this almost shrubby umbellate to the cliffs of our shores; though the root is inferior to a carrot, perhaps cultivation would improve it.

Thea Chinensis, Sims.* (Camellia Thea, Link.)

The Tea-shrub of South-eastern Asia. This evergreen and ornamental bush has proved quite hardy in our lowland clime, where in exposed positions it endures without any attention as well our night-frosts as also the free access of scorching summer-winds. But it is in our humid valleys, with rich alluvial soil and access to springs for irrigation, where only the most productive Tea-fields can be formed. The. plant comes into plentiful bearing of its product as early 
as the Vine and earlier than the Olive. Its culture is surrounded with no difficulties, and it is singularly exempt from diseases, if planted in proper localities. Pruning is effected in the cool season, in order to obtain a large quantity of small tender leaves from young branches. Both the Chinese and Assam Tea are produced by varieties of one single species, the Tea-Shrub being indigenous in the forestcountry of Assam. Declivities are best adapted and usually chosen for Tea-culture, particularly for Congo, Pekoe and Souchong, while Bohea is often grown in flat countries. For many full details Fortune's work, "The Tea-Districts of China," might be consulted. The very troublesome Tea-bug of Asia is Helopeltis theivora. Fumigation and the application of birdlime are among the remedies to cope with this insect. The third volume of the Agricultural and Horticultural Society of India is mainly, occupied by Lieut.-Colonel Edw. Money's and Mr. Watson's elaborate essays on the cultivation and manufacture of Tea in India. For full advice on and culture preparation consult the writer's printed lecture, delivered in 1875 at the Farmers' Club of Ballarat.

The Tea of commerce consists of the young leaves, heated, curled and sweated. The process of preparing the leaves can be effected by steam machinery; a machine of particular construction has been suggested recently by Mr. Joachimi according to requirements explained by the writer. In 1866 three machines for dressing Tea have been patented in England, one by Messrs. Campbell and Burgess, one by Mr. Thomson and one by Mr. Tayser. To give an idea of the quantity of Tea, which is consumed at the present time, it may be stated, that from June to September, 1871, 11,000,000 lbs. of Tea were shipped from China alone to Australia, and that the produce of Tea in India from January to June of this year has been $18,500,000$ lbs. Seeds of the Tea-bush are now in many parts of this colony locally to be gathered from plants distributed by the writer, and for years to come the cultivation of the Tea-bush, merely to secure local supplies of fresh seeds, ready to germinate, will in all likelihood prove highly lucrative. Tea contains an alkaloid: Coffein, a peculiar essential oil and Bohea-acid along with other substances.

Theligonum cynocrambe, Linné.

Countries around the Mediterranean Sea. An annual Spinage plant of somewhat aperient effect.

Thouarea sarmentosa, Persoon.

Tropical shores of the eastern hemisphere. This curious and tender grass might be easily introduced, to help binding the sand on sea-beaches. 


\section{Thrinax parviflora, Swartz.}

West India, and also on the continent of Central America. The stem of this Fan-Palm attains a height of twenty-five feet. It belongs to the sand-tracts of the coast and may endure our clime. The fibre of this palm forms material for ropes. T. argentea (Lodd.) is a closely allied palm. The few other species of the genus deserve also trial-culture here.

Thuya gigantea, Nuttall.

North-West America, on the banks of the Columbia River. The Yellow Cypress of the colonists. A straight, graceful tree 200 feet high, furnishing a valuable building-timber of a pale or light-yellow colour, known as the Oregon White Cedar-wood, susceptible of high polish. The diameter of the stem attains ten feet or even more. The timber is light. Canoes carrying four tons have been obtained out of one stem. The bast can be converted into ropes and mats.

Thuya occidentalis, Linné.

North America, particularly frequent in Canada. Northern White Cedar. A fine tree, seventy feet high; the wood is reddish or yellowish, fine-grained, very tough and resinous, and well fit for building; especially for water-work; also for turnery and machinery. Michaux mentions that posts of this wood last forty years; a house built of it was found perfectly sound after sixty years. It prefers moist soil. Valuable for hedge-copses ; it can also be trained into garden-bowers. The shoots and also an essential oil of this tree are used in medicine; the bast can be converted into ropes. The branches serve for brooms.

Thuyopsis dolabrata, Siebold and Zuccarini.

Japan. A majestic tree, furnishing an excellent hard timber of a red colour.

Thymelæa tinctoria, Endlicher. (Passerina tinctoria, Pourr.) Portugal, Spain, South France. A small shrub. It yields a yellow dye. Cursorily it may be noted here, that some of our Pimelex contain a blue pigment, which has not yet been fully tested. Their bark produces more or less of Daphnin and of the volatile acrid principle, for which the bark of Daphne Mezereum (L.) is nsed. These are remarkably developed in the Victorian Pimelea stricta (Meissn). The bark of many is also pervaded by a tough fibre, that of the tall Pimelea clavata (Labill.), a West Australian bush, being particularly tenacious, and used for whips. 
Thymus capitatus, Hoffmann and Link. (Satureja capitata, Linné).

Around the whole Mediterranean Sea. Since the times of Hippocrates, Theophrastos and Galenus this small scented shrub has been employed in medicine.

Thymus Mastichina, Linné.

Spain, Portugal, Morocco. A half-shrub of agreeable scent, used also occasionally in medicine.

Thymus Serpillum, Linné.

Europe, Western Asia. A perennial herb of some medicinal value. It would live on our highest alps. An essential oil can be obtained from it. One particular variety is lemonscented.

Thymus vulgaris, Linné.

The Garden-Thyme. South Europe. This small shrubby plant is available for scent and for condiments. It is also well adapted for forming garden-edges. The essential oil of this plant can be separated into the crystalline Thymol and the liquid Thymen and Cymol. T. aestivus (Ruet.) and T. hiemalis (Lange) are closely cognate plants. Several other species with aromatic scent occur at the Mediterranean Sea.

Tilia Ámericana, Linné.

The Basswood-tree or North American Linden-tree, growing to $52^{\circ}$ north latitude. Height of tree eighty feet, diameter of stem four feet. Wood pale and soft. Tilia heterophylla (Vent.), the Silver-Lime of North America, and Tilia Manchurica (Rupr.) of South Siberia might be tested.

Tilia argentea, Desfontaines.*

The Silver Lime-tree of South-East Europe. The wood is not attacked by boring insects. The flowers are deliciously fragrant, and yield on distillation a precious oil.

Tilia Europæa, Linné.

The common Lime of Europe, extending naturally to Japan, the large-leaved variety of South European origin. Height up to 120 feet, exceptionally 50 feet in girth. The wood pale, soft and close-grained; sought for turnery and carving. The bast excellent for mats.

Tillandsia usneoides, Linné.

From Carolina and Florida to Uruguay and Chili, on trees. Might be naturalised in our forests. In its native country a favourite material for upholsterers' work.

Tinguarra Sicula, Parlatore.

In the countries at the Mediterranean Sea. The root is edible and celery-like. 
Torreya Californica, Torrey. (T. myristica, Hooker.)

In California. Tree eighty feet high.

Torreya grandis, Fortune.

China. A tree sixty feet high, with an umbrella-shaped crown; it produces good timber.

Torreya nucifera, S. and Z. (Caryotaxus nucifera, Zuccarini.)

Japan. Height of tree about thirty feet. From the nuts the Japanese press an oil, used as an article of food.

Torreya taxifolia, Arnott.

Florida. A tree fifty feet in height, with a firm, closegrained, durable wood of a reddish colour.

Touchardia latifolia, Gaudichaud.

In the Hawaian Islands. A shrub allied to Boehmeria nivea, yielding a tough and easily separable fibre, as first shown by Dr. Hillebrand. Probably best adapted for our ferntreegullies.

Tragopogon porrifolius, Linné.

The Salsify. Middle and Southern Europe, Middle Asia. Biennial. The root of this herb is well known as a useful culinary vegetable.

Trapa bicornis, Linné fil.*

The Leng or Ling or Links of China. The nuts of this water-plant are extensively brought to market in that country. The horns of the fruit are blunt. The kernel, like that of the two following species, is of excellent taste. The plant is regularly cultivated in lakes and ponds of China.

Trapa bispinosa, Roxburgh.*

Middle and South Asia, extending to Ceylon and Japan; found also in Africa as far south as the Zambesi. Here in our culture it lasts through several years. In some countries, for instance in Cashmere, the nuts form an important staple of food to the population. To this species probably belong T. Cochin-chinensis (Lour.) and T. incisa (Sieb. and Zucc.)

Trapa natans; Linné.*

The ordinary Waternut. Middle and South Europe, Middle Asia, North and Central Africa. Recorded as an annual. T. quadrispinosa (Roxb.), from Sylhet, is an allied plant.

Trifolium agrarium, Linné.

The perennial Yellow Clover. or Hop-Clover. All Europe, Western Asia. Of considerable value in sandy soil as a fodder-herb. It is easily naturalised. 


\section{Trifolium Alexandrinum, Linné.*}

The Bersin-Clover. North-Eastern Africa, South-Western Asia, South Europe. Much grown for forage in Egypt. Recorded as annual.

Trifolium alpestre, Linné.

Europe, West Asia. Perennial. Content with lighter soil than that needed for most Clovers, but its constituents must be fairly marly or limy. It is early out and very palatable (Langethal).

Trifolium fragiferum, Linné.

The Strawberry-Clover. Europe, North Africa, Middle and North Asia. A perennial species, well adapted for clay-soils. Foliage closer and more tender than that of the White Clover, but its vegetation later (Langethal).

Trifolium hybridum, Linné.*

The Alsike-Clover. Europe, North Africa, Western Asia. A valuable perennial pasture-herb, particularly for swampy localities. It succeeds where the ground becomes too sandy for Lucerne and too wet for Red Clover.

Trifolium incarnatum, Linné.

The Carnation-Clover. Middle and South Europe. Though annual only, or sometimes biennial, it is valued in some of the systems of rotations of crops. It forms particularly a good fodder for sheep; it is recommended especially for gypsum-regions. A white-flowering variety exists.

Trifolium medium, Linné.*

The Red Zigzag-Clover. Europe, North and Middle Asia. A deep-rooting perennial herb, much better adapted for dry sandy places than $T$. pratense. It would also endure the inclemency of the clime of our higher alpine regions, if disseminated there. One of the best Clovers for forest-regions. For regular culture it needs lime, like most plants of its class. More hardy than T. hybridum, less productive than T. pratense (Langethal). It ought not to be omitted among mixed Clovers and grasses. T. Quartinianum (A. Rich) is an allied plant from Abyssinia, where several endemic species exist. Some of the twenty-five known Californian Clovers would deserve test-culture.

Trifolium montanum, Linné.

Europe, West Asia. Perennial. Not without importance for limy or marly ground.

Trifolium ochroleucum, Linné.

Middle and South Europe, West Asia. Pale-yellow Clover. Perennial. This species is much cultivated in Upper Italy; its value is that of T. medium (Langethal). 


\section{Trifolium pratense, Linné.*}

The ordinary Red Clover. All Europe, North Africa, North and Middle Asia, extending to Japan. A biennial or under special circumstances also perennial herb, of great importance for stable-fodder. It prefers rich soil, and particularly such which is not devoid of lime; gypsum dressings are recommended for its fields. It enters very advantageously into the rotation-system of crops. Also this species would live in our alps, where it would much enrich the pastures.

Trifolium repens, Linné.*

The ordinary White Clover. Europe, North Africa, North and Middle Asia, Sub-Arctic America. Perennial. Most valuable as a fodder-plant on pastoral land. It has a predilection for moist soil, but springs again from dry spots after rain. It likes soil containing lime, prospers on poorer ground than Red Clover, is more nourishing and better digested and less exhaustive to the soil. It has naturally spread over many of our humid valleys, and its growth should be encouraged in such localities.

Trifolium spadiceum, Linné.

Brown Clover. Europe, West Asia. Though only annual or biennial, this has been recommended for wet sandy moorland, on which it redisseminates itself with readiness.

Trifolium subrotundum, Hochstetter.

The Mayad-Clover. North and Middle Africa, ascending to 9000 feet. A perennial species, in its native countries with advantage utilised for Clover-culture. This by no means closes the list of the Clovers desirable for introduction, inasmuch as about 150 well-marked species are recognised, many doubtless of pastoral value. But the notes of rural observers on any of these kinds are so sparingly extant, that much uncertainty about the yield and nutritive value of the various kinds continues to prevail. Most Clovers come from the temperate zone of Europe and Asia; only two are indigenous to the eastern of the United States of North America, none occurs in Australia, few are found in South Africa, several in California and the adjoining countries, several also in. Chili; no species is peculiar to Japan.

Trigonella Fœnum Græcum, Linné.

Countries on the Mediterranean Sea. The seeds of this annual herb find their use in veterinary medicine.

Trigonella suavissima, Lindley.

Interior of Australia, from the Murray-River and its tributaries to the vicinity of Shark's Bay. This perennial, 
fragrant, clover-like plant proved a good pasture-herb. A lithogram, illustrating this plant, occurs in the work on the "Plants Indigenous to Victoria." Some of the many European, Asian and African plants of this genus deserve our local tests.

Triphasia Aurantiola, Loureiro.

South-East Asia. This shrub is worth cultivation for the exquisite fragrance of its flowers. The fruits though small are of pleasant sweetness. The plant may prove also adapted for hedges. Glycosmis citrifolia (Lindley) and Claussena punctata (Oliver), also both East Asiatic fruit-shrubs, may possibly show themselves hardy in our sheltered forestregions.

Tripsacum dactyloides, Linné.

Central and North America. A reedy perennial grass, more ornamental than utilitarian. It is the original Buffalograss, and attains a height of seven feet, assuming the aspect of Maize. It is of inferior value for fodder, but serves for binding sand. The seeds are available for food. To T. monostachyon belongs, according to Decaisne, the Teosinté or Reana luxurians (Durien.)

Tristania conferta, R. Brown.

New South Wales and Queensland. A noble shady tree, attaining a height of 150 feet. It is not only eligible as an avenue-tree, but also as producing select, lasting timber; ribs of vessels from this tree have lasted unimpaired thirty years and more.

Triticum junceum, Linné.

Europe and North Africa. A rigid grass with pungent leaves and extensively creeping roots, requiring sea-sand for its permanent growth. One of the best grasses to keep rolling sand-ridges together, and particularly eligible where cattle and other domestic animals cannot readily be prevented from getting access.

\section{Triticum vulgare, Villars.*}

The Wheat. Apparently arisen through culture from Egilops ovata (L.), and then a South European, North African and Oriental plant. This is not the place to enter into details about a plant universally known. It may therefore suffice merely to mention, that three primary varieties must be distinguished between the very numerous sorts of cultivated Wheat: 1. Var. muticum, T. hybernum (L.), the Winter Wheat or Unbearded Wheat; 2. Var. aristatum, T. æstivum (L.), the Summer Wheat or Bearded Wheat; 3. Var. adhærens, T. Spelta (L.), Wheat with fragile axis 
and adherent grain. Metzger enumerates as distinct kinds of cultivated Wheat:-

T. vulgare (Vill.), which includes among other varieties the ordinary Spring Wheat, the Fox Wheat and the Kentish Wheat. It comprises also the best Italian sorts for plaiting straw-bonnets and straw-hats, for which only the upper part of the stem is used, collected before the ripening of the grain and bleached through exposure to the sun while kept moistened.

T. turgidum (L.), comprising some varieties of White and Red Wheat, also the Clock Wheat and the Revet Wheat.

T. durum (Desfont.), which contains some sorts of the Bearded Wheat.

T. Polonicum (L.), the Polish Wheat, some kind of which is well-adapted for peeled Wheat.

T. Spelta (L.), the Spelt Corn or Dinkel Wheat, a kind not readily subject to disease, succeeding on soil of very limited fertility, not easily attacked by birds, furnishing a flour of excellence for cakes, also yielding a superior grain for peeled Wheat. For preparing the latter it is necessary to collect the spikes while yet somewhat green and to dry them in baking-houses.

T'. dicoccum (Schrank). (T. amyleum, Ser.) The Emmer Wheat. Its varieties are content with and prolific on poor soil, produce excellent starch, are mostly hardy in frost and not subject to diseases. To this belongs the Arras Wheat of Abyssinia, where a few other peculiar sorts of Wheat are to be found.

T. monococcum (L.) St. Peter's Corn, which is hardier than most other Wheats; exists in the poorest soils, but produces grains less adapted for flour than for peeled Wheat.

\section{Tropæolum majus, Linné.}

Peru. This showy perennial climber passes with impropriety under the name of Nasturtium. The herbage and flowers serve as Cress, and are also considered antiscorbutic. A smaller species T. minus (L.), also from Peru, can likewise be chosen for a Cress-salad; both besides furnish in their flower-buds and young fruits a substitute for Capers. A volatile oil of burning taste can be distilled from the foliage of both; and this is more acrid even than the distilled oil of Mustard-seeds. In colder countries these plants are only of one year's duration. Numerous other species, all highly ornamental, occur in South America and a few also in Mexico. 
Tropæolum sessilifolium, Pœppig.

Chili. Among the species of this genus one of the most eligible for its tubers, which can be consumed even in a raw state and are larger than those of most other Tropæolums, while the stems are short and procumbent (Philippi).

Tropæolum tuberosum, Ruiz and Pavon.

Peru. The tuberous root serves as an esculent.

Trophis Americana, Linné.

West Indian Archipelagus. The foliage of this milky tree has been recommended as food for the silk-insect. In Cuba and Jamaica it is used as provender for cattle and sheep.

Tuber aestivum, Vittadini.

The Truffle most in the markets of England. The white British Truffle, Chairomyces meandriformis (Vitt.), though large is valued less. In the Department Vaucluse (France) alone about 60,000 lbs. of Truffles are collected annually at a value of about $£ 4000$. Many other kinds of Truffles are in use. Our own native Truffle, Mylitta Australis (Berk.) attains sometimes the size of the Cocos-nut, and is also a fair esculent. It seems also quite feasible to naturalise the best of edible fungi of other genera, although such may not be amenable to regular culture.

Tuber albidum, Fries.

Occurs with T. æstivum, but is smaller and less agreeable in taste. The means of transferring Truffles and any other edible fungi from one country to another require yet to be further studied and finally devised, but they appear quite. feasible.

Tuber cibarium, Sibthorp.

Middle and South Europe. The Black Truffle. Like all others growing under ground, and generally found in forestsoil of limestone formations. It attains a weight over one pound. Experiments for naturalisation may be effected with every prospect of success by conveying the Truffle in its native soil to us, and locating it in calcareous places of our forest-regions. As condiment or merely in a roasted state it affords an aromatic food. T. melanosporum (Vitt.) from France, Germany and Italy, is of a still more exquisite taste than ' $\mathrm{T}$. cibarium, indeed of strawberry flavour.

Tuber magnatum, Pico.

Grey Truffle. South Europe. One of the most esteemed Truffles, with some garlic flavour.

Tuber rufum, Pico.

Red Truffle, especially in vineyards. Much used for food, but smaller than the Terfezia Truffles. 
Ulex Europæus, Linné.

Middle and South Europe, Azores, Canary Islands. The Whin, Gorse or Furze. A bush important for covering quickly drift-sands on coasts. Too apt to stray as a hedgeplant.

Ullucus tuberosus, Lozano. (Melloca tuberosa, Lindley.)

Andes of New Granada and Peru, up to an elevation of 9000 feet. A perennial herb, the tubers of which are edible.

Ulmus alata, Michaux.

The Whahoo-Elm of North America. Height of tree thirty feet. Wood fine-grained, heavier and stronger than that of the White Elm, of a dull red colour, used by wheelwrights, but like that of U. Americana not equal to the European Elm.

Ulmus Americana, Linné.

The White Elm of North America. A tree fond of moist river-banks. One hundred feet high, trunk sixty feet, five feet in diameter.

Ulmus campestris, Linné.*

The ordinary Elm, indigenous to South Europe and temperate Asia, as far east as Japan. Several marked varieties, such as the Cork-Elm and Wych-Elm, exist. The Elm in attaining an age of several centuries becomes finally of enormous size. In Britain much attacked by Scolytus destructor. The wood is tough, hard, fine-grained and remarkably durable, if constantly under water. Next to the Yew it is the best of European woods, where great elasticity is required, as for archery bows. It is also used for keels, blocks and wheels. Bast tough.

Ulmus crassifolia, Nuttall.

The evergreen Elm of Mexico and Texas.

Ulmus Floridana, Chapman.

The West Florida Elm. Forty feet high.

Ulmus fulva, Michaux.

The Slippery or Red Elm of North America. Sixty feet high. Wood red, tenacious.

Ulmus Mexicana, Planchon.

c. Cordilleras of North America. This Elm attains a height of sixty feet or perhaps more. Many of these Elms are available as quick-growing avenue trees for shade-lines.

Ulmus parvifolia, Jacquin.

The evergreen Elm of China, Japan and Queensland. A similar tree is found in the Himalaya Mountains. 
Ulmus pedunculata, Fougeraux. (U. ciliata, Ehrhart.) Europe and Asia, through their middle zone. A fine avenuetree.

Ulmus racemosa, Thomas.

The Cork-Elm of North America.

Ulmus Wallichiana, Planchon.

Himalayan Elm. In the mountains of India from 3500 to 10,000 feet. A tree up to ninety feet high with deciduous foliage, the stem attaining a girth of twenty-four feet.

Uniola paniculata, Linné.

North-East America. This tall maritime grass can be chosen on account of its creeping roots to bind rolling coast-sands. It serves also as a nourishing forage-plant on sand-tracts.

Urginia Scilla, Steinheil. (Scilla maritima, Linné.)

South Europe, North Africa. The medicinal Squill. The plant needs not regular cultivation, but settlers living near the coast might encourage its dissemination, and thus obtain the bulbs as drug from natural localities. Its peculiar bitter principle is called Scillitin. U. altissima (Baker) serves in South Africa as Squill.

Uvularia sessilifolia, Linné.

North America, in forests. This pretty herb is mentioned as yielding a good substitute for Asparagus.

Vaccinium alatum, Dombey. (Thibaudia alata, Dunal.) Frigid regions of the Andes of Peru. A tall evergreen shrub, with pink berries of the size of a cherry. This highly ornamental plant could be grown in our sub-alpine regions.

Vaccinium bicolor, F. v. Mueller. (Thibaudia bicolor, Ruiz and Pavon.)

Cold zone of the Peruvian Andes. A high evergreen bush, with red berries of the size of a hazel-nut. All Thibaudias seem best to form a section in the genus Vaccinium, some species of the latter, for instance Vaccinium Imrayi (Hook.), from Dominica, mediating the transit. The species of the section Thibaudia are, as a rule, producing red berries of acidulous grateful taste. Many others may deserve therefore culture in our forest-ravines or on our alpine heights. They occur from Peru to Mexico, also in West India. One species, Vaccinium melliflorum (Thibaudia melliflora, R. and P.), has its flowers rich in honey-nectar.

Vaccinium caespitosum, Michaux.

Canada and Northern States of North America. A deciduousleaved small bush, with bluish edible berries. V. ovalifolium (Smith) is an allied species. 


\section{Vaccinium corymbosum, Linné.*}

The Swamp-Blueberry or Blue Huckle-berry. Canada and United States of North America. A good-sized shrub with deciduous foliage. Berries bluish-black of sweetish taste, ripening late in the season.

Vaccinium erythrocarpum, Michaux. (Oxycoccus erectus, Pursh.)

Carolina and Virginia, on high mountains. An upright bush of a few feet in height, with deciduous leaves. The transparent scarlet berries, according to Pursh, are of excellent taste.

Vaccinium grandiflorum, Dombey. (Ceratostemma grandiflorum, Ruiz and Pavon.)

Andes of Peru. A tall evergreen shrub. The berries of a pleasant acidulous taste.

Vaccinium humifusum, Graham.

North-Western America, on the Rocky Mountains. Berries of this bush well flavoured.

Vaccinium Leschenaultii, Wight. (Agapetes arborea, Dunal.) India, Neilgherries and Ceylon. This evergreen species attains the size of a tree, flowering and fruiting throughout the year. The fruits resemble cranberries.

Vaccinium leucanthum, Cham.

Mountains of Mexico. An arborescent species. The blackish berries are edible.

Vaccinium macrocarpon, Aiton.* (Oxycoccus macrocarpus, Persoon.)

The large Cranberry. From Canada to Virginia and Carolina, particularly in sandy and peaty bogs and in cold mossy swamps. A trailing evergreen bush, with stems attaining a length of three feet. It is this species which has become so extensively cultivated in the eastern parts of the United States, where on moory land, often not otherwise to be utilised, enormous quantities of this fruit have been produced by regular culture at a highly profitable scale. The berries are of the acid taste, pleasant aroma and scarlet brightness of the British Cranberry, but considerably larger.

Vaccinium meridionale, Swartz.

Jamaica, from the summits of the highest ranges down to the coffee-regions. It attains a height of thirty feet and is evergreen. The small berries are of the taste and colour of those of V. Vitis Idæa.

Vaccinium Mortinia, Bentham.

Mountains of Columbia. A shrub several feet high. The fruits resemble those of $\mathrm{V}$. Myrtillus, but are more acid. They come under the name Mortina to the Quito market. 
Vaccinium myrtilloides, Michaux.

Michigan, Canada, Newfoundland, Labrador. The large edible berries are called Bluets. This little bush is adapted for our higher alpine country.

\section{Vaccinium Myrtillus, Linné.*}

The British Whortleberry or Bilberry. Throughout Europe, North and Middle Asia, remotest North America, in heathy and turfy forest-land. A shrub, a few feet high or less, deciduous, erect, of great value for its copious supply of berries. They are, as well known, black with a blueish-grey hue and of exceedingly grateful taste. The naturalisation of this plant on our alpine ranges and in our cooler woodlands, particularly in our forests of Fagus Cunninghami, would prove a boon. The berries can be utilised for their dye. The whole bush contains Quina acid.

Vaccinium Oxycoccus, Linné. (Oxycoccus palustris, Persoon.)

The British Cranberry. Through Europe, North and Middle Asia, North America, on turf-moss in moory heaths. A creeping evergreen shrub of particular neatness. The berries give a most agreeable preserve and are of anti-scorbutic value. This species is particularly eligible for the spongy mossy bogs of our snowy mountains.

Vaccinium parvifolium, Smith.

North-Western America. A tall shrub. The berries are excellent for preserves.

Vaccinium Pennsylvanicum, Lamarck.* ( $V$. angustifolium, Aiton.)

The early Blueberry or Blue Huckleberry. North America, on dry woody hills. A dwarf-bush with deciduous foliage, producing fruit in abundance. The berries are large, blueishblack and of sweet taste. V. Canadense (Kalm), according to Dr. Asa Gray, is closely allied.

Vaccinium præstans, Rudolphi.

Kamschatka. A minute plant, but with large delicious fruits.

It might easily be disseminated on our Alps.

Vaccinium uliginosum, Linné.

British Bog-Bilberry. Europe, North and Middle Asia, North America. A deciduous bush, with blackish berries, similar to those of V. Myrtillus, but hardly of equal excellence.

Vaccinium vacillans, Solander.

North America, in sandy forest-lands. A deciduous small bush, coming with its blue berries later into season than V. Pennsylvanicum. 
Vaccinium Vitis Idaea, Linné.

Europe, North and Middle Asia, North America. A dwarf shrub with evergreen leaves. The purplish-red berries are sought for jellies and other preserves.

It is as yet impossible to say, how many other species of Vaccinium produce good-sized and well-flavoured fruits. The genus ranges in many species from Continental Asia to the Indian Archipelagus, and has a wide extension also in South America, occupying in hot countries higher mountain regions, but few reliable notes on the tropical species are extant, as far as the fruits are concerned.

Valeriana Celtica, Linné.

Alps of Europe. The root of this perennial herb is particularly aromatic.

Valeriana edulis, Nuttall.

North-Western America, from Oregon to the Rocky Mountains. The thick spindle-shaped root of this herb affords food to the natives of that part of the globe. When baked the root proves agreeable and wholesome. When we consider the wild states of the plants, from which many of our important root-crops arose, then this Valeriana and several other plants, suggestively mentioned in these pages, may well be admitted for trial-culture.

Valeriana officinalis, Linné.

Europe, North and Middle Asia, in swampy grass-land, with a predilection for forests and river-banks. This perennial herb would do particularly well on our alps. It is the only one among numerous congeners of Europe, Asia and America, which is drawn to a considerable extent into medicinal use. The root and herb contain Valerianic acid and a peculiar tannic acid; the root furnishes an essential oil, which again resolves itself into Valerol (70 per cent.), Valereen, Barneol and Valerianic acid. The order of Valerianæ is not represented by any native plant in Australia.

Valerianella olitoria, Moench.

Lamb's Lettuce. Europe, North Africa, North and Middle Asia. A fair and early Salad-plant. It is an annual plant, and has several congeners in Europe and Asia.

Veratrum album, Linné.

Europe, North and Middle Asia, extending eastwards to Japan. It delights particularly in sub-alpine localities. The root furnishes Veratrin, Jervin and Sabadillic acid. 
Veratrum viride, Aiton.

Canada and United States of North America. A near relative of the former plant. Its root has come recently into medicinal use.

Vicia Cracca, Linné.

Europe, North Africa, North and Middle Asia, North America. Perennial. Recommendable for naturalisation as a fodder-plant in silvan and alpine lands. It yields in shade a three times larger return than in open places (Langethal). The cognate V. Cassubica and V. biennis (Linné) serve also for field-culture.

Vicia Ervilia, Willdenow. (Ervum Ervilia, L.)

South Europe, North Africa, South-Western Asia. An annual herb, praised as a valuable fodder-plant on dry calcareous soil.

\section{Vicia Faba, Linné.*}

The Straight Bean. Orient, particularly on the Caspian Sea. This productive annual herb affords not only its seeds for table-use, but provides also a particularly fattening stablefood. The seeds contain about 33 per cent. starch. V. Narbonensis (L.), from South Europe and South-West Asia is preferable for the table, because its seeds contain less bitter principle, though they are smaller.

Vicia peregrina, Linné.

South Europe. Annual. In Italy preferred to the ordinary Tare for sand-soil; it recommends itself also for its close growth.

\section{Vicia sativa, Linné.* ( $V$. angustifolia, Roth.)}

The ordinary Vetch or Tare. Europe, North Africa, North and Middle Asia. One of the best fodder-plants, but only of one or two years' duration. Important also for greenmanure, and as a companion of clovers. The allied V. cordata (Wulfen) and V. globosa (Retzius) are similarly cultivated in Italy (Langethal). Many of the other European and Asiatic species of Vicia are deserving our attention.

Vicia sepium, Linné.

Europe, West and North Asia. Deserves attention as a perennial Vetch, enduring an alpine clime. It might with advantage be naturalised in our forests and alps, but it can also readily be subjected to field-culture, the yield being large and nutritious in regions with humid air, though the soil might be poor. This Vetch can be kept for about fifteen years continually on the same field (Langethal). V. Pannonica (Jacquin) is an allied but annual species. 
Vicia silvatica, Linné.

Europe, North Asia. The Wood-Vetch. Perennial. Recommendable to culturists settling in new forest-land, available also for our alpine copses. Pasture animals have a predilection for this Vetch; its yield is large. In limestone soil of forests V. pisiformis and V. dumetorum (Linné) can best be selected for introduction.

Vicia Sitchensis, Bongard.

From California to Sitka. Asa Gray remarks that the young seeds of this tall Vetch are eatable like green peas.

Vicia tetrasperma, Koch. (Ervum tetraspermum, Linné.)

The Lentil-Tare. Europe, West Asia, North Africa. Annual. According to Langethal this species is preferable to the ordinary Tare for sandy soil. It is also less hard as fodder, and very palatable. Lime in the sand enlarges the yield. V. monantha and V. hirsuta (Koch) serve nearly as well.

Vigna lanceolata, Bentham.

Tropical and sub-tropical Australia. Mr. O'Shanesy observes that this twiner produces, along with the ordinary cylindrical pods, other's underground from buried flowers, and these somewhat resemble the fruit of Arachis. The plant is available for culinary purposes.

Vigna Sinensis, Endlicher.* (Dolichos Sinensis, Linné.)

Tropical Asia and Africa. The cultivation of this twining annual Pulse-herb extends to Southern Europe and many other countries with a clime like ours. The pods are remarkable for their great length, and used like French Beans. Vigna Catjang (A. Rich) and Vigna sesquipedalis and V. melanophthalma are varieties of this species. In fair soil the produce is fortyfold.

Villebrunia integrifolia, Gaudichaud.

India, ascending the Himalayan mountains to 5,000 feet. A small tree, allied to the Rami-plant, Boehmeria nivea. Mr. C. B. Clarke regards the fibre as one of the strongest available in India, it being used for bow-strings. Other Villebrunias, for instance $V$. frutescens, and also some species of Debregeasia, particularly D. velutina, deserve likewise regular culture, for the sake of their fibre. Moist forest-tracts seem particularly adapted for these plants, because V. integrifolia grows in Sikkim at an elevation where, according to Dr. G. King, the rainfall ranges from 100 to 200 inches. This fibre is much more easily separable than that of Maoutia Puya, according to Dr. King's observations. 
Viola odorata, Linné.

The Violet. Middle and South Europe, North Africa, Middle Asia. Passingly alluded to here, as this modest though lovely plant should be extensively naturalised in our forest-glens, to furnish its delicate scent for various compositions of perfumery.

Vitis acetosa, F. v. Mueller.

Carpentaria and Arnhem's Land. Stems rather herbaceous than shrubby, erect. The whole plant is pervaded with acidity, and proved valuable in cases of scurvy. The berries are edible. This species, if planted here, would likely spring annually afresh from the roots.

Vitis aestivalis, Michaux.*

The Summer-Grape of the United States of North America. Flowers fragrant. The berries are deep blue, of pleasant taste, and ripen late in the season.

Vitis Baudiniana, F. v. Mueller. (Cissus Antarctica, Ventenat.)

East Australia. With V. hypoglauca the most southern of all Grapes, none extending to New Zealaud. It is evergreen, and here a vigorous plant for bowers, but suffers even from slight frosts. The berries are freely produced and edible, though not large.

Vitis cordifolia, Michaux.* (Vitis riparia, Michaux.)

The Winter-Grape or Frost-Grape. From Canada to Florida. A deciduous vine. The scent of the flowers reminds of Reseda. The berries are small, either blackish or ambercoloured, and very acid. They can be used for preserves, and are only fully matured when touched by frosts. A succession of seedlings may give us a superior and simultaneously a very hardy vine.

Vitis hypoglauca, F. v. Mueller.

East Australia, as far south as Gipps Land. An evergreen climber of enormous length, forming a very stout stem in age. The black herries attain the size of small cherries. Also this species may perhaps be vastly changed in its fruit by continued culture.

Vitis Indica, Linné.

On the mountains of various parts of India, ascending an altitude of 3000 feet in Ceylon. The small berries are edible. The plant should be subjected to horticultural experiments. This is an apt opportuity to draw attention to the various Indian species of Vitis with large edible berries; for instance: V. laevigata (Bl.), V. thyrsiflora (Miq.), V. mutabilis (Bl.), V. Blnmeana (Steud.), all from the 
mountains of Java, and all producing berries as large as cherries, those of $\mathrm{V}$. Blumeana being particularly sweet. Further may here be inserted V. imperiaiis (Miquel) from Borneo, V. auriculata (Wallich), and V. elongata (Wallich), both the last from the mountainous mainland of Coromandel, and all producing very large juicy berries even in the jungle wilderness. V. quadrangularis ( $\mathbf{L}$. ) stretches from Arabia to India and Central Africa, and has also edible fruits. Many such plants may be far more eligible for Grape-culture in hot wet climes than the ordinary vine. About 250 species of Vitis are already known, mostly from intra-tropical latitudes, and mostly evergreen ; but in regard to their elevation above the ocean, and to the nature of their fruits, we are almost utterly without data.

Vitis Labrusca, Linné.*

The Isabella-Grape. North America, from Canada to Texas and Florida, also in Japan. The Schuylkill-Grape is derived from this species. A pale-fruited variety furnishes the Bland's Grape. Another yields the American AlexanderGrape. The berries are large among American kinds and are of pleasant taste. Flowers fragrant. This and the other hardy North American Vines seem never to be attacked by the Oidium disease.

Vitis Schimperiana, Hochstetter.

From Abyssinia to Guinea. This Vine may become perhaps valuable with many other Central African kinds for tropical culture, and may show itself hardy here. Barter compares the edible berries to clusters of Frontignac-grape.

Vitis vinifera, Linné.*

The Grape Vine. Turkey, Persia, Tartary; probably also in the Himalayas and Greece. This is not the place to discuss at length the great industrial questions concerning this highly important plant, even had these not engaged already since many years the attention of a large number of our colonists. The whole territory of Victoria stretches essentially through the Vine-zone, and thus most kinds of Vine can be produced here, either on the lowlands or the less elevated mountains in various climatic regions and in different geologic formations.

The Corinthian variety, producing the "Currants" of commerce, thrives also well in some districts, where with Raisins its fruit may become a staple article of our exports beyond home consumption. Dr. W. Hamm, of Vienna, has recently issued a Vine-map of Europe, indicating the distribution of the different varieties and the principal sources of the various sorts of Wine. The writer would now merely add, that the 
preservation of the Grapes in a fresh state, according to $\mathbf{M}$. Charmeux's method, and the sundry modes of effecting the transit of ripe Grapes to long distances, ought to be turned to industrial advantage. The pigment of the dark Wineberries is known as Oenolic acid. The juice contains along with Tartaric acid also Grape acid. All these chemically defined substances have uses of their own in art and science. It might be worthy of trial, how far the Grape-vine can be grafted on such other species of the extensive genus Vitis as may not be attacked by the destructive Pemphygus or Phylloxera. Irrespective of sulphur, latterly also borax has been recommended against the Oidium-disease.

Vitis vulpina, Linné. (Vitis rotundifolia, Michaux.) The Muscadine or Fox-Grape. South-Eastern States of North America. Extends also to Japan, Manchuria and the Himalayas. This species includes as varieties also the Bullace, the Mustang, the Bullet-Grape and both kinds of the Scuppernangs. The berries are of a pleasant taste, but in some instances of a strong flavour; they are the largest among American Grapes. The Clinton- and Elsinboro-Grapes, according to Mr. Meehan, the eminent American horticulturist, seem to have had their origin with V. cordifolia and V. riparia. V. Labrusca extends also to the Himalayas. Dr. Planchon's important memoir, "Les Vignes Americaines," published in 1875, should be consulted in reference to American grapes.

Voandzeia subterranea, Thouars.

Madagascar and various parts of Africa, as far south as Natal. This Earth-Pea is annual, and pushes its pods under ground in the manner of Arachis hypogæa for maturation. The pods are edible, and much consumed in tropical countries.

Wallichia oblongifolia, Griffith.

Himalaya, as far as $27^{\circ}$ north. There one of the hardiest of all Palms. It is not a tall one, yet a graceful and useful object for cultural industries. Several species exist.

Wettinia augusta, Poeppig.

Peru, on mountains several thousand feet high. This Palm is therefore likely to endure our clime.

Wettinia Maynensis, Spruce.

Cordilleras of Peru. Like the foregoing, it attains a height of forty feet and advances to elevations of 3000 or 4000 feet. Before finally parting from the American Palms, it may be appropriate, to allude briefly to some of the hardier kinds, 
which were left unnoticed in the course of this compilation. From Dr. Spruce's important essay on the Palms of the Amazon-River may be learnt that, besides other species as yet imperfectly known from the sources of this great river, the following kinds are comparatively hardy; thus they might find places for cultivation or even naturalisation within the limits of our colony:-Geonema undata (Klotzsch), Iriartea deltoïdea (R. and P.), Iriartea ventricosa (Mart.), which latter rises in its magnificence to fully 100 feet; Iriartea exorrhiza (Mart.); this with the two other Iriarteas ascends the Andes to 5000 feet.-Oenocarpus multicaulis (Spruce) ascends to 4000 feet; from six to ten stems are developed from the same root, each from fifteen to thirty feet high.-Euterpe; of this two species occur in a zone between 3000 and 6000 feet.-Phytelephas microcarpa (R. and P.), eastern slope of the Peru Andes, ascending to 3000 feet.Phytelephas macrocarpa (R. and P.), also on the eastern side of the Andes, up to 4000 feet; it is this superb species, which yields by its seeds part of the vegetable ivory.-Phytelephas aequatorialis (Spruce), on the west slope of the Peruvian Andes, up to 5000 feet; this Palm is one of the grandest objects in the whole vegetable creation, its leaves attaining a length of thirty feet! The stem rises to twenty feet. Palmivory is also largely secured from this plant. Though aequinoctial it lives only in the milder regions of the mountains; therefore in the equable temperature of East Gipps Land it would likely prosper without protective cover. - Carludovica palmata (R. and P.), on the east side of the Andes of Peru and Ecuador, up to 4000 feet; the fan-shaped leaves from cultivated specimens furnish the main material for the best Panama-hats. The illustrious Count de Castelnau saw many Palms on the borders of Paraguay during his great Brazilian expedition. Most of these together with the Palms of Uruguay and the wide Argentine territory would likely prove adapted for acclimation in our latitudes; but hitherto the limited access to those countries has left us largely unacquainted with its vegetable treasures also in this direction. Von Martius demonstrated already in 1850 the occurrence of the following Palms in extra-tropic South America:Ceroxylon australe (Mart.), on high mountains in Juan Fernandez at $30^{\circ}$ south latitude; Jubra spectabilis (Humb.), in Chili at $40^{\circ}$ south latitude; Trithrinax Brasiliana (Mart.), at $31^{\circ}$ south latitude; Copernicia cerifera (Mart.), at $29^{\circ}$ south latitude; Acrocomia Totai (Mart.), at $28^{\circ}$ south latitude; Cocos australis (Mart.), at $34^{\circ}$ south latitude; Cocos Yatai (Mart.), at $32^{\circ}$ south latitude; Cocos Romanzoffiana (Cham.), at $28^{\circ}$ south latitude; Diplothemium littorale (Mart.) at $30^{\circ}$ 
south latitude. All the last-mentioned Palms occur in Brazil, the Acrocomia and Trithrinax extending to Paraguay, and Cocos australis to Uruguay and the La Plata States.

While some Palms, as indicated, descend to cooler latitudes, others ascend to temperate and even cold mountain regions. Among the American species are prominent in this respect:Euterpe andicola (Brogn.), E. Haenkeana (Brogn.), E. longivaginata (Mart.), Diplothemium Porallyi (Mart.) and Ceroxylon pithyrophyllum (Mart.), all occurring on the Bolivian Andes at an elevation of about 8000 feet.-Ceroxylon andicola (Humb.), Kunthia montana (Humb.), Oreodoxa frigida (Humb.) and Geonoma densa (Linden) reach also on the Andes of New Granada a height of at least 8000 feet.Ceroxylon Klopstockia (Mart.) advances on the Andes of Venezeula to a zone of 7500 feet altitude, where Karsten saw stems 200 feet high with leaves twenty-four feet long! There also occur Syagrus Sancona (Karst.) and Platenia Chiragua (Karst.) at elevations of 5000 feet, both very lofty Palms. From the temperate mountain-regions of sub-tropical Mexico are known, among others:-Chamaedora concolor (Mart.), Copernicia Pumos (Humb.), C. nana (Kunth), and Brahea dulcis (Mart.), at elevations from 7000 to 8000 feet.

Widdringtonia juniperoides, Endlicher.

South Africa, 3000 to 4000 feet above sea-level. A middling-sized tree, rich in resin.

Witheringia solanacea, L'Heritier.

South America. This perennial herb needs trial-culture, on account of its large edible tubers.

\section{Xanthorrhiza apiifolia, L'Heritier.}

North America. A perennial almost shrubby plant of medicinal value. The root produces a yellow pigment similar to that of Hydrastis Canadensis (L.). Both contain also Berberin.

Ximenia Americana, Linné.

Tropical Asia, Africa and America, passing however the tropics in Queensland, and gaining also an indigenous position in Florida. This bush may therefore accommodate itself to our clime in localities free of frost. The fruits are edible, resembling yellow plums in appearance; their taste is agreeable. The wood is scented.

Yucca filamentosa, Linné.

The Adam's Needle. From Carolina and Florida to Texas and Mexico. An almost stemless species. It would hardly be right to omit here the plants of this genus altogether, as 
they furnish a fibre of great strength, similar to that of the Agaves. Moreover all these plants are decorative, and live in the poorest soil, even in drifting coast-sand. They are also not hurt, as is the case with the Fourcroyas, by the frosts of our lowlands. Among the species with stems of several feet in height may be recorded Y. gloriosa (L.) and Y. aloifolia (L.), both from the sandy south coast of North America.

Zalacca secunda, Griffith.

Assam, as far north as $28^{\circ}$. A stemless Palm with large feathery leaves, exquisitely adapted for decorative purposes. Before we finally quit the Asiatic Palms we may yet learn from Von Martius's great work, how many extra-tropic members of this princely order were known in 1850 already, when that masterly work was concluded. Martius enumerates as belonging to the boreal extra-tropic zone in Asia: From Silhet at $24^{\circ}$ north latitude: Calamus erectus, Roxb.; C. extensus, Roxb.; C. quinquenervius, Roxb.;-from Garo at $26^{\circ}$ north latitude: Wallichia caryotoides, Roxb.; Ptychosperma gracilis, Miq.; Caryota urens, L.; Calamus leptospadix, Griff.;-from Khasya in $26^{\circ}$ north latitude : Calamus acanthospathus, Griff.; C. macrospathus, Griff.; Plectocomia Khasyana, Griff.;-from Assam about $27^{\circ}$ north latitude: Areca Nagensis, Griff.; A. triandra, Roxb.; Livistona Jenkinsii, Griff.; Daemonorops nutantiflorus, Griff;; D. Jenkinsii, Griff.; D. Guruba, Mart.; Plectocomia Assamica, Griff.; Calamus tenuis, Roxb.; C. Flagellum, Griff.; C. Heliotropium, Hamilt.; C. floribundus, Griff.; Phœnix Ouseloyana, Griff.;-from Upper Assam between $28^{\circ}$ and $29^{\circ}$ north latitude: Caryota obtusa, Griff.; Zalacca secunda, Griff.; Calamus Mishmelensis, Griff.;-from Darjiling at $27^{\circ}$ north latitude: Wallichia obtusifolia, Griff; Licuala peltata, Roxb.; Plectocomia Himalaiana, Griff.; Calamus schizospathus, Griff.;-from Nepal between $28^{\circ}$ and $29^{\circ}$ north latitude : Chamaerops Martiana, Wall.;-from Guhrval in $30^{\circ}$ north latitude : Calamus Royleanus, Griff;;-from Saharampoor in $30^{\circ}$ north latitude : Borassus flabelliformis, L.;-from Duab in $31^{\circ}$ north latitude: Phœnix silvestris, Roxb.;-from Kheree in $30^{\circ}$ north latitude: Phœnix humilis, Royle;from Dekan : Bentinckia Coddapanna, Berry; at an elevation of 4000 feet.

Miquel mentions as Palms of Japan (entirely extra-tropical): Rhapis flabelliformis, Aiton; R. humilis, Blume; Chamaerops excelsa, Thunb.; Livistona Chinensis, $\mathrm{Br}$. and Arenga saccharifera, La Bill. or a species closely allied to that Palm. 
Zea Mays, Linné.*

The Maize or Indian-Corn. Indigenous to the warmer parts of South America. St. Hilaire mentions as its native country Paraguay. Found in Central America already by Columbus. This conspicuous though annual cereal-grass interests us on this occasion as being applicable here to far more uses than those, for which it has hitherto been employed. In North America, for instance, Maize is converted into a variety of dishes for the daily table, being thus boiled in an immature state as "green corn." Mixed with other flour it furnishes good bread. For some kinds of cakes it is solely used, also for Maizena, Macaroni and Polenta. Several varieties exist; the Inca-Maize of Peru being remarkable for its gigantic size and large grains. Maize is not readily subject to the ordinary corn-diseases; but to prosper it requires fair access to potash and lime. Good writing and printing papers can be prepared from Maize-straw. Meyen calculated that the return from Maize under most favourable circumstances in tropical countries would be eight hundred fold, and under almost any circumstance it is the largest yielder among cereals in warm countries. As a fattening saccharine green-fodder Maize is justly appreciated. Any Ergot from it is used, like that of Rye, for medicinal purposes. Maizecorn contains about 75 per cent. of starch. Dierbach recommends mellago or treacle from Maize, instead of that prepared from the roots of Triticum repens (L.), and the molasses, so obtained, serve also culinary uses.

Zelkova acuminata, Planchon. (Planera acuminata, Lindley; P. Japonica, Miquel.)

The "Keaki," considered one of the best timber-trees of Japan; proved here of rapid growth and valuable as a shadetree.

Zelkova crenata, Spach. (Planera Richardi, Michaux.) South-West Asia, ascending to 5000 feet. In favourable localities a good-sized tree, with qualities resembling those of the Elms. The allied Z. cretica (Spach) is restricted to South Europe.

\section{Zingiber officinale, Roscoe.}

The Ginger. India and China. Possibly this plant may be productive in the hottest parts of our colony, and give satisfactory results. The multiplication is effected by division of the root. For candied Ginger only the young succulent roots are used, which are peeled and scalded prior to the immersion into the saccharine liquid. 
Zizania aquatica, Linné.* (Hydropyrum esculentum, Link.) The Canada-Rice. In shallow streams and around ponds and lakes from Canada to Florida. This tall grass might be readily naturalised. Although its grain can be utilised for bread-corn, we would wish to possess the plant chiefly to obtain additional food of a superior kind for water-birds.

\section{Zizania latifolia, Hance.* (Hydropyrum latifolium, Grise-} bach.)

The Kau-sun of China. In lakes of Amur, Manchuria, China and Japan. Nearly related to the preceding species. From Dr. Hance we know, that the solid base of the stem forms a very choice vegetable, largely used in China, where this tall water-grass undergoes regular cultivation like the Trapa.

Zizania miliacea, Michaux.

Southern part of North America, West India. Likewise tall and perennial, but more restricted to the tide-water meadows and ditches, according to Pursh; but according to Chapman's note generally distributed like Z. aquatica, with which it has similar use. In South Brazil occurs a similar grass, namely Z. microstachya (Nees).

Zizyphus Joazeiro, Martius.

Brazil. Recommended as yielding fruit in arid regions.

Zizyphus Jujuba, La Marck.

From India to China, East Australia, extending also to tropical Africa, ascending the Himalayas to 4500 feet. This shrub or tree can only be expected to bear its pleasant fruits in the warmest part of our colony. The fruit is red or yellow, and of the size of a cherry.

Zizyphus Lotus, La Marck.

Countries around the Mediterranean Sea. The fruits are small and less sweet than those of $Z$. vulgaris ; nevertheless they are largely used for food in the native country of this bush. Z. nummularia (Wight and Arnott) is an allied species from the mountains of India, ascending to 3000 feet. It is much used for garden-hedges. The fruit is sweet and acidulous and of a pleasant flavour (Brandis).

Zizyphus rugosa, La Marck.

Nepal and other mountainous parts of India. A small tree, hardier than the last. The drupe of this is also edible, and the same may be said of a few other Indian species.

Zizyphus Sinensis, La Marck.

China and Japan. Similar in use to the last. 
Zizyphus Spina Christi, Willdenow.

Middle and North Africa, South-West Asia. Rather a hedge-plant than a fruit-bush.

Zizyphus vulgaris, La Marck.

Orient, particularly Syria; in the Himalayas up to 6500 feet. A small tree, well adapted for our clime. Fruits scarlet, about an inch long, with edible pulp; they are known as South European Jujubs. The allied Z. oxyphylla (Edgeworth) has a very acid fruit.

Zoysia pungens, Willdenow.

Eastern and Southern Asia, East Australia. This creeping grass, although not large, is important for binding coastsands.

\section{ADDITIONS.}

Acacia Arabica.

Add: Wood very durable if water-seasoned, extensively used for wheels, wellcurbs and many kinds of implements, also for the knees of boats. A. latronum (Willdenow) and A. modesta (Wallich) form thorny hedges in India (Brandis).

Acacia armata, R. Brown.

Extra-tropic Australia. The Kangaroo-Thorn. Much grown for hedges, though less manageable than various other hedgeplants. Important for covering coast-sand with an unapproachable prickly vegetation.

Acacia Catechu, Willdenow.

India, up to 3000 feet. Tree of forty feet height. The extract prepared from the heartwood is the Catechu of medicine or Cutch of tannery. A Suma (Kurz) is closely allied.

Acacia longifolia, Willdenow.

South-Eastern Australia. Although this tree occurs indigenously here, it is introduced into this list inasmuch as the very bushy variety known as $\mathrm{A}$. Sophoræ (R. Brown) renders most important services in subduing loose coast-sand; it 
should therefore be disseminated on our extensively bare sand-shores. To the recommendations of this bush can be added that it grows so quickly.

Acer niveum, Blume.

Continental and Insular India, up on the forest-ranges. This is the tallest of the Maples, attaining a height of 150 feet. Several other large Maples worthy of introduction, particularly into our parks, occur on the mountains of India.

Esculus Indica, Colebrooke.

In the Himalayas, from 3500 to 9000 feet. Height finally fifty feet; trunk comparatively short, occasionally with a girth of twenty-five feet. Never quite without leaves. Can be used like the Horse-Chestnut as an ornamental shadetree.

Albizzia bigemina, F. v. Mueller. (Pithecolobium bigeminum, Martius.)

India, up to Sikkim and Nepal, ascending in Ceylon to 4000 feet. Available for our forests for its peculiar dark and hard wood. Another congener, A. subcoriacea (Pithecolobium subcoriaceum, Thwaites) from the mountains of India is deserving with numerous other tall species here test-culture.

Albizzia lophantha.

Add: Here better still than the Broom-bush for shelter of new forest-plantations in open sand-lands.

Alnus Nepalensis, D. Don.

Himalayas, between 3000 and 9000 feet. Reaches a height of sixty feet. With an other Himalayan Alder, A. nitida (Endlicher), it can be grown along streams for the sake of its wood.

Artocarpus integrifolia, Linné.

India. The famous Jack-tree, ascending like the allied A. Lakoocha (Roxburgh) to 4000 feet. Trials might be made to see, whether it would ripen its fruit in the hottest and moistest regions of our colony.

Berberis Nepalensis, Sprengel.

Himalayas, at elevations between 4000 and 8000 feet. The fruit of this evergreen species is edible.

Betula acuminata, Wallich.

Himalaya, between 3000 and 10,000 feet. Attains a height of sixty feet, and delights on forest-streams. The wood hard, strong and durable. Another Himalayan Birch, B. utilis (D. Don), grows on arid ground, and produces good timber of less hardness. 
Borassus flabelliformis, Linné.

The Palmyra. From the Persian Gulf to India, extending to $30^{\circ}$ North. This noble Palm attains a height of 100 feet. The pulp of the fruit serves as food. Enormous masses of sugar or toddy are produced in India from the sap, which flows from incisions of the stalk of the unexpanded flowers. By us to be reared for scenic plantations.

Boswellia thurifera, Colebrooke.

India. A deciduous tree, living in arid forest-regions, probably hardy here. Yields an aromatic resin. The real Olibanum is exuded by B. Carteri (Birdwood), of Arabia and tropical Africa.

\section{Brassica alba.}

Add: Can be grown in shallow soil, even on land recently reclaimed from swamps. It prefers argillaceous ground. The return is in a few months. The stalks and foliage after the seed-harrest serve as sheep-fodder.

\section{Butea frondosa.}

Add: Ascends to elevations of 4000 feet.

Camellia Thea, Link.

This name should be adopted by priority for the Tea-plant, Thea Chinesis (Sims.)

\section{Carum Petroselinum.}

Add: Always desirable on pastures as a preventive or curative of some kidney and liver diseases of sheep, horses and cattle. The root is also valuable for the table.

Castanopsis Indica, A. de Candolle.

Mountains of India, at about 4000 feet. This Oak-Chestnut produces seeds with the taste of filberts.

Casuarina distyla, Ventenat.

Extra-tropical Australia. A shrubby species, well adapted for fixing the sand-drifts of sea-coasts. All Casuarinas can be pollarded for cattle-fodder.

Cedrela Chinensis, A. de Jussieu.

China. An elegant tree, hardy in Middle Europe. It furnishes a wood not unlike that of the Singapore Cedar, reddish in colour, particularly sought for cigar-boxes.

\section{Cedrela Taona.}

Add: Ascends the Himalayas to 8000 feet. The Rev. Dr. Woolls noted in New South Wales trees so large as to yield 30,000 feet of timber.

\section{Celtis Australis.}

Add: Ascends the Himalayas to 9000 feet. 


\section{Chlorogalum pomeridianum.}

Add: The bulb contains Saponin.

\section{Cupressus torulosa.}

Add : Dr. Brandis thinks that it may attain an age of 1000 years.

Dalbergia Sissoo, Roxburgh.

The Indian Sissoo-tree, ascending to elevations of 5000 feet, attaining a height of 60 feet. It may be worthy of test whether in localities free of frost, particularly along sandy river-banks, this important timber-tree could be naturalised. Brandis found the transverse strength of the wood greater than that of teak and of sal ; it is very elastic, seasons well, does not warp or split and takes a fine polish. It is also durable as a wood for boats. The tree is easily raised from seeds or cuttings, is of quick growth and resists slight frosts. The supply of its wood has fallen short of the demand in India.

Dendrocalamus Hamiltoni, Nees.

Himalayas, between 2000 and 6000 feet. Height up to 60 feet. The young shoots of this stately Bamboo are edible in a boiled state (Brandis). D. strictus attains a height of 100 feet and occasionally forms forests of its own.

Eucalyptus amygdalina.

Add: It is this species which yields more volatile oil than any other hitherto tested, and which therefore is largely chosen for distillation; thus it is also one of the best for subduing malarian effluvia in fever-regions, although it does not grow with quite the same ease and celerity as E. globulus. The respective hygienic value of various Eucalypts may to some extent be judged from the percentage of oil in their foliage, as stated below and as ascertained by $\mathrm{Mr}$. Bosisto, at the author's instance, for the exhibition of 1862 :
E. amygdalina $\quad \ldots \quad 3.313$ per cent. volatile oil.
E. oleosa $. . \quad \ldots \quad 1.250 \quad ", \quad$,
E. leucoxylon $\quad . . \quad 1.060 \quad$ "
E. goniocalyx $\quad \ldots \quad 0.914 \quad, \quad "$
$\begin{array}{lllll}\text { E. globulus } \quad \ldots & 0.719 \quad " \quad,\end{array}$
$\begin{array}{llll}\text { E. obliqua ... } & \ldots & 0.500 \quad ", & \end{array}$

The lesser quantity of oil of $\mathbf{E}$. globulus is however compensated for by the vigour of its growth and the early copiousness of its foliage. The proportion of oil varies also somewhat according to locality and season. E. rostrata, though one of the poorest in oil, is nevertheless important for malarian regions, as it will grow well on periodically inundated places, and even in stagnant water not saline. E. oleosa (F. v. M.), from the desert regions of extra-tropic Australia, 
might be reared on barren sands of other countries for the sake of its oil. According to Mr. Osborne's experiment, Eucalyptus-oils dissolve the following among other substances for select varnishes and other preparations: Camphor, Pineresins, Mastich, Elemi, Sandarac, Kauri, Dammar, Asphalt, Xanthorrhœa-resin, Dragon's-blood, Benzoë, Copal, Amber, Anime, Shellac, Caoutchouc, also Wax, but not Gutta-Percha. These substances are arranged here in the order of their greatest solubility. The potash obtainable from the ashes of various Eucalypts varies from five to twenty-seven per cent. One ton of the fresh foliage of E. globulus yields about $8 \frac{1}{2}$ lbs. of Pearl-ash, a ton of the green wood about $2 \frac{1}{4} \mathrm{lbs}$., of dry wood about $4 \frac{1}{2}$ lbs. For resins, tar, acetic acid, tannin and other products of many Eucalypts see various documents and reports of the writer, issued from the Melbourne Botanic Garden.

\section{Ficus infectoria, Willdenow.}

India, ascending to 5000 feet. Probably hardy, and then adapted for street-planting. Brandis and Stewart found its growth quicker than that of Siris or Albizzia procera. F. religiosa (L.) ascends to the same height, and is in moist climates of quick growth. It is one of the trees on which the Lac-insect largely exists. The fruits of some huge Himalayan species, for instance F. virgata (Roxb.), F. glomerata (Roxb.), F. Roxburghii (Wallich), are edible.

\section{Fraxinus floribunda.}

Add: Himalaya, between 5000 and 11,000 feet. It attains a height of 120 feet, and serves as a fine avenue-tree; girth of stem sometimes fifteen feet. The wood much sought for oars, ploughs and various implements (Stewart and Brandis). For forest-plantations Ashes are best mixed with Beeches and some other trees.

Hardwickia binata, Roxburgh.

India, up to elevations of nearly 4000 feet. Maximum height of tree 120 feet. Wood from red-brown to nearly black, close-grained, exceedingly hard, heavy and durable, valued for underground work. The bark furnishes easily a valuable material for cordage. The tree can readily be pollarded for cattle-fodder (Brandis).

\section{Helianthus annuus.}

Add: Important also for raising quickly vegetation around fever-morasses, the absorbing and exhaling power of this plant being very large (Dr. v. Hamm). 


\section{Juniperus communis.}

Add: Colder parts of Europe, Asia, North Africa and North America, ascending the European Alps to 8000 feet, the Indian mountains to 14,000 feet. Important for fuel in the coldest regions.

Juniperus excelsa.

Add: Extends to the Himalayas, where its range of elevation is from 5000 to 14,000 feet. Trunk short but of great girth, over twenty feet circumference being known (Stewart and Brandis).

\section{Lavandula Stoechas.}

Add: Mr. James Dickinson, of Portarlington, informs us, that this is the best plant known to him for staying sand. It grows much quicker than the Ulex; every seed which falls germinates, so that around each bush every stroke of the spade brings up lots of seedlings fit for transplantation. Here five months in full flower annually, it being early in bloom. Bees are passionately fond of the mucilaginous secretion of the flowers. Mr. Dickinson calculates, that annually from an acre of this Lavender a ton of the finest-flavoured honey can be obtained.

\section{Morus alba.}

p. 135, last line, read Pebrine-disease instead of Pedrinedisease.

Quercus Mongolica, Fischer.*

Manchuria. It is on this tree and on Q. serrata (Thunberg) that the silk-insect peculiar to Oak-trees mainly, if not solely, is reared, as shown by Dr. Hance.

Tripsacum dactyloides.

Add: Known vernacularly as Gama-grass. 


\section{GEOGRAPHIC INDEX.}

\section{NORTHERN AND MIDDLE EUROPE.}

Acer campestre, A. platanoides, A. Pseudo-platanus, Achillea atrata, A. Millefolium, A. moschata, A. nana, Aconitum Napellus, Acorus Calamus, Actæa spicata, Agaricus auricula, A. cæsareus, A. Cardarella, A. deliciosus, A. eryngii, A. esculentus, A. extinctorius, A. giganteus, A. Marzuolus, A. melleus, A. Mouceron, A. odorus, A. oreades, A. socialis, A. splendens, Agrostis alba, A. rubra, A. vulgaris, Aira cæspitosa, Allium Schœnoprasum, A. Scorodoprasum, Alnus glutinosa, A. incana, Alopecurus bulbosus, A. geniculatus, A. pratensis, Althæa officinalis, Anemone Pulsatilla, Anthemis nobilis, A. tinctoria, Anthriscus Cerefolium, Archangelica officinalis, Arctostaphylos uva-ursi, Arnica montana, Artemisia Absinthium, A. Mutellina, A. Pontica, Asparagus officinalis, Astragalus arenarius, A. glycyphyllos, A. hypoglottis, Atropa Belladonna, Avena elatior, A. fatua, A. flavescens, A. pubescens, A. sativa, Barbaræa vulgaris, Beta vulgaris, Betula alba, Brassica alba, B. Napus, B. nigra, B. oleracea, B. Rapa, Bromus asper, Calamintha officinalis, Camelina sativa, Carex arenaria, Carpinus Betulus, Carum Bulbocastanum, C. Carui, C. segetum, Chæromyces meandriformis, Chærophyllum bulbosum, C. sativum, Cichorium Intybus, Cochlearia Armoracia, C. officinalis, Colchicum autumnale, Conium maculatum, Corylus Avellana, Crambe maritima, Cratægus Oryacantha, Cynosurus cristatus, Cytisus scoparius, Dactylis glomerata, Daucus Carota, Digitalis purpurea, Dipsacus fullonum, Elymus arenarius, Fagus silvatica, Festuca arundinacea, F. drymeia, F. duriuscula, F. elatior, F. gigantea, F. heterophylla, F. loliacea, F. ovina, F. pratensis, F. rubra, F. silvatica, F. spadicea, Fragaria collina, F. vesca, Fraxinus excelsior, Gentiana lutea, Helleborus niger, Heracleum Sibiricum, Holcus lanatus, H. mollis, Hordeum secalinum, Humulus Lupulus, Hydnum album, H. auriscalpium, $H$. Caput-Medusæ, $H$. coralloides, $H$. diversidens, $H$. erinaceum, $H$. fuligineo-album, H. graveolens, H. Hystrix, H. imbricatum, H. infundibulum, H. laevigatum, H. subsquamosum, H. violascens, Hyoscyamus niger, Ilex Aquifolium, Inula Helenium, Juniperus communis, Lactuca virosa, Laserpitium aquilegium, Lathyrus macrorrhizus, L. pratensis, L. sativus, Lavatera arborea, Leersia oryzoides, Lolium perenne, Lotus corniculatus, L. major, Marrubium vulgare, Matricaria Chamomilla, Medicago falcata, M. sativa, Melica ciliata, M. nutans, M. uniflora, Melilotus alba, M. officinalis, Mentha citrata, M. crispa, M. piperita, M. Pulegium, M. rotundifolia, M. silvestris, M. viridis, Menyanthes trifoliata, Milium effusum, Morchella deliciosa, M. esculenta, M. Gigas, M. patula, Onobrychis sativa, Origanum vulgare, Peucedanum officinale, P. Ostruthium, P. sativum, Phleum alpinum, P. pratense, Physalis Alkekengi, Pimpinella Saxifraga, Pinus Abies, P. Cembra, P. Larix, P. montana, P. Picea, P. silvestris, Poa airoides, P. alpina, P. angustifolia, P. aquatica, P. distans, P. fertilis, P. fluitans, P. maritima, P. nemoralis, P. pratensis, P. trivialis, Populus alba, P. canescens, P. dilatata, P. fastigiata, P. nigra, P. tremula, 
Prunus Mahaleb, P. spinosa, Psamma arenaria, P. Baltica, Pyrus Germanica, P. nivalis, Quercus Robur, Reseda Luteola, Rhamnus catharticus, Ribes Grossularia, R. nigrum, R. rubrum, Rosa Gallica, R. spinosissima, Rubia peregrina, Rubus cæsius, R. Chamaemorus, R. fruticosus, R. Idæus, Rumex Acetosa, R. scutatus, Ruscus aculeatus, Salix alba, S. caprea, S. daphnoides, S. fragilis, S. lanceolata, S. purpurea, S. rubra, S. triandra, S. viminalis, Sambucus nigra, Sanguisorba minor, Saponaria officinalis, Scorzonera Hispanica, Sesleria coerulea, Sison Amomum, Smyrnium Olusatrum, Solanum Dulcamara, Spartina stricta, Spergula arvensis, Tanacetum vulgare, Taraxacum officinale, Tilia Europæa, Tragopogon porrifolius, Trapa natans, Trifolium agrarium, T. alpestre, T. fragiferum, T. hybridum, T. incarnatum, T. medium, T. montanum, T. ochroleucum, T. pratense, T. repens, T. spadiceum, Triticum junceum, Tuber æstivum, T. albidum, T. cibarium, T. magnatum, T. melanosporum, Ulex Europaeus, Ulmus campestris, U. pedunculata, Vaccinium Myrtillns, V. Oxycoccus, V. uliginosum, V. Vitis-Idæa, Valeriana Celtica, Valerianella olitoria, Veratrum album, Vicia sativa, V. sepium, V. silvatica, Viola odorata.

\section{COUNTRIES AT OR NEAR THE MEDITERRANEAN SEA.}

Acacia Arabica, A. Seyal, A. tortilis, A. Verek, Acer Creticum, Achillea fragrantissima, Agilops ovata, Esculus Hippocastanum, Agaricus cæsareus, Agrostis alba, A. vulgaris, Aira cæspitosa, Alkanna tinctoria, Allium Ascallonicum, A. Cepa, A. Neapolitanum, A. Porrum, A. roseum, A. Scorodoprasum, A. sativum, Aloe vulgaris, Alopecurus bulbosus, A. geniculatus, A. pratensis, Althæa officinalis, Amarantus Blitum, Anacyclus Pyrethrum, Andropogon Haleppensis, A. Schoenanthus, Anthemis nobilis, A. tinctoria, Anthoxanthum odoratum, Anthyllis vulneraria, Apium graveolens, Argania Sideroxylon, Artemisia Absinthium, A. Pontica, Arundo Ampelodesmos, A. Donax, A. Pliniana, Asparagus acutifolius, A. albus, A. aphyllus, A. horridus, A. officinalis, Astragalus Cephalonicus, A. Cicer, A. Creticus, A. gummifer, A. Parnassi, A. strobiliferus, A. verus, Atropa Belladonna, Avena elatior, A. fatua, A. flavescens, A. pubescens, A. sativa, Balsamodendron Ehrenbergii, B. Mukul, B. Opobalsamum, Beta vulgaris, Betula alba, Bongardia Rauwolfii, Borrago officinalis, Brassica alba, B. campestris, B. Cretica, B. juncea, B. Napus, B. nigra, B. oleracea, B. Rapa, Bromus erectus, Buxus Balearica, B. longifolia, B. sempervirens, Cajanus Indicus, Calamintha Nepeta, C. officinalis, Callitris quadrivalvis, Camelina sativa, Cannabis sativa, Capparis spinosa, Carpinus Betulus, Carthamus tinctorius, Carum Bulboscastanum, C. Carui, C. ferulifolium, C. Petroselinum, C. segetum, Cassia acutifolia, C. angustifolia, C. obovata, Castanea sativa, Catha edulis, Cedronella triphylla, Celtis Australis, Ceratonia Siliqua, Chærophyllum bulbosum, C. sativum, Chamærops humilis, Chelidonium majus, Chenopodium Blitum, Chrysanthemum carneum, C. roseum, Cicer arietinum, Cichorium Endivia, C. Intybus, Cistus Creticus, C. Cyprius, Cochlearia Armoracia, Coffea Arabica, Colchicum autumnale, Colocasia antiquorum, Conium maculatum, Conopodium denudatum, Convolvulus floridus, C. Scammonia, C. scoparius, Coriandrum sativum, Corylus Colurna, Corynosicyos edulis, Crambe cordifolia, C. Klotschyana, C. maritima, C. Tataria, Cratægus Azarolus, C. Oxyacantha, C. pyracantha, Crithmum maritimum, Crocus sativus, C. serotinus, Crozophora tinctoria, Cucumis Citrullus, C. Colocynthis, C. Melo, C. sativus, Cucurbita maxima, C. Melopepo, C. moschata, C. Pepo, Cuminum Cyminum, C. Hispanicum, Cupressus sempervirens, Cynara Cardunculus, C. Scolymus, Cynodon Dactylon, Cynosurus cristatus, Cyperus esculentus, C. Papyrus, C. proliferus, C. Syriacus, Cytisus scoparius, Dactylis glomerata, Daphne Mezereum, Daucus Carota, Digitalis purpurea, Dios. 
pyros Lotus, Dipsacus fullonum, Dolichos Lablab, D. uniflorus, Dorema Ammoniacum, Dracocephalum Moldavica, Ecballion Elaterium, Eleusine flagellifera, E. Tocussa, Elymus arenarius, Ervum Lens, Fagopyrum esculentum, F. Tataricum, Fagus silvatica, Ferula galbaniflua, F. longifolia, Festuca elatior, F. gigantea, F. silvatica, Ficus Carica, F. Sycamorus, Fœniculum officinale, Fragaria collina, F. pratensis, F. vesca, Fraxinus excelsior, F. Ornus, Genista monosperma, G. sphærocarpa, Gentiana lutea, Glycyrrhiza echinata, G. glabra, Gossypium arboreum, Guilandina Bonduc, G. Bonducella, Hedysarum coronarium, Helichrysum orientale, Helleborus niger, Hippocrepis comosa, Holcus lanatus, H. mollis, Hordeum deficiens, $H$. distichon, H. hexastichon, H. macrolepis, H. secalinum, H. vulgare, $H$. zeocriton, Humulus Lupulus, Hydnum imbricatum, Hyoscyamus niger, Hyphæne Argun, H. coriacea, Imperata arundinacea, Indigofera argentea, Inula Helenium, Isatis tinctoria, Jasminum odoratissimum, J. officinale, Juglans regia, Juniperus brevifolia, J. Cedrus, J. drupacea, J. excelsa, J. fœtidissima, J. Phœnicea, J. procera, Koeleria cristata, K. glauca, Lactuca virosa, Lathyrus Cicera, L. pratensis, L. tuberosus, Laserpitium aquilegium, Laurus nobilis, Lavandula angustifolia, L. latifolia, L. Stœchas, Lavatera arborea, Lawsonia alba, Leersia oryzoides, Lepidium latifolium, L. sativum, Linum usitatissimum, Liquidambar Altingia, L. Orientalis, Lolium Italicum, L. perenne, Lotus corniculatus, L. major, L. siliquosus, L. tetragonolobus, Lupinus albus, L. luteus, L. varius, Lycium Afrum, Lygeum Spartum, Marrubium vulgare, Matricaria Chamomilla, Medicago arborea, M. lupulina, M. media, M. sativa, Melica ciliata, M. nutans, M. uniflora, Melilotus alba, M. cœrulea, M. macrorrhiza, M. officinalis, Melissa officinalis, Mentha citrata, M. crispa, M. piperita, M. Pulegium, M. rotundifolia, M. silvestris, M. viridis, Menyanthes trifoliata, Meriandra Abyssinica, Milium effusum, Morchella deliciosa, M. esculenta, Moringa aptera, Morus nigra, Musa Ensete, M. Livingstoniana, Myrica Faya, Myrrhis odorata, Myrtus communis, Nelumbo nucifera, Nicotiana Persica, Ocimum Basilicum, O. sanctum, O. suave, Olea Europæa, Onobrychis sativa, Origanum Dictamus, O. hirtum, O. Majorana, O. Maru, O. normale, O. Onites, O. virens, O. vulgare, Ornithopus sativus, Ostrya carpinifolia, Oxytenanthera Abyssinica, Oxytropis pilosa, Paliurus Spina-Christi, Panicum brizanthemum, P. Crus-Galli, P. glabrum, P. maximum, P. prostratum, P. repens, P. sanguinale, P. spectabile, P. turgidum, Papaver somniferum, Pennisetum thyphoideum, Persea Teneriffæ, Peucedanum cachrydifolium, P. officinale, Phalaris brachystachys, P. Canariensis, P. minor, P. truncata, Phaseolus coccineus, Phleum alpinum, P. pratense, Phønix dactylifera, Physalis Alkekengi, P. angulata, Pimpinella Anisum, P. magna, P. nigra, P. Saxifraga, P. Sisarum, Pinus Abies, P. Canariensis, P. Cedrus, P. Cembra, P. Cilicica, P. Haleppensis, P. Laricio, P. Larix, P. montana, P. orientalis, P. Pinaster, P. Pinea, P. Pinsapo, P. Pyrenaica, Pistacia Atlantica, P. Lentiscus, P. Terebinthus, P. vera, Peucedanum sativum, Platanus orientalis, Poa Abyssinica, P. airoides, P. angustifolia, P. aquatica, P. cynosuroides, P. distans, P. fluitans, P. maritima, P. nemoralis, P. trivialis, Populus alba, P. canescens, P. dilatata, P. Euphratica, P. fastigiata, P. nigra, P. tremula, Prosopis Stephaniana, Prunus Amygdalus, P. Armenica, P. avium, P. Cerasus, P. domestica, P. Lauro-Cerasus, P. Mahaleb, .P. Padus, P. Persica, P. spinosa, Psamma arenaria, Punica granatum, Pyrus communis, P. Cydonia, P. malus, P. nivalis, P. salicifolia, Quercus Egilops, Q. Cerris, Q. coccifera, Q. Ilex, Q. infectoria, Q. Robur, Q. Suber, Q. Toza, Reseda luteola, R. odorata, Rhamnus amygdalinus, R. catharticus, R. Græcus, R. infectorius, R. oleoides, R. prunifolius, R. saxatilis, Rhaponticum acaule, Rheum Rhaponticum, Rhus Coriaria, R. Cotinus, Ribes Grossularia, R. nigrum, R. rubrum, Ricinus communis, Roccella tinctoria, Rosa centifolia, R. Damascena, R. Gallica, R. moschata, R. sempervirens, R. spinosissima, Rosmarinus officin- 
alis, Rubia peregrina, R. tinctorum, Rubus fruticosus, R. Idæus, Rumex Acetosa, R. scutatus, Ruscus aculeatus, Ruta graveolens, R. silvestris, Sagittaria sagittifolia, Salix alba, S. Babylonica, S. daphnoides, S. fragilis, S. purpurea, S. rubra, S. viminalis, Salvia officinalis, Sambucus nigra, Sanguisorba minor, Santolina Cyparissias, Saponaria officinalis, Satureja Græca, S. hortensis, S. Juliana, S. montana, S. Thymbra, Saussurea Lappa, Scandix grandiflora, Scorzonera Astrachanica, S. crocifolia, S. deliciosa, S. Hispanica, S. lanata, S. ramosa, S. Scowitzii, S. semicana, S. tuberosa, S. undulata, Secale cereale, Sesuvium Portulacastrum, Sison Amomum, Smilax aspera, Smyrnium Olusatrum, Solanum Ethiopicum, S. Dulcamara, S. edule, S. xanthocarpum, Spartina stricta, Spartium junceum, Spergula arvensis, Spinacia tetrandra, Stenotaphrum Americanum, Stipa arenaria, S. tenacissima, Styrax officinalis, Symphytum asperrimum, S. officinale, Tamarindus Indica, Tamarix articulata, T. Gallica, T. Germanica, Tanacetum vulgare, Taraxacum officinale, Taxus baccata, Terfezia Leonis, Teucrium Chamædrys, T. Creticum, T. Marum, T. Polium, T. Scordium, Thapsia edulis, Theligonum Cynocrambe, Thouarea sarmentosa, Thymelæa tinctoria, Thymus æstivus, T. capitatus, T. hiemalis, T. Mastichina, T. Serpillum, T. vulgaris, Tilia argentea, T. Europæa, Tinguarra Sicula, Tragopogon porrifolius, Trapa natans, Trifolium agrarium, T. Alexandrinum, T. alpestre, T. fragiferum, T. hybridum, T. incarnatum, T. medium, 'T'. montanum, T. ochroleucum, T. pratense, T. Quartinianum, T. repens, T. spadiceum, T. subrotundum, Trigonella Fœnum-Græcum, Triticum junceum, T. vulgare, Tuber æstivum, T. albidum, T. cibarium, T. magnatum, Ulex Europæus, Ulmus campestris, U. pedunculata, Urginia Scilla, Vaccinium Myrtillus, V. Oxycoccus, V. uliginosum, V. Vitis-Idæa, Valeriana officinalis, Valerianella olitoria, Veratrum album, Vicia Cracca, V. Ervilia, V. Faba, V. peregrina, V. sativa, V. sepium, V. silvatica, V. tetrasperma, Viola odorata, Vitis Schimperiana, V. vinifera, Zelkova crenata, Z. Cretica, Zizyphus Lotus, Z. Spina-Christi, Z. vulgaris.

\section{MIDDLE AND TEMPERATE EASTERN ASIA.}

Acer palmatum, A. pictum, Agrostis vulgaris, Ailantus glandulosa, Albizzia Julibrissin, Allium fistulosum, Alopecurus geniculatus, Aralia cordata, Arenga saccharifera (under Zalacca), Aristolochia recurvilabra, Artemisia Cina, A. Dracunculus, Arundinaria Japonica (under Schizostachyum), Atriplex hortensis, Avena elatior, A. fatua, A. flavescens, A. pubescens, Balsamodendron Mukul, Bambusa Beechyana, B. flexuosa, B. tultoides, (under Schizostachyum), Barbaræa vulgaris, Basella rubra, Betula alba, Bœhmeria nivea, Brassica alba, B. Chinensis, B. juncea, B. nigra, Bromis asper, Broussonetia papyrifera, Buxus microphylla, Cæsalpinia sepiaria, Camellia Thea, Cannabis sativa, Caragana arborescens, Carpinus cordata, C. erosa, C. Japonica, C. laxiflora, Carum Bulbocastanum, C. Carui, Cedrela Sinensis, Cephalotaxus Fortunei, Chamærops excelsa, C. Fortunei, Cinnamomum Camphora, Citrus Japonica, Corchorus capsularis, Cordyline Ti, Corylus heterophylla, Cryptomeria Japonica, Cucumis Conomon, Cupressus obtusa, C. pisifera, Cycas revoluta, Daucus Carota, Debregeasia edulis, Dendrocalamus strictus, Dioscorea Japonica, D. oppositifolia, D. quinqueloba, D. sativa, Diospyros Kaki, D. Lotus, Ehrharta caudata, Elæagnus parvifolius, Eleusine Coracana, Excecaria sebifera, Euryale ferox, Euryangium Sumbul, Fagopyrum cymosum, F. emarginatum, F. esculentum, F. Tataricum, Fagus Sieboldii, Fatsia papyrifera, Flueggea Japonica, Fraxinus Chinensis, Ginkgo biloba, Gleditschia horrida, Glycine hispida, G. Soya, Heleocharis tuberosa, Heracleum Sibiricum, Hovenia dulcis, Hydrangea Thunbergi, Illicium anisatum, Imperata arundinacea, Isatis indigotica, I. tinctoria, Jasminum grandiflorum, J. officinale, J. Sambac, Juglans cordiformis, J. Mandschurica, J. Sieboldiana, J. stenocarpa, Juniperus 
Chinensis, J. sphærica, Lathyrus macrorrhizus, Lepidium latifolium, Lespedeza striata, Ligustrum Japonicum, Livistona Chinensis, Magnolia Yulan, Morus alba, Musa Cavendishii, Myrtus tomentosa, Nageia cupressina, Nephelium Litchi, N. Longanum, Pachyma Hœlen, Paliurus ramosissimus, Pennisetum cereale, Perilla arguta, Phœnix pusilla, Phyllostachys bambusoides, P. nigra (under Schizostachyum), Physalis Alkekengi, P. angulata, Pinus Alcocquiana, P. densiflora, P. firm?, P. Fortunei, P. Jezoensis, P. Kæmpferi, P. Koraiensis, P.leptolepis, P. Massoniana, P. parviflora, P. Sibirica, P. Tsuga, Planera Japonica, Poa airoides, P. alpina, P. fertilis, Polygaster Sampadarius. Polygonum tinctorium, Populus nigra, P. tremula, Prangos pabularia, Pterocarpus Inclicus, Pterocarya fraxinifolia, P. stenoptera, Pyrus Japonica, Quercus Chinensis, Q. cornea, Q. glabra, Q. Mongolica, Q. serrata, Rhamnus chlorophorus, R. utilis, Rhapis flabelliformis, R. humilis, Rheum officinale, R. palmatum, R. Rhaponticum, R. Tartaricum, R. undulatum, Rhus semialata, R. succedanea, R. vernicifera, Rosa Indica, R. lævigata, R. moschata, R. sempervirens, R. spinosissima, Rubia cordifolia, Rumex Acetosa, R. Patentia, Saccharum officinarum, S. Sinense, Sagittaria sagittifolia, Salix Babylonica, Sanguisorba minor, Sciadopitys verticillata, Scorzonera albicaulis, Selinum Monnieri, Sophora Japonica, Spergula arvensis, Spinacia oleracea, Tetragonia expansa, Tetranthera Japonica, Thea Chinensis, Tilia Europæa, T. Manchurica, Thuyopsis dolabrata, Torreya grandis, T. nucifera, Trapa bicornis, T. bispinosa, Trifolium pratense, Triphasia Aurantiola, Ulmus campestris, U. parvifolia, Vaccinium præstans, Veratrum album, Vicia Cracca, V. sepium, V. silvatica, Vigna Sinensis, Vitis Labrusca, V. vulpina, Zelkova acuminata, Zizania latifolia, Zizyphus Jujuba, Z. Sinensis, Zoysia pungens.

\section{SOUTHERN ASIA.}

Acacia Arabica, A. Catechu, A. concinna, A. Farnesiaua, A. latronum, A. Sundra, Acer lævigatum, A. niveum, A. sterculiaceum, A. villosum, Aconitum ferox, Aegiceras majus, Aeschynomene aspera, Aesculus Indica, Albizzia bigemina, A. Lebbeck, Aleurites cordata, Alnus Nepalensis, Aloe socotrina, Aloexylon Agallochum, Amarantus paniculatus, Andropogon Calamus; A. cernuus, A. citratus, A. Ivarancusa, A. Martini, A. muricatus, A. Nardus, A. pertusus, A. saccharatus, A. Schoenanthus, A. Sorghum, Anthistiria ciliata, A ponogeton crispus, Aquilaria Agallocha, Areca Nagensis, A. triandra (under Zalacca), Aristolochia Indica, Artocarpus integrifolia, Arundinaria falcata, A. callosa, A. debilis, A. Hookeriana, A. Khasiana, A. suberecta (under Schizostachyum), Arundo Karka, Averrhoa Bilimbi, A. Carambola, Avicennia officinalis, Azima tetracantha, Bambusa arundinacea, B. aspera, B. attenuata, B. Blumeana, B. elegantissima, B. monadelpha, B. spinosa, B. stricta, B. verticillata, B. vulgaris, B. Balcooa, B. Blumeana, B. Brandisii, B. marginata, B. nutans, B. pallida, B. polymorpha, B. regia, B. Tulda (under Schizostachyum), Basella lucida, B. rubra, Beesha elegantissima, B. Rheedei, B. stridula, B. Travancorica (under Schizostachyum), Benincasa cerifera, Bentinckia Coddapanna (under Zalacca), Berberis aristata, B. Asiatica, B. Lycium, B. Nepalensis, Betula acuminata, Boehmeria nivea, Borassus flabelliformis, Boswellia thurifera, Brassica juncea, Butea frondosa, Buxus Wallichiana, Cæsalpinia Sappan, C. sepiaria, Cajanus Indicus, Calamus montanus, C. acanthospathus, C. erectus, C. extensus, C. Flagellum, C. floribundus, C. leptospadix, C. macrospathus, C. Mishmelensis, C. quinquenervius, C. Royleanus, C. schizospathus, C. tenuis (under Zalacca), Capparis aphylla, C. horrida, C. Roxburghi, C. sepiaria, Carex Moorcroftiana, Carissa Carandas, Carpinus viminea, Carthamus tinctorius, Carum Ajowan, C. gracile, C. nigrum, Caryota obtusa (under Zalacca), C. urens, Cassia fistula, Castanopsis argentea, C. Indica, Casuarina equisetifolia, Cephalostachyum capitatum, 
C. pallidum, C. pergracile (under Schizostachyum), Chamærops Khasyana, C. Martiana, C. Richieana, Chloroxylon Swietenia, Chrysanthemum roseum, Citrus Aurantium, C. medica, Colocasia antiquorum, C. Indica, Corchorus acutangulus, C. capsularis, C. olitorius, Crambe cordifolia, Crotalaria Burhia, C. juncea, C. retusa, Croton lacciferus, Cucumis cicatrisatus, C. Colocynthis, C. Momordica, C. utilissimus, Cupressus torulosa, Cynodon Dactylon, Cyperus corymbosus, C. tegetum, Dæmonorops Guruba, D. Jenkinsii, D. nutantiflorus (under Zalacca), Dalbergia Sissoo, Dammara alba, Debregeasia dichotoma, D. hypolenca, D. velutina, D. Wallichiana, Dendrocalamus flagellifer, D. giganteus, D. Hamiltoni, D. Hookeri, D. sericeus, D. strictus (under Schizostachyum), Desmodium triflorum, Dioscorea aculeata, D. alata, D. deltoidea, D. globosa, D. nummularia, D. oppositifolia, D. pentaphylla, D. purpurea, D. sativa, D. spicata, D. tomentosa, D. triphylla, Diospyros chloroxylon, D. Ebenum, D. Melanoxylon, D. oppositifolia, D. quæsita, Dolichos uniflorus, Eleusine Corocana, E. stricta, Engelhardtia spicata, Eugenia cordifolia, E. Jambos, E. maboides, E. Malaccensis, E. revoluta, E. rotundifolia, Euryale ferox, Fagopyrum cymosum, F. emarginatum, F. rotundatum, F. triangulare, Ficus elastica, F. Indica, F. infectoria, F. laccifera, Flacourtia cataphracta, F. Ramontchi, Flemingia tuberosa, Fraxinus floribunda, Garcinia Travancorica, Gigantochloa apus, G. aspera, G. atter, G. heterostachya, G. maxima (under Schizostachyum), G. nigrociliata, G. verticillata, G. robusta, Glycine hispida, Gossypium arboreum, G. herbaceum, Guizotia oleifera, Gunnera macrophylla, Hardwickia binata, Harina caryotoides, Heleocharis fistulosa, H. plantaginea, Hemarthria compressa, Hibiscus cannabinus, Holoptolea integrifolia, Indigofera argentea, I. tinctoria, Ipomœa mammosa, I. paniculata, Jasminum grandiflorum, J. Sambac, Juniperus recurva, J. Wallichiana, Justicia Adhatoda, Lactuca sativa, Lawsonia alba, Licuala peltata (under Zalacca), Limonia acidissima, Liquidambar Altingia, Livistona Jenkinsii (under Zalacca), Magnolia Campbelli, M. sphærocarpa, Maharanga Emodi, Mallotus Philippinensis, Mangifera Indica, Maoutia Puya, Melaleuca Leucadendron, Melia Azedarach, Meloccanna bambusoides, M. humilis, Mimosa rubicaulis, Moringa pterygosperma, Morus atropurpurea, Musa coccinea, M. paradisiaca, M. sapientum, M. simiarum, M. troglodytarum, Myrica sapida, Myrtus tomentosa, Nageia amara, N. bracteata, N. cupressina, Nardostachys grandiflora, N. Jatamansi, Nastus Borbonicus (under Schizostachyum), Nephelium lappaceum, N. Longanum, Nyctanthes Arbor-tristis, Ocimum Basilicum, O. canum, O. gratissimum, O. sanctum, Ophelia Chirata, O. elegans, Oryza sativa, Oxytenanthera albo-ciliata, O. nigrociliata, O. Thwaitesii (under Schizostachyum), Pandanus furcatus, Panicum brizanthum, P. fluitans, P. frumentaceum, P. Italicum, P. Koenigii, P. miliaceum, P. prostratum, P. repens, P. sarmentosum, P. virgatum, Parrotia Jacquemontiana, Paspalum distichum, P. scrobiculatum, Pennisetum thyphoideum, Perilla ocimoides, Peucedanum Sowa, Phaseolus adenanthus, P. lunatus, P. Max, P. vulgaris, Phœnix humilis, P. Ouseloyana (under Zalacca), P. paludosa, P. pusilla, P. silvestris, Phyllostachys bambusoides (under Schizostachyum), Pinus Brunoniana, P. Cedrus, P. excelsa, P. Gerardiana, P. Griffithii, P. longifolia, P. Pindrow, P. Smithiana, P. Webbiana, Pipturus propinquus, P. velutinus, Plectocomia Assamica (under Zalacca), P. Himalayana, P. Khasyana (under Zalacca), Poa cynosuroides, Podophyllum Emodi, Pogostemon Heyneanus, P. parviflorus, P. Patchouli, Polygala crotalaroides, Polygaster sampadarius, Populus ciliata, P. Euphratica, Prosopis spicifera, Pseudostachyum polymorphum (under Schizostachyum), Pterocarpus Indicus, P. Marsupium, P. santalinus, Ptychosperma disticha, P. gracilis (under Zalacca), Pueraria tuberosa, Pyrularia edulis, Quercus annulata, Q. dilatata, Q. incana, Q. lancifolia, Q. semicarpifolia, Q. squamata, Q. Sundaica, Raphanus caudatus, R. sativus, Rheum Australe, R. officinale, Rhododendron Falconeri, Rhus vernicifera, Ribes glaciale, R. 
Griffithii, R. laciniatum, R. villosum, Ricinus communis, Rosa Indica, R. moschata, R. sempervirens, Rubia cordifolia, Rubus lasiocarpus, R. rugosus, Saccharum officinarum, S. spontaneum, S. violaceum, Salix tetrasperma, Sanseviera Zeylanica, Santalum album, Schizostachyum Blumei, S. brachycladum, S. Hasskarlianum, S. irratum, S. Zollingeri, Scutia Indica, Sesamum Indicum, Sesbania aculeata, S. cannabina, Sesuvium Portulacastrum, Shorea robusta, S. Talura, Solanum album, S. ferox, S. Guineense, S. insanum, S. longum, S. Melongena, S. pseudo-saponaceum, S. undulatum, S. xanthocarpum, Spinifex squarrosus, Stenotaphrum Americanum, Streblus asper, Symplocos ramosissima, Tamarindus Indica, Tamarix articulata, T. dioica, T. Gallica, Tectona grandis, Teinostachyum attenuatum, T. Griffithii (under Schizostachyum), Terminalia Catappa, T. parviflora, Tetranthera calophylla, T. laurifolia, Thamnocalamus Falconeri, T. spathiflorus (under Schizostachyum), Thea Chinensis, Thouarea sarmentosa, Trapa bispinosa, T. Cochinchinensis, T. incisa, T. quadrispinosa, Triphasia Aurantiola, Ulmus Wallichiana, Vaccinium Leschenaulti, Vigna Sinensis, Villebrunea frutescens, V. integrifolia, Vitis auriculata, V. Blumeana, V. elongata, V. imperialis, V. Indica, V. Labrusca, V. lævigata, V. mutabilis, V. quadrangularis, V. thyrsiflora, V. vulpina, Wallichia caryotoides, W. oblongifolia, W. obtusifolia, Ximenia Americana, Zalacca secunda, Zingiber officinale, Zizyphus Jujuba, Z. rugosa, Zoysia pungens.

\section{WESTERN SOUTH AMERICA.}

Acacia Cavenia, Adenostemum nitidum, Adesmia balsamica, Alstroemeria pallida, Andropogon argenteus, Anona Cherimolia, Apium prostratum, Arachis hypogæa, Araucaria imbricata, Aristotelia Macqui, Arracacha xanthorriza, Berberis buxifolia, B. Darwinii, Cæsalpinia brevifolia, C. tinctoria, Canna edulis, Ceroxylon andicola, Cereus Quisco, Ceroxylon Australe, C. pithyrophyllum (under Wettinia), Cervantesia tomentosa, Chenopodium Quinoa, Chusquea Culcon, C. Dombeyana, C. montana, C. Quila, C. tenuiflora (under Schizostachyum), Cinchona Calisaya, C. micrantha, C. nitida, C. officinalis, C. succirubra, Dactylis cæspitosa, Dioscorea piperifolia, Diplothemium Porallys (under Wettinia), Diposis Bulbocastanum, Drimys Winteri, Elymus condensatus, Embothrium coccineum, E. emarginatum, E. lanceolatum, Erythroxylon Coca, Eucryphia cordifolia, Eugenia Hailii, Euterpe andicola, E. Hænkena, E. longivaginata (under Wettinia), Fagus Dombeyi, F. obliqua, F. procera, Festuca Coiron, Fitzroya Patagonica, Fragaria Chiloensis, Geonoma densa (under Wettinia), Gossy. pium religiosum, Guadua angustifolia, G. latifolia, Guevina Avellana, Gunnera Chilensis, Helianthus annuus, H. tuberosus, Heliotropium Peruvianum, Hibiscus esculentus, Hypochoeris apargioides, H. Scorzoneræ, Ipomœa Batatas, Jubæa spectabilis, Krameria triandra, Lapageria rosea, Lardizabala biternata, Laurelia aromatica, L. serrata, Libocedrus Chilensis, L. tetragona, Lippia citriodora, Manihot Aipi, Maranta arundinacea, Mauritia flexuosa, Maytenus Boaria, Melicocca bijuga, Morus celtidifolia, M. insignis, Myrtus Luma, M. Meli, M. nummularia, M. Ugni, Nageia andina, N. Chilina, N. nubigena, Opuntia vulgaris, Oreodoxa frigida (under Wettinia), Oryza latifolia, Oxalis crassicaulis, O. crenata, O. enneaphylla, O. succulenta, O. tuberosa, Pacchyrrhizus angulatus, Panicum pilosum, Paspalum ciliatum, P. dilatatum, Passiflora alata, P. ligularis, P. macrocarpa, Persea gratissima, Peumus Boldus, Physalis Peruviana, Phytelephas æquatorialis (under Wettinia), Prosopis horrida, P. juliflora, P. Siliquastrum, Priva lævis, Quillaja saponaria, Rhus caustica, Rubus geoides, Salix Humboldtiana, Saxono-Gothæa conspicua, Sesuvium Portulacastrum, Smilax officinalis, Solanum Gilo, S. Guineense, S. Lycopersicum, S. muricatum, S. Quitoense, S. tuberosum, S. torvum, Sophora tetraptera, Spilanthes oleracea, Tagetes glanduligera, Tetragonia expansa, Tillandsia 
usneoides, Tropæolum majus, T. minus, T. sessilifolium, T. tuberosum, Ullucus tuberosus, Vaccinium alatum, V. bicolor, V. grandiflorum, V. melliflorum, Wettinia augusta, W. Maynensis, Witheringia solanacea, Zea Mays, Zizyphus Ioazeiro.

\section{WESTERN NORTH AMERICA.}

Acer macrophyllum, Arbutus Menziesii, Baccharis consanguinea, B. pilularis, Barbaræa vulgaris, Bouteloua barbata, Castaneopsis chrysophylla, Ceanothus prostratus, C. rigidus, C. thyrsiflorus, Cercocarpus ledifolius, C. parvifolius, Chlorogalum pomeridianum, Cupressus Lawsoniana, C. macrocarpa, C. Nutkaensis, Cymopterus glomeratus, Fraxinus Oregana, Gaultiera chyrsinites, Juglans rupestris, Juniperus occidentalis, Libocedrus decurrens, Lupinus Douglasii, Myrrhis occidentalis, Nicotiana multivalvis, Nyssa aquatica, Parkinsonia acnleata, P. microphylla, Pinus amabilis, P. bracteata, P. contorta, P. Coulteri, P. Douglasii, P. grandis, P. Jeffreyi, P. Lambertiana, P. Menziesii, P. Mertensiana, P. monophylla, P. monticola, P. muricata, P. nobilis, P. Pattoniana, P. ponderosa, P. radiata, P. Sabiniana, Platanus racemosa, Populus tremuloides, P. trichocarpa, Prosopis pubescens, Prunus ilicifolia, Quercus agrifolia, Q. densiflora, Q. Douglasii, Q. Garryana, Q. lobata, Ribes aureum, R. divaricatum, R. niveum, R. tenuiflorum, R. villosum, Rubus macropetalus, Scilla esculenta, Sequoia sempervirens, S. Wellingtonia, Solanum Fendleri, S. tuberosum, Tetranthera Californica, Torreya Californica, Vaccinium humifusum, Valeriana edulis, Yucca Sitchensis.

\section{EASTERN NORTH AMERICA.}

Acer dasycarpum, A. Negundo, A. rubrum, A. saccharinum, Achillea Millefolium, Achras Sapota, Acorus Calamus, Actæa alba, Agave Americana, A. Mexicana, Agrostis alba, A. rubra, A. scabra, A. vulgaris, Aletris farinosa, Allium Canadense, A. Schœnoprasum, Amelanchier Botryapium, Andropogon nutans, Apios tuberosa, Apocynum cannabinum, Arctostaphylos uva-ursi, Aristolochia anguicida, A. ovalifolia, A. Serpentaria, Arundinaria macrosperma, Astragalus hypoglottis, Barbaræa vul-. garis, Betula lenta, B. lutea, B. nigra, B. papyracea, Bouteloua barbata, Buchloa dactyloides, Calamagrostis longifolia, Canna flaccida, Carya alba, C. amara, C. glabra, C. microcarpa, C. oliviformis, C. sulcata, C. tomentosa, Cassia Marylandica, Catalpa bignonioides, Cedronella cordata, Celtis. occidentalis, Chamædora concolor, Chamærops Hystrix, Cimicifuga racemosa, Cinna arundinacea, Cladastris tinctoria, Cochlearia officinalis, Cratægus æstivalis, C. apiifolia, C. coccinea, C. cordata, C. Crus-Galli, C. parvifolia, C. tomentosa, Cupressus Benthami, C. Lindleyi, C. thurifera, C. thuyoides, Diospyros Virginiana, Elymus mollis, Festuca flava, F. purpurea, Fragaria Chiloensis, F. grandiflora, F. Illinoensis, F. vesca, F. Virginiana, Fraxinus Americana, F. platycarpa, F. pubescens, F. quadrangulata, F. sambucifolia, F. viridis, Gaultieria Shallon, Gaylussacia frondosa, G. resinosa, Gelsemium nitidum, Gleditschia monosperma, G. triacanthos, Gordonia lasianthos, Guilandina Bonduc, Gymnocladus Canadensis, Hedeoma pulegioides, Hordeum secalinum, Humulus Lupulus, Hydrastis. Canadensis, Ilex Cassine, Indigofera Anil, Ipomœa plantanifolia, I. simulans, Juglans cinerea, J. nigra, Juniperus flaccida, J. Mexicana, J. Virginiana, Levisia rediviva, Liatris odoratissima, Lindera Benzoin, Liquidambar styraciflua, Liriodendron tulipifera, Lithospermum canescens, L. hirtum, L. longiflorum, Lupinus perennis, Lycopodium lucidulum, Maclura. aurantiaca, Magnolia acuminata, M. cordata, M. Fraseri, M. grandiflora, M. macrophylla, M. umbrella, Melica mutica, Menyanthes trifoliata, Milium effusum, Monarda didyma, M. fistulosa, M. punctata, Morchella. esculenta, Morus rubra, Myrica cerifera, Nelumbo lutea, Nicotiana quadrivalvis, N. repanda, N. rustica, N. Tabacum, Nyssa aquatica, N. multiflora, 
N. uniflora, Opuntia coccinellifera, O. Ficus-Indica, O. Hernandezii, 0. Missouriensis, O. Rafinesquii, O. spinosissima, O. Tuna, O. vulgaris, Oryza latifolia, O. perennis, Ostrya Virginica, Oxalis Deppei, O. esculenta, O. tetraphylla, O. violacea, Panicum amarum, P. virgatum, Parkinsonia aculeata, Parthenium integrifolium, Passiflora incarnata, P. lutea, P. suberosa, Peireskia aculeata, P. Bleo, P. portulacifolia, Phaseolus perennis, Physalis angulata, Pinus alba, P. Australis, P. Ayacahuite, P. balsamea, P. Canadensis, P. cembroides, P. Fraseri, P. glabra, P. Hartwegii, P. Hudsonica, P. leiophylla, P. mitis, P. Montezumæ, P. nigra, P. patula, P. pendula, P. Pinceana, P. Pseudo-strobus, P. religiosa, P. rigida, P. rubra, P. serotina, P. Strobus, P. Tæda, P. tenuifolia, P. Teocote, Pisonia aculeata, Planera aquatica, Platanus occidentalis, Poa airoides, P. alpina, P. angustifolia, P. aquatica, P. Canadensis, P. distans, P. fertilis, P. fluitans, P. maritima, P. nemoralis, Podophyllum peltatum, Polygala Senega, Populus balsamifera, P. grandidentata, P. heterophylla, P. monilifera, P. tremuloides, Prosopis dulcis, P. glandulosa, P. juliflora, P. pubescens, Prunus Americana, P. Caroliniana, P. Chisasa, P. maritima, P. Pennsylvanica, P. pumila, P. serotima, P. Virginiana, Psamma arenaria, Pycnanthemum incanum, P. montanum, Pyrularia edulis, Pyrus coronaria, Quercus acutifolia, Q. alba, Q. aquatica, Q. chrysophylla, Q. coccinea, Q. falcata, Q. glaucescens, Q. lanceolata, Q. laurina, Q. lyrata, Q. macrocarpa, Q. obtusata, Q. obtusiloba, Q. palustris, Q. Phellos, Q. Prinus, Q. reticulata, Q. rubra, Q. Sideroxylon, Q. stellata, Q. virens, Q. Xalapensis, Rhododendron maximum, Rhus copallina, R. glabra, R. typhina, Ribes aureum, R. Floridum, R. hirtellum, R. Hudsonianum, R. nigrum, R. rotundifolium, R. rubrum, Robina Pseudo-acacia, Rosa setigera, Rubus Arcticus, R. Canadensis, R. Chamæmorus, R. cuneifolius, R. deliciosus, R. occidentalis, R. odoratus, R. strigosus, R. trivialis, R. villosus, Rumex Acetosa, Sabal Adansoni, S. Palmetto, S. serrulata, Sagittaria lancifolia, S. obtusa, Salix cordata, S. longifolia, S. lucida, Sabbatia angularis, S. nigra, S. petiolaris, S. tristis, Sambucus Canadensis, Sanguinaria Canadensis, Sassafras officinale, Schoenocaulon officinale, Shepherdia argentea, Smilax medica, S. rotundifolia, Solanum calycinum, S. Fendleri, S. tuberosum, Spartina cynosuroides, S. juncea, S. polystachya, Spartina stricta, Spigelia Marylandica, Stenotaphrum Americanum, Tanacetum vulgare, Taraxacum officinale, Taxodium distichum, T. mucronatum, Taxus brevifolia, Thuya gigantea, T. occidentalis, Tilia Americana, T. heterophylla, Tillandsia usneoides, Torreya taxifolia, Trifolium repens, Tripsacum dactyloides, Ulmus alata, U. Americana, U. crassifolia, U. fulva, U. Mexicana, U. racemosa, Uniola paniculata, Uvularia sessilifolia, Vaccinium cæspitosum, V. corymbosum, V. erythrocarpum, V. leucanthum, V. macrocarpum, V. myrtilloides, V. Myrtillus, V. ovalifolium, V. Oxycoccus, V. parvifolium, V. Pennsylvanicum, V. uliginosum, V. vacillans, V. Vitis-Idæa, Valeriana edulis, Veratrum viride, Vicia Cracca, Vitis æstivalis, V. Labrusca, V. vulpina, Xanthorrhiza apiifolia, Ximenia Americana, Yucca aloifolia, Y. filamentosa, Y. gloriosa, Zizania aquatica, Z. miliacea.

\section{CENTRAL AMERICA.}

Achras Sapota, Agave Americana, A. rigida, Albizzia dulcis, A. latisiliqua, A. Saman, Amarantus paniculatus, Anona muricata, A. squamosa, Arracacha xanthorrhiza, Arthrostylidium excelsum, A. longiflorum, A. racemiferum (under Schizostachyum), Arundinaria acuminata, Aulonemia Quexo (under Schizostachyum), Bactris Gasipaes, Batis maritima, Bouteloua barbata, Brahea dulcis, Buxus acuminata, B. citrifolia, B. Cubana, B. glomerata, B. gonoclada, B. lævigata, B. Purdieana, B. retusa, B. subcolumellaris, B. Vahlii, B. Wrightii, Canna coccinea, C. glauca, Carludovica palmata (under Wettinia), Ceroxylon andicola, C. Klopstockia (under Wettinia), Chusquea abietifolia, C. Fendleri, C. Galeottiana, C. scandens 
C. simpliciflora, C. uniflora (under Schizostachyum), Copernicia nana, C. Pumos, Cyperus giganteus, Dioscorea Cajennensis, D. esurientum, D. trifida, Eupatorium triplinerre, Fourcroya Cubensis, F. gigantea, F. longæva, Geonema undata, Gossypium Barbadense, G. hirsutum, G. religiosum, Hibiscus esculentus, Indigofera Anil, Ipomøa Batatilla, Juniperus Bermudiana, Kunthia montana, Maranta arundinacea, Melicocca bijuga, Morus celtidifolia, Nageia coriacea, N. Purdieana, Opuntia coccinellifera, O. Dillenii, O. elatior, O. Hernandezii, O. spinosissima, O. Tuna, Oreodoxa regia, $\mathrm{Pa}$ chyrrhizus angulatus, Paspalum stoloniferum, Passiflora lauriflora, P. ligularis, P. maliformis, P. serrata, Peireskia aculeata, Persea gratissima, Platenia Chiragua (under Wettinia), Podachænium alatum, Psidium acidum, P. Araca, P. cordatum, P. Guayava, P. polycarpum, Quercus agrifolia, Q. Castanea, Q. Skinneri, Sabal umbraculifera, Sechium edule, Sesuvium Portulacastrum, Smilax officinalis, S. papyracea, Solanum Guineense, S. Plumieri, S. Topiro, S. torvum, Swietenia Mahagoni, Thrinax argentea, T. parviflora, Tillandsia usneoides, Trophis Americana, Vaccinium meridionale, V. Mortinia, Zizania miliacea.

\section{EASTERN SOUTH AMERICA.}

Acrocomia Totai (under Wettinia), Amyris terebinthifolia, Apium prostratum, Araucaria Brasiliensis, Arundinaria verticillata (under Schizostachyum), Arundo saccharoides, A. Sellowiana, Bromus unioloides, Cæsalpinia coriaria, C. Gilliesii, Calyptranthes aromatica, Canna Achiras, Capsicum annuum, C. baccatum, C. frutescens, C. longum, Cephælis Ipecacuanha, Chenopodium ambrosioides, Chusqueæ capituliflora, C. Gaudichaudiana (under Schizostachyum), Cocos Australis, C. Romanzoffiana, C. Zantai (under Wettinia), Copernicia cerifera, Cyperus giganteus, Dactylis cæspitosa, Desmodium triflorum, Dioscorea conferta, D. tuberosa, Diplothemium littorale (under Wettinia), Eugenia Nhanica, E. pyriformis, E. supra-axillaris, Guadua latifolia, G. angustifolia, G. capitata, G. macrostachya, G. paniculata, G. refracta, G. Tagoara, G. virgata, Hymenæa Courbaril, Ilex Paraguensis, Indigofera Anil, Ipomœa Batatas, I. Batatilla, I. operculata, I. paniculata, Iriartea deltoidea, I. exorrhiza, I. ventricosa (under Wettinia), Lippia citriodora, Lupinus arboreus, Manihot Aipi, M. utilissima, Maliera glomerata, M. tomentosa, Merostachys Claussenii, M. Kunthii, M. ternata (under Schizostachyum), Myrtus edulis, Nageia Lamberti, Nicotiana rustica, N. Tabacum, Ocimum gratissimum, Enocarpus multicaulis (under Wettinia), Opuntia vulgaris, Oryza latifolia, Oxalis carnosa, O. conorrhiza, Pacchyrrhizus angulatus, Panicum barbinode, P. latissimum, P. pilosum, Parkinsonia aculeata, Paspalum ciliatum, P. dilatatum, Passiflora alata, P. coccinea, P. cœrulea, P. edulis, P. filamentosa, P. laurifolia, P. maliformis, P. quadrangularis, P. serrata, P. suberosa, Peireskia aculeata, P. Bleo, P. portulacifolia, Periandra dulcis, Persea gratissima, Phaseolus adenanthus, P. lunatus, Phytelephas macrocarpa, P. microcarpa (under Wettinia), Prosopis dulcis, P. Siliquastrum, Psidium Araca, P. arboreum, P. Cattleyanum, P. chrysophyllum, P. cinereum, P. cuneatum, P. grandifolium, P. Guayava, P. incanescens, P. lineatifolium, P. malifolium, P. polycarpon, P. rufum, Salix Humboldtiana, Sesuvium portulacastrum, Smilax papyracea, Solanum Gilo, S. Guineense, S. indigoferum, S. Lycopersicum, S. torvum, S. tuberosum, Spilanthes oleracea, Syagrus Sancona, Tagetes glanduligera, Tillandsia usneoides, Trithrynax Brasiliana (under Wettinia), Trophis Americana, Ullucus tuberosus, Zea Mays, Zizania microstachya.

\section{MIDDLE AFRICA (AND MADAGASCAR).}

Beesha capitata, Buddleya Madagascariensis, Buxus Madagascarica, Casuarina equisetifolia, Corchorus acutangulus, Hagenia Abyssinica, 
Hyphæne Thebaica, Panicum fluitans, Phœnix spinosa, Pterolobium lacerans, Rubus rosifolius, Solanum edule, S. Thonningi, Telfairia occidentalis, T. pedata, Vigna Sinensis, Vitis Schimperiana.

\section{SOUTHERN AFRICA.}

Aberia Caffra, A. tristis, A. Zeyheri, Acacia Giraffæ, A. horrida, Aloe dichotoma, A. ferox, A. linguiformis, A. plicatilis, A. purpurascens, A. spicata, A. Zeyheri, Andropogon Caffrorum, Anthistiria ciliata, Aponogeton distachyon, Arundinaria tesselata, Asparagus laricinus, Azima tetracantha, Barosma serratifolia, Cannamois cephalotes, Carissa Arduina, C. ferox, C. grandiflora, Carum Capense, Combretum butyraceum, Elegia nuda, Euclea myrtina, E. undulata, Eugenia Zeyheri, Garuleum bipinnatum, Gladiolus edulis, Gonioma Kamassi, Grumilea cymosa, Hemarthria compressa, Hibiscus Ludwigii, Hyphæne ventricosa, Leucadendron argenteum, Leyssera gnaphalioides, Lyperia crocea, Matricaria glabrata, Melianthus major, Mesembrianthemum acinaciforme, M. edule, Monetia barlerioides, Myrica cordifolia, M. quercifolia, M. serrata, Nageia elongata, N. Thunbergi, Osmitopsis asteriscoides, Pappea Capensis, Parkinsonia Africana, Pentzia virgata, Phœnix reclinata, Plectronia ciliata, P. spinosa, P. ventosa, Rafnia amplexicaulis, R. perfoliata, Rhus lucida, Royenia Pseudebenus, R. pubescens, Rubus fruticosus, Salix Capensis, Selinum anesorrhizum, S. montanum, Tarchonanthus camphoratus, Voandzeia subterranea, Widdringtonia juniperoides.

\section{WESTERN AUSTRALIA.}

Acacia acuminata, A. armata, A. saligna, Albizzia lophantha, Boronia megastigma, Casuarina Decaisneana, C. distyla, C. Fraseriana, C. Huegeliana, C. trichodon, Dioscorea hastifolia, Encephalartos Preissii, Eucalyptus calophylla, E. cornuta, E. diversicolor, E. Doratoxylon, E. ficifolia, E. gomphocephala, E. marginata, Frenela Actinostrobus, Helichcrysum lucidum, H. Manglesii, Lepidosperma gladiatum, Oryza sativa, Phaseolus vulgaris, Pimelea clavata, Santalum cygnorum, S. Preissianum, Spinifex hirsutus, S. longifolius, Strychnos Nux-Vomica, Tamarindus Indica.

\section{EASTERN AUSTRALIA (INCLUDING TASMANIA).}

Acacia armata, A. decurrens, A. falcata, A. Farnesiana, A. fascifulifera, A. glaucescens, A. harpophylla, A. homalophylla, A. longifolia, A. Melanoxylon, A. pendula, A. pycnantha, A. salicina, A. stenophylla, Egiceras majus, Aira cæspitosa, Âlstonia constricta, Andropogon pertusus, Angophora intermedia, Anthristiria avenacea, A. ciliata, Apium prostratum, Aponogeton crispus, Arancaria Bidwilli, A. Cunninghami, Aristolochia Indica, Atalantia glauca, Atriplex halimoides, A. holocarpum, A. nummularium, Backhousia citriodora, Bologhia lucida, Brachychiton acerifolium, Carissa Brownii, Caryota Alberti, Casuarina distyla, C. equisetifolia, C. glauca, C. quadrivalvis, C. suberosa, C. torulosa, Cedrela Taona, Chenopodium auricomum, Chloris truncata, Citrus Australasica, C. Planchoni, Colocasia Indica, Corchorus acutangulus, C. Cunninghami, C. olitorius, Crotolaria juncea, C. retusa, Cudrania Javanensis, Cycas angulata, C. Normanbyana, Cynodon Dactylon, Cyperus textilis, Dammara robusta, Danthonia nervosa, D. pectinata, D. triticoides, Dioscorea sativa, D. transversa, Ehrharta stipoides, Embothrium Wickhami, Encephalartos Denisonii, E. spiralis, Eucalyptus acmenoides, E. alpina, E. amygdalina, E. botryoides, E. brachypoda, E. citriodora, E. coccifera, E. coriacea, E. crebra, E. drepanophylla, E. eugenioides, E. globulus, E. goniocalyx, E. Gunnii, E. hemiphloia, E. leptophleba, E. leucoxylon, E. maculata, E. melanophloia, E. melliodora, E. miniata, E. obliqua, E. paniculata, E. 
Phœnicea, E. pilularis, E. platyphylla, E. polyanthemos, E. resinifera, E. robusta, E. rostrata, E. siderophloia, E. Stuartiana, E. tereticornis, E. tesselaris, E. trachyphloia, E. urnigera, E. vernicosa, E. viminalis, Eucryphia Billardieri, E. Moorei, Eugenia myrtifolia, Fagus Cunninghami, F. Moorei, Festuca distichophylla, F. dives, F. Hookeriana, F. littoralis, Ficus colossea, F. columnaris, F. Cunninghami, F. macrophylla, F. rubiginosa, Flindersia Bennettiana, F. Oxleyana, Frenela Macleayana, F. Parlatorei, F. verrucosa, Geitonoplesium cymosum, Grevillea robusta, Harpullia Hillii, Heleocharis sphacelata, Helichrysum lucidum, Hemarthria compressa, Hibiscus cannabinus, Hierochloa redolens, Hymenanthera Banksii, Imperata arundinacea, Ipomœa paniculata, Jasminum calcareum, J. didymum, J. lineare, J. racemosum, J. simplicifolium, J. suavissimum, Kentia Belmoreana, K. Canterburyana, K. Mooreana, Lepidosperma gladiatum, Leptospermum laevigatum, Lycopodium clavatum, L. densum, L. laterale, L. varium, Maba fasciculosa, M. geminata, Macadamia ternifolia, Mallotus Philippinensis, Marlea Vitiensis, Melaleuca parviflora, M. trichostachya, Melia Azedarach, Mentha Australis, M. gracilis, M. laxiflora, M. saturejoides, Mesembrianthemum æquilaterale, Microseris Forsteri, Mylitta Australis, Myoporum insulare, Myrtus acmenoides, Nageia elata, Niemeyera prunifera, Ocimum sanctum, Oryza sativa, Pandanus Forsteri, P. pedunculatus, Panicum depositum, P. Italicum, P. miliaceum, P. prostratum, P. repens, P. sanguina?e, P. virgatum, Pappophorum commune, Paspalum distichum, Phaseolus adenanthus, P. Max, Phyllocladus rhomboidalis, Pimelea stricta, Pipturus propinquus, Pisonia aculeata, Pittosporum undulatum, Poa Australis, P. Brownii, P. digitata, Ptychosperma Alexandræ, P. Cunninghami, P. elegans, Rhagodia Billardieri, Rubus Gunnianus, R. parvifolius, R. rosifolius, Santalum Preissianum, Sclerachne cyathopoda, Sebæa albidiflora, S. ovata, Selaginella uliginosa, Sesbania aculeata, Sesuvium Portulacastrum, Smilax Australis, S. glycyphylla, Solanum vescum, Spinifex hirsutus, Spondias pleiogyna, Stenocarpus sinuosus, Synoon glandulosum, Tacca pinnatifida, Tetragonia expansa, T. implexicoma, Tetranthera laurifolia, Trigonella suavissima, Tristania conferta, Ulmus parvifolia, Vigna lanceolata, Vitis acetosa, V. Baudiniana, V. hypoglauca, Ximenia Americana, Zizyphus Jujuba, Zoysia pungens.

\section{NEW ZEALAND.}

Apium prostratum, Arundo conspicua, Cordyline Banksii, C. Forsteri, C. indivisa, Corynocarpus lævigata, Dacrydium Colensoi, D. cupressinum, Dammara Australis, Danthonia Cunninghami, Ehrharta Diplax, E. stipoides, Festuca littoralis, Fuchsia excorticata, Fagus fusca, F. Menziesii, F. Solandri, Hierochloa redolens, Hymenanthera Banksii, Kentia sapida, Libocedrus Doniana, Metrosideros florida, M. lucida, M. robusta, M. tomentosa, Myoporum lætum, Nageia dacrydioides, N. ferruginea. N. spicata, N. Totara, Phormium tenax, Phyllocladus trichomanoides, Pittosporum eugenioides, P. tenuifolium, Ripogonum scandens, Sebæa ovata, Tetragonia expansa, T. implexicoma.

\section{POLYNESIA.}

Agiceras majus, Araucaria Cookii, A. excelsa, A. Rulei, Aristolochia Indica, Batis maritima, Broussonetia papyrifera, Casuarina equisetifolia, Colocasia antiquorum, C. Indica, Cordyline Baueri; Cyrtosperma edulis, Dammara macrophylla, D. Moorei, D. obtusa, D. ovata, D. Vitiensis, Dioscorea aculeata, D. alata, D. nummularia, D. pentaphylla, D. sativa, Gossypium Taitense, G. tomentosum, Ipomœa paniculata, Kentia Baueri, Musa Troglodytarum, Ocimum gratissimum, Pipturus propinquus, Pringlea antiscorbutica, Saccharum officinarum, Santalum Freycinetianum, S. Yasi, Solanum Uporo, Spondias dulcis, Stilbocarpa polaris, Tacca pinnatifida, Tetragonia expansa, Touchardia latifolia. 


\title{
INDICATED GENERA,
}

\author{
CONTAINING
}

\section{Alimentary Plants:}

\section{Yielding Herbage:}

Allium, Amarantus, Anthriscus, Apium, Aralia, Atriplex, Barbaræa, Basella, Beta, Bongardia, Borrago, Brassica, Chenopodium, Corchorus, Crambe, Cynara, Fagopyrum, Gunnera, Hibiscus, Lactuca, Lepidium, Musa, Pringlea, Rheum, Rumex, Sanguisorba, Scandix, Scorzonera, Spinacia, Tetragonia, Theligonum, Tropæolum, Valerianella, Zizania.

2. Yielding Roots:

Allium, Apios, A ponogeton, Arracacha, Asparagus, Beta, Brassica, Butomus, Carum, Chærophyllum, Cichorium, Cochleria, Colocasia, Conopodium, Cordyline, Cymopterus, Cyperus, Daucus, Dendrocalamus, Dioscorea, Diposis, Ferula, Flemingia, Flueggea, Geitonoplesium, Gigantochloa, Gladiolus, Heleocharis, Helianthus, Hypochœris, Ipomæa, Manihot, Microseris, Nelumbo, Oxalis, Pachyrrhizus, Peucedanum, Pimpinella, Priva, Pueraria, Raphanus, Rhaponticum, Ruscus, Scilla, Scorzonera, Sechium, Selinum, Solanum, Stilbocarpa, Thapsia, Tinguarra, Tragopogon, Tropæolum, Ullucus, Uvularia, Valeriana, Witheringia.

3. Yielding Cereal Grain:

Andropogon, Avena, Eleusine, Hordeum, Oryza, Panicum, Pennisetum, Poa, Secale, Triticum, Zea, Zizania.

4. Yielding Table-Pulse:

Cajanus, Caragana, Cicer, Dolichos, Errum, Lupinus, Phaseolus, Pisum, Vicia, Vigna.

5. Yielding various Esculent Fruits:

Aberia, Achras, Adenostemon, Albizzia, Amarantus, Amelanchier, Anona, Arachis, Araucaria, Aristotelia, Artocarpus, Atalantia, Averrhoa, Benincasa, Berberis, Borassus, Carissa, Carya, Castanea, Castanopsis, Celtis, Ceratonia, Cereus, Cervantesia, Citrus, Corynocarpus, Corynosicyos, Cratægus, Cucumis, Cucurbita, Cudrania, Cynara, Debregeasia, Diospyros, Euclea, Eugenia, Fagopyrum, Ficus, Fragaria, Gaultiera, Gaylussacia, Gingko, Guevina, Hibiscus, Hovenia, Hymenæa, Juglans, Juniperus, Lapageria, 
Limonia, Macadamia, Maclura, Mangifera, Marlea, Marliera, Melicocca, Mesembrianthemum, Moringa, Morus, Musa, Myrica, Myrtus, Nageia, Nelumbo, Nephelium, Niemeyera, Nyssa, Opuntia, Pappea, Parinarium, Passiflora, Peireskia, Persea, Peumus, Phœenix, Physalis, Pinus, Pistacia, Prunus, Psidium, Punica, Pyrularia, Pyrus, Quercus, Ribes, Rubus, Sambucus, Santalum, Sechium, Shepherdia, Solanum, Spondias, Tamarindus, Telfairia, Terminalia, Trapa, Triphasia, Vaccinium, Vitis, Voandzeia, Ximenia, Zizyphus.

6. Truffles:

Agaricus, Hydnum, Morchella, Pachyma, Polygaster, Terfezia, Tuber.

Bamboo-Plants:

Arundinaria (Arundo), Bambusa, Beesha, Dendrocalamus, Gigantochloa, Guadua, Melocanna, Oxytenanthera, Schizostachyum (many other genera mentioned under Schizostachyum), Teinostachyum.

Camphor-Plant :

Cinnamomum.

Coffee-Plant :

Coffea (doubtful).

Condiment-Plants :

Acorus, Allium, Apium, Archangelica, Artemisia, Borrago, Brassica, Calamintha, Calyptranthes, Capparis, Capsicum, Carum, Chærophyllum, Citrus, Cochlearia, Coriandrum, Crithmum, Cuminum, Fœniculum, Glycine, Illicium, Laserpitum, Laurus, Lepidium, Lindera, Mentha, Meriandra, Myrrhis, Ocimum, Olea, Origanum, Peucedanum, Pimpinella, Prunus (Amygdalus), Pycnanthemum, Satureja, Sison, Smyrnium, Spilanthes, Tropæolum, Thymus, Tuber, Valerianella, Zingiber.

Cork-Plant :

Quercus.

\section{Dye-Plants:}

Acacia, Acer, Albizzia, Aleurites, Alkanna, Alnus, An themis, Baloghia, Cæsalpinia, Carthamus, Carya, Chlorogalum, Cladastris, Crocus, Crozophora, Cytisus, Dracæna, Excæcaria, Fagopyrum, Garcinia, Gunnera, Helianthus, Indigofera, Isatis, Juglans, Lawsonia, Lithospermum, Lyperia, Maclura, Maharanga, Mallotus, Opuntia, Peireskia, Perilla, Peumus, Phyllocladus, Pinus, Polygonum, Quercus, Reseda, Rhamnus, Rhus, Roccella, Rubia, Sambucus, Saponaria, Solanum, Sophora, Spartium, Terminalia, Thymelæa, Vaccinium, Xanthorrhiza. 


\section{Fibre-Plants :}

Agave, Apocynum, Boehmeria, Broussonetia, Camelina, Cannabis, Caryota, Chlorogalum, Copernicia, Corchorus, Cordyline, Crotalaria, Cyperus, Debregeasia, Fitzroya, Fourcroya, Gossypium, Hardwickia, Helianthus, Hibiscus, Humulus, Lardizabala, Lavatera, Linum, Maoutia, Musa, Pachyrrhizus, Phormium, Pipturus, Poa, Sanseviera, Sesbania, Spartina, Spartium, Thuya, Tillandsia, Touchardia, Villebrunea, Yucca.

\section{Fullers-Plant :}

Dipsacus.

\section{Fodder-Plants :}

1. Grasses :

Agrostis, Aira, Alopecurus, Andropogon, Anthistiria, Anthoxanthum, Avena, Bouteloua, Bromus, Buchloa, Carex, Chloris, Cinna, Cynodon, Cynosurus, Dactylis, Danthonia, Ehrharta, Eleusine, Festuca, Hemarthria, Hierochloa, Holcus, Hordeum, Koeleria, Leersia, Lolium, Melica, Milium, Panicum, Pappophorum, Paspalum, Pennisetum, Phalaris, Phleum, Poa, Sclerachne, Secale, Sesleria, Spartina, Stenotaphrum, Tripsacum, Triticum, Uniola, Zizania.

2. Other Herbage:

Achillea, Anthyllis, Arachis, Astragalus, Atriplex, Brassica, Cichorium, Desmodium, Ervum, Heracleum, Hippocrepis, Lespedeza, Lotus, Pentzia, Peucedanum, Prangos, Sanguisorba, Spergula, Symphytum, Trophis.

3. STtable Pulse (Pods and Herbs):

Cicer, Dolichos, Hedysarum, Lathyrus, Lupinus, Medicago, Melilotus, Onobrychis, Ornithopus, Oxytropis, Pisum, Trifolium, Trigonella, Vicia.

4. Other Fruits:

Argania, Carya, Ceratonia, Helianthus, Prosopis, Quercus. Garland-Plants:

Baccharis, Helichrysum, Laurus, Lycopodium, Melaleuca, Quercus.

\section{Grave-Plants:}

Boronia, Cupressus, Fraxinus, Helichrysum, Lycopodium, Salix, Tamarix, Thuya, Viola.

\section{Gum-Plants :}

Acacia, Albizzia, Astragalus, Bambusa, Brachychiton, Caragana, Olea, Prosopis.

Hedge-Plants :

Aberia, Acacia, Acer, Agave, Albizzia, Azima, Baccharis, Bambusa, Berberis, Buxus, Cæsalpinia, Capparis, Carissa, 
Ceanothus, Cratægus, Cupressus, Elæagnus, Flacourtia, Gleditschia, Guilandina, Hymenanthera, Justicia, Lawsonia, Ligustrum, Lycium, Maclura, Mimosa, Monetia, Opuntia, Paliurus, Parkinsonia, Peireskia, Pisonia, Pistacia, Pittosporum, Plectronia, Prosopis, Prunus, Punica, Pyrus, Rhamnus, Rhus, Rosa, Rubus, Ruscus, Salix, Scotia, Streblus, Thuya, Zizyphus.

\section{Honey-Plants :}

Acacia, Agave, Brassica, Eucalytus, Eucryphica, Helianthus, Lavandula, Medicago, Melissa, Mentha, Origanum, Rosa, Rosinarinus, Salvia, Thymus, Tilia, Trifolium, Tropæolum, Viola.

Hop-Plant :

\section{Humulus.}

\section{Medicinal Plants:}

1. Yielding Herbage or Flowers:

Achillea, Aconitum, Agave, Aletris, Aloe, Althæa, Anemone, Anthemis, Arctostaphylos, Aristolochia, Árnica, Artemisia, Atropa, Barosma, Cannabis, Cassia, Catha, Chelidonium, Chenopodium, Chrysanthemum, Cochlearia, Conium, Crocus, Cytisus, Digitalis, Erythroxylon, Eupatorium, Garuleum, Hagenia, Hedeoma, Hyoscyamus, Ilex, Justicia, Lactuca, Leyssera, Marrubium, Matricaria, Melianthus, Mentha, Menyanthes, Ophelia, Osmitopsis, Papaver, Parthenium, Polygala, Prunus, Rafnia, Ricinus, Rosmarinus, Ruta, Salvia, Sambucus, Santolina, Sebæa, Selinum, Solanum, Sophora, Spigelia, Spilanthes, Tanacetum, Tarchonanthus, Teucrium, Thuya, Thymus.

2. YIELDING BARK:

Alstonia, Cinchona, Juglans, Salix.

3. Yielding Roots :

Acorus, Actæa, Althæa, Anacyclus, Archangelica, Aristolochia, Arnica, Atropa, Carex, Cephælis, Cimicifuga, Colchicum, Convolvulus, Euryangium, Gentiana, Glycyrrhiza, Helleborus, Hydrastis, Inula, Ipomæa, Krameria, Nardostachys, Periandra, Peucedanum, Pimpinella, Podophyllum, Polygala, Punica, Rafnia, Rheum, Sabbatia, Sanguinaria, Saponaria, Sassafras, Saussurea, Schoenocaulon, Scorzonera, Smilax, Smyrnium, Symphytum, Taraxacum, Urginia, Valeriana,, Veratrum, Xanthorrhiza.

4. Yielding Fruits (or only Seeds):

Cassia, Cucumis, Cuminum, Ecballion, Fœniculum, Illicium, Mallotus, Punica, Rhamnus, Rheum, Ricinus, Schoenocaulon, Smyrnium, Tamarindus, Trigonella. 
Oil-Plants :

Aleurites, Arachis, Argania, Brassica, Camelina, Cannabis, Carya, Combretum, Cucurbita, Cyperus, Excæcaria, Ginkgo, Gossypium, Guizotia, Helianthus, Juglans, Linum, Olea, Papaver, Prunus (Amygdalus), Pyrularia, Ricinus, Sesamum, Telfairia, Tetranthera.

\section{Palm-Plants :}

Bactris, Borassus, Calamus, Caryota, Ceroxylon, Chamærops, Cocos, Copernicia, Hyphæne, Jubæa, Kentia, Livistona, Mauritia, Oreodoxa, Phœnix, Plectocomia, Ptychosperma, Rhapis, Sabal, Thrinax, Wallichia, Wettinia, Zalacca. (Many other American genera under Wettinia, many other Asian genera under Zalacca).

\section{Paper-Plants :}

Arundo, Broussonetia, Cyperus, Fatsia, Lepidosperma, Lygeum, Populus, Psamma, Spartina, Stipa, Zea. (See also Fibre-Plants).

\section{Resin-Plants :}

Acacia, Balsamodendron, Boswellia, Butea, Cajanus, Callitris, Ceroxylon, Chloroxylon, Cistus, Croton, Dammara, Dorema, Ferula, Ficus, Frenela, Garcinia, Hymenæa, Juniperus, Liquidambar, Myrica, Pinus, Pistacia, Pterocarpus, Rhus, Shorea, Styrax, Widdringtonia.

\section{Sand-coast-Plants :}

Acacia, Agrostis, Ailantus, Aloe, Apium, Asparagus, Calamagrostis, Carex, Casuarina, Crambe, Crithmum, Cynodon, Cytisus, Dactylis, Ehrharta, Elegia, Elymus, Festuca, Frenela, Genista, Hemitaphrum, Imperata, Lavandula, Lepidosperma, Leptospermum, Lupinus, Melaleuca, Mesembrianthemum, Myrcia, Panicum, Paspalum, Phorminm, Pinus, Poa, Prunus, Psamma, Quercus, Rhagodia, Sabal, Salix, Sesuvium, Spartina, Spinifex, Stenotaphrum, Stipa, Tamarix, Tetragonia, Thouarea, Thrinax, Tripsacum, Triticum, Ulex, Uniola, Urginia, Yucca, Zoysia.

Scenic Plants (others than Palms or Bamboos):

Agave, Aloe, Andropogon, Arundo, Berberis, Boehmeria, Canna, Colocasia, Cordyline, Cynara, Cyperus, Elegia, Fatsia, Encephalartos, Ferula, Festuca, Fœniculum, Fourcroya, Gunnera, Helianthus, Heracleum, Lavatera, Leucadendron, Melianthus, Musa, Opuntia, Pandanus, Phormium, Pipturus, Podachænium, Rheum, Ricinus, Touchardia, Yucca, Zea. 


\section{Scent-Plants:}

Acacia, Adesmia, Aloexylon, Andropogon, Anthoxanthum, Aquilaria, Backhousia, Boronia, Calamintha, Cedronella, Citrus, Convolvulus, Dracocephalum, Eucalyptus, Gelsemium, Hedeoma, Heliotropium, Jasminum, Lavandula, Liatris, Lippia, Liquidambar, Melia, Melissa, Mentha, Monarda, Myrtus, Nyctanthes, Ocimum, Origanum, Pelargonium, Pittosporum, Pogostemon, Prunus (Amygdalus), Pycnanthemum, Reseda, Rosa, Rosmarinus, Santalum, Satureja, Styrax, Synoon, Teucrium, Thymus, Tilia, Triphasia, Viola.

\section{Silk-Plants :}

Ailantus, Cajanus, Morus, Quercus, Ricinus, Symplocos, Trophis.

Starch-Plants :

Alstroemeria, Canna, Caryota, Colocasia, Copernicia, Cycas, Fagopyrum, Hordeum, Levisia, Manihot, Maranta, Oreodoxa, Oryza, Secale, Solanum, Tacca, Triticum, Zea.

Sugar-Plants :

Acer, Andropogon, Beta, Borassus, Caryota, Copernicia, Cucumis, Phœnix, Saccharum, Zea.

\section{Tannic-Plants:}

Acacia, Aesculus, Albizzia, Butea, Cæsalpinia, Cytisus, Eucalyptus, Gordonia, Gunnera, Pinus, Populus, Prosopis, Pterocarpus, Quercus, Rhus, Salix.

Tea-Plants :

Andropogon, Hydrangea, Ilex, Thea.

Tide-Plants :

Egiceras, Avicennia, Batis, Myoporum, Spartina.

\section{Timber-Plants :}

1. TREes, CONIFERous :

a. Evergreen-

Araucaria, Cephalotaxus, Cryptomeria, Cupressus, Dacrydium, Dammara, Fitzroya, Frenela, Juniperus, Libocedrus, Nageia, Phyllocladus, Pinus, Saxono-Gothæa, Sciadopitys, Sequoia, Taxus, Thuya, Thuyopsis, Torreya, Widdringtonia.

\section{b. Deciduous-}

Ginkgo, Pinus, Taxodium.

2. Trees, Not Coniferous.

a. Evergreen-

Acacia, Adenostemon, Albizzia, Amyris, Angophora, Brachychiton, Castanopsis, Casuarina, Cedrela, Cercocarpus, Chloroxylon, Corynocarpus, Dalbergia, Diospyros, Embothrium, Eucalyptus, Eucryphia. Fagus, Ficus, Flindersia, 
Gonioma, Gordonia, Grevillea, Grumilea, Harpullia, Hymenæa, Laurelia, Maba, Magnolia, Marlea, Maytenus, Metrosideros, Myrtus, Persea, Peumus, Quercus, Rhus, Royenia, Santalum, Shorea, Swietenia, Tectona, Tetranthera, Tristania.

b. Deciduous-

Acer, Essculus, Ailantus, Alnus, Betula, Butea, Carpinus, Carya, Castanea, Catalpa, Celtis, Corylus, Diospyros, Engelhardtia, Excæcaria, Fagus, Fraxinus, Gleditschia, Gymnocladus, Holoptelea, Juglans, Liriodendron, Magnolia, Melia, Ostrya, Pircunia, Planera, Platanus, Populus, Pterocarpus, Pterocarya, Quercus, Robinia, Salix, Sophora, Tilia, Ulmus, Zelkova.

Tobacco-Plants:

Nicotiana.

Water-Plants :

Acorus, Aschynomene, Aponogeton, Butomus, Cyperus, Euryale, Menyanthes, Nelumbo, Nyssa, Oryza, Poa, Sagittaria, Trapa, Zizania.

Wicker-Plants :

Cyperus, Parrotia, Salix (also genera mentioned under Bamboo-Plants). 


\section{METEOROLOGICAL TABLES}

\section{FROM THE OBSERVATORY RECORDS OF MELBOURNE.}

TEMPERATURE IN SHADE FROM 1858-1874.

\begin{tabular}{|c|c|c|c|c|}
\hline & & Extreme Maximum. & Extreme Minimum. & Yearly Mean. \\
\hline $\begin{array}{l}\text { Melbourne ... } \\
\text { Sandhurst } \\
\text { Ballarat } \\
\text { Portland } \quad \ldots \\
\text {... }\end{array}$ & $\begin{array}{l}\ldots \\
\ldots \\
\ldots \\
\ldots\end{array}$ & $\begin{array}{l}\text { Degrees. } \\
112 \cdot 2 \\
117 \cdot 4 \\
109 \cdot 0 \\
108 \cdot 0\end{array}$ & $\begin{array}{c}\text { Degrees. } \\
27 \cdot 0 \\
27 \cdot 5 \\
22 \cdot 0 \\
30 \cdot 0\end{array}$ & $\begin{array}{c}\text { Degrees. } \\
57 \cdot 6 \\
58 \cdot 9 \\
53 \cdot 6 \\
61 \cdot 6\end{array}$ \\
\hline
\end{tabular}

AVERAGE YEARLY RAINFALL AT MELBOURNE, From 1857 то $1874-26 \cdot 35$ INCHES.

RAINFALL AND TEMPERATURE FROM 1872-1874.

\begin{tabular}{|c|c|c|c|c|c|}
\hline & & $\begin{array}{c}\text { Average } \\
\text { Yearly } \\
\text { Rainfall. }\end{array}$ & $\begin{array}{c}\text { Yearly } \\
\text { Mean } \\
\text { Temperature } \\
\text { in shade. }\end{array}$ & $\begin{array}{c}\text { Extreme } \\
\text { Maximum } \\
\text { Tenperature } \\
\text { in shade. }\end{array}$ & $\begin{array}{c}\text { Extreme } \\
\text { Minimum } \\
\text { Temperature } \\
\text { in shade. }\end{array}$ \\
\hline Ararat & & $\begin{array}{l}\text { Inches. } \\
24 \cdot 47\end{array}$ & Degrees. & Degrees. & Degrees. \\
\hline Ballarat $\quad \ldots$ & $\cdots$ & $29 \cdot 04$ & $55 \cdot 4$ & $107 \cdot 3$ & $25 \cdot 0$ \\
\hline Berwick ... & $\ldots$ & $44 \cdot 33$ & $57 \cdot 1$ & - & - \\
\hline Camperdown & $\ldots$ & $32 \cdot 77$ & - & - & - \\
\hline Cape Otway & $\cdots$ & $37 \cdot 38$ & $55 \cdot 4$ & $101 \cdot 0$ & $35 \cdot 0$ \\
\hline Daylesford & $\ldots$ & $38 \cdot 85$ & - & - & - \\
\hline Geelong $\quad .$. & $\ldots$ & $23 \cdot 00$ & 一 & 一 & - \\
\hline Hamilton .... & $\ldots$ & $25 \cdot 54$ & - & - & - \\
\hline Kew $\quad \ldots$ & $\ldots$ & $33 \cdot 18$ & - & - & - \\
\hline Kingston ... & $\ldots$ & $35 \cdot 46$ & - & - & $\rightarrow$ \\
\hline Melbourne... & $\cdots$ & $28 \cdot 74$ & $57 \cdot 4$ & $103 \cdot 3$ & $29 \cdot 3$ \\
\hline Portland ... & $\ldots$ & $33 \cdot 30$ & $61 \cdot 8$ & - & - \\
\hline Rokewood ... & $\cdots$ & $24 \cdot 83$ & - & - & - \\
\hline Sale $\quad \ldots$ & $\ldots$ & $29 \cdot 16$ & - & - & - \\
\hline Sandhurst ... & $\ldots$ & $22 \cdot 12$ & $58 \cdot 4$ & $109 \cdot 5$ & $30 \cdot 0$ \\
\hline Schnapper Point & $\ldots$ & $37 \cdot 32$ & - & - & - \\
\hline Wahgunyah & $\ldots$ & $25 \cdot 35$ & - & 一 & - \\
\hline Warrandyte & $\ldots$ & $40 \cdot 84$ & - & - & 一 \\
\hline
\end{tabular}




\section{INDEX OF VERNACULAR NAMES.}

\begin{tabular}{|c|c|c|c|c|c|c|c|c|}
\hline & & Page & & & Page & & & Page \\
\hline oe & & 182 & Basil & 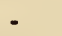 & 143 & Cainito & - & 142 \\
\hline Acacia, locu & ast- & - 203 & Bass-wood & - & - 241 & Cajaput-tree & & 117 \\
\hline Adam's neec & dle & & Bay-tree & - & & Calambac & - & 20 \\
\hline ira - & - & $\begin{array}{l}-\quad 39\end{array}$ & Beach-plum & - & - & Cambuca & - & 125 \\
\hline gallochum & & - $\quad 20$ & Beans - & & - 160 & Camphor-tre & & 53 \\
\hline th-damn & mar & & Bean, straig & & - 253 & Canada-rice & & - 262 \\
\hline tar & & 20 & Beebalm-tea & & - 131 & Canary-gras: & & - 160 \\
\hline Albert-palm & & 44 & Beeches & - & 85 & enut- $t$ & tree & 13 \\
\hline $\mathrm{r}$ & & 13,264 & Beet & & 31 & $\mathrm{Ca}$ & & 74 \\
\hline & & - 91 & Bent-grass & - & 10,188 & Gooseb & berry & 165 \\
\hline andra-p & palm & - 190 & Berberry & - & 31,264 & -plant & t. & 40 \\
\hline fa & 5 & - 126 & Bilberry & & -251 & $\mathrm{Ca}$ & 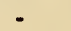 & 42 \\
\hline ba & & - 185 & Brit & sh bo & 251 & $\mathrm{Ca}$ & - & 65 \\
\hline Alisander & - & - 227 & Birch - & 33 & 85,264 & -tree & - & 47 \\
\hline Alkanna, & Nortl & & Birdsfoot-tr & efoil & $\cdot 121$ & Carrot - & 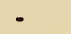 & 69 \\
\hline $\mathrm{n}$ & 1 - & - $12 C$ & butt-t & ree & 81 & tre & - & 238 \\
\hline et & - & - 120 & Blackberry & & - 207 & Cassava & - & 125 \\
\hline Aln & - & - 185 & & sand & - 207 & Castor oil-pl & lant & 202 \\
\hline gigant & & & horn & - & - 187 & $\mathrm{Ca}$ & 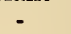 & 46 \\
\hline yellow & oflow & & Blackwood & & & Catjang & - & 38 \\
\hline -wood & - & 15,20 & Blueberry, & early & -251 & Catstail-gras & & 162 \\
\hline Anis & - & -165 & & swam & 250 & Cavan - & - & 1 \\
\hline Apple, crab & - & - 191 & $\mathrm{am}-\mathrm{tr}$ & & 78 & Cedars - & - & 63 \\
\hline haw & & & almet & & 49 & Cedar, Bast & tard & 225 \\
\hline ra & - & 8 & $\mathrm{Blt}$ & - & - 251 & Deod & dar & 167 \\
\hline -tree & - & 22 & Bo & lover & - 128 & Leba & anon & 167 \\
\hline$A$ & - & 26 & Bo & - & - 130 & northe & ern wh & hite 240 \\
\hline oot & 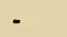 & - 125 & & - & 160 & redw & vood & 225 \\
\hline Artichoke & - & 65 & der & 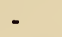 & 6 & white ( & Orego & on 240 \\
\hline Ash & . & 93,266 & Bo & - & 37 & Celandine & - & 49 \\
\hline Aspen, Eur & opean & n - 184 & Bra & - & 207 & Cel & - & 20 \\
\hline N.Am & nerica & an 184 & bush & & 67 & Celery-pines & & - 164 \\
\hline soft & - & & corn & & 18 & Chamomile & - & 19 \\
\hline Ato & 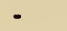 & 32 & & - & - 198 & & annua & 125 \\
\hline $0-$ pe & & 159 & $\mathrm{Bu}$ & & or & & - & 224 \\
\hline & - & -158 & & & 84 & $\mathrm{Ch}$ & - & 10 \\
\hline erb & - & - 128 & $\mathrm{~B}$ & & 226 & noyer & - - & 19 \\
\hline fir, & doubl & le 170 & -gras & s 36 & 232,245 & $\mathrm{Ch}$ & - & - 187 \\
\hline Bamboos - & 23,2 & 29,100 & -grass & & & Cherry, chol & oke & - 187 \\
\hline & & & & & & & & 48,137 \\
\hline ec & & & & tree & 111 & ut-tre & & 45 \\
\hline & - & - 134 & -tree & - & 56 & $\mathrm{Ch}$ & - & - 101 \\
\hline & - & - 103 & & & 35 & & - & 50 \\
\hline 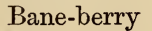 & - & & & $\mathrm{rgu}$ & en 184 & $\mathrm{Ch}$ & 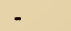 & 40 \\
\hline ree & & 89 & love & & 128 & $\mathrm{Ch}$ & - & 148 \\
\hline & - & - 104 & & & 149 & & - & 13 \\
\hline רדי & & -15 & orn & - & 78 & $\mathrm{Cl}$ & & 224 \\
\hline
\end{tabular}




\begin{tabular}{|c|c|c|c|c|c|c|c|c|}
\hline & & & & & & & & \\
\hline hristmas & ose & 103 & Date-plum & & 73 & Genipi - & - & - \\
\hline hri & & 152 & Deadly nights & shade & 27 & Gentian & 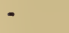 & 95 \\
\hline Chufa - & & 66 & Deccan-grass & & 153 & yinger - & - & 261 \\
\hline Chusan-paln & $\mathbf{m}$ & 48 & Dewberry - & - & 206 & Gingerbread & -palm & 107 \\
\hline Chusqueas & & 100 & Dhak - & - & 37 & Ginger-grass & & 17 \\
\hline Jicely - & - & 137 & Dill & - & 159 & fili - & - & 225 \\
\hline Ciruelillo & - & 75 & -divi & & 37 & go-tree & . & 96 \\
\hline Citron - & - & 54 & Dogstail-gras & & 65 & 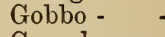 & - & - 103 \\
\hline Cloud-berry & & 206 & -boom & & 3 & Gooseberry & & 201 \\
\hline Clover, alsi & ike & 243 & palm - & & 107 & & Barba- & \\
\hline ", ber & $r \sin$ & 243 & Du & & 18 & does - & & 15 \\
\hline bro & own . - & 244 & f-palm - & & 113 & eberry, & $\mathrm{Ca}$ & e- \\
\hline car & mation & 243 & TWoad & & 110 & - & - & - \\
\hline hop & & 242 & Earth-chestn & & 56 & Gourd - & - & 62 \\
\hline , $\quad \mathrm{ma}$ & yad ; & 244 & ,, nut & & 21 & Gram - & - & 30 \\
\hline , ordin & ary red & 244 & pea & & 257 & , green & - & 161 \\
\hline ", & white & 244 & Ebony-wood & & 72 & Grape-pear & - & 16 \\
\hline ", pale & yellow & 243 & ree - & - & 123 & fox & 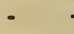 & 257 \\
\hline , red & zigzag & 243 & Egg-plant & & 229 & frost & & - \\
\hline ", strav & wberry & 243 & Elc & - & 215 & Isabel & lla & - \\
\hline yel & 110 & 242 & mpane - & $\therefore$ & 109 & Musca & adin & 57 \\
\hline oapim & - & 154 & Elm & 248 & 104 & summ & ner & - \\
\hline oc & - & 76 & tte & - & 148 & vine & & - \\
\hline oot-g? & rass & 67 & & - & 232 & wintes & & 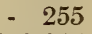 \\
\hline $1-1$ & plant - & 148 & Es] & - & 1 & Grass, buffalo & & סט \\
\hline g & rrass - & 152 & $\mathrm{n}$ & - & 23 & gama ( & (br & \\
\hline t & thorn - & 60 & -worte & & 42 & grass & & 24 \\
\hline ant & & 55 & $\mathrm{~F}$ & & 91 & nanne & & I \\
\hline & 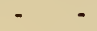 & 85 & $\ln \cdot$ & - & 65 & rattles & esnake & e \\
\hline 11 & - & 85 & $\mathrm{Fe}$ & - & 87 & Ground-almo & lone & - \\
\hline t & - & 12 & $\mathrm{~F}$ & - & 174 & nut & - & 1 \\
\hline omfrey & is & 234 & Fig & - & 88 & Jeroba & - & $8 S$ \\
\hline pri & ic] & 23 & Fio & & 10 & Guaparang: & & 125 \\
\hline & $\begin{array}{l}\ln d \\
\operatorname{lm}\end{array}$ & $\begin{array}{l}107 \\
111\end{array}$ & $\begin{array}{l}\mathrm{Fin} \\
\mathrm{Fin}\end{array}$ & & 60 & Guavas & & \\
\hline & & 230 & $\begin{array}{l}\text { of } G \\
m-\end{array}$ & Gi & $\begin{array}{l}167 \\
167\end{array}$ & $\begin{array}{l}\text { uinea-corn } \\
\text { grass }\end{array}$ & & \\
\hline & - & 97 & ," & & 176 & yang & & 3 \\
\hline rood & d-tree - & 183 & lus & 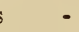 & 174 & ael- & - & - \\
\hline & - & 85 &, Scc & - & 176 & -grass & - & 11 \\
\hline Cranberry, & British & 251 & ,, Sil & pi & 179 & & - & 161 \\
\hline & large & 250 &, $\mathrm{~S}_{]}$ & & 175 & horn & - & 60 \\
\hline Cress - & 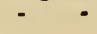 & 116 & Ha & & 223 & $\mathrm{Ha}$ & - & 59 \\
\hline Para & - & 231 & Flame-tree & - & 34 & 1-tree & - & 00 \\
\hline ber & - & 62 & Fla & - & 118 & trope & - & - \\
\hline & - & 63 & lily & 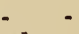 & 163 & Hemlock & 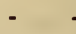 & \\
\hline alm & 1 - & 113 & Flowering ru & ush & 37 & 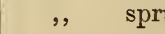 & me & \\
\hline$t, b l$ & lack & 201 & Fo & - & 176 & & & ali- \\
\hline & & 202 & Fox-glove & & 70 & fornian & - & 172 \\
\hline es & & 63 & iil-grass & & 15 & & & 40 \\
\hline press, ba & ald & 236 & 's herb & & 216 & & 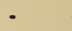 & \\
\hline Mon & itezuma & 236 & teas & & 73 & equen & - & \\
\hline ," & wa & 230 & $\mathrm{Fuu}$ & & 248 & a-bush & & 16 \\
\hline & ellow & 240 & fale-rus & sh & 66 & & & \\
\hline & & 13 & grass ( & (Buffal & & Hickory-tree & & 43,44 \\
\hline & - & $226^{\circ}$ & & & 245 & & & 117 \\
\hline & 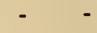 & 236 & boge & & & y-locus & & \\
\hline $\ln$ & - & 162 & Garlic - & & & Hoop-koop & & 17 \\
\hline
\end{tabular}




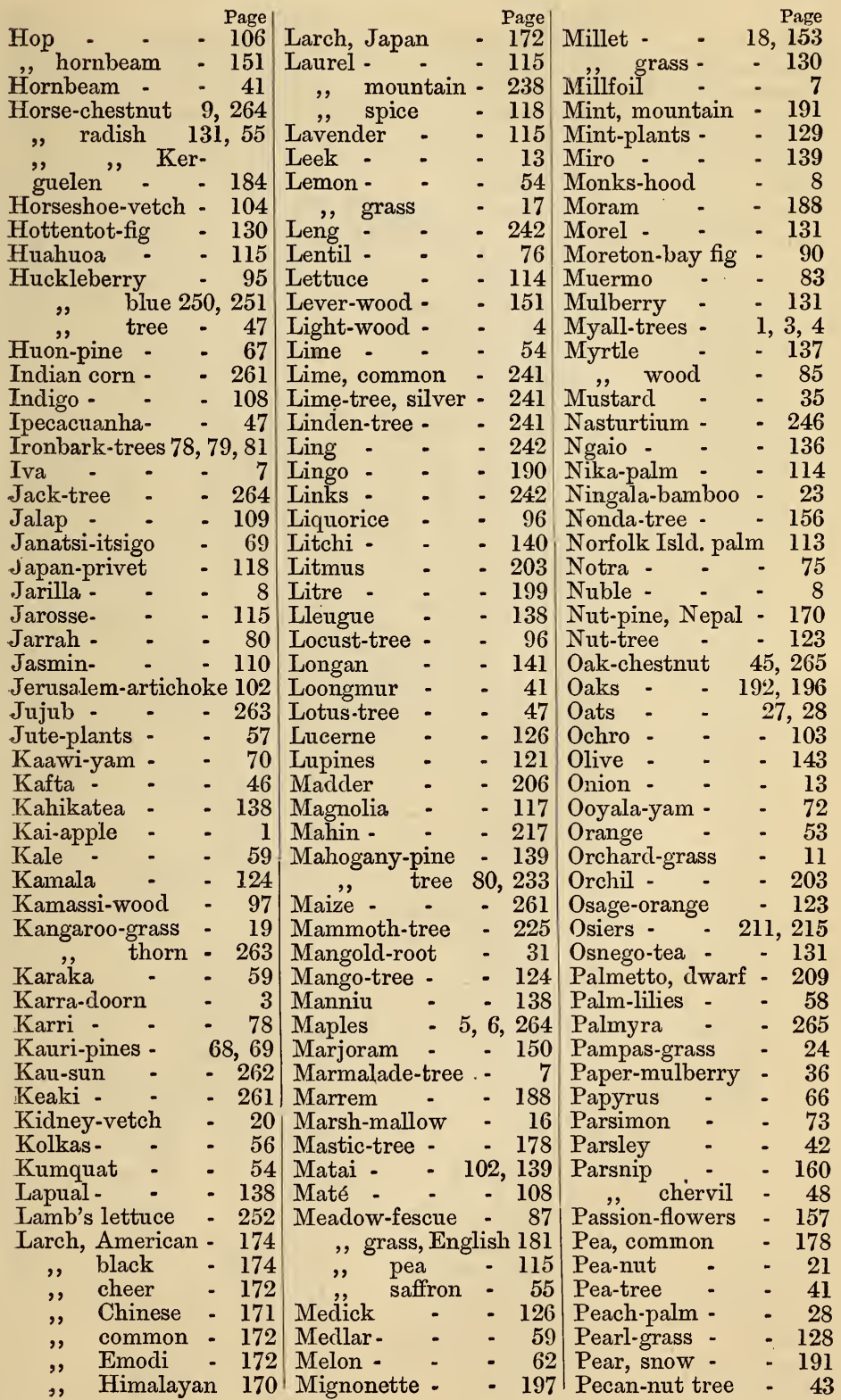




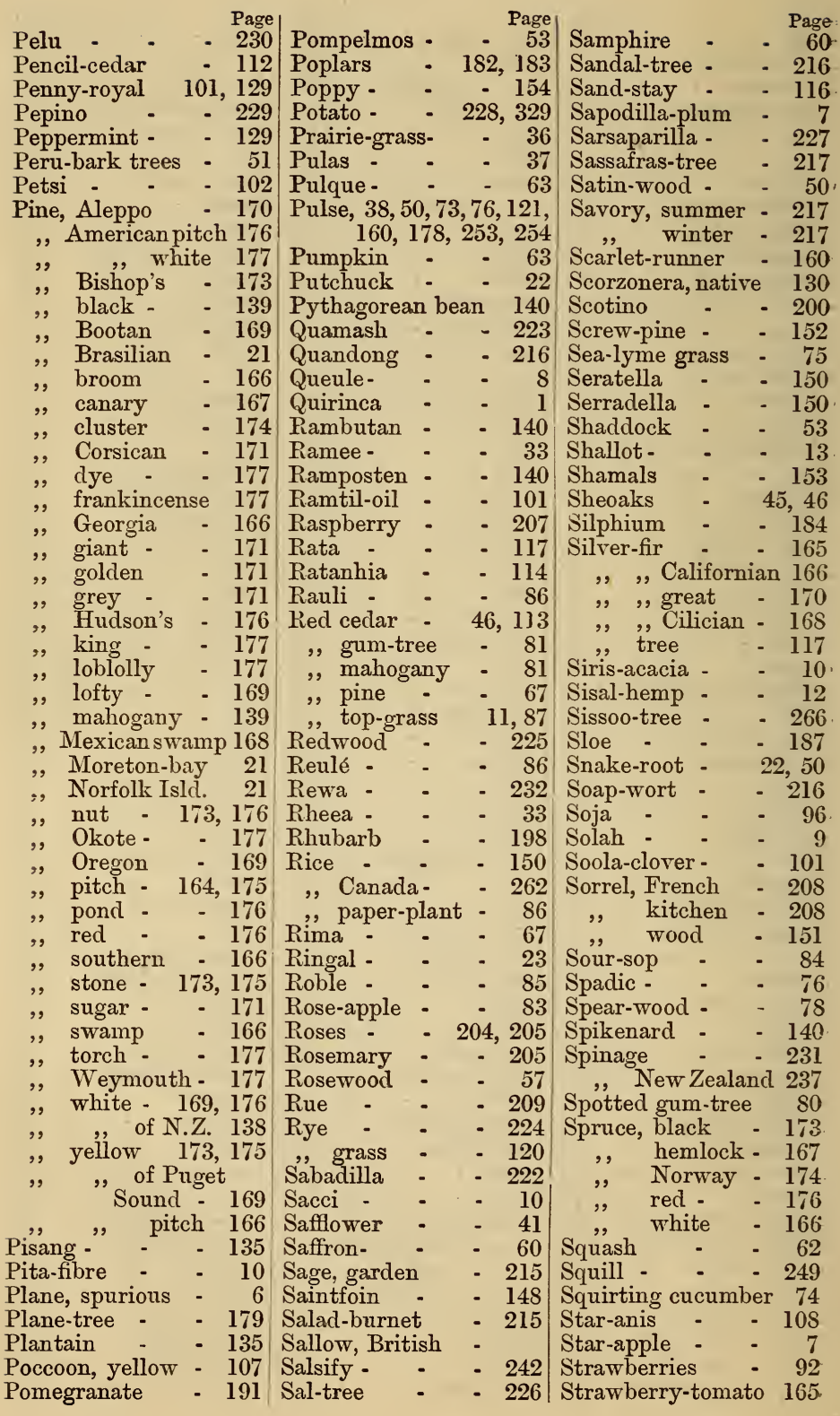




\begin{tabular}{|c|c|c|c|c|c|}
\hline \multirow{2}{*}{ Stringy-bark tree } & \multirow{2}{*}{$\begin{array}{r}\text { Page } \\
80\end{array}$} & & \\
\hline & & Tea-shrub & - 238 & Violet - & \\
\hline -tree. & - 117 & Teff - & 179 & Vouvan & \\
\hline ugar-cane - & - 210 & Thimble-berry & - 207 & Walnut-tree & 111 \\
\hline Sulphur-root & - 159 & Thyme, garden & - 241 & spurior & 75 \\
\hline Sumach & - 199 & Timothy-grass & - 162 & Water-melon & 61 \\
\hline staghorn & 200 & Tivoli-yam - & 71 & Water-nut & - 242 \\
\hline Sumbul & 84 & Tobacco & - 141 & Wattle, black & - \\
\hline Sunflower & - 102 & Tomato & 228 & silver & . \\
\hline artichok & 102 & Toon-itsigo - & 69 & Wax-myrtle & - 136 \\
\hline unn-hemp . & 61 & Tooart - & 79 & ,, palm & 48 \\
\hline - & 1 & Tree-mallow & 116 & tree & - 200 \\
\hline weet flag - & & Truffle - & 52,247 & Weld - & - 197 \\
\hline ", gum-tree & - 119 & black & 247 & Wheat - & 245 \\
\hline potato & - 109 & grey • & - 247 & Whin - & 248 \\
\hline sop & 84 & red & 247 & White cedar & - 118 \\
\hline word-sedge & - 116 & Tuggur & 20 & fir, noble & 173 \\
\hline Sycamore-fig & 91 & Tulip-tree & 119 & thorn & 59,60 \\
\hline Tagasasti & 66 & wood - & - 101 & Whorl-grass, wat & eer 179 \\
\hline w-tree & 84 & Tupelo & - 142 & Whortle-berry, B & rit. 251 \\
\hline rack & 174 & Turn & 35 & Willows & 211,215 \\
\hline ind & 235 & Turnsole & 61 & Winter-cherry & - 165 \\
\hline aha & - 164 & Tussock-grass & 67 & Woad - & - 110 \\
\hline e-berry & & Ulm & 83 & Wood-sorrel & - 151 \\
\hline $\operatorname{Tan}$ & 165 & Umbrella-palm & - 113 & Worm-wood. & 23 \\
\hline $\operatorname{Tan}$ & 235 & Uvalho do campo & 83 & Wangee & 61 \\
\hline oca & - 125 & Uv & 70 & Yams - & 70 \\
\hline Tare & 253 & Vale & - 252 & Yarrow & - \\
\hline lentil - & 254 & Valonia & 192 & Yellow cedar & \\
\hline Taro & 56 & Vegetable marr & w & wood & 91 \\
\hline Tarragon & & Vernal-grass & 19 & Yew & - \\
\hline Tata - & - $\quad 84$ & Vetch - & - 253 & ,, western & - 236 \\
\hline Teak • & 37 & - & 254 & & \\
\hline
\end{tabular}


MELBOURNE :

M'CARRON, BIRD AND CO., PRINTERS, 37 FLINDERS LANE WEST. 




$3,3,3,3,3,3$

3.33

3.

$\sum_{i} \sum_{i \infty} \sum_{0}$

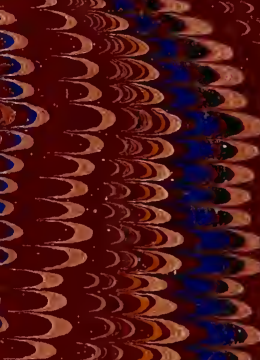

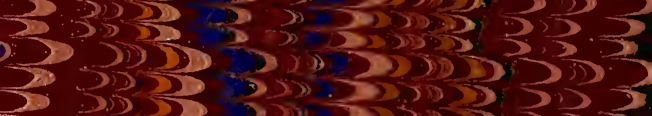

$3,2,3,3,3, \frac{3}{3}, \frac{3}{3}$

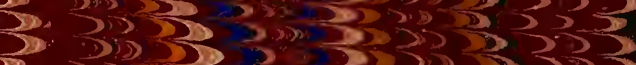

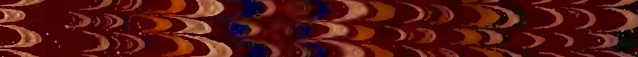

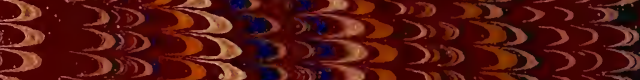

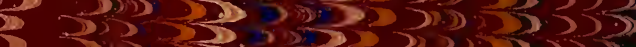

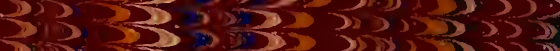

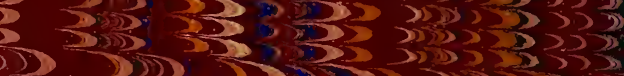

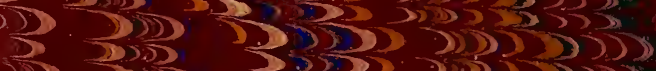

30.53

25.25

3025

3.253

D. $\frac{2035}{3}$

(3) 535 .

ग) 35

3325

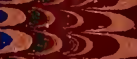

2353

3323

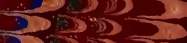

$-2 \lim ^{2}=0$

$3.353 \times 535$

3232

3253

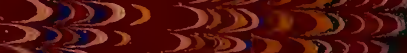

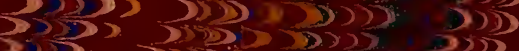

3,35

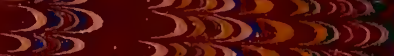

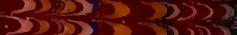

$2 \sum_{5}-325355$

32

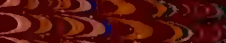

$3 \sum_{3}$

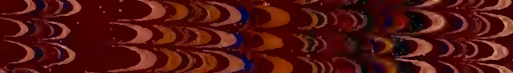

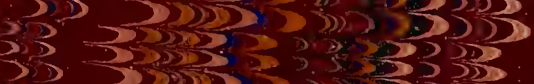

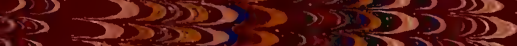

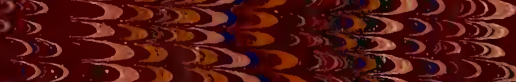

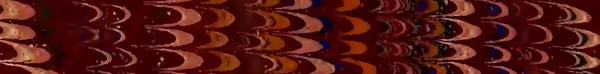

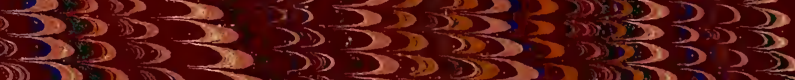

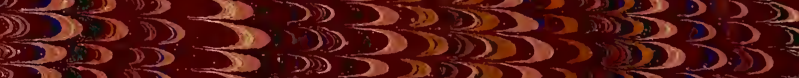

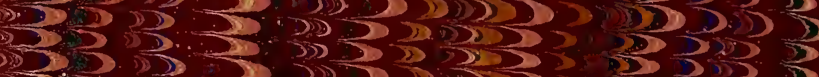

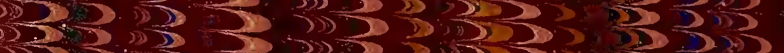

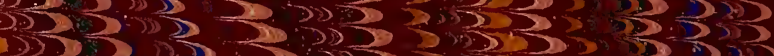

3.353 is 323

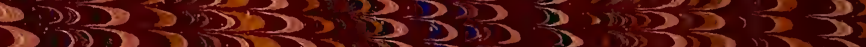

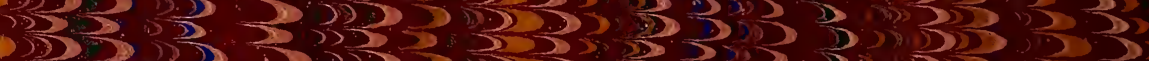

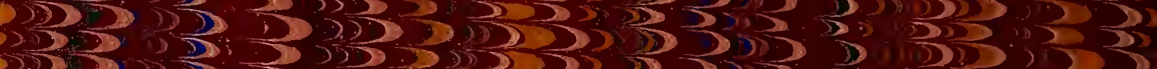

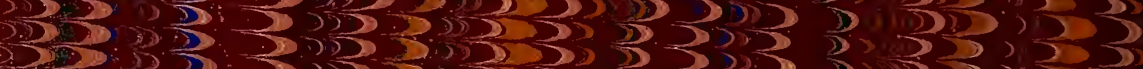

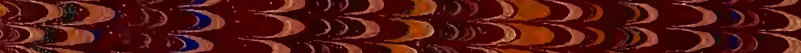

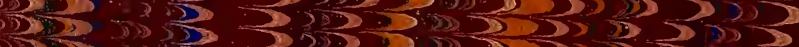
2535 35 Dis

3

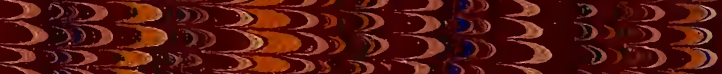
2520

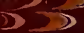

D) $2>$
(1) $)$
D)

2)

. 3250

$3 \times \frac{5 x}{3} 3$

(3).5. (2) 12

$\sum \frac{2}{3} 35$

D) 305

ग

20003

(2) 355

(2) $\rightarrow 2$

(1) 2 13

$25,2,35$

(3)

305 ग 


\section{LBRARY OF CONGRESS}

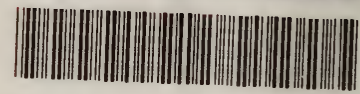

00027630133

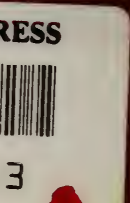

6. 